This work is licensed under a Creative Commons Attribution Licence (CC BY 4.0).

\author{
Mon og r a p h \\ urn:1sid:zoobank.org:pub:A6CB58F5-1ECC-47F0-AA07-798844AF80A7
}

\title{
The millipede genus Leucogeorgia Verhoeff, 1930 in the Caucasus, with descriptions of eleven new species, erection of a new monotypic genus and notes on the tribe Leucogeorgiini (Diplopoda: Julida: Julidae)
}

\author{
Dragan Ž. ANTIĆ ${ }^{1, *} \&$ Hans S. REIP ${ }^{2}$ \\ ${ }^{1}$ University of Belgrade - Faculty of Biology, Institute of Zoology, \\ Studentski Trg 16, 11000 Belgrade, Serbia. \\ ${ }^{1}$ Serbian Biospeleological Society, Trg Dositeja Obradovića 2, 21000 Novi Sad, Serbia. \\ ${ }^{2}$ Department of Soil Zoology, Senckenberg Museum of Natural History Görlitz, \\ Am Museum 1, 02826 Görlitz, Germany. \\ ${ }^{2}$ Thüringer Höhlenverein e.V., Johann-Sebastian-Bach-Str. 16a, 98529 Suhl, Germany. \\ *Corresponding author: dragan.antic@bio.bg.ac.rs \\ 22Email: reip@myriapoden-info.de \\ ${ }^{1}$ urn:1sid:zoobank.org:author:A3774DC0-0710-4F91-8F36-F18620D694E0 \\ ${ }^{2}$ urn:lsid:zoobank.org:author:2FEC1E52-27EF-4393-AB77-D21C66081CD5
}

\section{Table of contents}

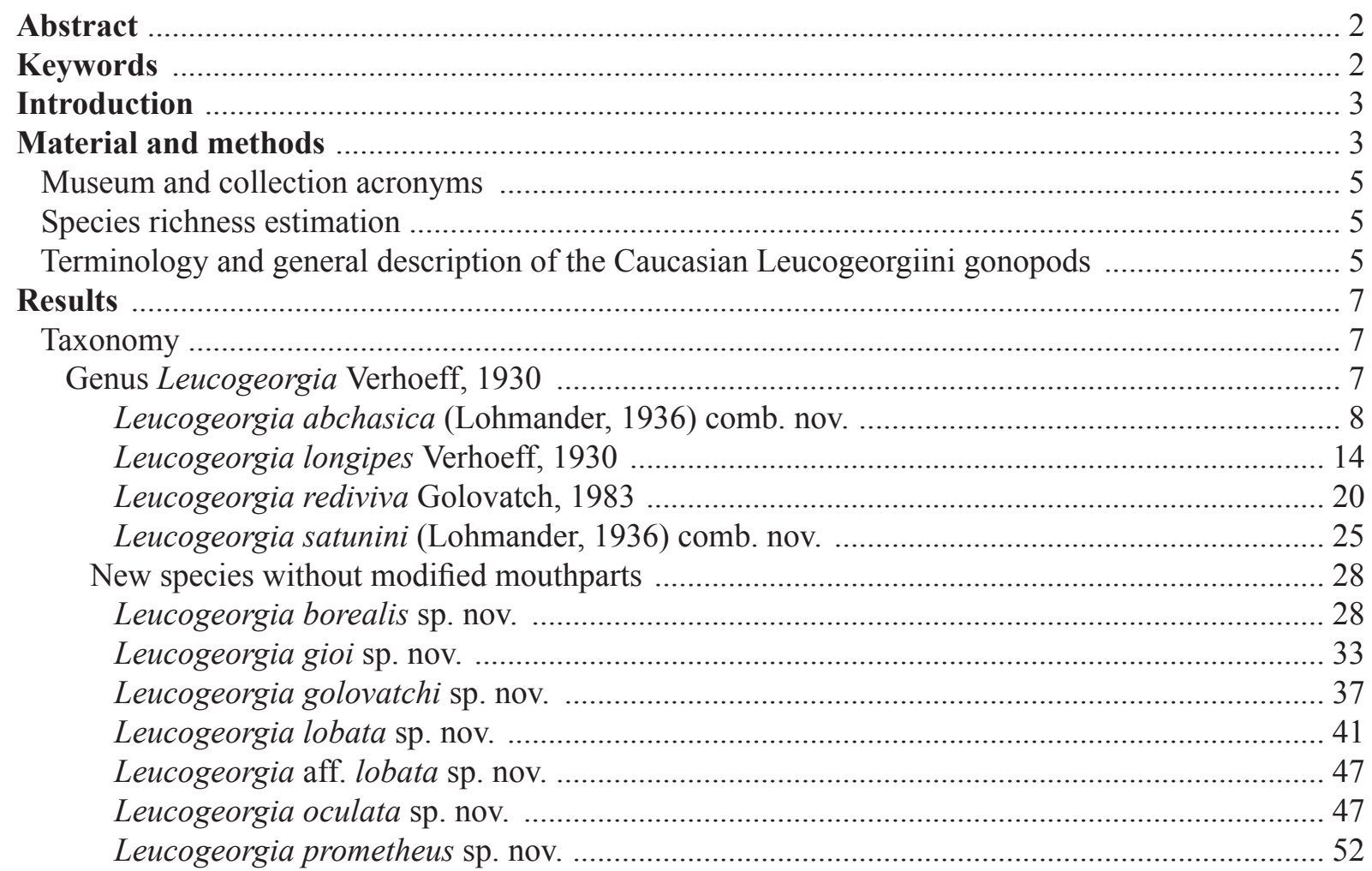




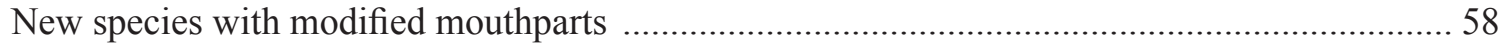

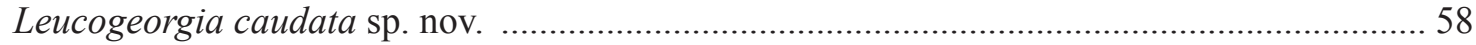

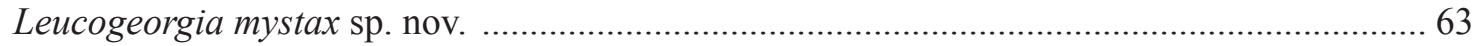

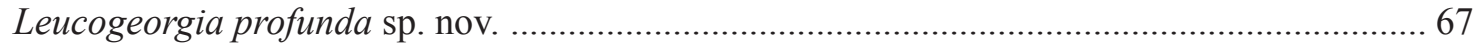

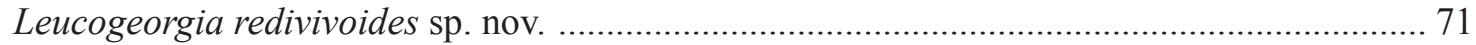

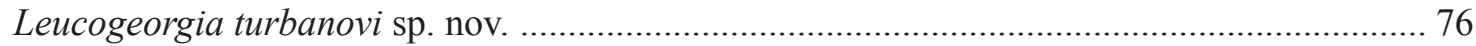

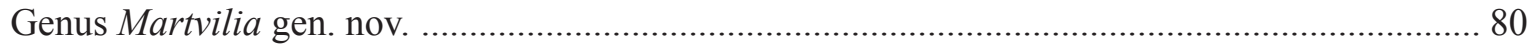

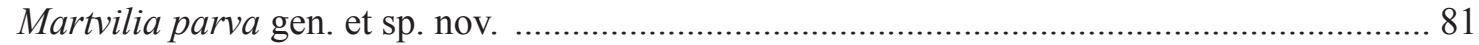

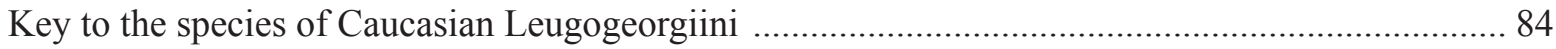

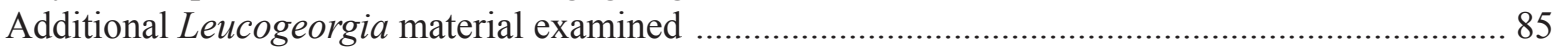

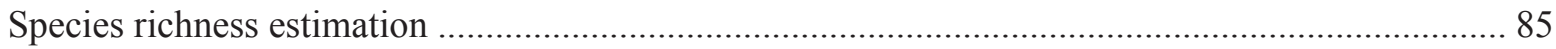

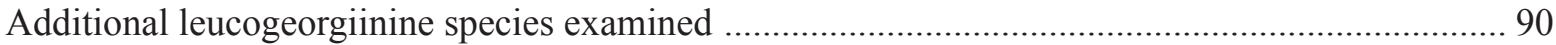

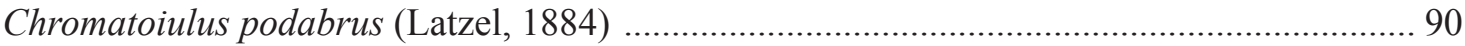

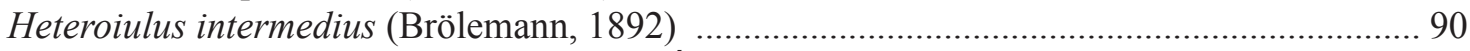

Lamellotyphlus sotirovi Makarov, Mitić \& Ćurčić, 2002 ........................................................ 90

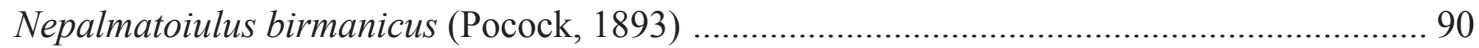

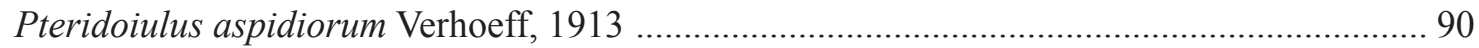

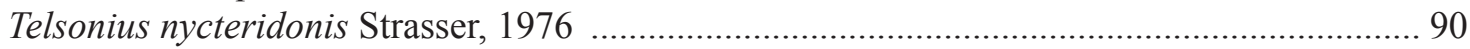

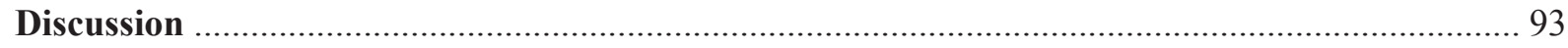

Notes on troglomorphism and mouthpart modifications in Caucasian Leucogeorgiini .................... 93

Notes on the distribution and relationships within the genus Leucogeorgia .................................... 96

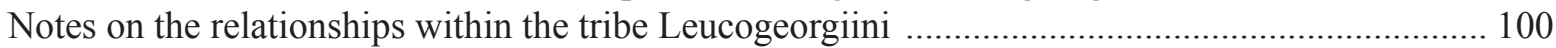

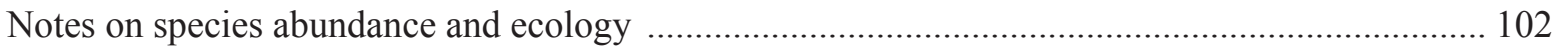

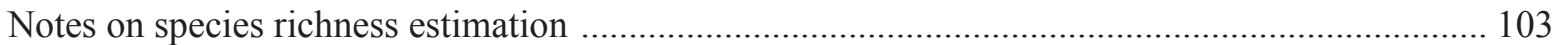

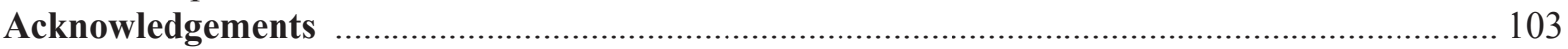

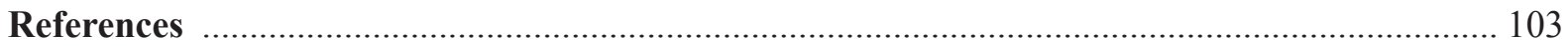

Abstract. The Caucasian leucogeorgiinine genera Archileucogeorgia Lohmander, 1936 and Leucogeorgia Verhoeff, 1930 are revised, with Leucogeorgia being considered as a senior subjective synonym of Archileucogeorgia, syn. nov. The following new combinations are thus warranted: Leucogeorgia abchasica (Lohmander, 1936) and L. satunini (Lohmander, 1936), both comb. nov. ex Archileucogeorgia. All four previously described species, viz., L. longipes Verhoeff, 1930, L. abchasica, L. satunini and L. rediviva Golovatch, 1983, are redescribed based on new material, partly also on the type series, with a lectotype being designated for L. longipes. In addition, eleven new species of Leucogeorgia are described, both with normal (L. borealis sp. nov., L. gioi sp. nov., L. golovatchi sp. nov., L. lobata sp. nov., L. oculata sp. nov. and L. prometheus sp. nov.) and modified mouthparts (L. caudata sp. nov., L. mystax sp. nov., L. profunda sp. nov., L. redivivoides $\mathrm{sp}$. nov. and L. turbanovi sp. nov., all clearly troglobionts). Additionally, a new monotypic genus, Martvilia gen. nov., is erected, with $M$. parva gen. et sp. nov. as the type species, another presumed troglobiont. An identification key to both genera and all 16 species of Caucasian Leucogeorgiini is presented. Several other members of this tribe are also re-examined, including a syntype male of Telsonius nycteridonis Strasser, 1976, from Greece, herewith designated as the lectotype. Troglomorphisms and mouthpart modifications, as well as the distributions and relationships within both Leucogeorgia and Leucogeorgiini, and a Leucogeorgiini species richness estimate for the western Caucasus are discussed.

Keywords. Western Caucasus, modified mouthparts, troglomorphism, taxonomy, leucogeorgiinines.

Antić D.Ž. \& Reip H.S. 2020. The millipede genus Leucogeorgia Verhoeff, 1930 in the Caucasus, with descriptions of eleven new species, erection of a new monotypic genus and notes on the tribe Leucogeorgiini (Diplopoda: Julida: Julidae). European Journal of Taxonomy 713: 1-106. https://doi.org/10.5852/ejt.2020.713 


\section{Introduction}

The genus Leucogeorgia Verhoeff, 1930 (Fig. 1) was established for the hydrophilous cave-dweller L. longipes Verhoeff, 1930 found in ponds ("Pfützen") in Rionhesi Cave (flooded nowadays) in Georgia, Caucasus. Based on highly modified mouthparts, unknown until then in the order Julida, Verhoeff (1930) also established a new family for this genus and species, the Leucogeorgiidae. However, this family was short-lived, as just a few years later Lohmander (1936) described another blind julid genus from Georgia, Archileucogeorgia Lohmander, 1936, with two species, viz., A. abchasica Lohmander, 1936 and A. satunini Lohmander, 1936 from Abkhazia. Based on the structure of the gonopods and vulvae, as well as the unmodified mouthparts, Lohmander (1936) established a new tribe, Archileucogeorgiini, for the genus Archileucogeorgia, also mentioning the possibly close relationship between Archileucogeorgia and Leucogeorgia. At the same time, he expressed doubts concerning the validity of the family Leucogeorgiidae and suggested that Leucogeorgia could be regarded as a very aberrant member of Archileucogeorgiini (Lohmander 1936). This point of view was later supported by Strasser (1974), who had also studied some species of Typhloiulus Latzel, 1884 with highly modified mouthparts. However, two years later Strasser (1976) fully accepted the tribe Archileucogeorgiini and placed therein not only both Archileucogeorgia and Leucogeorgia, but also Syniulus Strasser, 1974 (one species from Sardinia, Italy), Paratyphloiulus Ceuca, 1971 (two species from Spain) and Telsonius Strasser, 1976 (one species from Greece). Hoffman (1980) correctly used Leucogeorgiini as the oldest name available for this tribe, but dropped Paratyphloiulus as it had been invalidly proposed without a type species. Paratyphloiulus was later typified and validated by Mauriès (1983), who thus became its true author: Paratyphloiulus Mauriès, 1983.

Not until more than half a century since the description of the first hydrophilous cave julid with heavily modified mouthparts from the Caucasus, Golovatch (1983) published a second one: Leucogeorgia rediviva Golovatch, 1983 from the Sobachya (Dzaglis) Cave, Abkhazia. Both Archileucogeorgia and Leucogeorgia have hitherto remained accepted as genera of full rank, even though at least a few other European julid genera, including speciose ones such as Typhloiulus and Trogloiulus Manfredi, 1931, have long been known to comprise some species, always troglobionts, with modified mouthparts, as well as some others, sometimes even epigean, with normal ones. Similar mouthpart modifications, especially their brush-like appearance, sporadically occur in a few other Euro-Mediterranean cave-dwelling genera or lineages of the order Polydesmida. These are generally considered as peculiar, sporadic species-level adaptations to hydrophily associated with cavernicoly (Enghoff 1985; Antić et al. 2017).

The present paper revises the genera Archileucogeorgia and Leucogeorgia based mainly on freshly collected material. Archileucogeorgia is regarded here as a junior subjective synonym of Leucogeorgia. In addition, eleven new species of Leucogeorgia are described, as well as a new monotypic genus of Leucogeorgiini, all from the Caucasus. A dichotomous key to both genera and all 16 species of Caucasian Leucogeorgiini is also provided. Mouthpart modifications, troglomorphisms, distributions and relationships within the Caucasian Leucogeorgiini are discussed.

\section{Material and methods}

Most material was derived from the huge collection of the Zoological Museum of Moscow State University, Russia, provided to us by Sergei Golovatch. Some samples date back to 1939, collected by the famous Russian cave biologist J.A. Birstein. Also, a large amount of fresh material was provided by Shalva Barjadze and Giorgi Nebieridze (Tbilisi, Georgia), Ilya S. Turbanov (Borok, Yaroslavl Region, Russia) and several other courageous cave explorers (see Material examined sections). The second author (HR) added some fresh material from a cave exploration tour in 2019.

Specimens preserved in $70 \%$ ethanol were examined with a Nikon SMZ $745 \mathrm{~T}$ binocular stereo microscope. All taxonomically important structures were dissected and mounted in glycerine as 

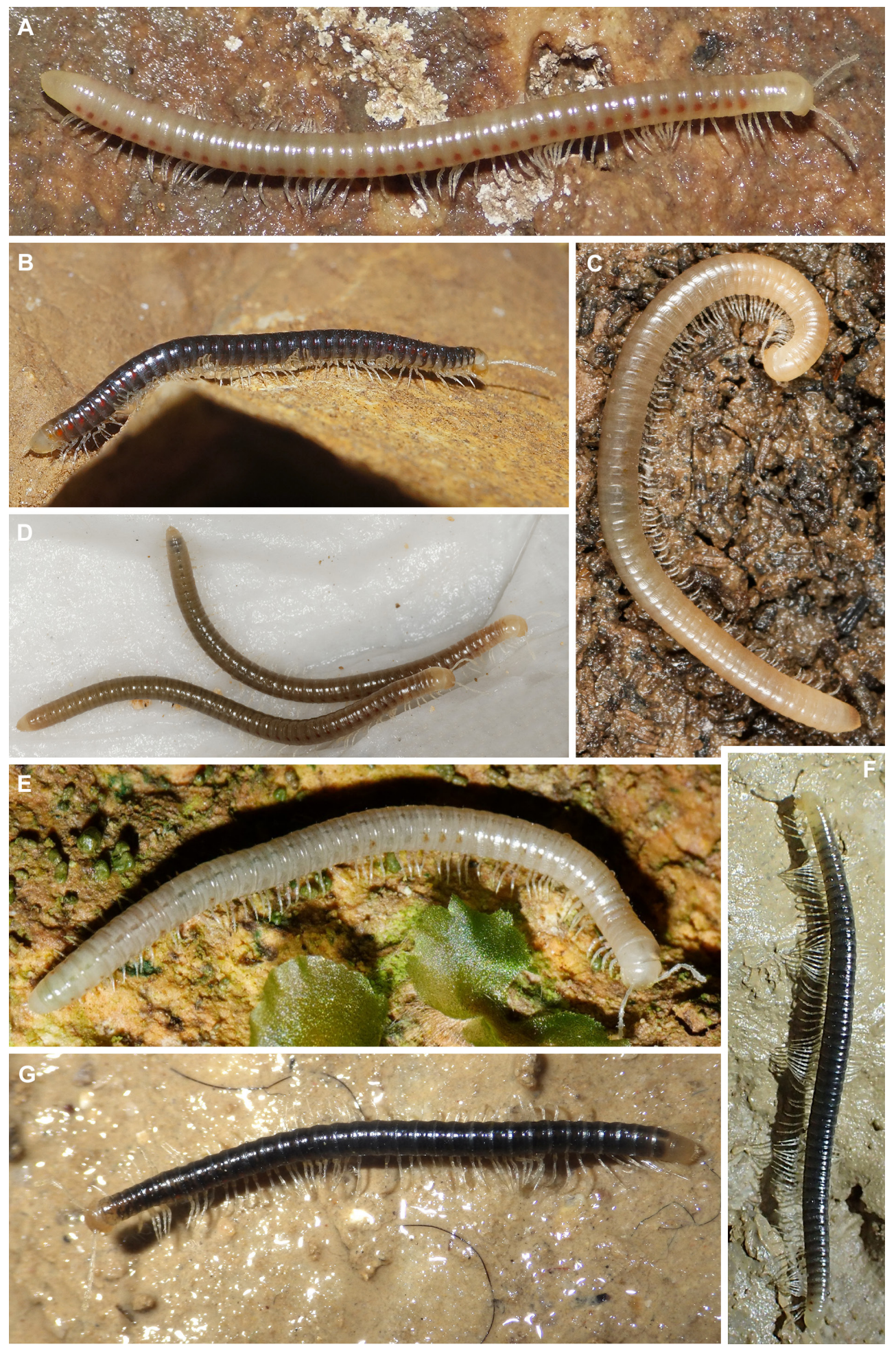

Fig. 1. Leucogeorgia Verhoeff, 1930 species in situ. A. L. abchasica (Lohmander, 1936) comb. nov., $\widehat{\partial}$ from Abraskila Cave (photo: Ilya Turbanov). B. L. caudata sp. nov., type $\widehat{\partial}$ from Novoafonskaya Cave (photo: Olga Chervyatsova). C. L. gioi sp. nov., paratype ( (SMNG) (photo: Hans Reip). D. L. lobata sp. nov., specimens from Motena Cave (photo: Hans Reip). E. L. prometheus sp. nov., specimen from Prometheus Cave (photo: Hans Reip). F. L. profunda sp. nov., non-type $\bigcirc$ from Veryovkina Cave (photo: Sergei Ivanov). G. L. turbanovi sp. nov., non-type $\widehat{\delta}$ from Krubera Cave (photo: Ilya Turbanov). 
temporary microscope preparations and observed with a Carl Zeiss Axioscope 40 microscope. Pictures of the gonopods (and of the penes of Leucogeorgia abchasica and L. rediviva) were taken with a Canon PowerShot A80 digital camera connected to the Axioscope 40 microscope. Line drawings of the gonopods, penes and first male leg-pairs were executed using tracing paper placed on a computer monitor as well as on photographs of those structures. Pictures of the specimens and relevant habitus structures were taken using a Nikon DS-Fi2 camera with a Nikon DS-L3 camera controller attached to a Nikon SMZ 1270 binocular stereo microscope (IZB), either with a Nikon DS-Fi2 camera mounted on a Nikon SMZ25 stereo microscope (NHMW), with a Canon EOS 600D camera, or with a Keyence VHX5000 Digital Microscope and with a Keyence VHX-5000 Digital Microscope (University of Graz). Focal stacking was completed with Zerene Stacker or Helicon Focus software. For SEM micrographs, the different body parts of the specimens were glued to a pin, placed on an SEM-stub, air dried for two days in a glass filled with Silica gel and finally coated with gold. The SEM micrographs were taken using a JEOL JSM-6510LV (SMNG) scanning electron microscope. After examination, body parts were removed from the pins and returned to alcohol.

The distribution map was created using Google Earth Pro (ver. 7.3.0.3832) and Adobe Photoshop CS6. The final images were processed with Adobe Photoshop CS6.

With the location names Abkhazia and Central-West Georgia, we only refer to the geographical region. We completely abstain from attributing any political meaning to these names.

The names of the caves are cited fully in English transliteration. Because some of the caves are also inhabited by some rare insects and other animals that could be endangered by commercial collectors, the coordinates of the caves are abbreviated to two decimals. Interested scientists are referred to local speleology clubs, the Ilia State University, Tbilisi (IZISU) or local guides.

\section{Museum and collection acronyms}

IZB = Institute of Zoology, University of Belgrade - Faculty of Biology, Belgrade, Serbia

IZISU = Institute of Zoology, Ilia State University, Tbilisi, Georgia

NHMW = Naturhistorisches Museum Wien, Vienna, Austria

NMNHS $=$ National Museum of Natural History, Sofia, Bulgaria

SMNG = Senckenberg Museum of Natural History in Görlitz, Germany

ZMUM = Zoological Museum of Moscow State University, Moscow, Russia

\section{Species richness estimation}

The potential number of Leucogeorgiini species for the Caucasus area was estimated with EstimateS ver. 9.1.0 (Colwell 2013; http://viceroy.eeb.uconn.edu/estimates/). For this, the CHAO1-estimator (Chao 1984) based on the species distribution was calculated from the underlying data in Table 1. Together with the ACE-index, the CHAO1-estimator is the main estimator for collection-based (here caves) abundance data (Gotelli \& Colwell 2011). It is based on the total number of species with one confirmed locality (e.g., a cave) in relation to the total number of species with two confirmed localities. With 1000 randomized runs, the species accumulation curve (rarefaction curve) and the 95\% lower and upper boundaries of confidence intervals were calculated and additionally also their extrapolation curves (for details on formulas, see Colwell et al. 2012).

\section{Terminology and general description of the Caucasian Leucogeorgiini gonopods}

To denote certain parts of the rather simple gonopods observed in the Caucasian Leucogeorgiini, we used the standard terminology for labeling the gonopods in Julidae, with some combinations and modifications (see Fig. 2). We marked the anterior gonopods as a promere (p). Promere mainly long and slender; apex rounded in anteroposterior view and with a posterior excavation surrounded by small denticles; telopodite absent; basal half with two posterior, longitudinal ridges, mesal one sometimes 

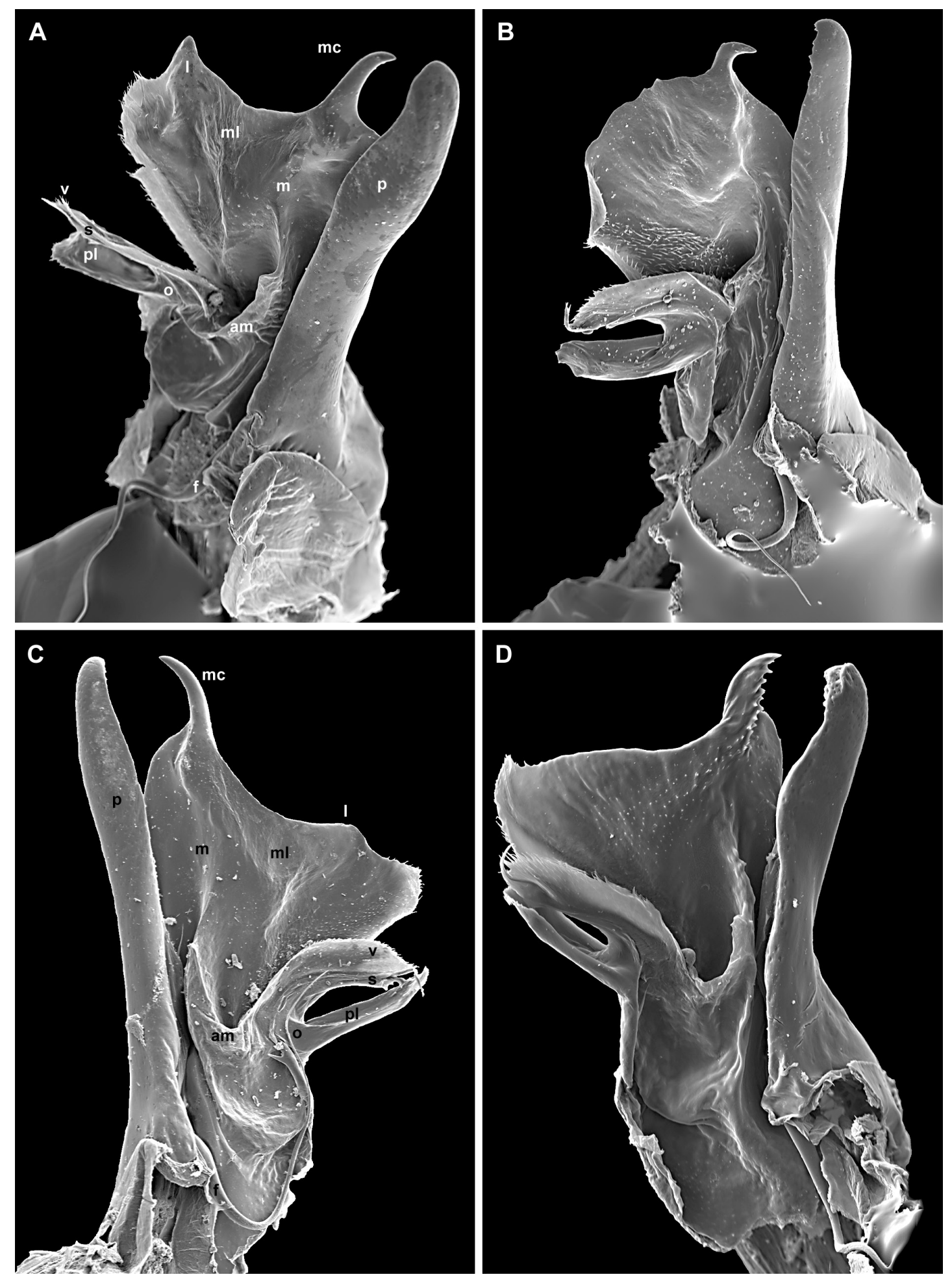

Fig. 2. Gonopods, mesal view. A. Leucogeorgia lobata sp. nov., right gonopods, paratype $\widehat{\jmath}$ from Kalitshona Cave (ZMUM). B. L. longipes Verhoeff, 1930, right gonopods, $\widehat{\sigma}$ from Dolabistavi Cave (SMNG). C. L. prometheus sp. nov., left gonopods, non-type đ̊ from Sataplia II Cave (ZMUM). D. L. satunini (Lohmander, 1936) comb. nov., right gonopods, ô from Kelasurskaya Cave (ZMUM). Abbreviations: $\mathrm{am}=$ accessory membrane; $\mathrm{f}=$ flagellum; $\mathrm{l}=$ lobe; $\mathrm{m}=$ mesomere; $\mathrm{mc}=$ mesomeral claw; $\mathrm{ml}=$ mesomeral lamella; $\mathrm{o}=$ opisthomere; $\mathrm{p}=$ promere; $\mathrm{pl}=$ protective lamella; $\mathrm{s}=$ solenomere; $\mathrm{v}=$ velum. 
with one seta. Flagellum (f) long, retracted into an opisthomeral membranous fold supplied with a spine, further continuing longitudinally along posterior edge of solenomere all the way to base of solenomere tip. Posterior gonopods consisting of two main parts, a mesomere (m) and an opisthomere (o). Since the mesomere is almost completely divided from the opisthomere, we prefer to use both these terms. Mesomere strongly developed, anterodistally with a mesomeral claw $(\mathrm{mc})$ developed to varying degrees: long, slender, hook-shaped, robust, with or without denticles. A strongly developed mesomeral lamella (ml) (velum sensu Mauriès 1983 and Enghoff 1987) lying posterior to mesomeral claw. The mesomeral lamella is also variable: with a smooth or serrate distal margin, sometimes with a poorly or strongly developed lobe (1), fimbriate posteriorly. Opisthomere bipartite. Anterior branch includes solenomere (s) with a short, medium-sized or long and fimbriate tip, opening at base of tip on posterior side; anteriorly with a well-developed and fimbriate velum (v). Posterior branch a shield-like protective lamella (pl) (paracoxite sensu Enghoff 1987), positioned posteromesally, straight or sometimes curved anteriad. On the mesal side of the posterior gonopods, there is an accessory membrane (am) (sensu Enghoff 1987) forming a pocket to connect the mesomere and opisthomere.

\section{Results}

\section{Taxonomy}

Class Diplopoda de Blainville in Gervais, 1844

Order Julida Leach, 1815

Family Julidae Cook, 1896

Subfamily Oncoiulinae Verhoeff, 1909

Tribe Leucogeorgiini Verhoeff, 1930

Genus Leucogeorgia Verhoeff, 1930

Leucogeorgia Verhoeff, 1930: 33 (name regarded as a feminine noun).

Archileucogeorgia Lohmander, 1936: 99. Syn. nov. (type species: A. abchasica Lohmander, 1936, by original designation).

\section{Type species}

Leucogeorgia longipes Verhoeff, 1930 (by monotypy).

\section{Diagnosis}

Differs from other members of the tribe Leucogeorgiini (see Discussion for the tribe composition), except Martvilia gen. nov., by the deep division of the opisthomere into two branches. It can easily be distinguished from Martvilia gen. nov. by the presence of a mesomeral lamella attached just below the mesomere claw (vs mesomere almost free, with basally attached lamella in Martvilia gen. nov.).

\section{Included species}

Leucogeorgia abchasica (Lohmander, 1936) comb. nov. (ex Archileucogeorgia)

Leucogeorgia longipes Verhoeff, 1930

Leucogeorgia rediviva Golovatch, 1983

Leucogeorgia satunini (Lohmander, 1936) comb. nov. (ex Archileucogeorgia)

\section{New species without modified mouthparts}

Leucogeorgia borealis sp. nov.

Leucogeorgia gioi sp. nov.

Leucogeorgia golovatchi sp. nov.

Leucogeorgia lobata sp. nov.

Leucogeorgia oculata sp. nov.

Leucogeorgia prometheus sp. nov. 
New species with modified mouthparts

Leucogeorgia caudata sp. nov.

Leucogeorgia mystax sp. nov.

Leucogeorgia profunda sp. nov.

Leucogeorgia redivivoides sp. nov.

Leucogeorgia turbanovi sp. nov.

\section{Previously described species}

Leucogeorgia abchasica (Lohmander, 1936) comb. nov.

Figs 1A, 3-6, 56-57

Archileucogeorgia abchasica Lohmander, 1936: 91.

\section{Diagnosis}

This species belongs to the group of Leucogeorgia spp. without modified mouthparts, also characterized by the presence of teeth on the mesomeral claw (vs absent in L. golovatchi sp. nov., L. lobata sp. nov. and L. prometheus sp. nov.). Leucogeorgia abchasica differs from L. satunini by the height of the mesomeral lamella, which slopes down caudad, also lacking a posterior rise (vs lamella of the same height all along and with a posterior rise in L. satunini), by the presence of short midbody setae, ca $5 \%$ of vertical diameter of rings (vs longer midbody setae, ca $10 \%$ of vertical diameter of rings in L. satunini), and by the presence of a subtriangular ventral margin on male body ring 7 , with strong teeth in ventral view (vs a rounded ventral margin on male body ring 7, devoid of strong ventral teeth in L. satunini). Leucogeorgia abchasica differs from L. borealis sp. nov. by the presence of an elongate and erect mesomeral claw (vs robust in L. borealis sp. nov.). Leucogeorgia abchasica differs from $L$. gioi sp. nov. by the presence of a more robust and more or less strongly denticulate mesomeral claw (vs a more slender mesomeral claw with just a few teeth in L. gioi sp. nov.), by the presence of a slightly serrate mesomeral lamella (vs a strongly serrate mesomeral lamella in $L$. gioi sp. nov.) and by the presence of a subtriangular ventral margin on male body ring 7 (vs a strongly developed triangular ventral margin in L. gioi sp. nov.). Leucogeorgia abchasica differs from L. oculata sp. nov. by the height of the mesomeral lamella gradually decreasing caudad and lacking a posterior rise (vs a lamella of the same height all along and with a posterior rise in L. oculata sp. nov.), by the presence of an elongate and erect mesomeral claw (vs robust in L. oculata sp. nov.), and by the absence of both pigmentation and ommatidia and the presence of metazonal setae (vs a pigmented body, the presence of ommatidia and the absence of metazonal setae in L. oculata sp. nov.).

\section{Material examined}

ABKHAZIA - Gudauty District - 2 $\widehat{\partial}, 4$ 우 ; Bzyb Mt Ridge, Hipstinsky karst Massif, Hipsta Mountain, Snezhnaya Cave, small crevice near entrance; $43.26^{\circ}$ N, $40.72^{\circ}$ E; Aug. 1980; V. Dolzhansky leg.; ZMUM. - Gulripsh District • 4 $q$; Tsebeldinsky karst Massif, near Amtkel village, Holodnaya Rechka Canyon, Pakhuchaya Cave, depth -65 m; $43.06^{\circ}$ N, $41.31^{\circ}$ E; 18 Sep. 2014; I.S. Turbanov leg.;

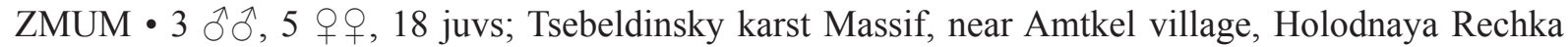
Canyon, Bolshaya Medveditza Cave, depth -15 m; $43.06^{\circ}$ N, $41.31^{\circ}$ E; 17 Sep. 2014; I.S. Turbanov leg.;

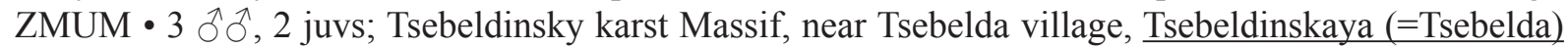

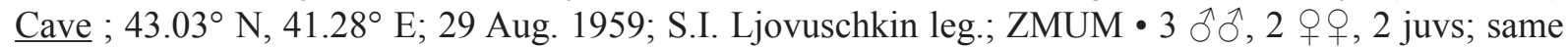

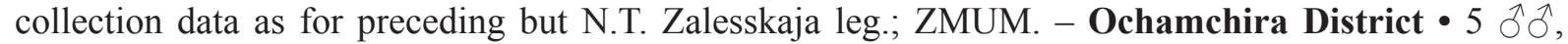
8 우, 3 juvs; Panavsky karst Massif, near Otap village, Dzykhayskaya I Cave, $15 \mathrm{~m}$ from the entrance; $42.93^{\circ} \mathrm{N}, 41.52^{\circ}$ E; 7 Sep. 2014; I.S. Turbanov leg.; ZMUM $\bullet 2 \delta^{\top} 0^{\top}, 4$ 우, 3 juvs; Panavsky karst Massif, near Otap village, Dzykhayskaya II Cave, $10 \mathrm{~m}$ from the entrance; $42.94^{\circ} \mathrm{N}, 41.53^{\circ} \mathrm{E} ; 7 \mathrm{Sep}$. 2014; I.S. Turbanov leg.; ZMUM • 1 क; Panavsky karst Massif, near Otap village, Abraskila (=Achzhe- 

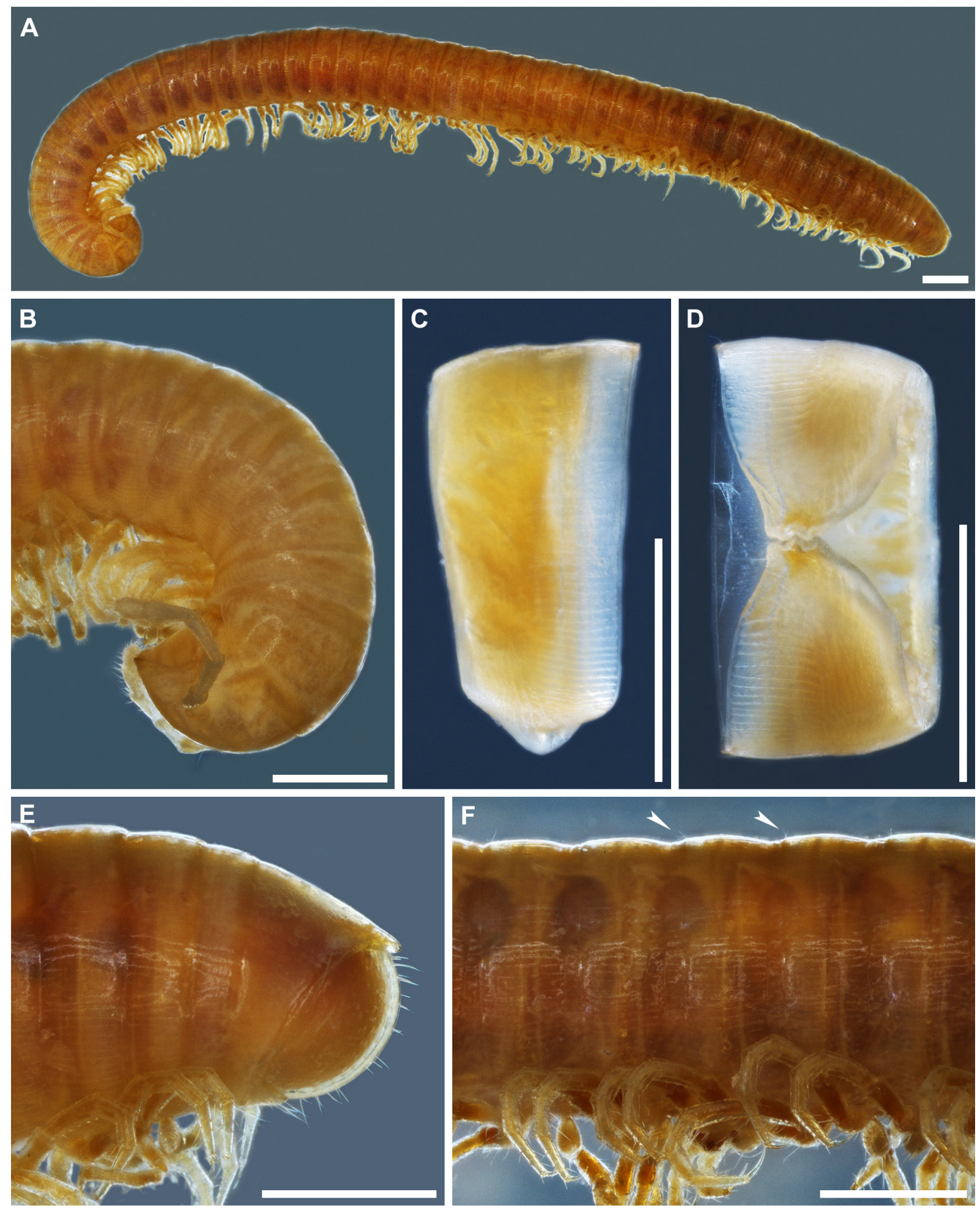

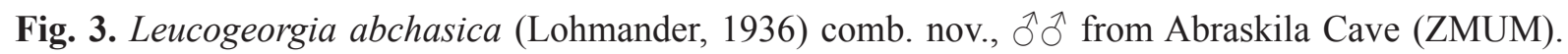
A. Habitus, lateral view. B. Anterior part of body, lateral view. C. Body ring 7, lateral view. D. Body ring 7, ventral view. E. Posterior part of body, lateral view. F. Midbody rings, lateral view. Arrows indicate metazonal setae. Scale bars: $1 \mathrm{~mm}$. 


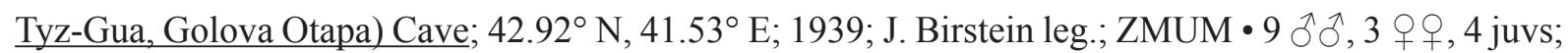
same collection data as for preceding but 8 Aug. 1939; ZMUM $\bullet 1$ §, 1 क; same collection data as for preceding but 29 Aug. 1964; S.I. Ljovuschkin leg.; ZMUM $\bullet 8$ $\widehat{\lambda}, 5$ 우, 6 juvs; same collection data as for preceding but $21 \mathrm{Aug}$. 1962; ZMUM $\bullet 11 \hat{\jmath} \hat{\delta}, 5$ q $ᄋ, 8$ juvs; same collection data as for preceding but 8 Sep. 2014; I.S. Turbanov leg.; ZMUM • $4 \hat{\partial} \hat{\partial}, 4$ q $q$; same collection data as for preceding but 9 Sep. 2014; IZB • $7 \hat{\jmath} \hat{\jmath}, 10$ 우, 7 juvs; same collection data as for preceding but 20 Aug. 2015; SMNG - 6 $\hat{\jmath}, 8$ 우, 8 juvs; same collection data as for preceding but Feb. 1989; S. Smirnov leg.; ZMUM - 5 ふふ, 9 우, 3 juvs; Panavsky karst Massif, near Otap village, Uatapachy (= Kolodets nad Golovoy Otapa) Cave; $42.93^{\circ} \mathrm{N}, 41.54^{\circ} \mathrm{E}$; 24 Aug. 2015; I.S. Turbanov leg.; ZMUM • $2 \delta^{\Uparrow}{ }^{\lambda}, 1$ q; Panavsky karst Massif, near Otap village, Samshitovaya Cave; 42.93 N, 41.54 E; 21 Aug. 2015; I.S. Turbanov leg.; ZMUM.

\section{Redescription}

SIZE AND NUMBER OF BODY RINGS. Males $21-37 \mathrm{~mm}$ long, vertical diameter of largest body ring $1.5-2 \mathrm{~mm}$, body with $42-51$ podous rings $+1-3$ apodous rings + telson. Females $22-35 \mathrm{~mm}$ long, vertical diameter of largest body ring 1.6-2.1 mm, body with 41-51 podous rings $+0-2$ apodous rings + telson.

Colour (Figs 1A, 3). Live colouration pigmentless, pallid. In alcohol from pale yellow to dark brown.

HeAd (Fig. 3B). Without ommatidia. Frontal setae absent. Labrum with three (four in one specimen) labral teeth, four supralabral and 14-17 labral setae. Gnathochilarium with rhomboid promentum. Lamellae linguales with $3+3-5+5$ setae, stipites with $3+3$ long distolateral setae and $2+3-5+5$ short medial setae. Antennae $3 \mathrm{~mm}$ long (in males with $2 \mathrm{~mm}$ vertical diameter of the body rings), their length $150 \%$ of vertical diameter of the largest body ring. Lengths of antennomeres I-VIII (in $\mathrm{mm}$ ): 0.2 (I), 0.7 (II), 0.61 (III), 0.53 (IV), 0.57 (V), 0.27 (VI), 0.09 (VII) and 0.03 (VIII). Length/width ratio of antennomeres I-VII: 0.8 (I), 3.8 (II), 3 (III), 2.8 (IV), 2.2 (V), 1.1 (VI) and 0.5 (VII). Antennomeres $\mathrm{V}$ and VI each with a terminal corolla of large sensilla basiconica bacilliformia; antennomere VII with a terminal corolla of small sensilla basiconica bacilliformia.

Body RINGS (Fig. 3F). Entire metazonal area with longitudinal striations. Metazonal setae short, length of midbody setae ca $5 \%$ of vertical diameter of rings.

TELSON (Fig. 3E). Epiproct variable, with an almost absent to short and blunt preanal process. Paraprocts rounded, setose. Hypoproct without any modifications.

LEGS IN MALEs. First pair of legs modified, hook-shaped (Fig. 4C-E), with three complete podomeres; coxa with one seta; prefemur with 4-9 setae; femur, postfemur and tibiotarsus coalesced; femur with 2-3 setae; postfemur with two setae; tibiotarsus with a small distal lobe (tarsal remnant), sometimes also with one short seta. Podomeres slightly tuberculate. Postfemoral and tibial ventral pads well developed on anterior legs, then gradually disappearing towards posterior legs.

Ventral MARGin OF MALE BOdY RING 7 (Fig. 3C-D). Well-developed, more or less subtriangular in lateral view, with strong teeth in ventral view.

Penes (Fig. 4G). In form of a short trapezoid, apically with two small subtriangular lobes.

Gonopods (Figs 4F, 5-6). Promere (p) long and slender, with a flagellum; apical part spatulate, with denticulate margins; basal half with two poorly developed ridges. Mesomere (m) with a well-developed and denticulate mesomeral claw $(\mathrm{mc})$; mesomeral lamella $(\mathrm{ml})$ mainly flattened, sometimes poorly elevated in central part, slightly serrate, posterior part finely fimbriate. Opisthomere (o) bipartite. Anterior branch of o with a solenomere (s) with a medium-sized tip, and a well-developed and fimbriate 

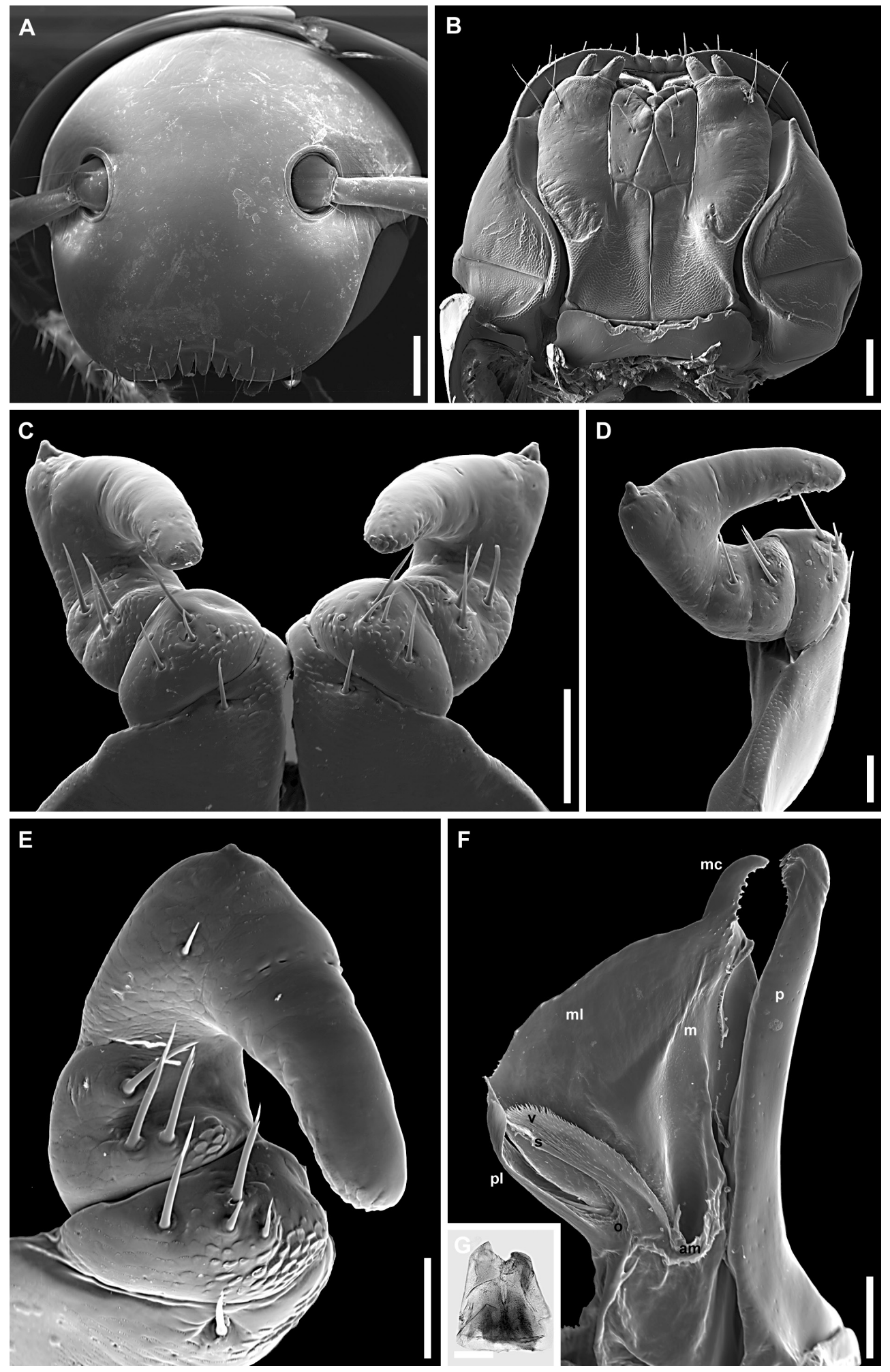

Fig. 4. Leucogeorgia abchasica (Lohmander, 1936) comb. nov. (A-F: §̋ from Bolshaya Medveditza Cave (ZMUM); G: $\delta$ from Uatapachy Cave (ZMUM)). A. Head, anterior view. B. Head, ventral view. C. Leg-pair 1, anterior view. D. Left leg 1, lateral view. E. Left leg 1, distolateral view. F. Right gonopods, mesal view. G. Penes, anterior view. Abbreviations: $\mathrm{am}=$ accessory membrane; $\mathrm{m}=$ mesomere; $\mathrm{mc}=$ mesomeral claw; $\mathrm{ml}=$ mesomeral lamella; $\mathrm{o}=$ opisthomere $; \mathrm{p}=$ promere $; \mathrm{pl}=$ protective lamella; $\mathrm{s}=$ solenomere; $\mathrm{v}=$ velum. Scale bars: $\mathrm{A}-\mathrm{B}=0.2 \mathrm{~mm} ; \mathrm{C}, \mathrm{F}-\mathrm{G}=0.1 \mathrm{~mm}$; $\mathrm{D}-\mathrm{E}=0.05 \mathrm{~mm}$. 
velum (v). Posterior branch of o in form of a shield-like protective lamella (pl), straight or sometimes curved anteriad. Mesomere and opisthomere connected basally with an accessory membrane (am).
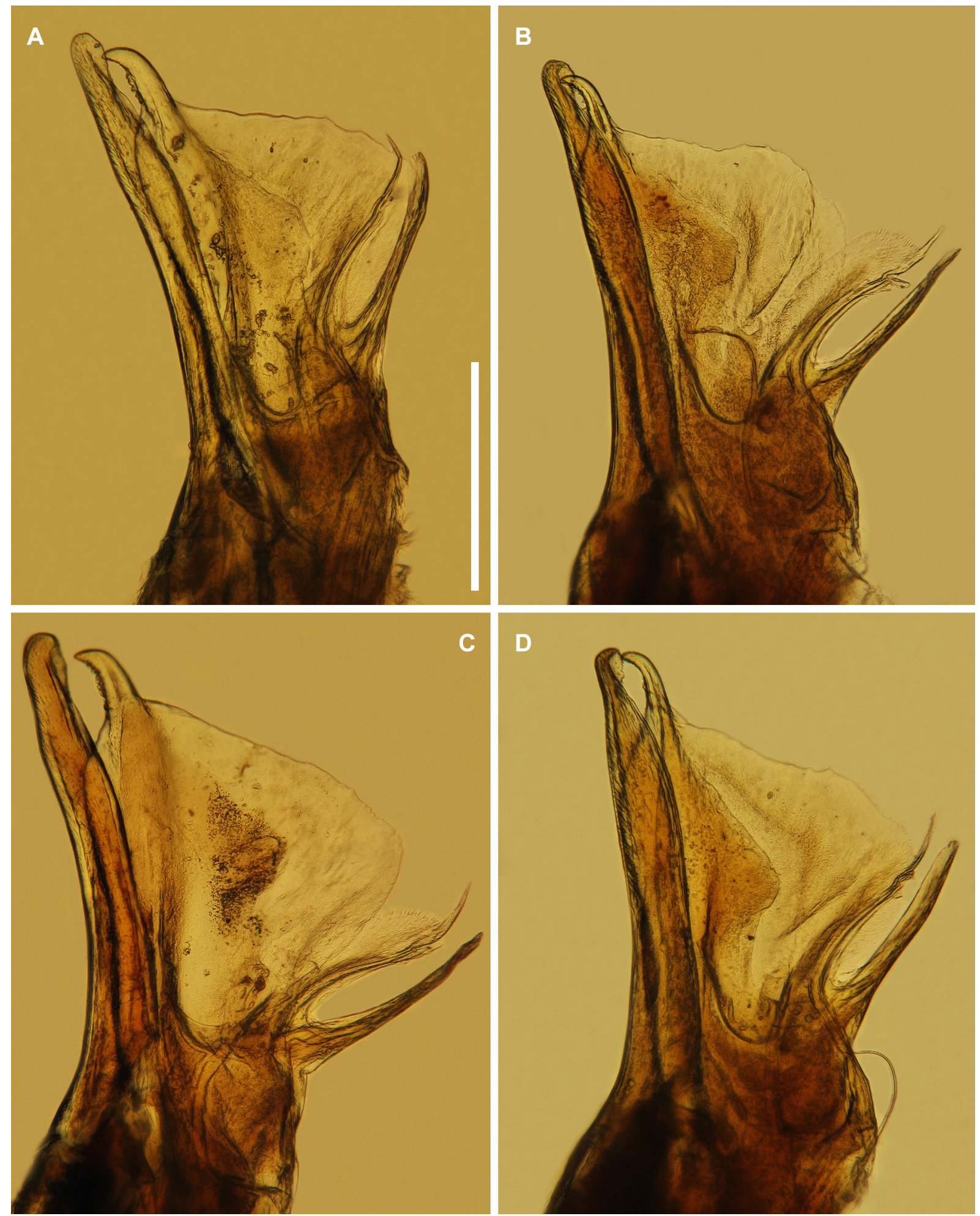

Fig. 5. Leucogeorgia abchasica (Lohmander, 1936) comb. nov., left gonopods, mesal views (ZMUM). A. $\widehat{\partial}$ from Tsebeldinskaya Cave. B. $\widehat{\partial}$ from Abraskila Cave. C. $\widehat{\sigma}$ from Bolshaya Medveditza Cave. D. ô from Snezhnaya Cave. Scale bar: $0.3 \mathrm{~mm}$. 


\section{Type locality}

Kelasurskaya Cave $\left(43.02^{\circ} \mathrm{N}, 41.14^{\circ} \mathrm{E}\right)$, Sukhum District, Abkhazia.
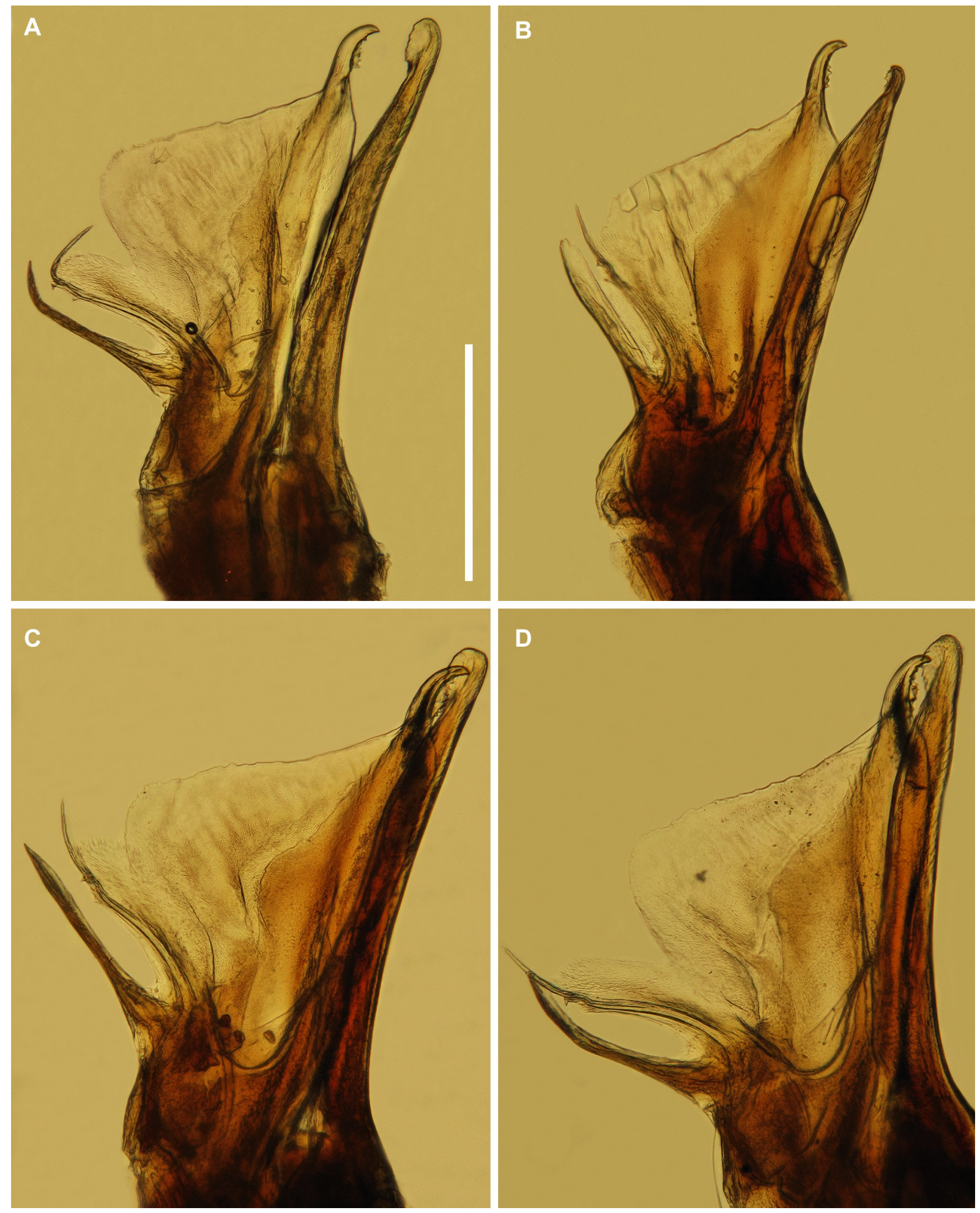

Fig. 6. Leucogeorgia abchasica (Lohmander, 1936) comb. nov., right gonopods, mesal views (ZMUM).

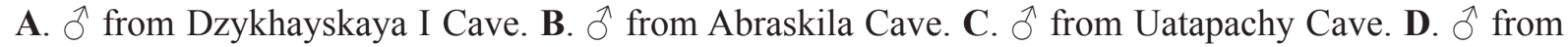
Samshitovaya Cave. Scale bar: $0.3 \mathrm{~mm}$. 


\section{Distribution}

Known only from caves in the Gudauty, Gulripsh, Sukhum and Ochamchira districts of Abkhazia (Fig. 57, green triangle).

\section{Remarks}

Several specimens have been found in a small crevice near the entrance to the Snezhnaya Cave where Leucogeorgia rediviva lives in the deeper parts. In Kelasurskaya Cave, L. abchasica occurs together with L. satunini and an unidentified species of Leucogeorgia with modified mouthparts.

See video about this species from the Abraskila (= Achzhe-Tyz-Gua, Golova Otapa) Cave: www.youtube.com/watch? $\mathrm{v}=\mathrm{sRDQ} 1$ iByPWA \& $\mathrm{t}=35 \mathrm{~s}$

\section{Leucogeorgia longipes Verhoeff, 1930}

Figs 2B, 7-10, 56, 58

Leucogeorgia longipes Verhoeff, 1930: 34.

\section{Diagnosis}

This species belongs to the group of Leucogeorgia spp. with modified mouthparts and it differs from all of them by several gonopodal and habitus structures, viz., the absence of teeth on the mesomeral claw (vs presence in all other Leucogeorgia with modified mouthparts), the absence of a process on the epiproct (vs presence of a very short to long process in all other Leucogeorgia with modified mouthparts), and the presence of a characteristic distal row of 3-5 long setae on the lamellae linguales (vs absence of such a row of setae in other Leucogeorgia with modified mouthparts or presence of 9-10 setae in two irregular rows in L. mystax sp. nov.).

\section{Material examined}

Lectotype (here designated)

CENTRAL-WEST GEORGIA - Kutaisi District - ${ }^{\top}$; Imereti, Rionhesi Cave; $42.29^{\circ} \mathrm{N}, 42.75^{\circ} \mathrm{E}$; "Kaukasus, Rion Höhle bei Kutais, Pfützen, 11.11.1929, Borutzky Dr. leg., Verhoeff don. 1940”; alcohol material; NHMW 3063.

\section{Paralectotype}

CENTRAL-WEST GEORGIA - Kutaisi District • $1{ }^{\lambda}$; same collection data as for lectotype; NHMW 9980.

\section{Other material}

CENTRAL-WEST GEORGIA - Ambrolauri District • 1 万ิ; Racha karst Massif, $1 \mathrm{~km}$ from Velevi village, Dolabistavi Cave, dark zone; $42.45^{\circ}$ N, $43.17^{\circ}$ E; 13 Oct. 2014; S. Barjadze leg.; SMNG • 2 o $ᄋ$; Verkhiye Tlugi village, Sakishore Cave, beyond siphon; $42.44^{\circ}$ N, 43.16 ${ }^{\circ}$ E; 20 Jan. 1987; V. Bogdanov

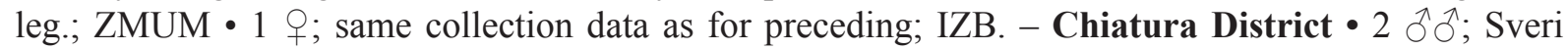
village, Kotias Cave; $42.21^{\circ} \mathrm{N}, 43.32^{\circ}$ E; 1 Mar. 2018; Z. Tsutskiridze, T. Arabuli and G. Nebieridze leg.; IZISU. - Kutaisi District • 1 ơ; Tskhal-Tsiteli Cave; $42.27^{\circ}$ N, $42.73^{\circ}$ E; 1 Aug. 1939; J. Birstein leg.; ZMUM.

\section{Redescription}

SiZE AND NUMBER OF BODY RINGS. Males 19-20 mm long, vertical diameter of largest body ring 1.3-1.4 mm, body with 33-36 podous rings $+0-1$ apodous ring + telson. Females $18-22 \mathrm{~mm}$ long, vertical diameter of largest body ring $1.5-1.6 \mathrm{~mm}$, body with $31-37$ podous rings $+0-1$ apodous ring + telson. 

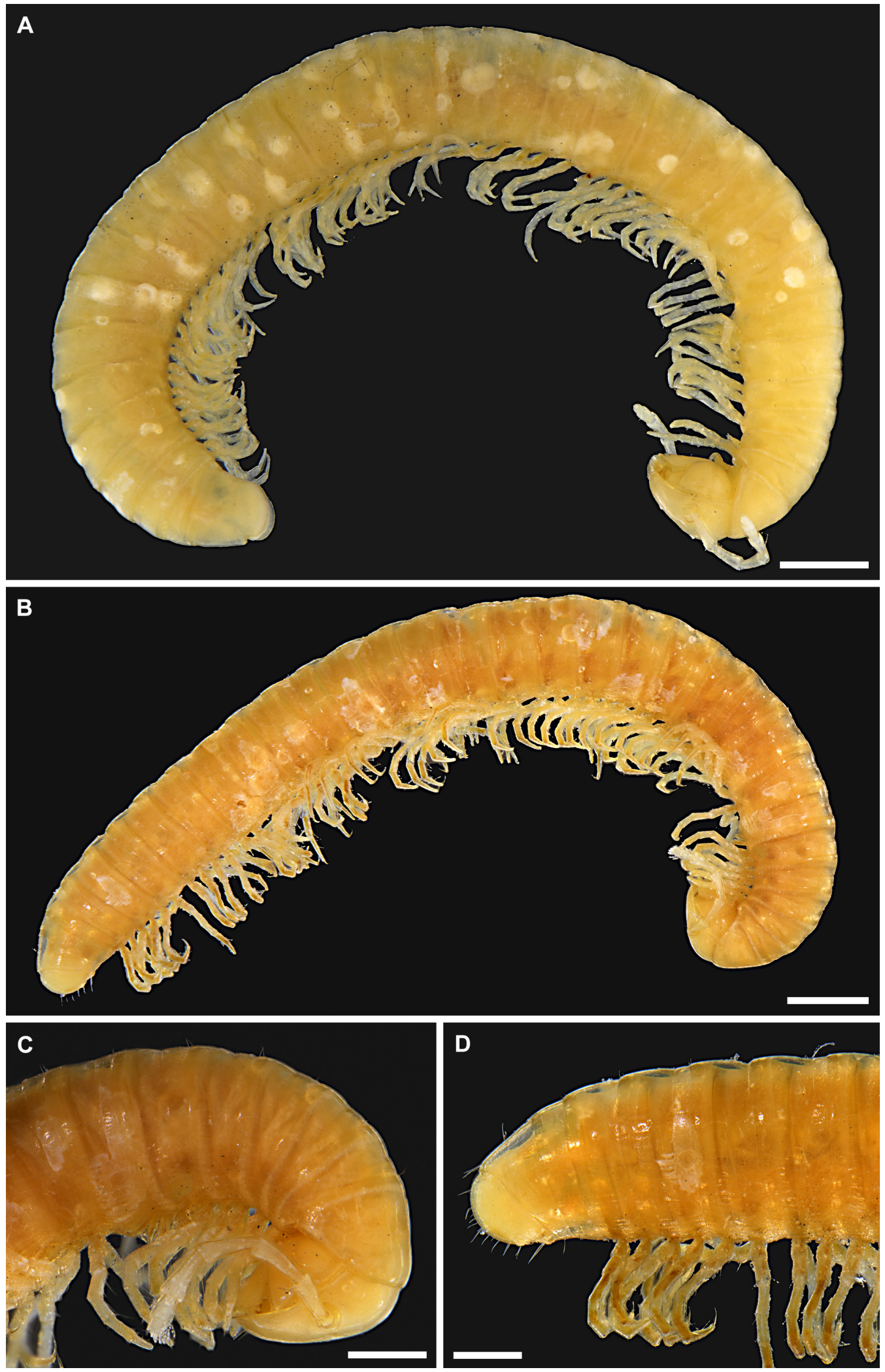

Fig. 7. Leucogeorgia longipes Verhoeff, 1930. A. Paralectotype $\widehat{\jmath}$ (NHMW 9980), habitus, lateral view. B-D. Lectotype (NHMW 3063). B. Habitus, lateral view. C. Anterior part of body, lateral view. D. Posterior part of body, lateral view. Photos: Oliver Macek (NHMW). Scale bars: A-B $=1 \mathrm{~mm}$; $\mathrm{C}-\mathrm{D}=0.5 \mathrm{~mm}$. 

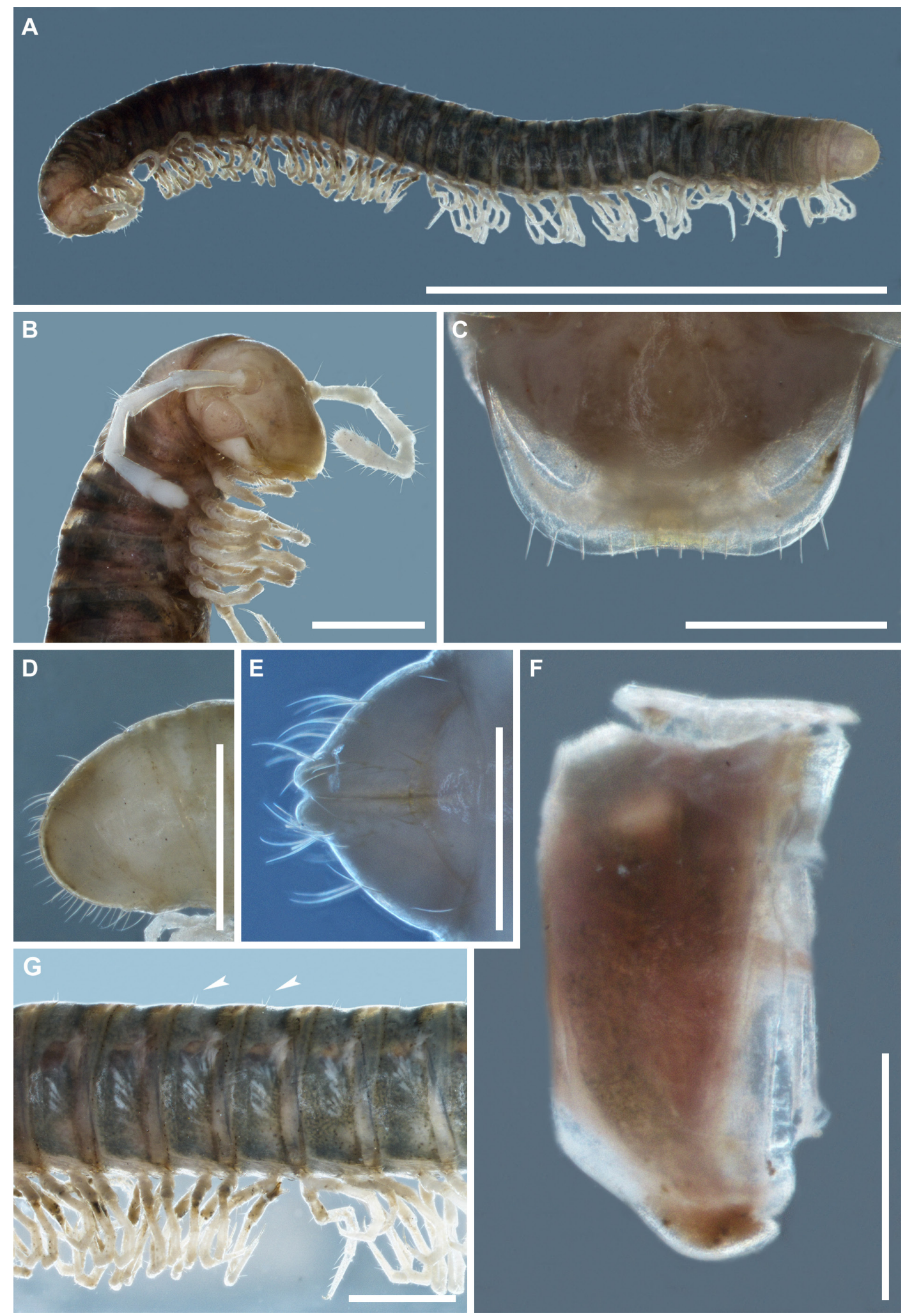

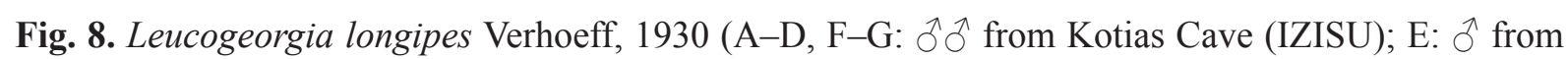
Dolabistavi Cave (SMNG)). A. Habitus, lateral view. B. Anterior part of body, anterolateral view. C. Head, anterodorsal view. D. Telson, lateral view. E. Telson, ventral view. F. Body ring 7, lateral view. G. Midbody rings, lateral view. Arrows indicate metazonal setae. Scale bars: A = 5 mm; B, D, F = $1 \mathrm{~mm}$; $\mathrm{C}, \mathrm{E}, \mathrm{G}=0.5 \mathrm{~mm}$. 
CoLour (Figs 7-8). Specimens in alcohol yellowish white to yellowish brown; a recently collected male greyish white.

Head (Figs 8B-C, 9B-E). Without ommatidia. Frontal setae absent. Labrum without labral teeth, with four supralabral and 12-19 labral setae. Gnathochilarium with rhomboid promentum; lamellae linguales with $2+2-3+3$ shorter basal setae and $3+5$ or $4+4$ long distal setae in a transverse row; stipites with $3+3-4+4$ distolateral setae and 5+5-9+9 medial setae. Antennae $1.8 \mathrm{~mm}$ long (in male from Kotias Cave), their length ca $130 \%$ of vertical diameter of largest body ring. Lengths of antennomeres I-VIII (in mm): 0.16 (I), 0.44 (II), 0.33 (III), 0.27 (IV), 0.35 (V), 0.15 (VI), 0.08 (VII) and 0.02 (VIII). Length/width ratio of antennomeres I-VII: 0.8 (I), 2.7 (II), 1.9 (III), 1.6 (IV), 1.8 (V), 0.9 (VI) and 0.7 (VII). Antennomeres V and VI each with a terminal corolla of large sensilla basiconica bacilliformia; antennomere VII with a terminal corolla of small sensilla basiconica bacilliformia.

Body RINGS (Fig. 8G). Ventrolateral sides of metazonae with longitudinal striations; dorsal and dorsolateral sides smooth. Length of midbody setae ca $6 \%$ of vertical diameter of rings.

Telson (Figs 7D, 8D-E). Epiproct without preanal process. Paraprocts rounded, setose, mesal edges strongly bulging, resembling lips. Hypoproct more or less lanceolate, with a slightly protruding mesodistal margin and two long apical setae.

LEGS IN MALES. First pair of legs modified, hook-shaped (Figs 9A, 10D), with three complete podomeres; coxa with one seta; prefemur with 3-5 setae; femur, postfemur and tibiotarsus coalesced; femur with three setae; postfemur with one seta. Tip slightly tuberculated. Postfemoral and tibial ventral pads poorly developed, more or less clearly visible on pregonopodal legs, only remnants on postgonopodal legs.

VeNTRAL MARGin OF MALE BOdY RING 7 (Fig. 8F). Low, more subquadrate in lateral view.

PenEs. Not checked.

Gonopods (Figs 2B, 9F, 10A-C). Promere (p) long and slender, with a flagellum (f); apical part spatulate, with denticulate margins; basal half with two developed ridges. Mesomere (m) with a hook-shaped mesomeral claw (mc), without denticles; mesomeral lamella (ml) high, slightly serrate, posterior part finely fimbriate. Opisthomere (o) bipartite. Anterior branch of o with a solenomere (s) with a mediumsized tip, and a well-developed and fimbriate velum (v). Posterior branch of o in form of a shield-like protective lamella $(\mathrm{pl})$. Mesomere and opisthomere connected basally with an accessory membrane (am).

\section{Distribution}

Known from five caves in Kutaisi, Ambrolauri and Chiatura districts in Central-West Georgia (Fig. 58, blue square).

\section{Remarks}

The type locality Rionhesi (= Sapichkhia) Cave is submerged due to the construction of the Rioni Hydroelectric Power Station near Kutaisi, in the early 1930s. This species was declared as probably extinct by Golovatch $(1983,1985)$ and Barjadze et al. (2018), but now with the discovery of new specimens in four additional caves in the same region, it has really been 'brought back to life'.

Verhoeff (1930) stated that specimens he examined had been found in small ponds. In addition to this, two males collected from the Kotias Cave were observed crawling on stones under the water (G. Nebieridze pers. comm.). In the same cave, L. longipes lives in sympatry with $L$. gioi sp. nov., a species with normal mouthparts. 

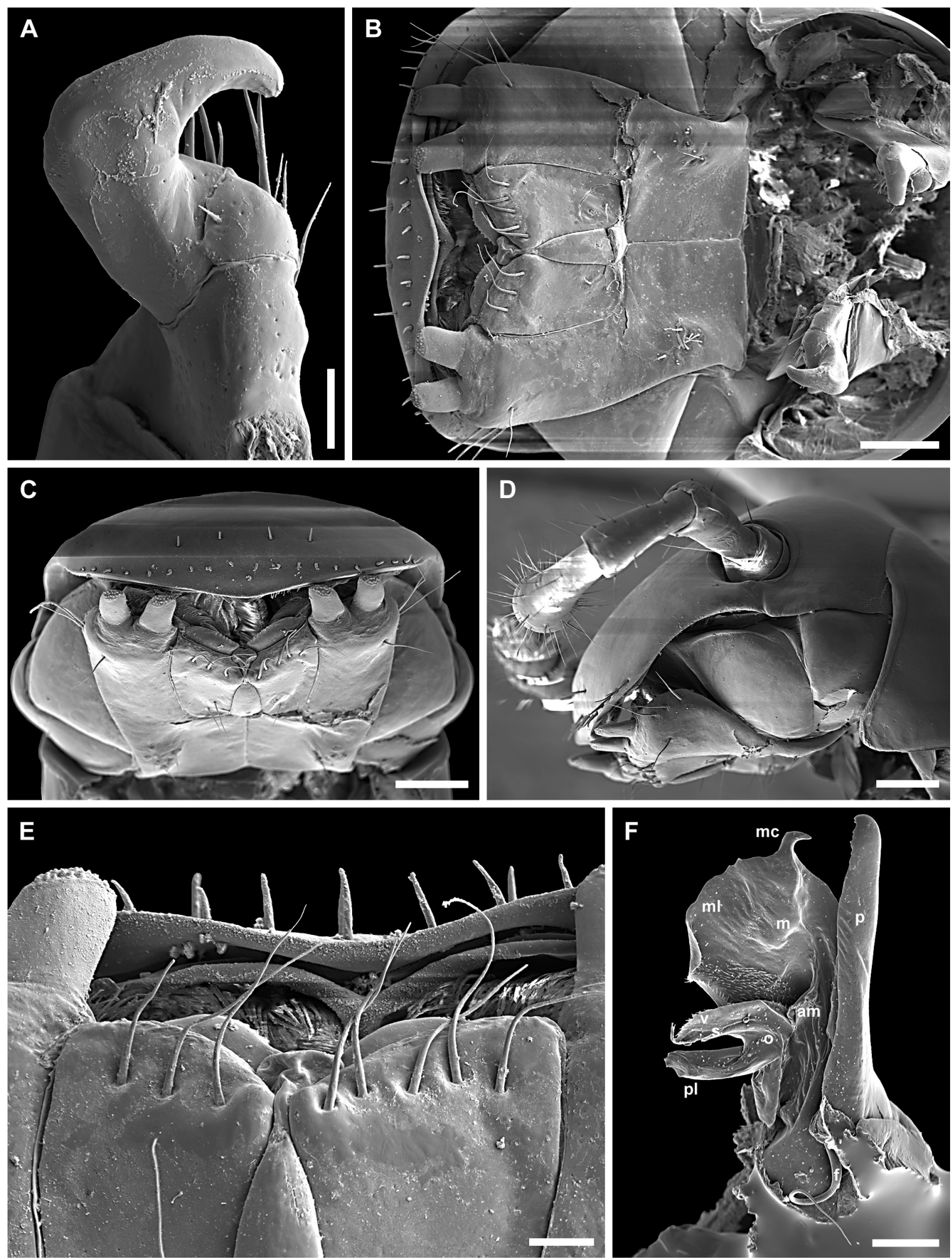

Fig. 9. Leucogeorgia longipes Verhoeff, 1930, ô from Dolabistavi Cave (SMNG). A. Left leg 1, lateral view. B. Head, ventral view. C. Head, anterior view. D. Head, lateral view. E. Anterior part of head, ventral view. F. Right gonopods, mesal view. Abbreviations: am = accessory membrane; $f=$ flagellum; $\mathrm{m}=$ mesomere $\mathrm{mc}=$ mesomeral claw $; \mathrm{ml}=$ mesomeral lamella; $\mathrm{o}=$ opisthomere; $\mathrm{p}=$ promere; $\mathrm{pl}=$ protective lamella; $\mathrm{s}=$ solenomere; $\mathrm{v}=$ velum. Scale bars: $\mathrm{A}, \mathrm{E}=0.05 \mathrm{~mm} ; \mathrm{B}-\mathrm{D}=0.2 \mathrm{~mm} ; \mathrm{F}=$ $0.1 \mathrm{~mm}$. 
Together with $L$. gioi sp. nov., these species represent the southeasternmost records of the genus Leucogeorgia.

A

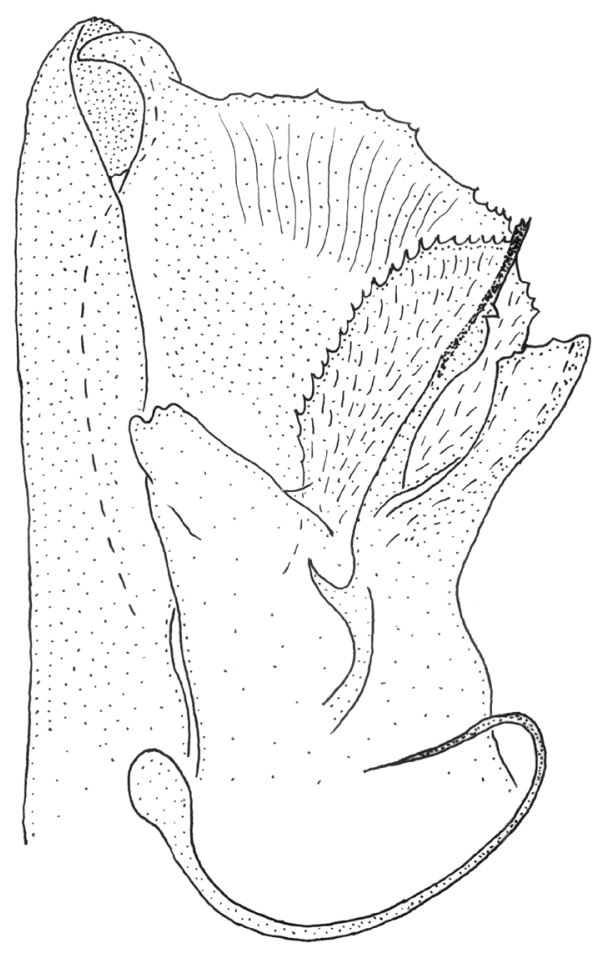

C

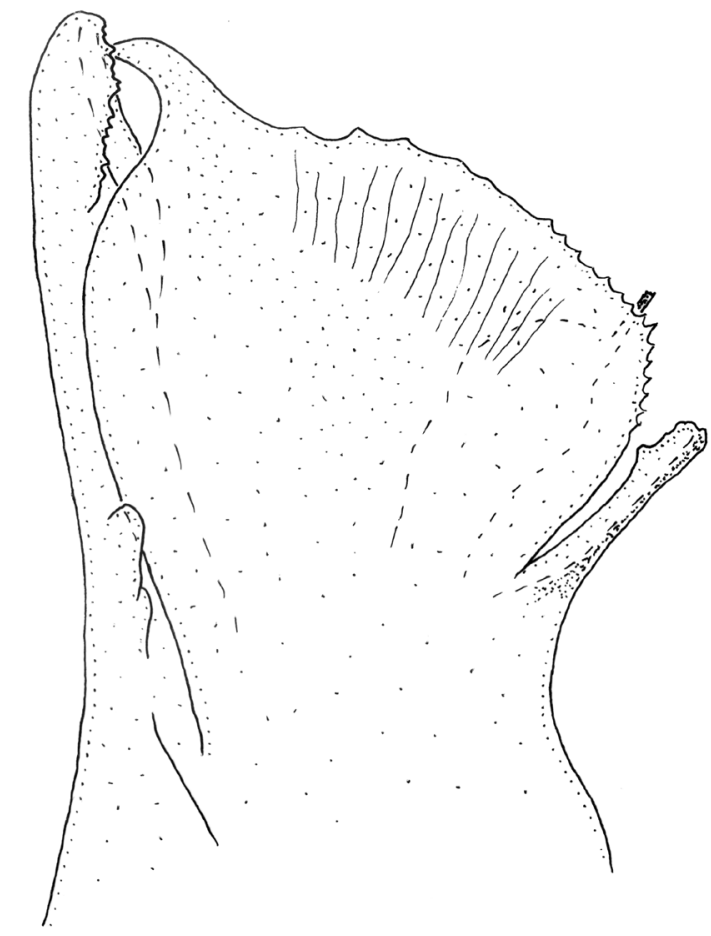

B

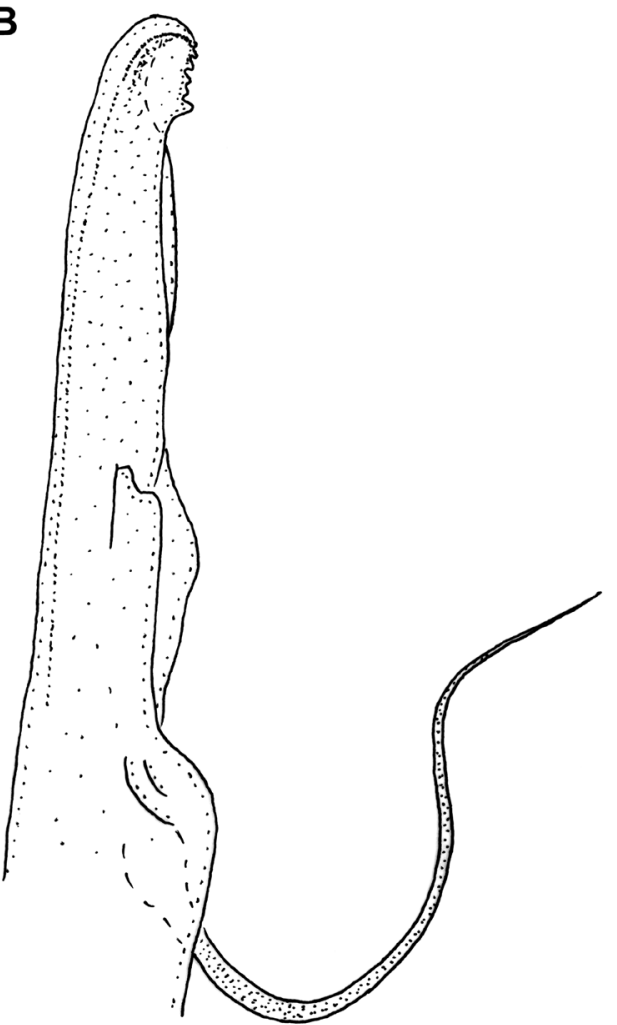

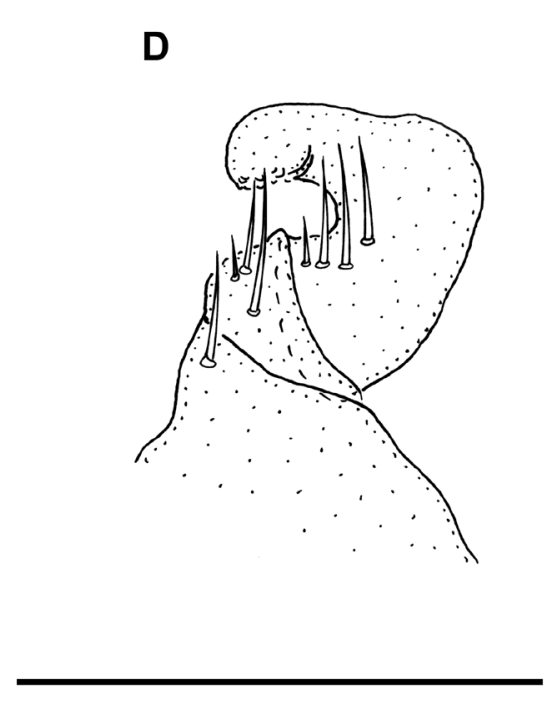

Fig. 10. Leucogeorgia longipes Verhoeff, 1930, ô from Kotias Cave (IZISU). A. Left gonopods, mesal view. B. Right promere, lateral view. C. Left gonopods, lateral view (flipped). D. Right leg 1, anterior view. Scale bar: $0.3 \mathrm{~mm}$. 


\section{Leucogeorgia rediviva Golovatch, 1983}

Figs 11-13, 56-57

Leucogeorgia rediviva Golovatch, 1983: 48.

\section{Diagnosis}

This species belongs to the group of Leucogeorgia spp. with modified mouthparts and with teeth on the mesomeral claw (vs absence of teeth in L. longipes). Leucogeorgia rediviva differs from L. mystax sp. nov., $L$. profunda sp. nov. and $L$. turbanovi sp. nov. by having a mesomeral claw that does not directly continue with the margin of the lamella, but is with a clear connection to the mesal side (vs a mesomeral claw that continues directly with the margin of the lamella, both parts being fully coalesced in L. mystax sp. nov., L. profunda sp. nov. and L. turbanovi sp. nov.). Leucogeorgia rediviva differs from L. caudata sp. nov. by having a more slender mesomeral claw and by the absence of a very long and sharp process on the epiproct, with a hyaline tip (vs a more robust mesomeral claw and the presence of a long and sharp process with a hyaline tip in L. caudata sp. nov.). Leucogeorgia rediviva differs from the superficially most similar $L$. redivivoides sp. nov. by having a somewhat more smooth and high central part of the mesomeral lamella, in the form of a lobe (vs the mesomeral lamella flattened, slightly denticulate in the central part in L. redivivoides sp. nov.), a lanceolate hypoproct (vs a subrhomboid hypoproct in L. redivivoides sp. nov.), a well-developed, rounded, ventral margin of male body ring 7 (vs ventral margin of male body ring 7 low, more squarish, with a right posterior angle in $L$. redivivoides sp. nov.) and a somewhat more elongate body with 38-47 podous rings in males (vs body more stocky, with $28-35$ podous rings in males of $L$. redivivoides sp. nov.).

\section{Material examined}

ABKHAZIA - Gudauty District • 1 §̊; Gumishkhinsky karst Massif, Novyi Afon, Novoafonskaya (= New Athos) Cave, hall Apsny; 43.09 N, 40.81 E; 20 May 2016; S.A. Kapralov leg.; ZMUM • 1 ठิ; Gumishkhinsky karst Massif, Gumishkha Mountain, near Khabyu village, Khabyu Cave; 43.20 N, 40.79 E; 1990; V.Kiselev leg.; SMNG • 2 ô $^{\wedge}$; Bzyb Mt Ridge, Khipstinsky karst Massif, Khipsta

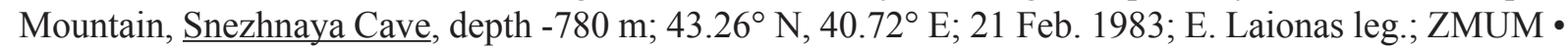
1 ; ; same locality as for preceding; 7 Jun. 1985; A. Kritsky leg.; ZMUM • 1 ${ }^{\lambda}$; same locality as for preceding; 5 Feb. 2015; S. Kebez and O. Lebedeva leg.; IZB • 1 \%; same locality as for preceding, depth $-1300 \mathrm{~m}$, between Iks and Penelopa halls; 13 Aug. 2017; A.S. Tyagunova leg.; ZMUM • 1 đ̃; same locality as for preceding, depth -1330 m, Tronnyi Hall; 15 Aug. 2017; A.S. Tyagunova leg.; ZMUM.

\section{Redescription}

SiZE AND NUMBER OF BODY RINGs. Males $26-35 \mathrm{~mm}$ long, vertical diameter of largest body ring 2-2.3 $\mathrm{mm}$, body with 38-47 podous rings $+0-2$ apodous rings + telson. Male from Novoafonskaya Cave 33 $\mathrm{mm}$ long, vertical diameter of largest body ring $2.1 \mathrm{~mm}$, body with 40 podous rings +0 apodous ring + telson.

CoLour (Fig. 11). In alcohol from pale yellow to dark brown.

HeAD (Figs 11B-C, 12C, E). Without ommatidia. Frontal setae absent. Labrum either without labral teeth or with three very small, reduced labral teeth; $3+2-3+3$ supralabral and $30-32$ labral setae. Male from Novoafonskaya Cave with three small labral teeth; with $3+3$ supralabral and 30 labral setae. Gnathochilarium with a triangular promentum; lamellae linguales with $1+1$ long distal setae and $3+4$ long proximal setae in male from Khabyu Cave; stipites with $3+3$ long distolateral setae; no other setae. Antennae $3.8 \mathrm{~mm}$ long (in male from Novoafonskaya Cave), their length ca $180 \%$ of vertical diameter of largest body ring. Lengths of antennomeres I-VIII (in mm): 0.19 (I), 0.76 (II), 0.86 (III), 0.73 (IV), $0.68(\mathrm{~V}), 0.37(\mathrm{VI}), 0.16$ (VII) and 0.05 (VIII). Length/width ratio of antennomeres I-VII: 0.8 (I), 3.4 (II), 3.7 (III), 3 (IV), 2.8 (V), 1.5 (VI) and 0.9 (VII). Lengths of antennae in other males $180-190 \%$ of 

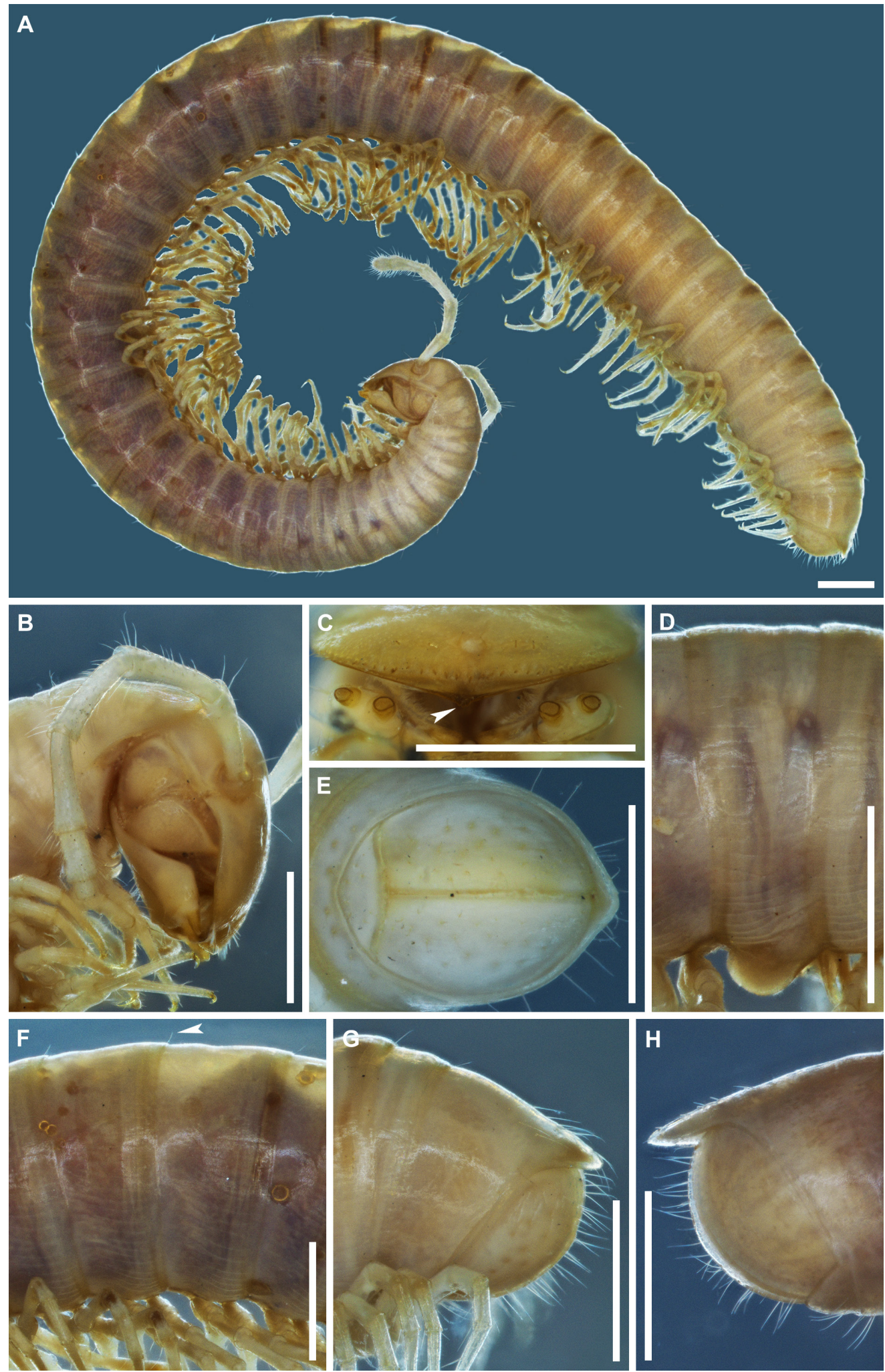

Fig. 11. Leucogeorgia rediviva Golovatch, 1983 (A-G: $ð$ from Novoafonskaya Cave (ZMUM); H: $\widehat{o}$ from Snezhnaya Cave (ZMUM)). A. Habitus, lateral view. B. Head, lateral view. C. Head, anterior view. D. Body ring 7, lateral view. E. Telson, posterior view. F. Midbody rings, lateral view. G. Telson, lateral view. H. Telson, lateral view. Arrows indicate three reduced labral teeth on C, or metazonal setae on F. Scale bars: $1 \mathrm{~mm}$. 
vertical diameter of largest body rings. Antennomeres V and VI each with a terminal corolla of large sensilla basiconica bacilliformia; antennomere VII with a terminal corolla of small sensilla basiconica bacilliformia.

Body RINGS (Fig. 11F). Ventral and ventrolateral sides of metazonal area with longitudinal striations. Dorsal side with poorly visible striations. Length of midbody setae ca $6 \%$ of vertical diameter of rings.

Telson (Fig. 11E, G-H). Epiproct variable, with a short to somewhat longer, blunt or somewhat acuminate preanal process. Paraprocts rounded, setose. Hypoproct lanceolate, with seven long setae in male from Novoafonskaya Cave.

LegS IN MALES. First pair of legs modified, hook-shaped (Fig. 12A-B), with three complete podomeres; coxa with one seta; prefemur with 5-6 setae; femur, postfemur and tibiotarsus coalesced; femur with 3-5 setae; postfemur with one seta; tibiotarsus with a small distal lobe (tarsal remnant). Tip tuberculated. Postfemoral and tibial ventral pads poorly developed on pregonopodal legs, then gradually disappearing on postgonopodal legs.

VeNTRAL MARGIN OF BODY RING 7 (Fig. 11D). Well-developed, rounded in lateral view.

Penes (Fig. 12F). Elongate, with two subtriangular apical lobes.

Gonopods (Figs 12D, 13). Promere (p) long and slender, with a flagellum (f); apical part spatulate, with denticulate margins; basal half with two developed ridges. Mesomere (m) with a well-developed denticulate mesomeral claw (mc); mesomeral lamella (ml) high, convex in central part, distal margin smooth, posterior part finely fimbriate. Opisthomere (o) bipartite. Anterior branch of o with a solenomere (s) with a medium-sized tip, and a well-developed and fimbriate velum (v). Posterior branch of o in form of a shield-like protective lamella (pl). Mesomere and opisthomere connected basally with an accessory membrane (am).

\section{Type locality}

Verkhne-Esherskaya Cave (= Sobachya $=$ Dzaglis), $43.08^{\circ} \mathrm{N}, 40.91^{\circ} \mathrm{E}$, near Verkhnyaya Eshera village, Sukhum District, Abkhazia.

\section{Distribution}

Known only from four caves in the Gudauty and Sukhum districts in Abkhazia (Fig. 57, violet square).

\section{Remarks}

Given that the holotype of L. rediviva appears to have been lost (S. Golovatch pers. comm.), while the female paratype is still available in the ZMUM collection, our identification of this species is based solely on the original description of Golovatch (1983). We have assigned to L. rediviva only males from three caves, viz., Snezhnaya, Novoafonskaya and Khabyu, of which the Novoafonskaya Cave is the closest (just a few kilometers away) to the type locality. The characters of the males from these caves generally coincide with Golovatch's (1983) description, albeit with some small exceptions. Both males from Novoafonskaya and Khabyu caves are characterized by the presence of three small, reduced labral teeth, while L. rediviva was characterized by Golovatch (1983) by the absence of labral teeth, a character shared with other congeners with modified mouthparts. Modified mouthparts, including the absence of labral teeth, are well-known not only in Leucogeorgia, but also in some species of Typhloiulus Latzel, 1884 and Trogloiulus Manfredi, 1931. Recently, one of us (DA) examined specimens of Typhloiulus with modified mouthparts from a cave in Italy, where intrapopulation variability was observed in the structure of the labrum, which may be toothless or with three teeth developed to varying degrees, but 

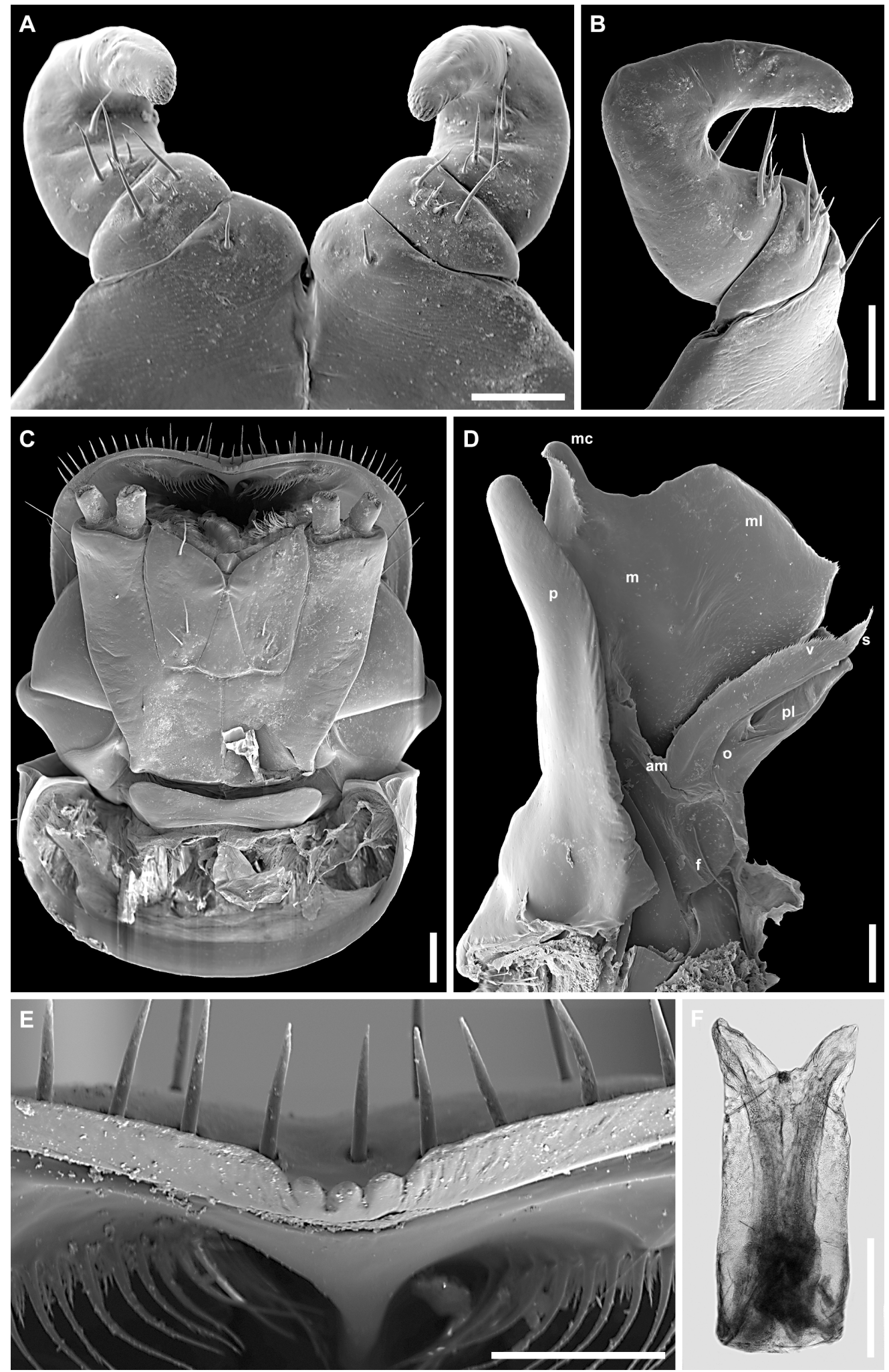

Fig. 12. Leucogeorgia rediviva Golovatch, 1983, ô from Khabyu Cave (SMNG). A. Leg-pair 1, anterior view. B. Left leg 1, lateral view. C. Head, ventral view. D. Left gonopods, mesal view. E. Detail of labrum, ventral view. F. Penes, posterior view. Abbreviations: $\mathrm{am}=$ accessory membrane; $\mathrm{f}=$ flagellum; $\mathrm{m}=$ mesomere $\mathrm{mc}=$ mesomeral claw; $\mathrm{ml}=$ mesomeral lamella; $\mathrm{o}=$ opisthomere $; \mathrm{p}=$ promere; $\mathrm{pl}=$ protective lamella; $\mathrm{s}=$ solenomere; $\mathrm{v}=$ velum. Scale bars: $\mathrm{A}-\mathrm{B}, \mathrm{D}-\mathrm{E}=0.1 \mathrm{~mm} ; \mathrm{C}, \mathrm{F}=0.2 \mathrm{~mm}$. 
never developed as in the congeners with normal mouthparts. Thus, we do not consider the presence of three reduced labral teeth in some specimens to be an important feature. Males from the Snezhnaya Cave possess a somewhat longer and more robust process on the epiproct (see Fig. 11G-H). Yet, this process can be variable in some species as well, even within the same population (see below and Antic et al. 2018b: 261, fig. 1e-g), and in this case we do not allot it too much importance either.

The Novoafonskaya Cave is the type locality of L. caudata sp. nov., also with modified mouthparts, where the two species are living at least sympatrically. The presence of two species of Leucogeorgia with modified mouthparts in the same cave is not rare, since there are a few more examples where two species are sympatric or even syntopic in the same cave (see below).
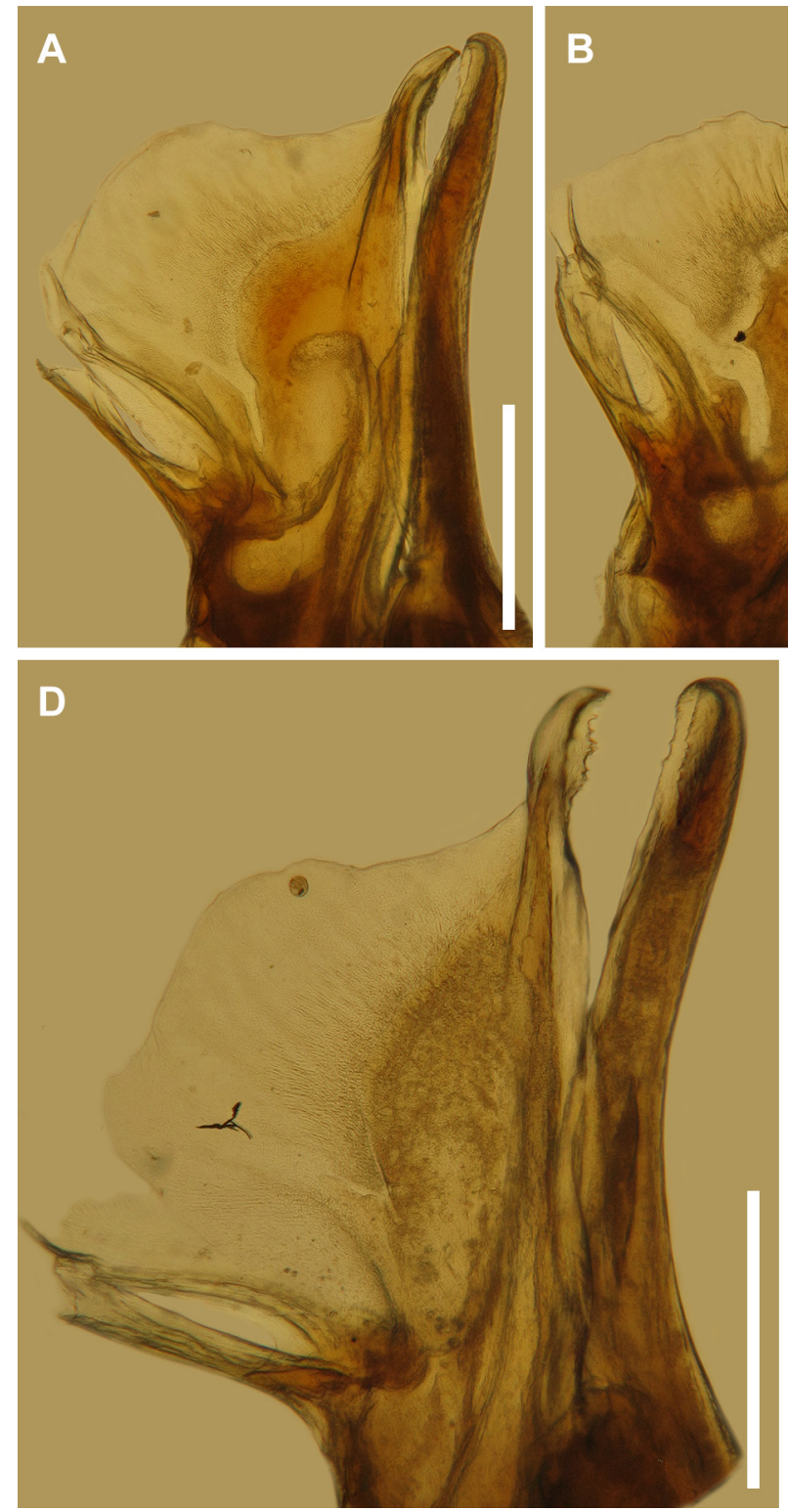
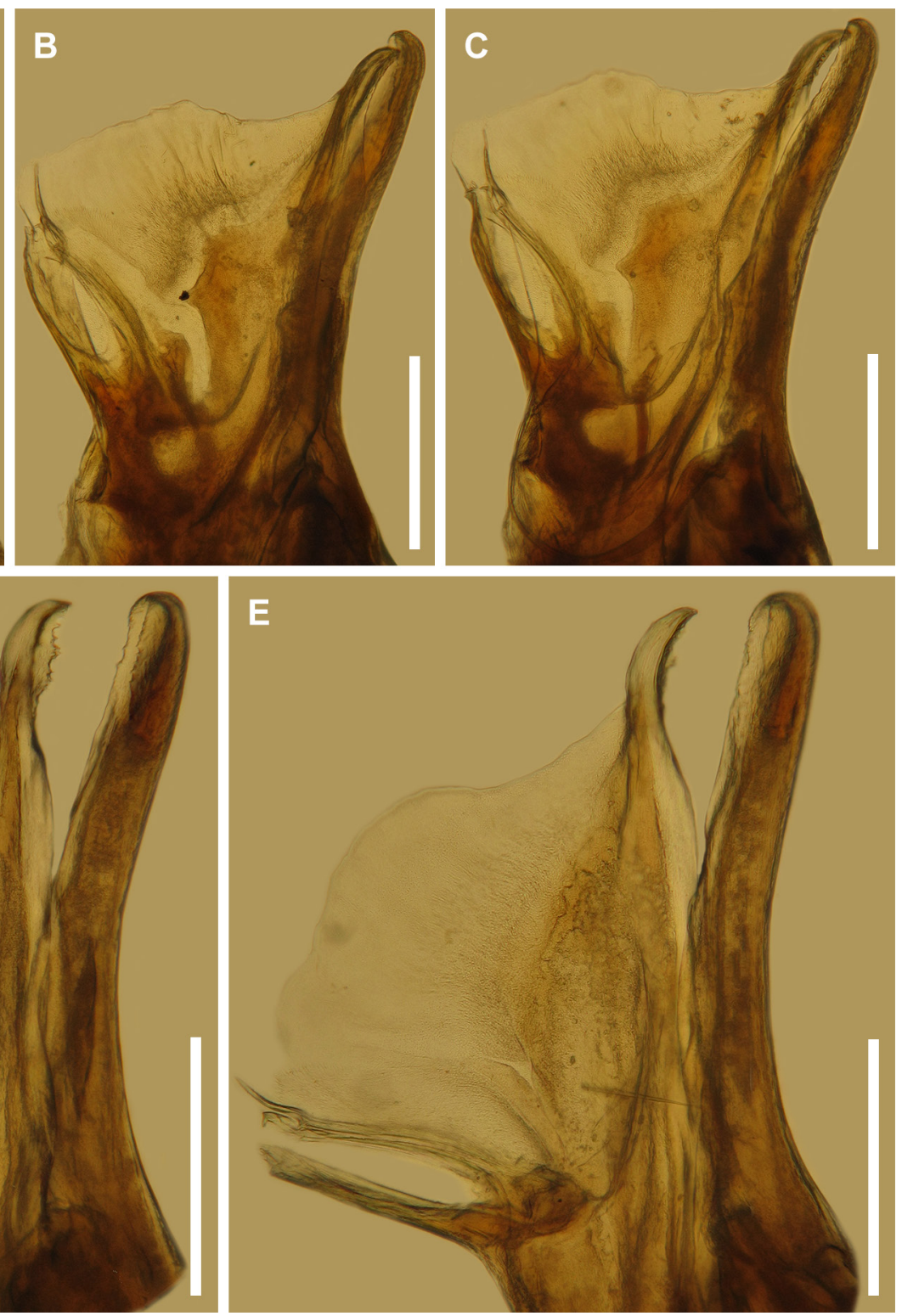

Fig. 13. Leucogeorgia rediviva Golovatch, 1983, gonopods. A. § from Khabyu Cave, right gonopods, mesal view (SMNG). B. $\hat{\sigma}$ from Novoafonskaya Cave, left gonopods, lateral view (ZMUM). C. $\widehat{\jmath}$ from Novoafonskaya Cave, right gonopods, mesal view (ZMUM). D. $\lesssim$ from Snezhnaya Cave, left gonopods, lateral view (ZMUM). E. §̊ from Snezhnaya Cave, right gonopods, mesal view (ZMUM). Scale bars: $0.3 \mathrm{~mm}$. 
In the Snezhnaya Cave, several specimens were observed underwater. Some of them were almost motionless and seemed to 'graze' the sediment, while others were poorly mobile and attached to the bottom, despite a strong water current (I. Turbanov pers. comm.).

Leucogeorgia satunini (Lohmander, 1936) comb. nov.

Figs 2D, 14-15, 56-57

Archileucogeorgia satunini Lohmander, 1936: 95.

\section{Diagnosis}

This species belongs to the group of Leucogeorgia spp. without modified mouthparts and with teeth on the mesomeral claw (vs their absence in L. golovatchi sp. nov., L. lobata sp. nov. and L. prometheus sp. nov.). Leucogeorgia satunini differs from L. abchasica by having a mesomeral lamella of the same height all along and the presence of a posterior rise (vs height of the mesomeral lamella gradually decreasing caudad, also lacking a posterior rise in L. abchasica), and by having a rounded ventral margin of male body ring 7 without strong teeth in ventral view (vs subtriangular ventral margin of male body ring 7 with strong teeth in ventral view in L. abchasica). Leucogeorgia satunini differs from both $L$. borealis sp. nov. and L. oculata sp. nov. by having an elongate and erect mesomeral claw (vs stout in L. borealis sp. nov. and L. oculata sp. nov.). Leucogeorgia satunini differs from L. gioi sp. nov. by having a more robust and strongly denticulate mesomeral claw (vs mesomeral claw being more slender and with just a few teeth in $L$. gioi sp. nov.) and a not too strongly denticulate mesomeral lamella (vs mesomeral lamella strongly denticulate in L. gioi sp. nov.). From L. oculata sp. nov., L. satunini in addition differs by the absence of both pigmenation and ommatidia (vs a pigmented body and ommatidia present in L. oculata sp. nov.). Besides all this, L. satunini differs from all of the previously mentioned species by the presence of longer midbody metazonal setae, these being ca $10 \%$ of vertical diameter of rings (vs either midbody metazonal setae $5-6 \%$ of vertical diameter of rings in L. abchasica, L. borealis sp. nov. and $L$. gioi sp. nov. or metazonal setae completely absent in L. oculata sp. nov.).

\section{Material examined}

ABKHAZIA - Gulripsh District • 1 $\partial_{,} 3$ q $\odot, 8$ juvs; Tsebeldinsky karst Massif, near Nizhniy Kyalasur village, Kelasurskaya Cave, depth -95 m; $43.02^{\circ}$ N, 41.14 E; 3 Sep. 2014; I.S. Turbanov leg.; ZMUM.

\section{Redescription}

SizE AND NUMBER OF BODY RINGS. Male $17 \mathrm{~mm}$ long, vertical diameter of largest body ring $1 \mathrm{~mm}$, body with 43 podous rings +1 apodous ring + telson. Females $14-16.5 \mathrm{~mm}$ long, vertical diameter of largest body ring $0.95-1.2 \mathrm{~mm}$, body with $38-40$ podous rings $+1-2$ apodous rings + telson.

Colour (Fig. 14). Yellowish white in alcohol.

HEAD (Figs 14B, 15A). Without ommatidia. Frontal setae absent. Labrum with three labral teeth, four supralabral setae and 14 labral setae. Gnathochilarium with rhomboid promentum. Lamellae linguales with $4+4$ setae, stipites with $3+3$ distolateral and 5+4 medial setae. Antennae $1.5 \mathrm{~mm}$ long in male, their length $150 \%$ of vertical diameter of largest body ring. Lengths of antennomeres I-VIII (in $\mathrm{mm}$ ): 0.08 (I), 0.34 (II), 0.27 (III), 0.24 (IV), 0.28 (V), 0.17 (VI), 0.1 (VII) and 0.02 (VIII). Length/width ratio of antennomeres I-VII: 0.8 (I), 3.4 (II), 2.5 (III), 2 (IV), 2.1 (V), 1.1 (VI) and 1 (VII). Antennomeres $\mathrm{V}$ and VI each with a terminal corolla of large sensilla basiconica bacilliformia; antennomere VII with a terminal corolla of small sensilla basiconica bacilliformia.

Body RINGS (Fig. 14C). Entire metazonal area with longitudinal striations. Metazonal setae relatively long, length of midbody setae ca $10 \%$ of vertical diameter of rings. 

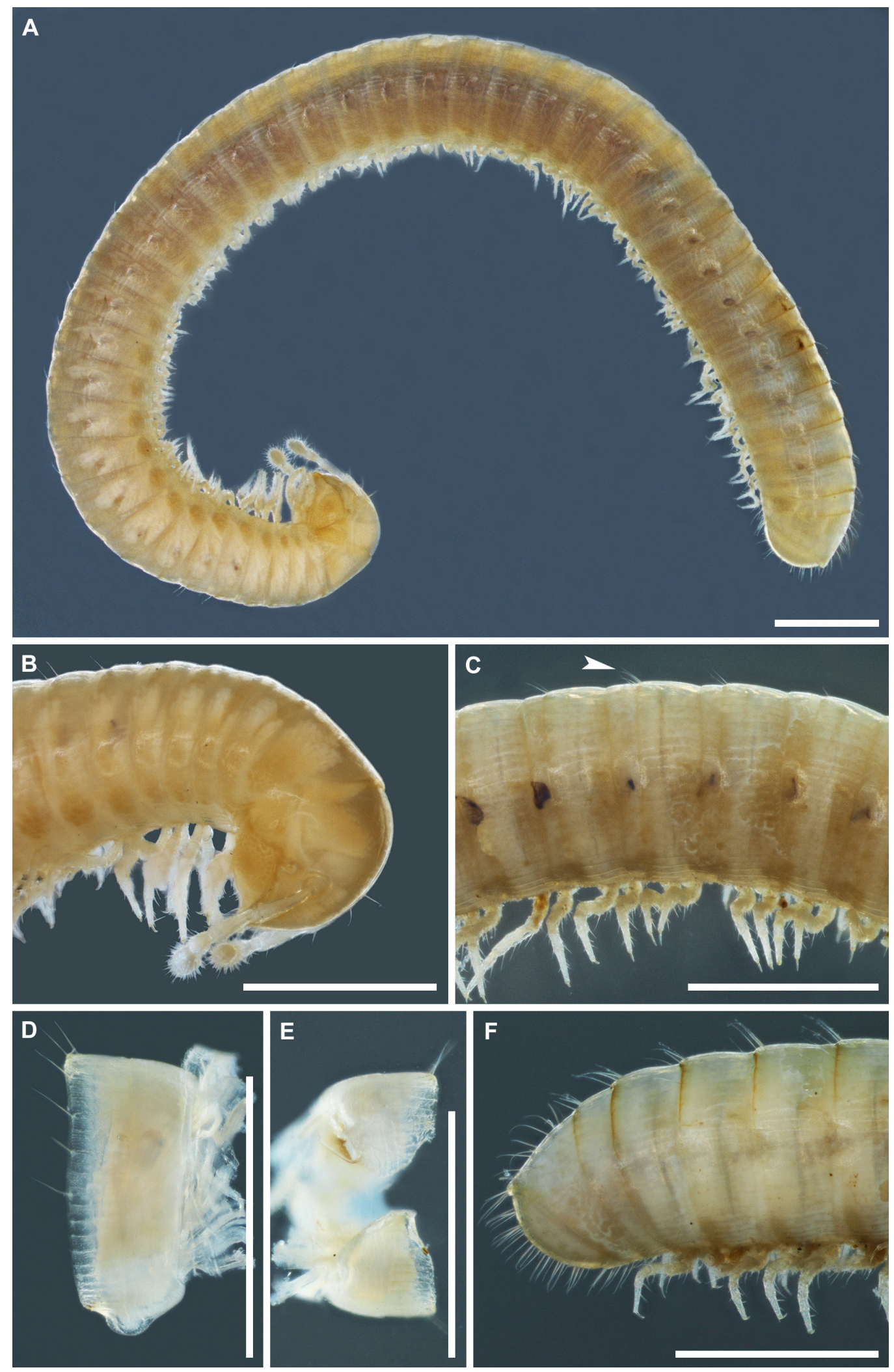

Fig. 14. Leucogeorgia satunini (Lohmander, 1936) comb. nov., $q$ and $\hat{\sigma}$ from Kelasurskaya Cave (ZMUM). A. + , habitus, lateral view. B. + , anterior part of body, lateral view. C. $\overbrace{}^{\lambda}$, midbody rings,

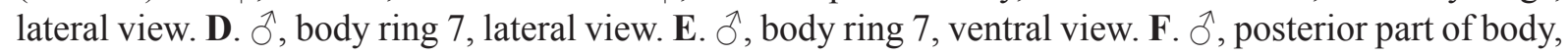
lateral view. Scale bars: $1 \mathrm{~mm}$. 

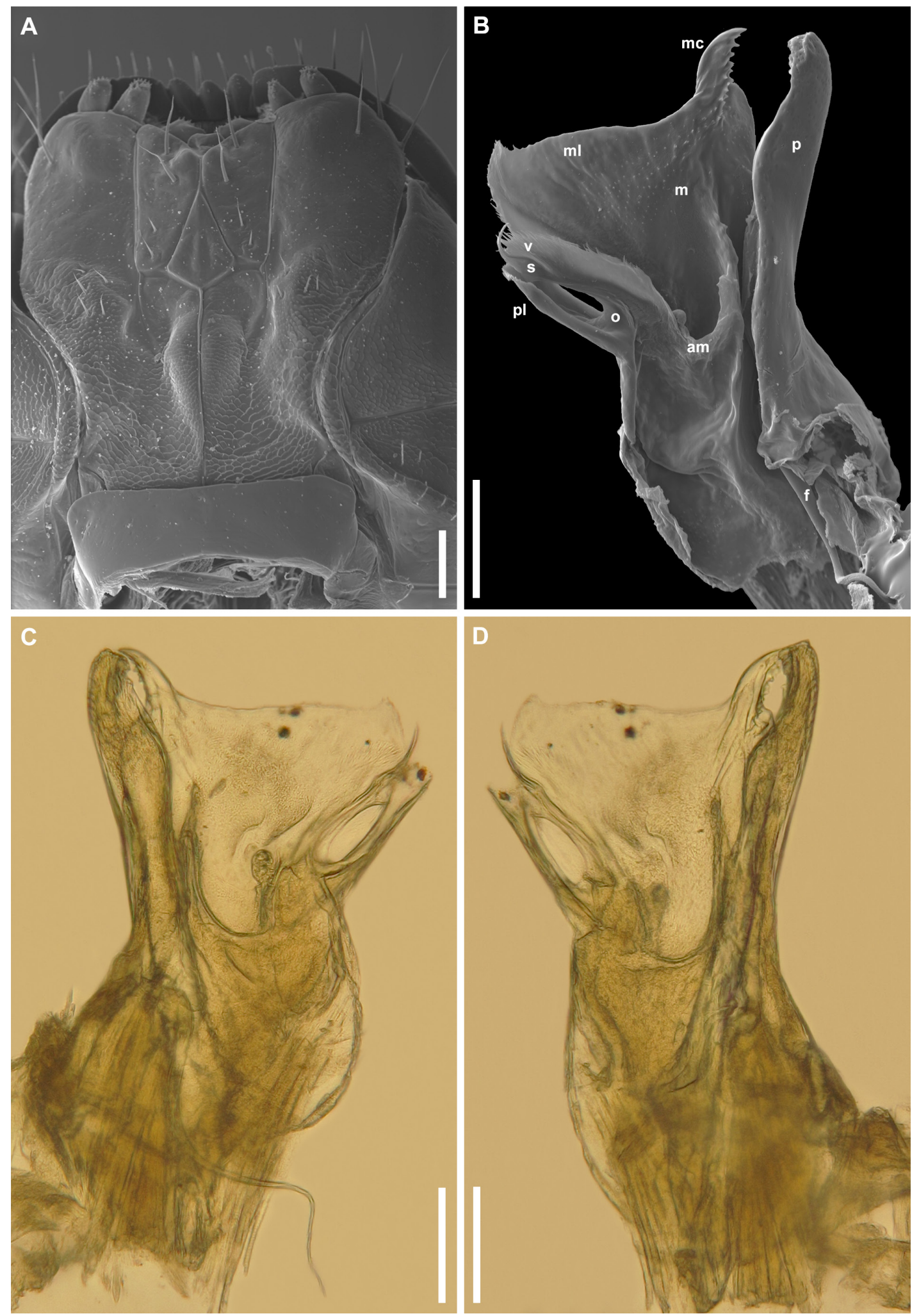

Fig. 15. Leucogeorgia satunini (Lohmander, 1936) comb. nov., ô from Kelasurskaya Cave (ZMUM). A. Head, ventral view. B. Right gonopods, mesal view. C. Left gonopods, mesal view. D. Left gonopods, lateral view. Abbreviations: $\mathrm{am}=$ accessory membrane; $\mathrm{f}=$ flagellum; $\mathrm{m}=$ mesomere; $\mathrm{mc}=$ mesomeral claw; $\mathrm{ml}=$ mesomeral lamella; $\mathrm{o}=$ opisthomere; $\mathrm{p}=$ promere; $\mathrm{pl}=$ protective lamella; $\mathrm{s}=$ solenomere; $\mathrm{v}=$ velum. Scale bars: $0.1 \mathrm{~mm}$. 
TeLSON (Fig. 14F). Epiproct with a very short and blunt preanal process, covered with dorsal and lateral setae. Paraprocts rounded, with numerous setae. Hypoproct without any modifications.

Legs IN MALES. First pair of legs lost during SEM manipulations. Postfemoral and tibial ventral pads well developed on anterior legs, then gradually disappearing towards posterior legs.

Ventral Margin of MALE Body RING 7 (Fig. 14D-E). Well-developed, rounded in lateral view, without strong teeth in ventral view.

PenEs. Not examined.

Gonopods (Figs 2D, 15B-D). Promere (p) long and slender, slightly wider in central part, with a flagellum (f); apical part spatulate, with denticulate margins; basal half with two developed ridges. Mesomere (m) with a well-developed and denticulate mesomeral claw (mc); mesomeral lamella of same height as entire length, with a posterior rise, distal margin smooth, posterior part finely fimbriate. Opisthomere (o) bipartite. Anterior branch of o with a solenomere (s) with a medium-sized tip, and a well-developed and fimbriate velum (v). Posterior branch of o in form of a shield-like protective lamella (pl). Mesomere and opisthomere connected basally with an accessory membrane (am).

\section{Type locality}

Canyon of the Kelasuri River, Sukhum and Gulripsh districts, Abkhazia.

\section{Distribution}

Known only from three localities in Sukhum and Gulripsh districts (Fig. 57, black triangle).

\section{Remarks}

In the Kelasurskaya Cave, this species lives together with L. abchasica and an unidentified Leucogeorgia with modified mouthparts.

\section{New species without modified mouthparts}

Leucogeorgia borealis sp. nov. urn:1sid:zoobank.org:act:D8CFFCD0-8D33-42A0-B7FD-E8FDE92E99E2

Figs $16-18,56-57$

\section{Diagnosis}

This species belongs to the group of Leucogeorgia spp. without modified mouthparts and with teeth on the mesomeral claw (vs absent in L. golovatchi sp. nov., L. lobata sp. nov. and L. prometheus sp. nov.). Leucogeorgia borealis sp. nov. differs from L. abchasica, L. satunini and L. gioi sp. nov. by having a stout mesomeral claw (vs elongate and slender in L. abchasica, L. satunini and L. gioi sp. nov). Leucogeorgia borealis sp. nov. differs from $L$. oculata sp. nov. by having a strongly serrate mesomeral lamella without a posterior rise (vs lamella non-serrate and with a posterior rise in L. oculata sp. nov.), and in the absence both of pigmentation and ommatidia, and the presence of metazonal setae (vs a pigmented body, ommatidia present and metazonal setae absent in L. oculata sp. nov.).

\section{Etymology}

From the Latin 'boreas' (= 'north'), reflecting its having the northernmost species in the genus. Adjective. 

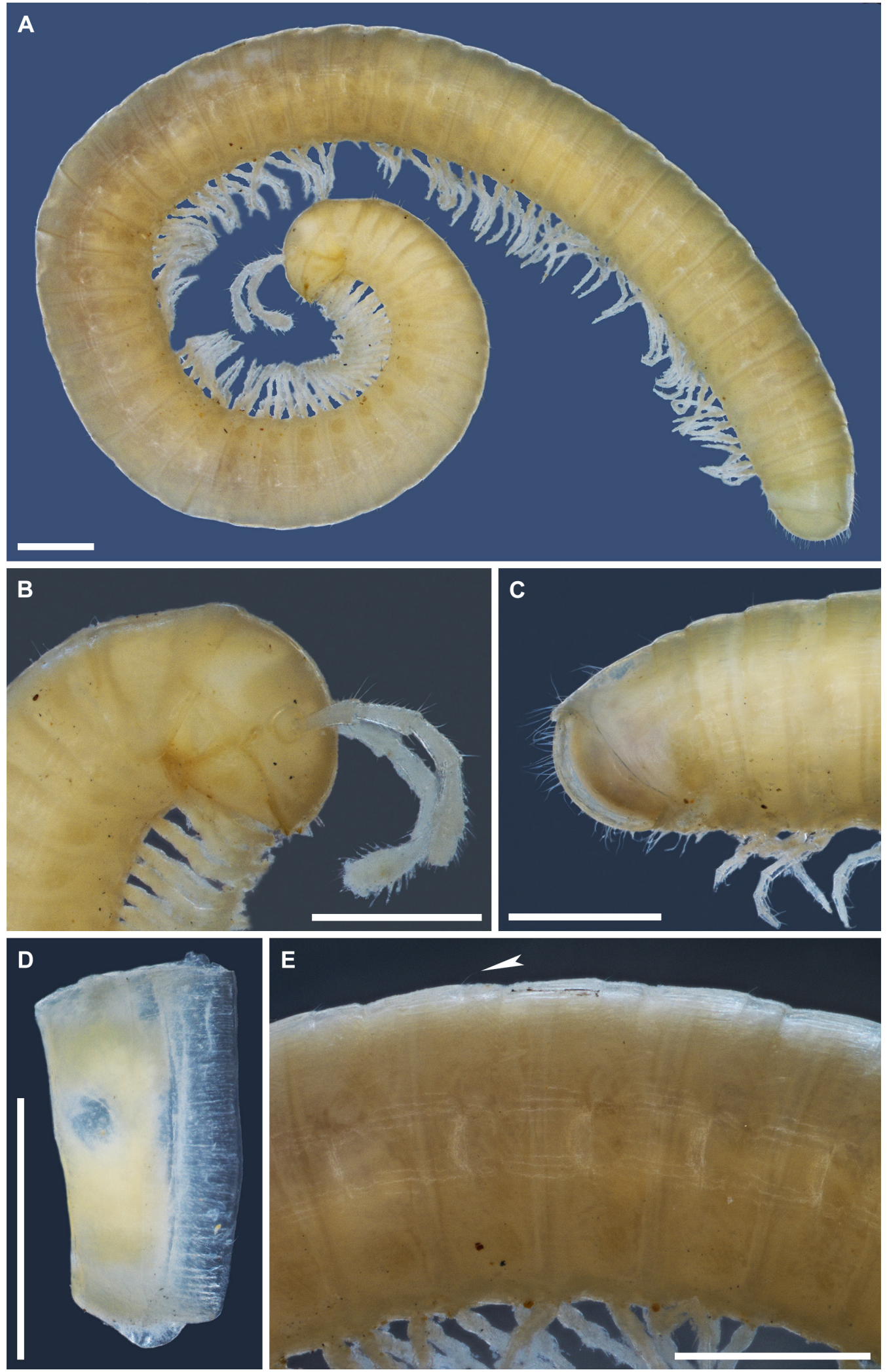

Fig. 16. Leucogeorgia borealis sp. nov., types from Fanagoriyskaya Cave (ZMUM). A. Paratype , habitus, lateral view. B. Paratype $q$, anterior part of body, lateral view. C. Paratype $\curvearrowright$, posterior part of body, lateral view. D. Holotype $\widehat{\partial}$, body ring 7, lateral view. E. Paratype $q$, midbody rings, lateral view. Arrow indicated metazonal seta. Scale bars: $1 \mathrm{~mm}$. 


\section{Type material}

\section{Holotype}

RUSSIA - गे; Krasnodar Province, near Goryachiy Klyuch, NW karst area of Greater Caucasus, Fanagoriyskaya (= Bolshaya Fanagoriyskaya, = Psekupskaya) Cave; $44.47^{\circ}$ N, $38.98^{\circ}$ E; 3 Nov. 1943; J. Birstein leg.; ZMUM.

\section{Paratypes}

RUSSIA • 1 đ̃, 1 क , 2 juvs; same collection data as for holotype but 8 Jul. 1961; S.I. Ljovuschkin leg.; ZMUM • 1 juv.; same collection data as for holotype but 19 May 1983; S.I. Golovatch leg.; ZMUM • 1 क; same collection data as for holotype but 20 Sep. 1968; ZMUM.

\section{Description}

SizE AND NUMBER OF BODY RINGS. Holotype male $24 \mathrm{~mm}$ long, vertical diameter of largest body ring 1.5 $\mathrm{mm}$, body with 43 podous rings +1 apodous ring + telson. Paratype male $28 \mathrm{~mm}$ long, vertical diameter of largest body ring $1.55 \mathrm{~mm}$, body with 49 podous rings +2 apodous rings + telson. Paratype females 21 and $24 \mathrm{~mm}$ long, vertical diameter of largest body ring $1.4-1.5 \mathrm{~mm}$, body with 37 or 44 podous rings +1 apodous ring + telson.

Colour (Fig. 16). Yellowish white in alcohol.

Head (Figs 16B, 17C). Without ommatidia. Frontal setae absent. Labrum with three labral teeth, four supralabral setae and 17 labral setae in paratype male. Gnathochilarium with a rhomboid promentum; lamellae linguales with $4+4$ setae, stipites with $3+3$ distolateral and $5+6$ medial setae. Antennae $1.9 \mathrm{~mm}$ long in smaller paratype female, their length ca $140 \%$ of vertical diameter of largest body ring. Lengths of antennomeres I-VIII (in mm): 0.13 (I), 0.45 (II), 0.36 (III), 0.30 (IV), 0.40 (V), 0.18 (VI), 0.06 (VII) and 0.02 (VIII). Length/width ratio of antennomeres I-VII: 0.8 (I), 3 (II), 2.4 (III), 2 (IV), 2.7 (V), 1 (VI) and 0.5 (VII). Antennomeres V and VI each with a terminal corolla of large sensilla basiconica bacilliformia; antennomere VII with a terminal corolla of small sensilla basiconica bacilliformia.

Body RINGS (Fig. 16E). Entire metazonal area with longitudinal striations. Length of midbody setae ca $5 \%$ of vertical diameter of rings.

Telson (Fig. 16C). Epiproct with a short and blunt preanal process, covered with dorsal and lateral setae. Paraprocts rounded, setose. Hypoproct without any modifications.

LEGS IN MALES. First pair of legs modified, hook-shaped (Figs 17A-B, 18D-E), with three complete podomeres; coxa with two setae; prefemur with four setae; femur, postfemur and tibiotarsus coalesced; femur with two setae; postfemur with one seta; tibiotarsus with a prominent distal lobe (tarsal remnant). Tip slightly tuberculated. Postfemoral and tibial ventral pads well developed on anterior legs, then gradually disappearing towards posterior legs.

Ventral margin of male body Ring 7 (Fig. 16D). Poorly developed, low, rounded in lateral view.

Penes (Fig. 18C). In form of a short trapezoid, apically with two small subtriangular lobes.

Gonopods (Figs 17D, 18A-B). Promere (p) long and slender, with a flagellum (f); apical part spatulate, with denticulate margins; basal half with two developed ridges. Mesomere $(\mathrm{m})$ with a well-developed, robust and denticulate mesomeral claw $(\mathrm{mc})$; mesomeral lamella $(\mathrm{ml})$ convex in central part, distal margin serrate, posterior part finely fimbriate. Opisthomere (o) bipartite. Anterior branch of o with a solenomere (s), with a medium-sized tip, and a well-developed and fimbriate velum (v). Posterior branch 
of $\mathrm{o}$ in form of a shield-like protective lamella (pl). Mesomere and opisthomere connected basally through an accessory membrane (am).
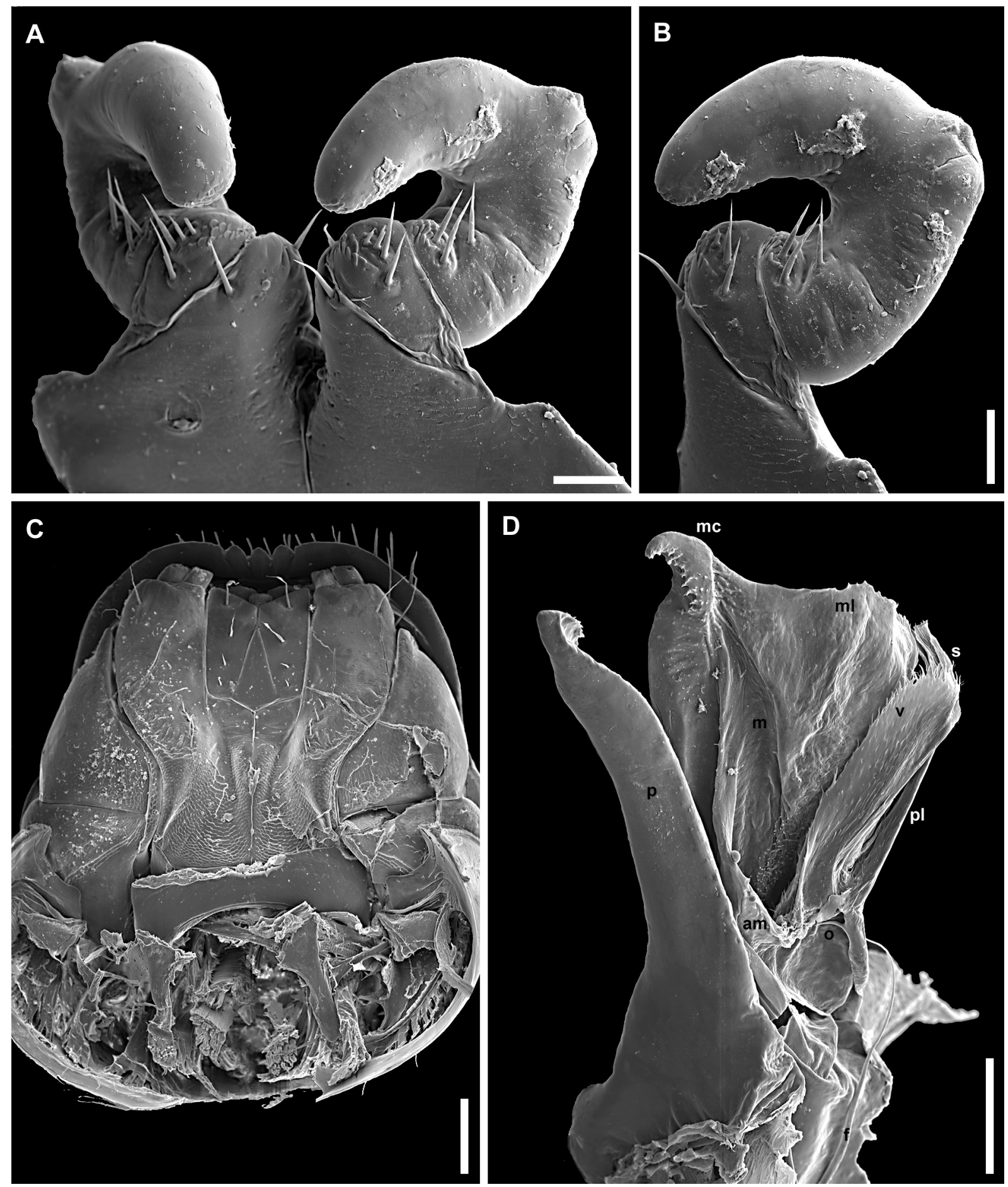

Fig. 17. Leucogeorgia borealis sp. nov., paratype $\delta^{\Uparrow}$ from Fanagoriyskaya Cave (ZMUM). A. Leg-pair 1, anterior view. B. Right leg 1, lateral view. C. Head, ventral view. D. Left gonopods, mesal view. Abbreviations: $\mathrm{am}=$ accessory membrane $\mathrm{f}=$ flagellum; $\mathrm{m}=$ mesomere $; \mathrm{mc}=$ mesomeral claw; $\mathrm{ml}=$ mesomeral lamella; $\mathrm{o}=$ opisthomere; $\mathrm{p}=$ promere; $\mathrm{pl}=$ protective lamella; $\mathrm{s}=$ solenomere; $\mathrm{v}=$ velum. Scale bars: A-B $=0.05 \mathrm{~mm} ; \mathrm{C}=0.2 \mathrm{~mm} ; \mathrm{D}=0.1 \mathrm{~mm}$. 


\section{Distribution}

Known only from its type locality (Fig. 57, blue triangle).

\section{Remarks}

This is the northwesternmost record of the entire genus.

A

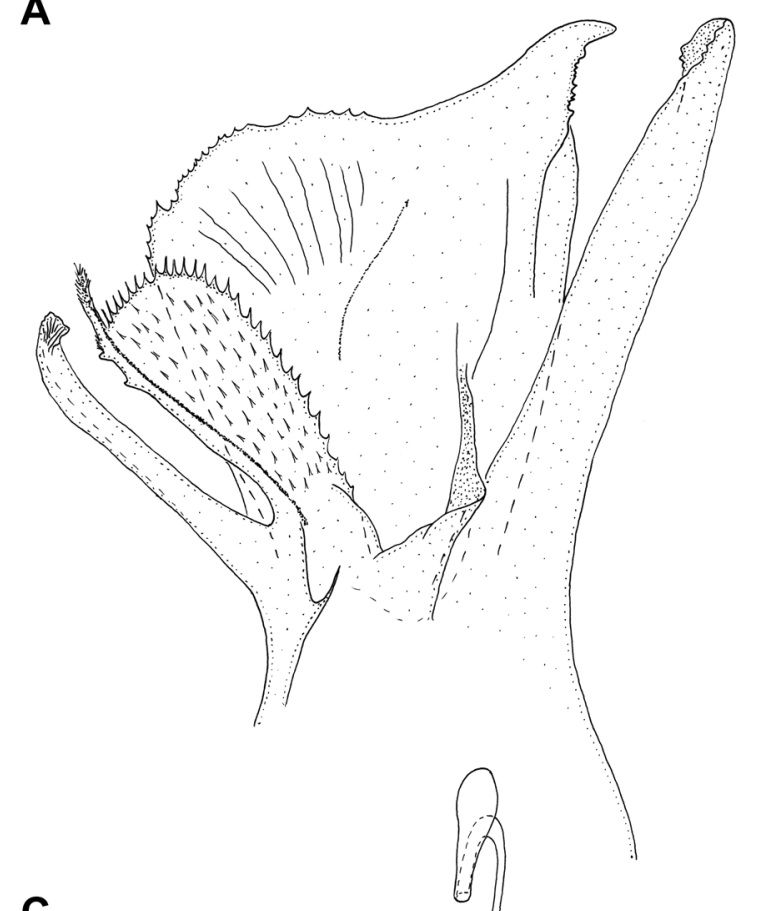

C

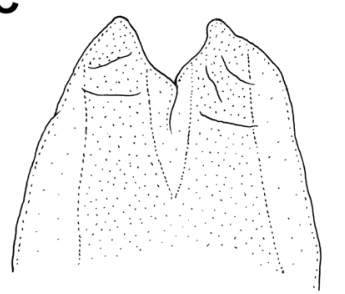

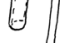

D

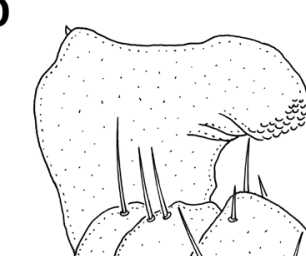

B

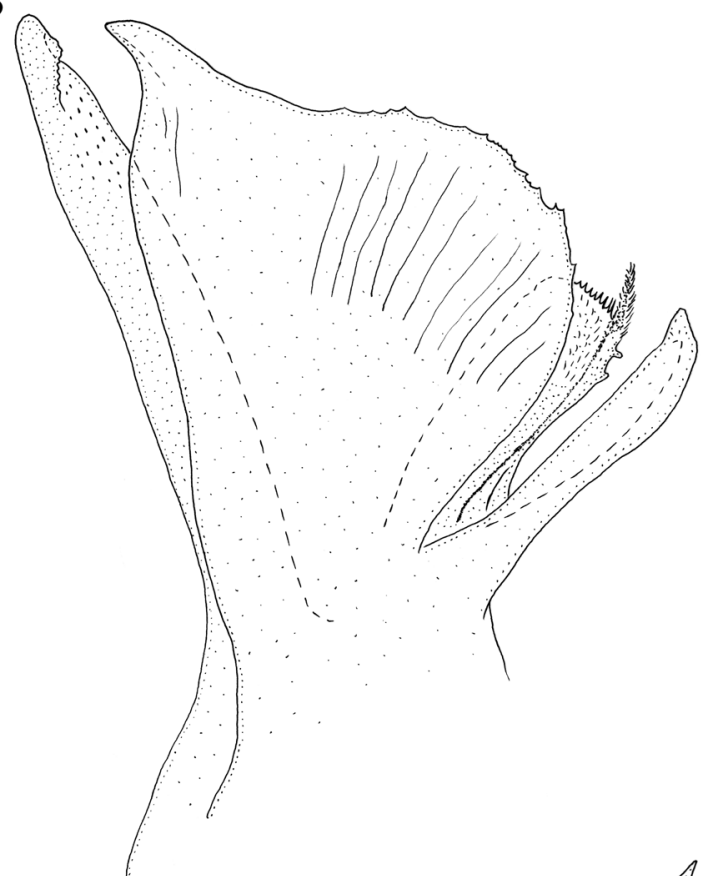

E

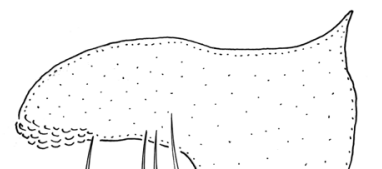

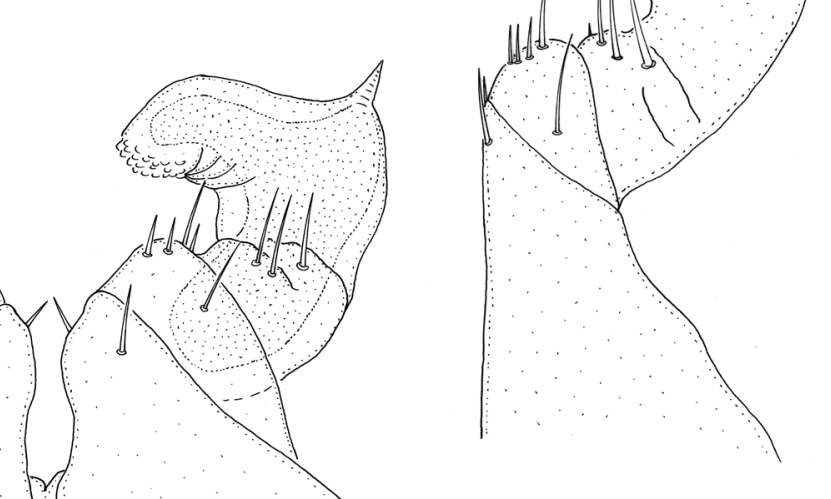

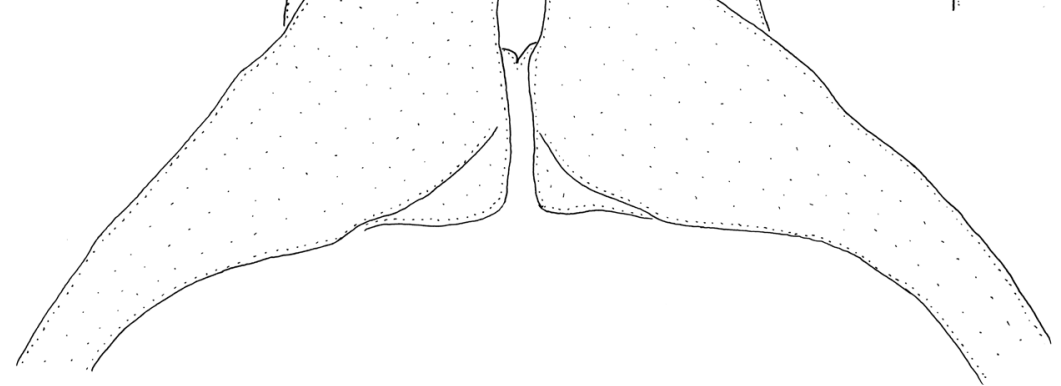

Fig. 18. Leucogeorgia borealis sp. nov., holotype $\delta$ from Fanagoriyskaya Cave (ZMUM). A. Right gonopods, mesal view. B. Right gonopods, lateral view. C. Penes, posterior view. D. Leg-pair 1, anterior view. E. Right leg 1, lateral view. Scale bar: $0.1 \mathrm{~mm}$. 


\section{Leucogeorgia gioi sp. nov. urn:1sid:zoobank.org:act:A102B926-4299-4931-A6D7-F026A81CDE57}

Figs 1C, 19-21, 56, 58

\section{Diagnosis}

This species belongs to the group of Leucogeorgia spp. without modified mouthparts and with teeth on the mesomeral claw (vs absent from L. golovatchi sp. nov., L. lobata sp. nov. and L. prometheus sp. nov.). Leucogeorgia gioi sp. nov. differs from both L. abchasica and L. satunini by having a more slender mesomeral claw with just a few teeth (vs a more robust, more or less strongly denticulate mesomeral claw in L. abchasica and L. satunini) and a strongly serrate mesomeral lamella (vs mesomeral lamella not too strongly serrate in L. abchasica and L. satunini). Leucogeorgia gioi sp. nov. differs from $L$. borealis sp. nov. and $L$. oculata sp. nov. by having an elongate and erect mesomeral claw with a few teeth (vs a stout mesomeral claw strongly denticulate in L. borealis sp. nov. and L. oculata sp. nov.).

\section{Etymology}

The new species is dedicated to its collector, Giorgi Gio Nebieridze from Georgia. Noun in the genitive case.

\section{Material examined}

\section{Holotype}

CENTRAL-WEST GEORGIA - Chiatura District • ô; $^{\circ}$ village Gundaeti, Sachinkia Cave; $42.23^{\circ}$ N, 43.32 E; 2 Mar. 2018; G. Nebieridze leg.; IZISU.

\section{Paratypes}

CENTRAL-WEST GEORGIA - Chiatura District $-1 \hat{\jmath}, 1$, 1 juv.; same collection data as for holotype; IZISU.

\section{Other material}

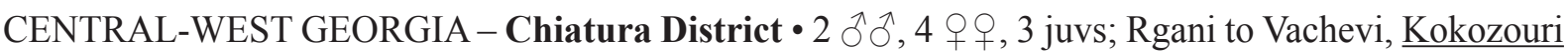
Cave; $42.32^{\circ} \mathrm{N}, 43.22^{\circ}$ E; 21 Nov. 2017; G. Nebieridze and S. Barjadze leg.; IZISU • 1 क; same collection data as for preceding but 15 Jun. 2019; H. Reip leg.; SMNG • 1 ¿ ; village Sveri, Kotias Cave; $42.21^{\circ}$ N, $43.32^{\circ}$ E; Nov. 2018; G. Nebieridze leg.; IZISU • 1 ○ं; Shvilobisa Cave; $42.32^{\circ}$ N, $43.26^{\circ}$ E; Nov. 2018; G. Nebieridze leg.; IZISU • 1 o; Devis Khvreli Cave; $42.31^{\circ} \mathrm{N}, 43.24^{\circ} \mathrm{E}$; Nov. 2018; G. Nebieridze leg.; IZISU.

\section{Description}

Size AND NUMBER OF BODY RINGS. Holotype male $22 \mathrm{~mm}$ long, vertical diameter of largest body ring 1.3 $\mathrm{mm}$, body with 50 podous rings +4 apodous rings + telson. Paratype male $32 \mathrm{~mm}$ long, vertical diameter of largest body ring $1.6 \mathrm{~mm}$, body with 67 podous rings +0 apodous rings + telson. Females $27-31 \mathrm{~mm}$ long, vertical diameter of largest body rings $1.4-1.7$, body with 58-62 podous rings $+1-3$ apodous rings + telson.

Colour (Figs 1C, 19). Live colouration yellowish white. Greyish white in alcohol.

HeAd (Fig. 19B). Without ommatidia. Frontal setae absent. Labrum with three labral teeth, four supralabral setae and 18 labral setae. Gnathochilarium with rhomboid promentum; lamellae linguales with $4+4$ setae in one row; stipites with $3+3$ distolateral and $2+3$ medial setae. Antennae $2 \mathrm{~mm}$ long in holotype male, their length ca $150 \%$ of vertical diameter of largest body ring. Lengths of antennomeres I-VIII (in mm): 0.14 (I), 0.43 (II), 0.34 (III), 0.34 (IV), 0.42 (V), 0.2 (VI), 0.1 (VII) and 0.03 (VIII). Length/width ratio of antennomeres I-VII: 0.9 (I), 3.3 (II), 3 (III), 2.5 (IV), 2.5 (V), 1.3 (VI) and 

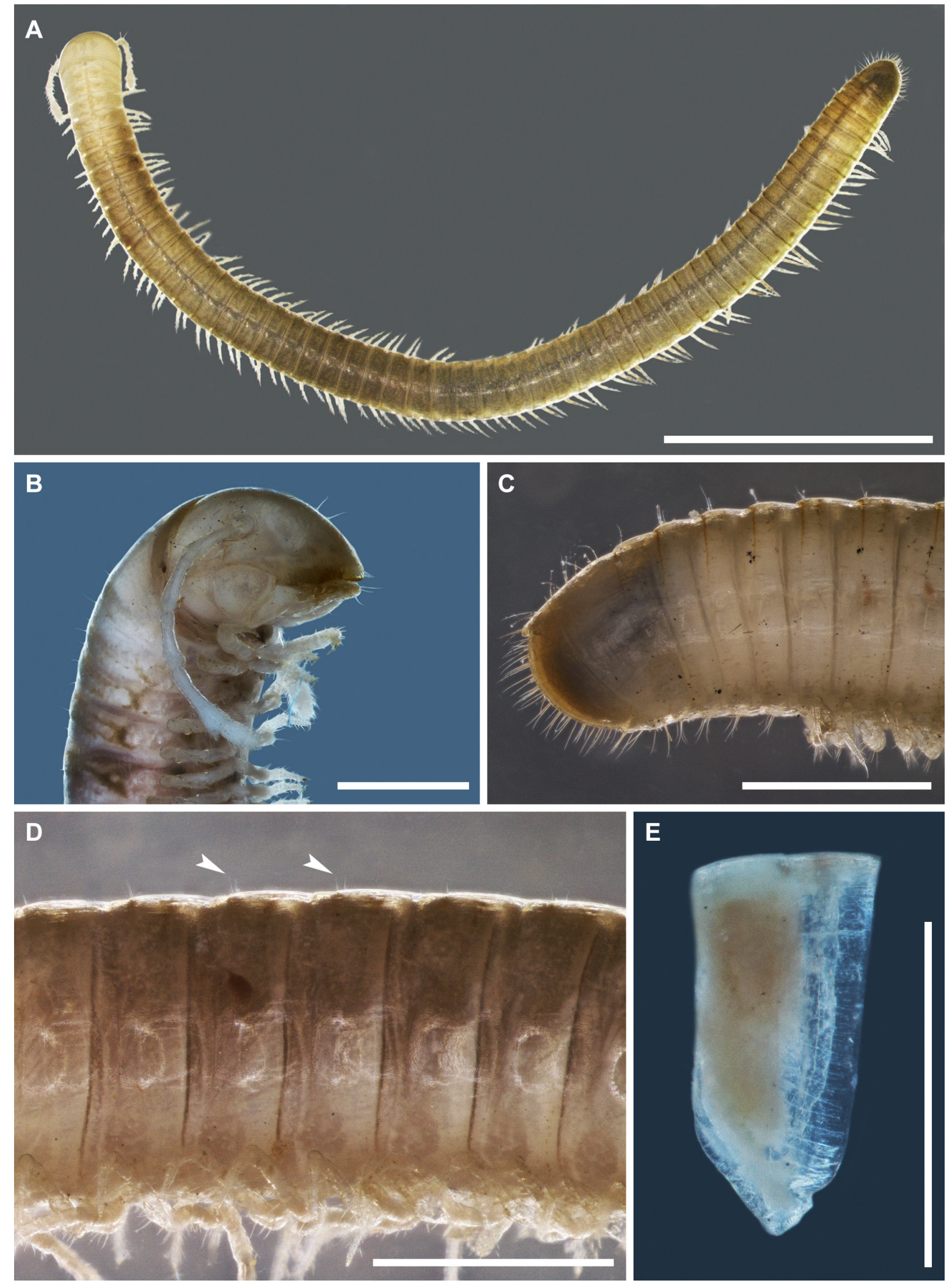

Fig. 19. Leucogeorgia gioi sp. nov., types from Sachinkia Cave (IZISU). A. Holotype $\widehat{\jmath}$, habitus, dorsal view. B. Paratype $q$, anterior part of body, lateral view. C. Holotype, posterior part of body, lateral view. D. Paratype $\hat{\sigma}$, midbody rings, lateral view. E. Paratype $\hat{\delta}$, body ring 7 , lateral view. Arrows indicate metazonal setae. Scale bars: A $=5 \mathrm{~mm}$; $\mathrm{B}-\mathrm{E}=1 \mathrm{~mm}$. 
0.8 (VII). Antennomeres V and VI each with a terminal corolla of large sensilla basiconica bacilliformia; antennomere VII with a terminal corolla of small sensilla basiconica bacilliformia.

BoDY RINGS (Fig. 19D). Entire metazonal area with longitudinal striations. Length of midbody setae ca $6 \%$ of vertical diameter of rings.

TELSON (Fig. 19C). Epiproct with a very short and blunt preanal process, covered with dorsal and lateral setae. Paraprocts rounded, with numerous setae. Hypoproct without any modifications.

LEGS IN MALES. First pair of legs modified, hook-shaped (Fig. 21E-F), with three podomeres; coxa with one seta; prefemur with five setae; femora, postfemora, and tibiotarsi coalesced; femur with 3-4 setae; postfemur with one seta. Tibiotarsal part with a small distal lobe (tarsal remnant). Tip tuberculated. Postfemoral and tibial ventral pads well developed on anterior legs, then gradually disappearing towards posterior legs.

Penes (Fig. 21D). In form of a short trapezoid, apically with two small subtriangular lobes.

VENTRAL MARGIN OF MALE BODY RING 7 (Fig. 19E). Well-developed, subtriangular in lateral view.

Gonopods (Figs 20, 21A-C). Promere (p) long and slender, with a flagellum (f); apical part spatulate, with denticulate margins; basal half with two developed ridges. Mesomere $(\mathrm{m})$ with a slender mesomeral claw (mc) with just a few teeth; mesomeral lamella $(\mathrm{ml})$ with a strongly serrate distal margin, posterior part finely fimbriate. Opisthomere (o) bipartite. Anterior branch of o with a solenomere (s) with a long tip significantly exceeding posterior part of lamella in height, and a well-developed and fimbriate velum (v). Posterior branch of o in form of a shield-like protective lamella (pl). Mesomere and opisthomere connected basally with an accessory membrane (am).

\section{Distribution}

Known only from four caves in the Chiatura district (Fig. 58, green triangles).
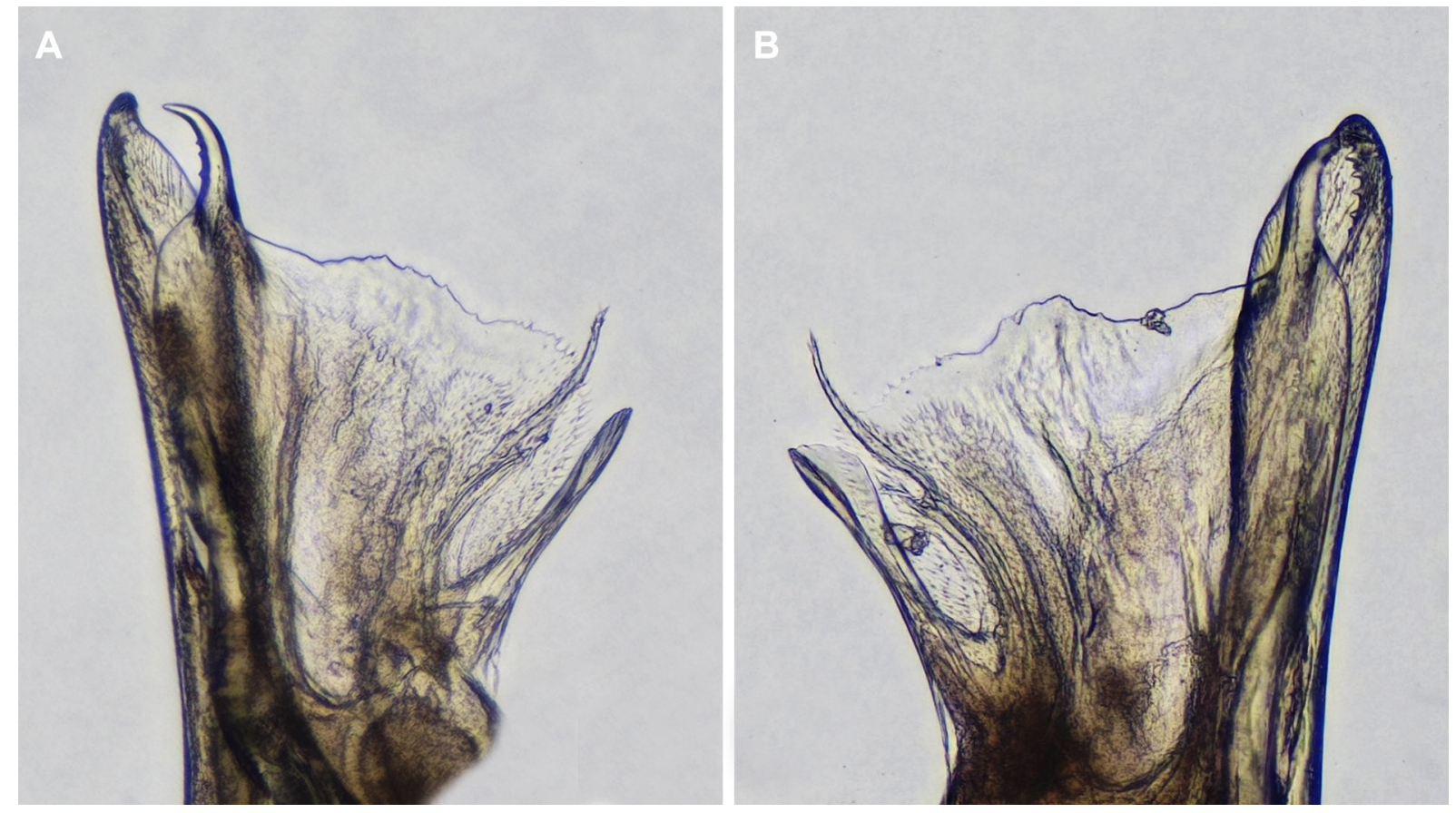

Fig. 20. Leucogeorgia gioi sp. nov., gonopods, lateral views (IZISU). A. $\widehat{\jmath}$ from Kotias Cave. B. $\widehat{o}$ from Shvilobisa Cave. 


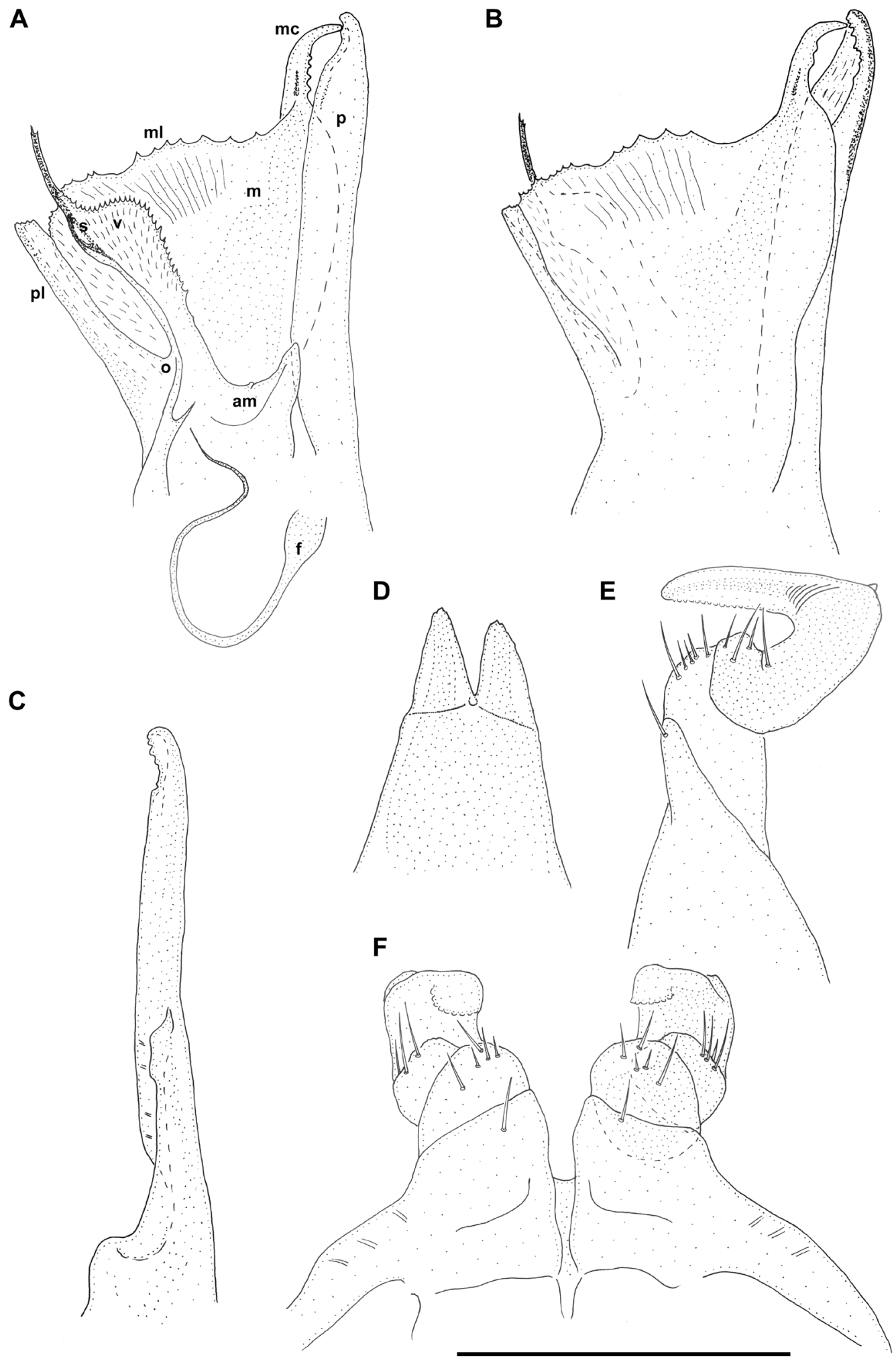

Fig. 21. Leucogeorgia gioi sp. nov., holotype $\widehat{\jmath}$ from Sachinkia Cave (IZISU). A. Right gonopods, mesal view. B. Left gonopods, lateral view. C. Left promere, lateral view. D. Penes, posterior view. E. Right leg 1, lateral view. F. Leg-pair 1, anterior view. Abbreviations: am = accessory membrane; $\mathrm{f}=$ flagellum; $\mathrm{m}=$ mesomere; $\mathrm{mc}=$ mesomeral claw; $\mathrm{ml}=$ mesomeral lamella; $\mathrm{o}=$ opisthomere; $\mathrm{p}=$ promere; $\mathrm{pl}=$ protective lamella; $\mathrm{s}=$ solenomere; $\mathrm{v}=$ velum. Scale bar: $0.3 \mathrm{~mm}$. 


\section{Remarks}

In the Kotias Cave, this species lives in sympatry with L. longipes, which has modified mouthparts; these two species represent the southeasternmost records of the genus Leucogeorgia.

Leucogeorgia golovatchi sp. nov. urn:lsid:zoobank.org:act:AFC4B93A-128A-4FF6-9E97-726F4DDE4CA1

Figs 22-24, 56, 58

\section{Diagnosis}

This species belongs to the group of Leucogeorgia spp. with neither modified mouthparts nor teeth on the mesomeral claw (vs teeth present in L. abchasica, L. borealis sp. nov., L. gioi sp. nov., L. oculata sp. nov. and L. satunini). Leucogeorgia golovatchi sp. nov. differs from L. lobata sp. nov. by the absence of a strongly developed lobe on the mesomeral lamella (vs presence of a strongly developed lobe in L. lobata sp. nov.). Leucogeorgia golovatchi sp. nov. differs from L. prometheus sp. nov. by both a shorter mesomeral claw and a long solenomere clearly exceeding the height of the mesomeral lamella (vs a longer mesomeral claw and a short solenomere not exceeding the height of the mesomeral lamella in L. prometheus sp. nov.). Additionally, L. golovatchi sp. nov. clearly differs from all other congeners by having strongly developed ventral lobes on body ring 2 in both sexes (vs absence of such lobes in all other congeners).

\section{Etymology}

This new species is dedicated to Sergei Golovatch, one of the collectors, a well-known diplopodologist worldwide, and our good friend and colleague. His collection of millipedes from the Caucasus, now in ZMUM, is one of the largest and most complete. Noun in the genitive case.

\section{Material examined}

\section{Holotype}

CENTRAL-WEST GEORGIA - Racha-Lechkhumi • đ̇; Ambrolauri District, near Gogoleti, Tsakhi (= Gogoleti) Cave; $42.54^{\circ}$ N, 42.90 E; 30 Jul. 1939; J. Birstein leg.; ZMUM.

\section{Paratypes}

CENTRAL-WEST GEORGIA - Racha-Lechkhumi $\bullet 8 \hat{\partial} \hat{\partial}, 1$ q, 6 juvs; same collection data as for holotype; ZMUM • 1 $\widehat{\delta}$; same collection data as for holotype; IZB $\bullet 1 \hat{\delta}$; same collection data as for holotype; SMNG; $・ 7 \hat{\jmath} \hat{\jmath}, 3$ qq, 7 juvs (mainly fragmented); same collection data as for holotype but 9 Aug. 1974; S.I. Golovatch leg.; ZMUM.

\section{Description}

SizE AND NUMBER OF BODY RINGS. Holotype male $25 \mathrm{~mm}$ long, vertical diameter of largest body ring 1.6 $\mathrm{mm}$, body with 50 podous rings +1 apodous ring + telson. Paratype males $22-29 \mathrm{~mm}$ long, vertical diameter of largest body ring $1.3-1.8 \mathrm{~mm}$, body with 43-52 podous rings $+0-2$ apodous rings + telson. Paratype females 21-29 mm long, vertical diameter of largest body ring 1.3-1.8 mm, body with 46-50 podous rings +1 apodous ring + telson.

Colour (Fig. 22). Yellowish white in alcohol.

Head (Figs 22B, 23C). Without ommatidia. Frontal setae absent. Labrum with three labral teeth, four supralabral setae and 15 labral setae. Gnathochilarium with rhomboid promentum. Lamellae linguales with $5+5$ setae, stipites with $3+3$ distolateral and $11+11$ medial setae. Antennae $2.3 \mathrm{~mm}$ long in holotype 

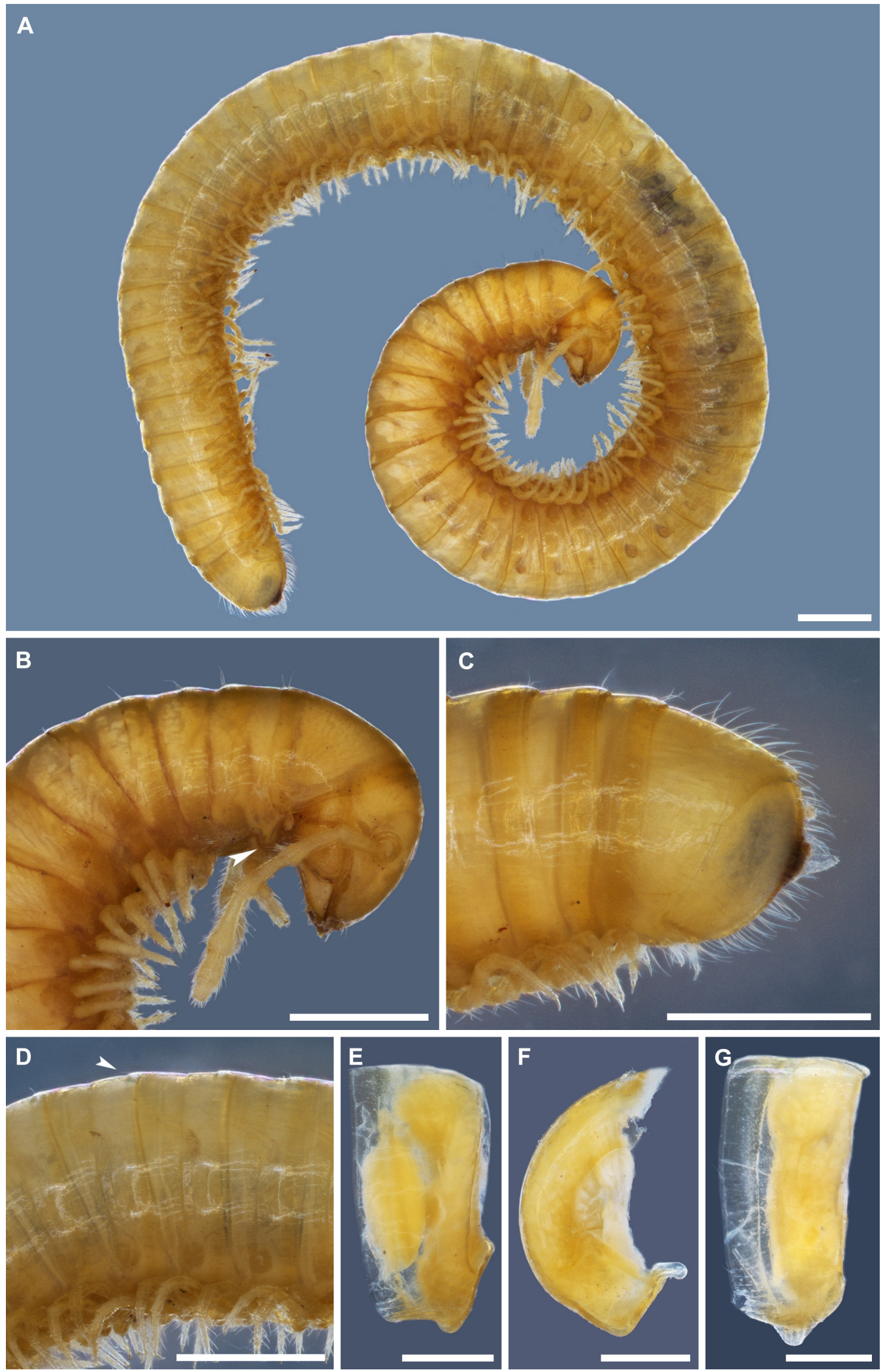

Fig. 22. Leucogeorgia golovatchi sp. nov., type $\widehat{\jmath} \hat{\jmath}$ from Tsakhi Cave (ZMUM) (A-D: holotype; E-G: paratype). A. Habitus, lateral view. B. Anterior part of body, lateral view. C. Posterior part of body, lateral view. D. Midbody rings, lateral view. E. Body ring 2, lateral view. F. Body ring 2, anterior view. G. Body ring 7, lateral view. Scale bars: $A-D=1 \mathrm{~mm} ; \mathrm{E}-\mathrm{G}=0.5 \mathrm{~mm}$. 
male, their length ca $140 \%$ of vertical diameter of largest body ring. Lengths of antennomeres I-VIII (in $\mathrm{mm}$ ): 0.12 (I), 0.47 (II), 0.41 (III), 0.4 (IV), 0.46 (V), 0.29 (VI), 0.12 (VII) and 0.03 (VIII). Length/width ratio of antennomeres I-VII: 0.8 (I), 3 (II), 3 (III), 2.7 (IV), 2.4 (V), 1.6 (VI) and 0.9 (VII). Antennomeres
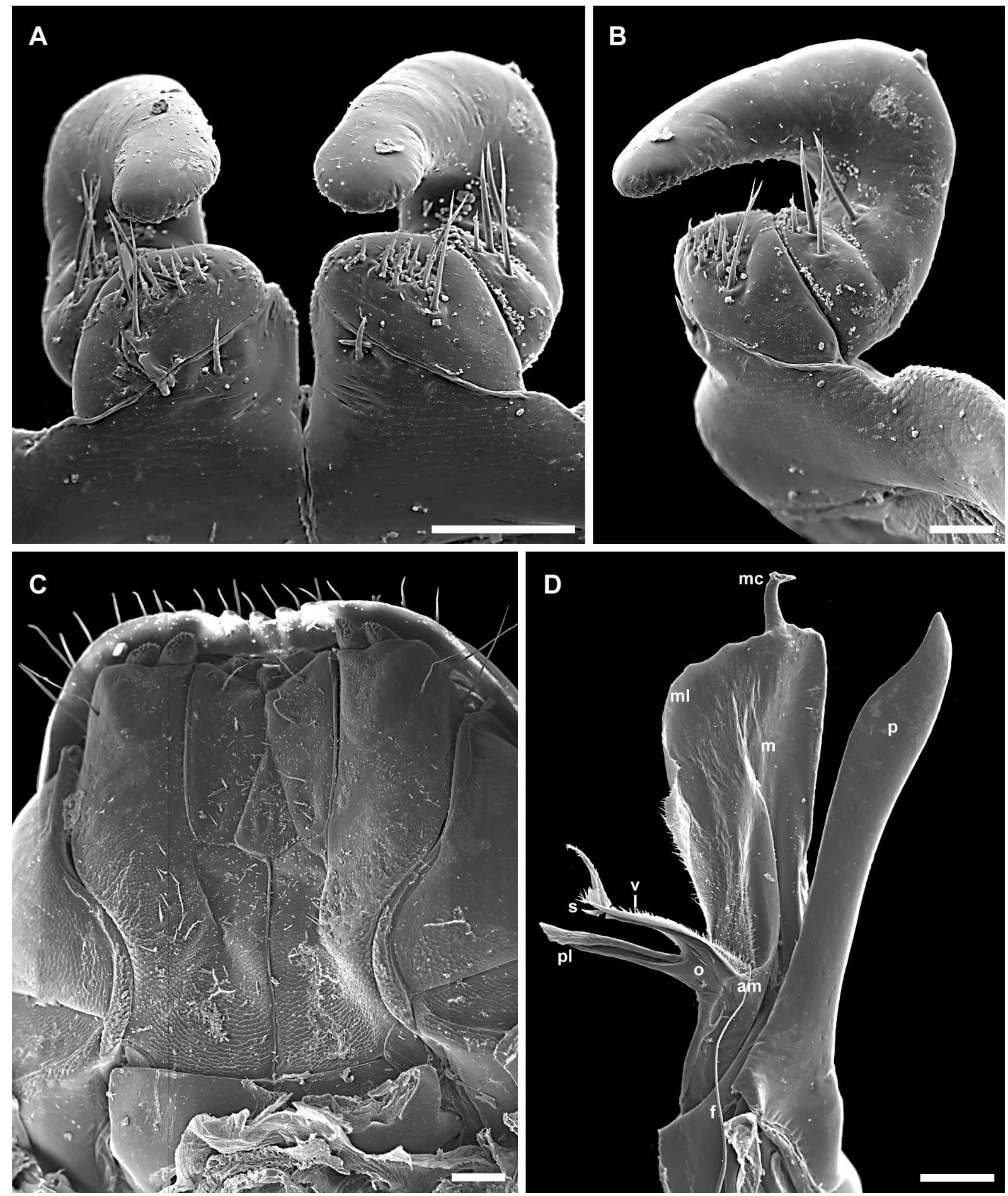

Fig. 23. Leucogeorgia golovatchi sp. nov., paratype from Tsakhi Cave (ZMUM). A. Leg-pair 1, anterior view. B. Right leg 1, lateral view. C. Head, ventral view. D. Right gonopods, mesal view. Abbreviations: $\mathrm{am}=$ accessory membrane; $\mathrm{f}=$ flagellum; $\mathrm{m}=$ mesomere; $\mathrm{mc}=$ mesomeral claw; $\mathrm{ml}=$ mesomeral lamella; $\mathrm{o}=$ opisthomere $\mathrm{p}=$ promere $; \mathrm{pl}=$ protective lamella; $\mathrm{s}=$ solenomere; $\mathrm{v}=$ velum. Scale bars: $\mathrm{A}, \mathrm{C}-\mathrm{D}=0.1 \mathrm{~mm} ; \mathrm{B}=0.05 \mathrm{~mm}$. 
A

B

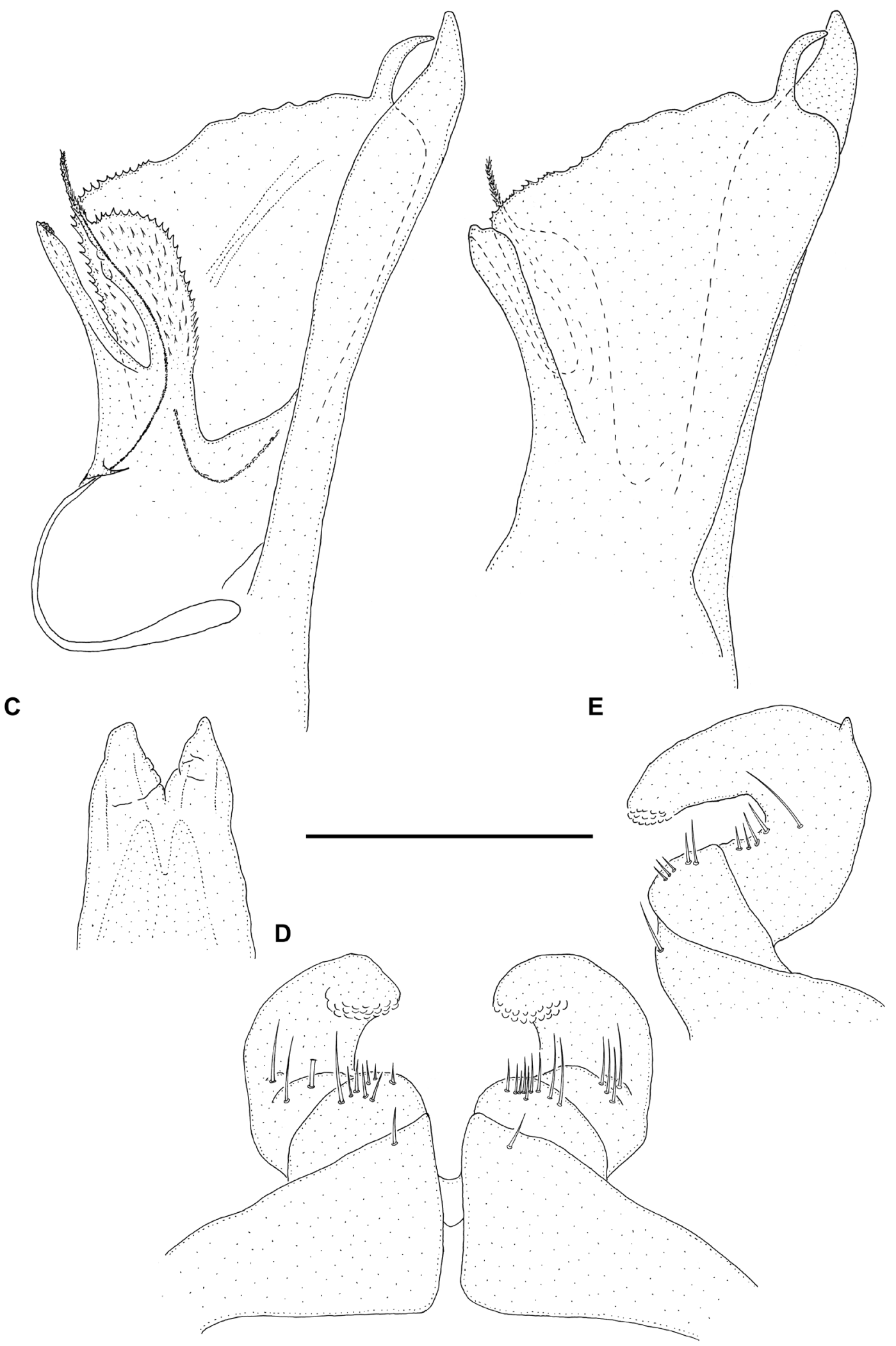

Fig. 24. Leucogeorgia golovatchi sp. nov., type $\partial^{\widehat{\jmath}}$ from Tsakhi Cave (ZMUM). A. Holotype, right gonopods, mesal view. B. Holotype, left gonopods, lateral view. C. Paratype, penes, posterior view. D. Paratype, leg-pair 1, anterior view. E. Right leg 1, lateral view. Scale bar: $0.3 \mathrm{~mm}$. 
V and VI each with a terminal corolla of large sensilla basiconica bacilliformia; antennomere VII with a terminal corolla of small sensilla basiconica bacilliformia.

Body RINGS (Fig. 22D-F). Entire metazonal area with longitudinal striations. Length of midbody setae ca $5 \%$ of vertical diameter of rings. Body ring 2 with strongly developed ventral lobes (Fig. 22B, E-F), rounded in lateral view.

TeLson (Fig. 22C). Epiproct with a very short and blunt preanal process, covered with dorsal and lateral setae. Paraprocts rounded, with numerous setae. Hypoproct without any modifications.

LegS IN MALES. First pair of legs modified, hook-shaped (Figs 23A-B, 24D-E), with three complete podomeres; coxa with one seta; prefemur with 8-10 setae; femur, postfemur and tibiotarsus coalesced; femur with 2-3 setae; postfemur with one seta. Tibiotarsus with a short distal lobe (tarsal remnant). Tip slightly tuberculated. Postfemoral and tibial ventral pads well-developed on anterior legs, then gradually disappearing towards posterior legs.

PeNes (Fig. 24C). In form of a short trapezoid, apically with two small subtriangular lobes.

Ventral margin of male body Ring 7 (Fig. 22G). Small, rounded in lateral view.

Gonopods (Figs 23D, 24A-B). Promere (p) long and slender, with a flagellum (f); apical part with poorly denticulated margins; basal half with two developed ridges. Mesomere $(\mathrm{m})$ with a slender mesomeral claw $(\mathrm{mc})$ lacking teeth; mesomeral lamella $(\mathrm{ml})$ gradually decreasing in height posteriad, distal margin serrate, posterior part finely fimbriate. Opisthomere (o) bipartite. Anterior branch of o with a solenomere (s) with a long tip exceeding posterior part of lamella, and a well-developed and fimbriate velum (v). Posterior branch of o in form of a shield-like protective lamella (pl). Mesomere and opisthomere connected basally with an accessory membrane (am).

\section{Distribution}

Known only from its type locality (Fig. 58, orange triangle).

Leucogeorgia lobata sp. nov. urn:1sid:zoobank.org:act:A52F58C6-7035-48FA-924D-6F237089CE7C

Figs 1D, 2A, 25-26, 27A-C, 28, 56, 58

\section{Diagnosis}

This species belongs to the group of Leucogeorgia spp. with neither modified mouthparts nor teeth on the mesomeral claw (vs teeth present in L. abchasica, L. borealis sp. nov., L. gioi sp. nov., L. oculata sp. nov. and $L$. satunini). Leucogeorgia lobata sp. nov. differs from $L$. golovatchi $\mathrm{sp}$. nov. and $L$. prometheus sp. nov. by having a strongly developed lobe on the mesomeral lamella, with a deep rift between mesomeral claw and the lobe (vs absence of such a lobe or rift in L. golovatchi sp. nov. or sometimes a poorly developed lobe without a deep rift between the mesomeral claw and lobe in L. prometheus sp. nov.).

\section{Etymology}

From the Latin 'lobata' (= 'having lobes', 'lobate'), reflecting the presence of a well-developed lobe on the mesomeral lamella. Adjective in feminine gender.

\section{Material examined}

\section{Holotype}

CENTRAL-WEST GEORGIA-Samegrelo-Zemo Svaneti • ${ }^{7}$; Chkhorotsku District, near Chkhorotsku, Odishi Plateau, Kalitshona (= Konglomeratnaya) Cave; $42.53^{\circ}$ N, $42.16^{\circ}$ E; 14 Aug. 2016; D.M. Palatov leg.; ZMUM. 
Paratypes

CENTRAL-WEST GEORGIA - Samegrelo-Zemo Svaneti 1 1 , 1 juv.; same collection data as for holotype; ZMUM • 3 ô, 2 우; same collection data as for holotype but 29 Oct. 1991; V. Kiselev leg.; ZMUM -2 ภे, 4 우, 5 juvs; same collection data as for holotype but 3 Feb. 2017; D.M. Palatov leg.; ZMUM • $1 \hat{\delta}$; same collection data as for holotype; IZB • $1 \hat{\delta}$; same collection data as for holotype; SMNG; • 1 \%; village Garakha, Odishi Plateau, Garakha Cave; $42.53^{\circ} \mathrm{N}, 42.17^{\circ} \mathrm{E} ; 30$ Apr. 2017; G. Nebieridze and S. Barjadze leg.; IZISU • 1 §; same collection data as for preceding but 2 Feb. 2017; D.M. Palatov leg.; ZMUM.

\section{Other material}

CENTRAL-WEST GEORGIA - Samegrelo-Zemo Svaneti - 1 juv.; Martvili District, Askhi karst Massif, near Balda village, Motena Cave; $42.47^{\circ}$ N, 42.39 E; 19 Oct. 1978; R.A. Djanashvili leg.;

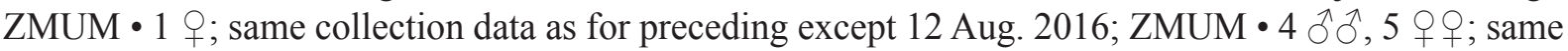

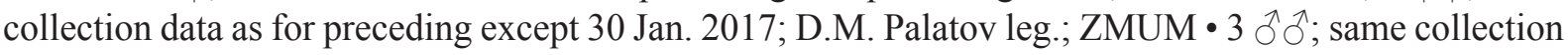
data as for preceding except 13 Jun. 2019; H. Reip leg.; SMNG • 2 우; Askhi karst Massif, Martvili village, Jortsku Cave; $42.51^{\circ}$ N, $42.42^{\circ}$ E; 2 Feb. 2017; D.M. Palatov and A.M. Sokolova leg.; ZMUM.

\section{Description}

SiZE AND NUMBER OF BODY RINGS. Holotype male $20 \mathrm{~mm}$ long, vertical diameter of largest body ring $1.5 \mathrm{~mm}$, body with 37 podous rings +1 apodous ring + telson. Paratype males $14.5-22 \mathrm{~mm}$ long, vertical diameter of largest body ring 1.1-1.6 mm, body with 32-41 podous rings $+1-2$ apodous rings + telson. Paratype females $20-22 \mathrm{~mm}$ long, vertical diameter of largest body ring $1.5-1.7 \mathrm{~mm}$, body with $37-40$ podous rings $+0-2$ apodous rings + telson. Additional males $19-33 \mathrm{~mm}$, vertical diameter of largest body ring 1.4-2 mm, body with 40-46 podous rings $+1-2$ apodous rings + telson. Additional females $21-34 \mathrm{~mm}$ long, vertical diameter of largest body ring $1.6-2.3 \mathrm{~mm}$, body with 39-46 podous rings $+1-2$ apodous rings + telson.

Colour (Figs 1D, 25). Yellowish white.

HeAd (Figs 25B, 26C). Without ommatidia. Frontal setae absent. Labrum with three labral teeth, four supralabral setae and 12-14 labral setae. Gnathochilarium with rhomboid promentum; lamellae linguales with 4+4-5+5 setae in one row, stipites each with 3 distolateral setae and 6-7 medial setae. Antennae $2.3 \mathrm{~mm}$ long in holotype male, their length ca $150 \%$ of vertical diameter of largest body ring. Lengths of antennomeres I-VIII (in mm): 0.12 (I), 0.45 (II), 0.46 (III), 0.4 (IV), 0.46 (V), 0.28 (VI), 0.11 (VII) and 0.02 (VIII). Length/width ratio of antennomeres I-VII: 0.75 (I), 3.7 (II), 3.5 (III), 3 (IV), 2.7 (V), 1.8 (VI) and 1 (VII). Antennomeres V and VI each with a terminal corolla of large sensilla basiconica bacilliformia; antennomere VII with a terminal corolla of small sensilla basiconica bacilliformia.

Body RINGS (Fig. 25D). Entire metazonal area with longitudinal striations. Length of midbody setae ca $7 \%$ of vertical diameter of rings.

TELSON (Fig. 25C). Epiproct with a short and blunt preanal process, covered with dorsal and lateral setae. Paraprocts rounded, with numerous setae. Hypoproct without any modifications.

LEGS IN MALES. First pair of legs modified, hook-shaped (Figs 26A-B, 28E-F), with three podomeres; coxae each with one seta; prefemora each with 6-9 setae; femora, postfemora and tibiotarsi coalesced, with $4+4$ setae $(3+3$ on remnants of femora and $1+1$ on remnants of postfemora). Tibiotarsal part with a small distal lobe. Tip slightly tuberculated. Postfemoral and tibial ventral pads well-developed on anterior legs, then gradually disappearing towards posterior legs.

Penes (Fig. 28D). In the form of a short trapezoid, apically with two small subtriangular lobes. 

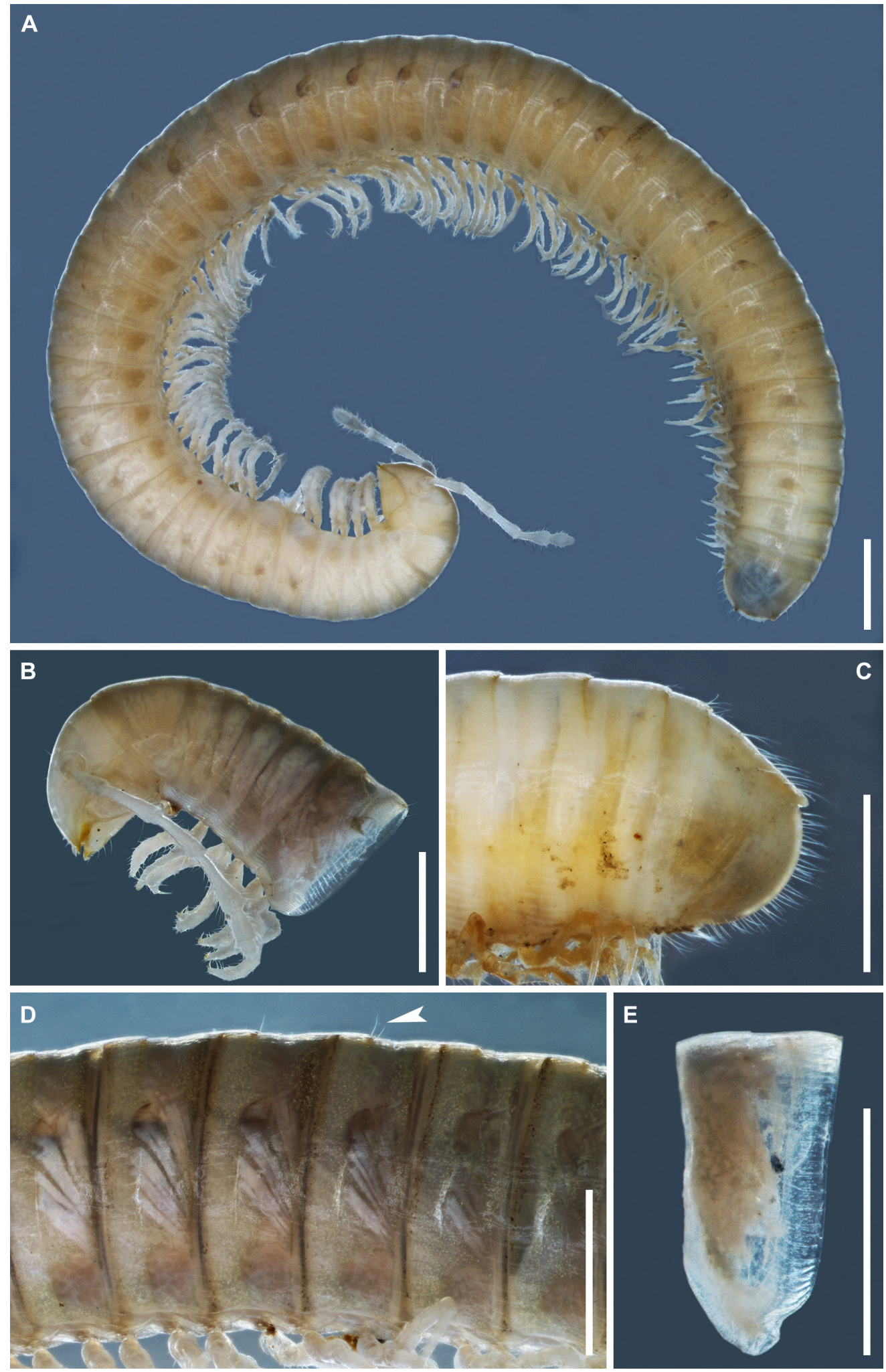

Fig. 25. Leucogeorgia lobata sp. nov., type $\widehat{\partial} \hat{\partial}$. A. Holotype from Kalitshona Cave, habitus, lateral view (ZMUM). B. Paratype from Garakha Cave, anterior part of body, lateral view (IZISU). C. Paratype from Kalitshona Cave, posterior part of body, lateral view (ZMUM). D. Paratype from Garakha Cave, midbody rings, lateral view (IZISU). E. Paratype from Garakha Cave, body ring 7, lateral view (IZISU). Arrow indicates metazonal setae. Scale bars: $1 \mathrm{~mm}$. 
Ventral margin of MALE BOdy RING 7 (Fig. 25E). Strongly developed, more or less rounded in lateral view.

Gonopods (Figs 2A, 26D, 27A-C, 28A-C). Promere (p) long and slender, with a flagellum (f); apical part spatulate, with denticulated margin; basal half with two developed ridges. Mesomere $(\mathrm{m})$ with a slender mesomeral claw (mc) lacking teeth, more or less curved anteriad; mesomeral lamella (ml) with a strongly developed lobe (1) and a deep rift between mesomeral claw and lobe, distal margin smooth, posterior part finely fimbriate. Opisthomere (o) bipartite. Anterior branch of o with a solenomere (s) with a short tip, and a well-developed and fimbriate velum (v). Posterior branch of o in form of a shield-like protective lamella $(\mathrm{pl})$. Mesomere and opisthomere connected basally with an accessory membrane (am).
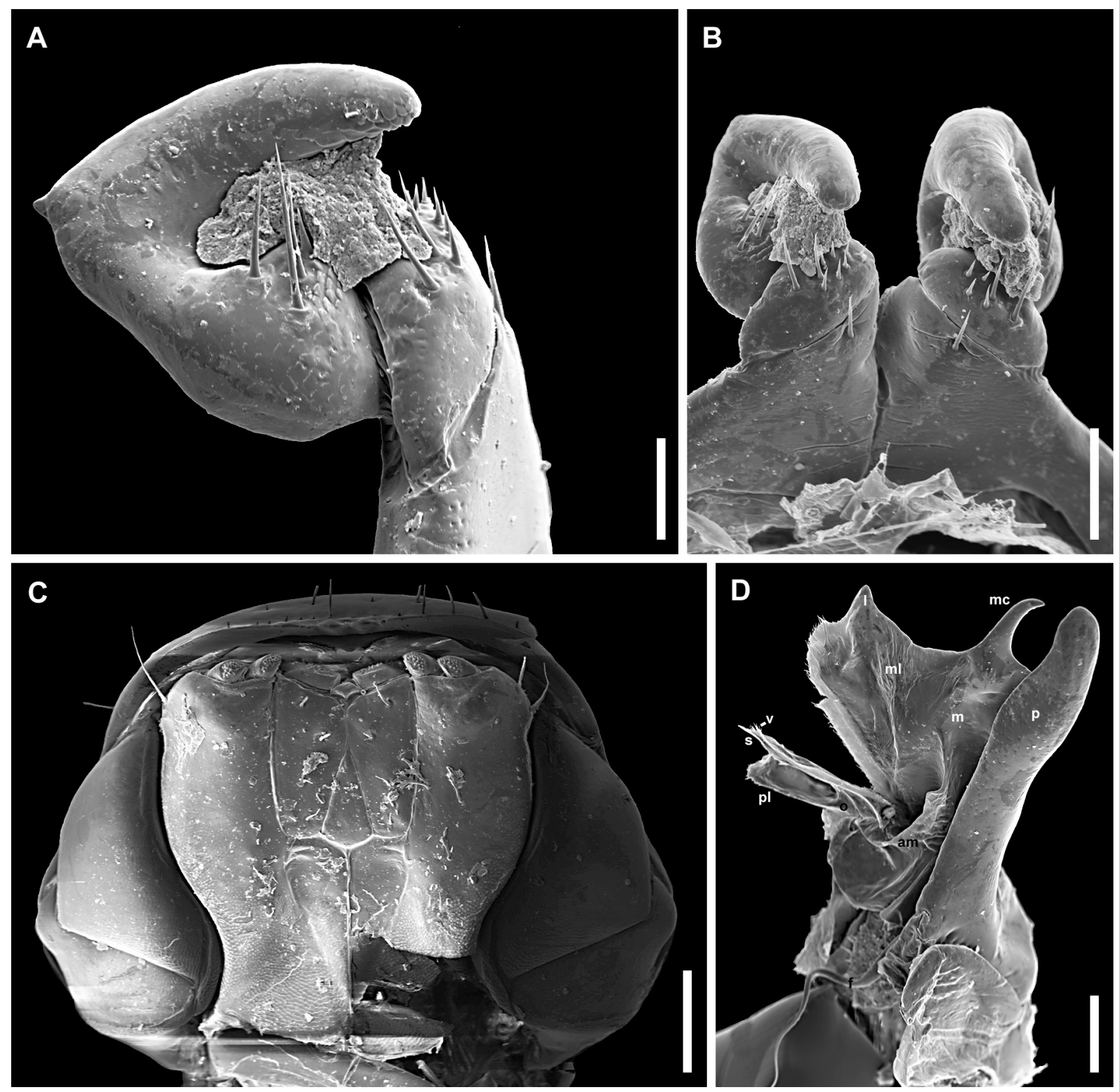

Fig. 26. Leucogeorgia lobata sp. nov., paratype $\widehat{\jmath}$ from Kalitshona Cave (ZMUM). A. Left leg 1 , lateral view. B. Leg-pair 1, anterior view. C. Head, ventral view. D. Right gonopods, mesal view. Abbreviations: $\mathrm{am}=$ accessory membrane; $\mathrm{f}=$ flagellum; $\mathrm{l}=$ lobe; $\mathrm{m}=$ mesomere; $\mathrm{mc}=$ mesomeral claw; $\mathrm{ml}=$ mesomeral lamella; $\mathrm{o}=$ opisthomere; $\mathrm{p}=$ promere; $\mathrm{pl}=$ protective lamella; $\mathrm{s}=$ solenomere; $\mathrm{v}=$ velum. Scale bars: $\mathrm{A}=0.05 \mathrm{~mm} ; \mathrm{B}, \mathrm{D}=0.1 \mathrm{~mm} ; \mathrm{C}=0.2 \mathrm{~mm}$. 

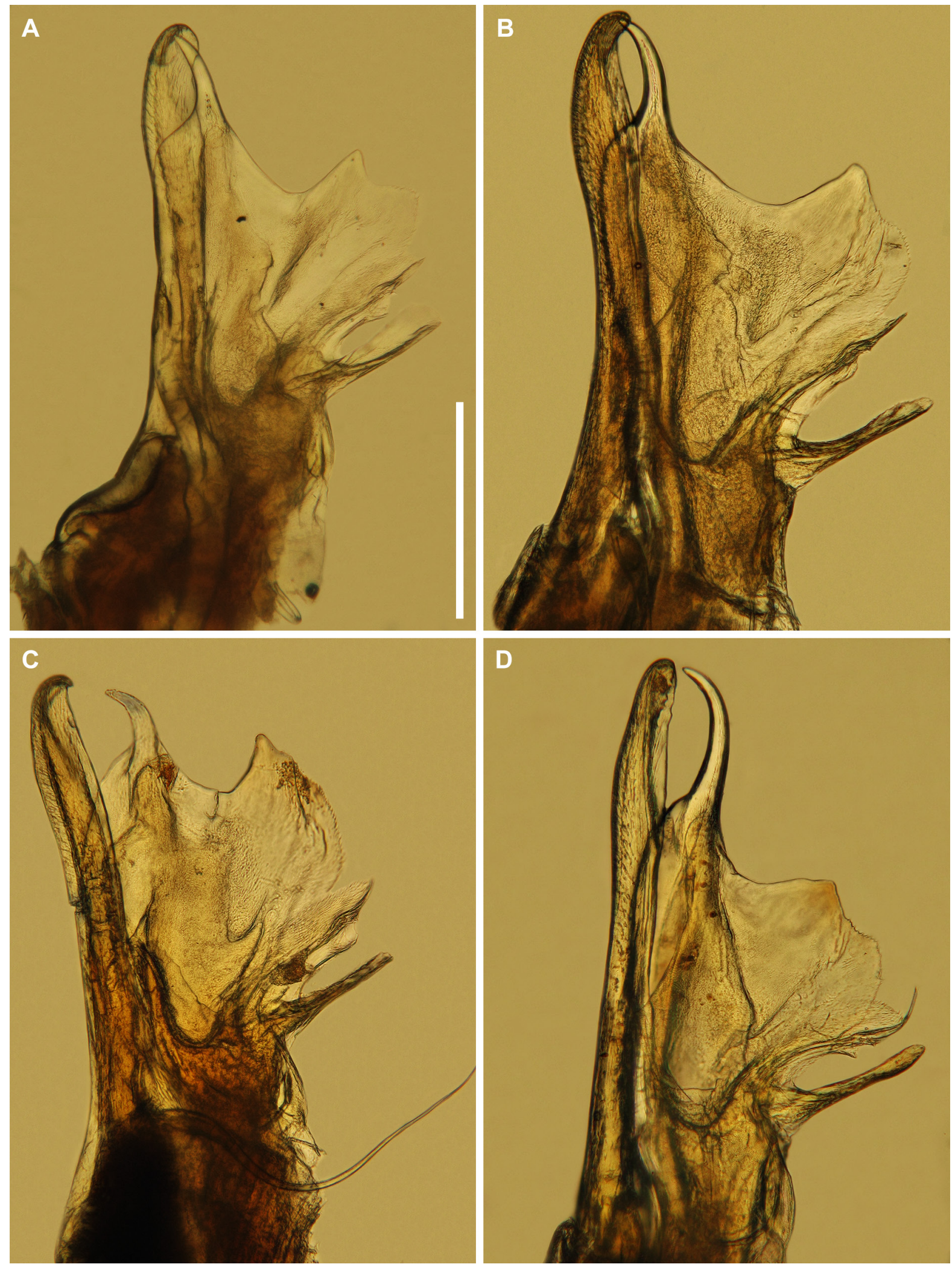

Fig. 27. Gonopods (A-C: Leucogeorgia lobata sp. nov.; D: L. aff. lobata sp. nov., ô from Eckis Cave). A. Paratype $\delta$ from Garakha Cave, right gonopods, lateral view (IZISU). B. $\widehat{\delta}$ from Motena Cave, left gonopod, mesal view (SMNG). C. $ð$ from Motena Cave, left gonopod, mesal view (ZMUM). D. Left gonopod, mesal view (SMNG). Scale bar: $0.3 \mathrm{~mm}$. 
A
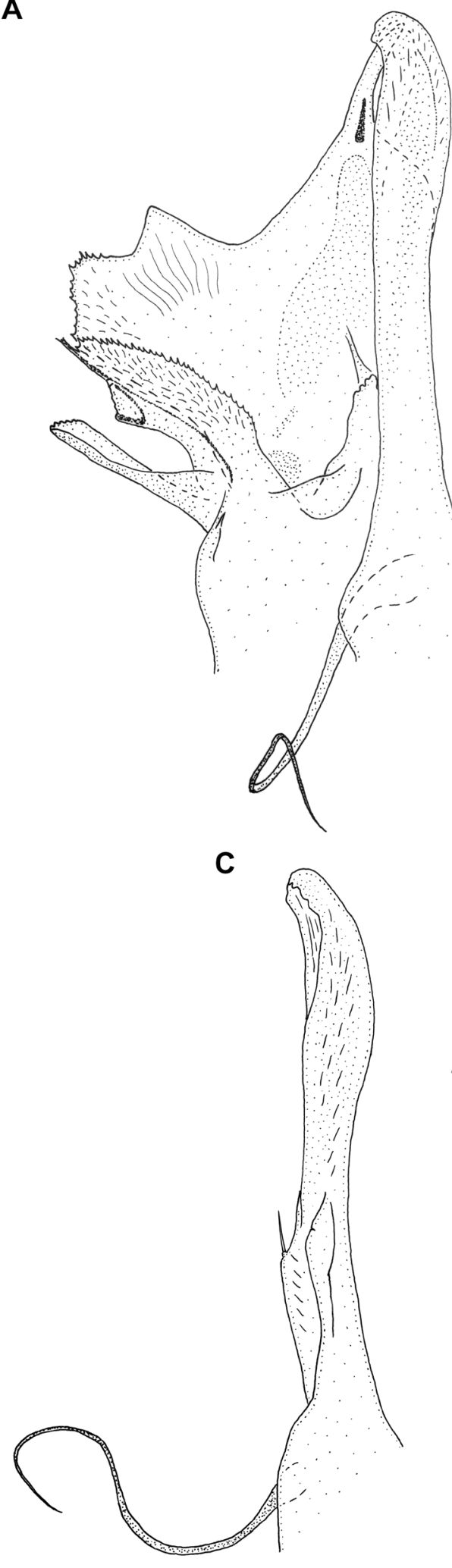

B
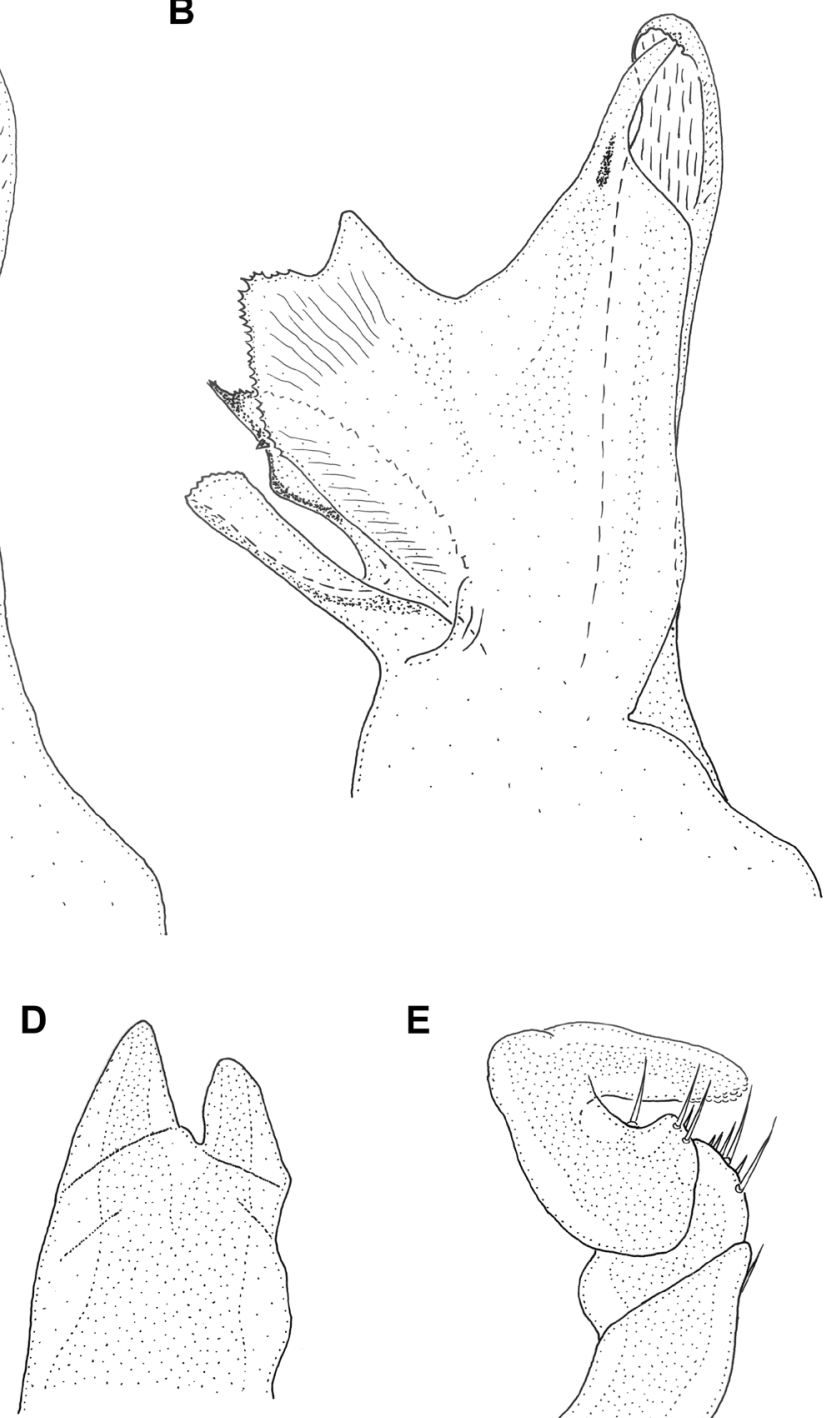

E
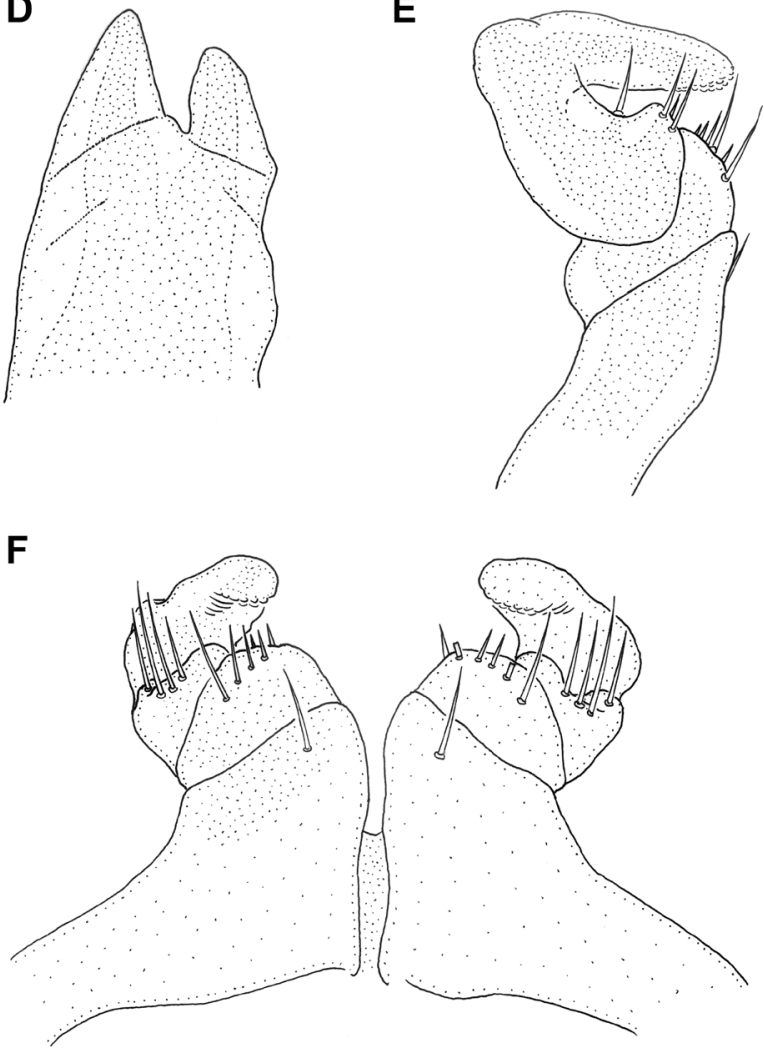

Fig. 28. Leucogeorgia lobata sp. nov., paratype $ð$ from Garakha Cave (IZISU). A. Right gonopods, mesal view. B. Left gonopods, lateral view. C. Left promere, lateral view. D. Penes, posterior view. E. Left leg 1, lateral view. F. Leg-pair 1, anterior view. Scale bar: $0.3 \mathrm{~mm}$. 


\section{Distribution}

Known only from four caves in the Samegrelo-Zemo Svaneti region in Central-West Georgia (Fig. 58, violet triangles).

\section{Remarks}

In the Motena and Jortsku caves, this species has been found together with another taxon of Leucogeorgiini, Martvilia parva gen. et sp. nov.

See also under Leucogeorgia aff. lobata sp. nov.

Leucogeorgia aff. lobata sp. nov.

Figs 27D, 56, 58

\section{Material examined}

CENTRAL-WEST GEORGIA - Ratscha-Letschchumi • 1 ¿ ; Ambrolauri District, W of Ambrolauri, Achara, above street SH17, riverside opposite Zeda Ghvardia, Eckis caves, right cave; $42.54^{\circ} \mathrm{N}$, $42.89^{\circ}$ E; 16 Jun. 2019; H. Reip leg.; SMNG.

\section{Remarks}

This male, collected in Achara, a new cave near Ambrolauri (Fig. 58, violet triangle with a question mark), is characterized by the presence of a lobe (1) on the mesomeral lamella and of a rift between the mesomeral claw and lobe, similar to conditions observed in the typical L. lobata sp. nov. However, this male is slightly different from those of $L$. lobata sp. nov. in showing a more slender and straight promere, an elongate mesomeral claw, a somewhat reduced mesomeral lamella, as well as an elongate tip of the solenomere. The length of the latter we generally find constant within the species. Further, the locality of this male is slightly separated from the four sites of $L$. lobata sp. nov. All this may indicate that another new, cryptic taxon might be involved here, but in the absence of more males we do not dare formalize this.

The newly discovered cave was probably part of a larger parted cave system, where the entrance to the second part is just a few meters left of the above cave. Both caves were opened and divided into separate caves during the building of street SH17. We call this small new cave system Eckis Caves after the name of the discoverer, Eckard Göbel.

Leucogeorgia oculata sp. nov. urn:1sid:zoobank.org:act:4F63C54D-B233-4BE1-A448-E2BAA27764F5

Figs 29-31, 56-57

Archileucogeorgia sp. - Ghilarov 1972: 38.

\section{Diagnosis}

This species belongs to the group of Leucogeorgia spp. without modified mouthparts, but it clearly differs from all other congeners by the pigmented body, the presence of ommatidia and the absence of metazonal setae (vs absence of both pigmentation and ommatidia and the presence of metazonal setae in all other congeners).

\section{Etymology}

From the Latin 'oculatus' (= 'having eyes'), reflecting the presence of ommatidia. Adjective. 


\section{Material examined}

Holotype

RUSSIA - Adygea, Caucasian Biosphere Nature Reserve • ${ }^{\text {; }}$; Lagonaki Plateau, Lunnaya glade, in soil 0-15 cm; $43.94^{\circ} \mathrm{N}, 39.88^{\circ}$ E; 8 Sep. 2012; Y. Chumachenko leg.; ZMUM.

\section{Paratypes}

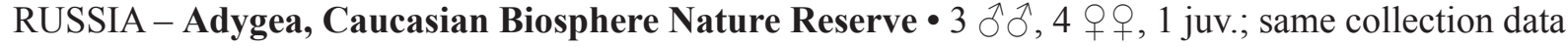
as for holotype; ZMUM.

\section{Other material}

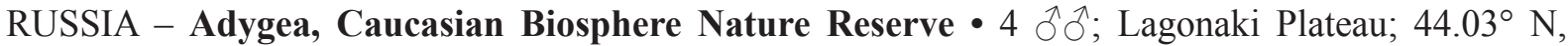

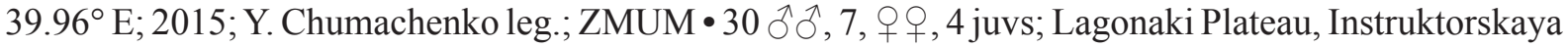

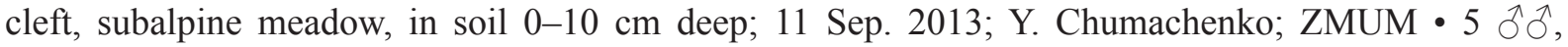

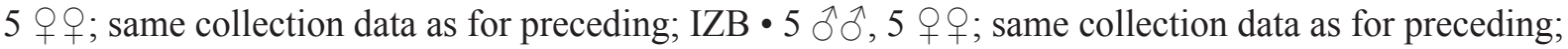

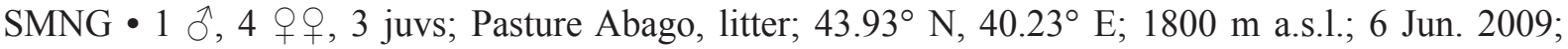
Y. Chumachenko leg.; ZMUM.

\section{Description}

SizE AND NUMBER OF BODY RINGS. Holotype male $9 \mathrm{~mm}$ long, vertical diameter of largest body ring 0.8 $\mathrm{mm}$, body with 35 podous rings +3 apodous rings + telson. Paratype males $7-10 \mathrm{~mm}$ long, vertical diameter of largest body ring $0.7-0.8 \mathrm{~mm}$, body with $28-37$ podous rings $+2-5$ apodous rings + telson. Paratype females 8-11.5 mm long, vertical diameter of largest body ring 0.8-1 mm, body with 32-39 podous rings $+2-4$ apodous rings + telson. Largest male $11 \mathrm{~mm}$ long, vertical diameter of largest body ring $0.8 \mathrm{~mm}$, body with 38 podous rings +2 apodous rings + telson. Largest female $13 \mathrm{~mm}$ long, vertical diameter of largest body ring $1.1 \mathrm{~mm}$, body with 44 podous rings +2 apodous rings + telson.

CoLour (Figs 29-30). Variable, from pale yellowish to dark grey.

HEAD (Fig. 29B-C). Males and females with $8-12$ and 8-13 ommatidia per roundish eye field, respectively. Labrum with three teeth, four supralabral setae and 16 labral setae (paratype male). Gnathochilarium (paratype male) with rhomboid promentum; lamellae linguales with $3+3$ setae in one row, stipites with $3+3$ long distolateral setae and $4+5$ short medial setae each. Antennae short, $0.7 \mathrm{~mm}$ long in holotype male, their length ca $90 \%$ of vertical diameter of largest body ring. Lengths of antennomeres I-VIII (in mm): 0.06 (I), 0.15 (II), 0.13 (III), 0.11 (IV), 0.12 (V), 0.08 (VI), 0.03 (VII) and 0.02 (VIII). Length/width ratio of antennomeres I-VII: 0.8 (I), 2 (II), 1.6 (III), 1.4 (IV), 1.2 (V), 0.9 (VI) and 0.5 (VII). Antennomeres V and VI each with a terminal corolla of large sensilla basiconica bacilliformia; antennomere VII with a terminal corolla of small sensilla basiconica bacilliformia.

Body RINGS (Fig. 29E). Entire metazonal area with longitudinal striations. Metazonal setae absent.

TeLson (Fig. 29F-G). Epiproct variable in length, from short to long, blunt, sloping slightly downwards and covered with dorsal and lateral setae. Paraprocts rounded, with 3+3 setae. Hypoproct without any modifications.

LEGS IN MALES. First pair of legs modified, hook-shaped (Fig. 31D-E), with three podomeres; coxae each with one seta; prefemora each with 4-5 setae; femora, postfemora and tibiotarsi coalesced; femur with two setae; postfemur with one seta. Tibiotarsal part with a small distal lobe (tarsal remnant). Tip slightly tuberculated. Postfemoral and tibial ventral pads poorly developed on anterior legs, then gradually disappearing towards posterior legs.

Ventral margin of Male body Ring 7 (Fig. 29D). Poorly developed, low. 

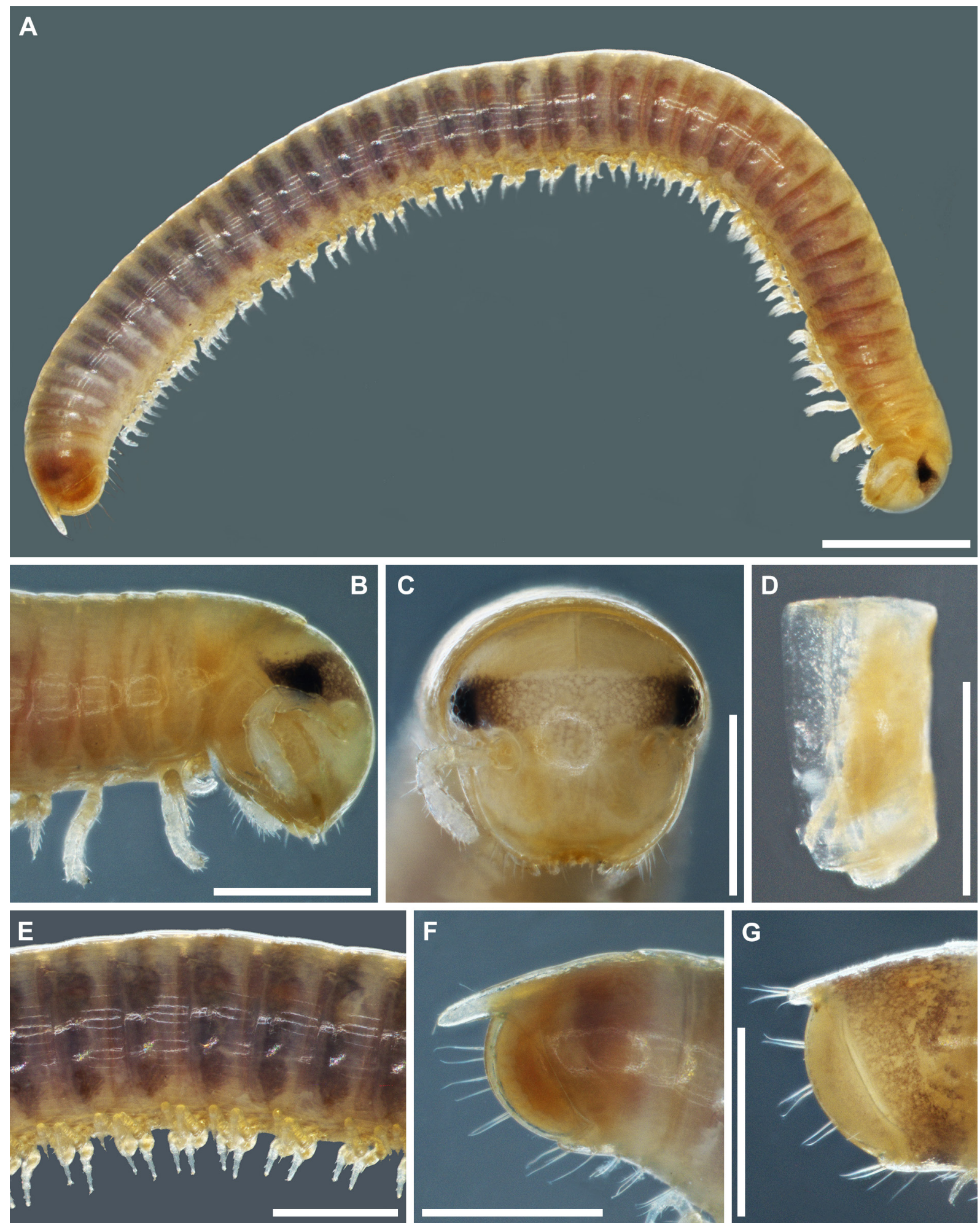

Fig. 29. Leucogeorgia oculata sp. nov., from Lagonaki Plateau (ZMUM). A. Holotype $\widehat{\jmath}$, habitus, lateral view. B. Holotype, anterior part of body, lateral view. C. Paratype + , head, anterior view. D. Non-type $\widehat{\partial}$, body ring 7, lateral view. E. Holotype, midbody rings, lateral view. F. Holotype, telson, lateral view. G. Non-type ${ }^{\widehat{ }}$, telson, lateral view. Scale bars: $\mathrm{A}, \mathrm{E}=1 \mathrm{~mm}$; B-D, F $=0.5 \mathrm{~mm}$. 
Penes (Fig. 31C). Short, apically with two small subtriangular lobes.

Gonopods (Fig. 31A-B). Promere (p) long and slender, with a flagellum (f); apical part spatulate, with poorly denticulated margins. Mesomere $(\mathrm{m})$ with a robust and denticulate mesomeral claw $(\mathrm{mc})$; mesomeral lamella $(\mathrm{ml})$ with a smooth and slightly concave distal margin and a posterior rise, posterior part finely fimbriate. Opisthomere (o) bipartite. Anterior branch of o with a solenomere (s) with a
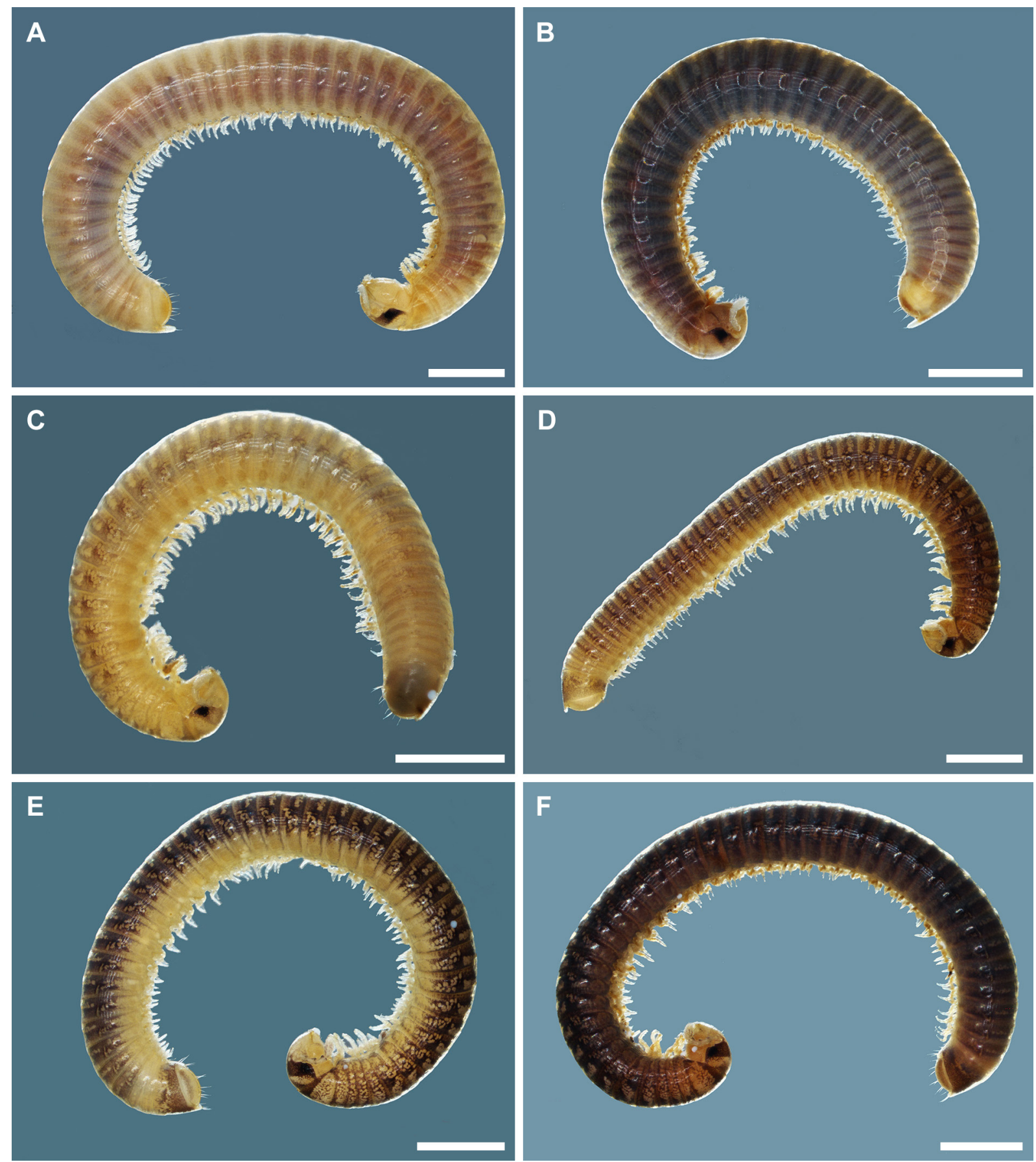

Fig. 30. Leucogeorgia oculata sp. nov., specimens from Lagonaki Plateau, habitus, lateral views. A. Largest paratype $q$ (ZMUM). B. Smallest paratype $q$ (ZMUM). C-F. Non-type $\widehat{o} \widehat{\partial}$ (IZB). Scale bars: $1 \mathrm{~mm}$. 
long tip significantly exceeding posterior part of lamella, and a well-developed and fimbriate velum (v). Posterior branch of o in form of a shield-like protective lamella (pl). Mesomere and opisthomere connected basally with an accessory membrane (am).

\section{Distribution}

Known only from Lagonaki Plateau and Pasture Abago, Caucasian Biosphere Nature Reserve, Russia (Fig. 57, red triangles).

A

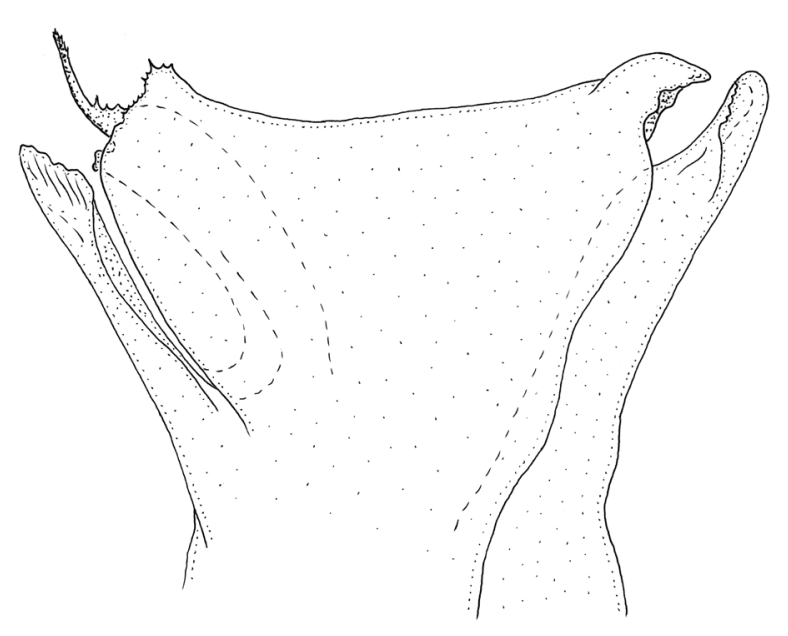

B

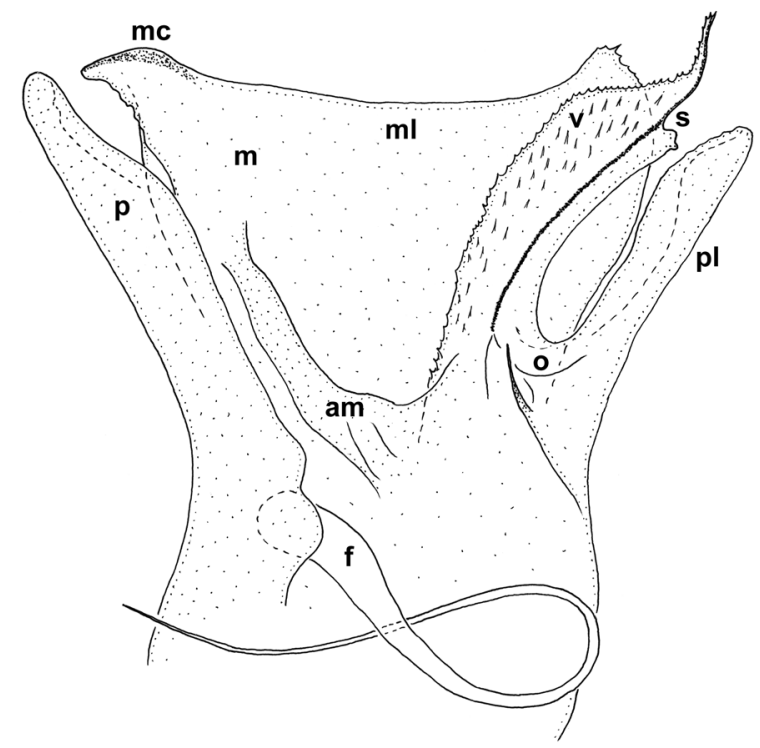

E

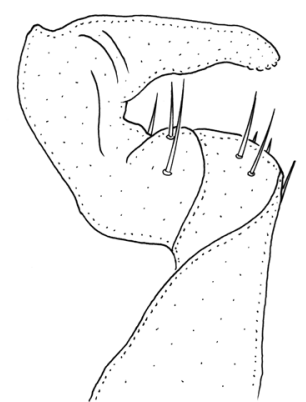

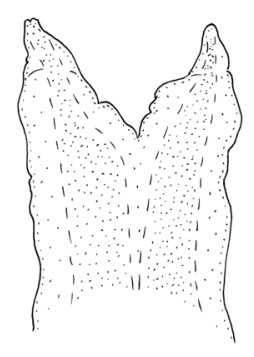
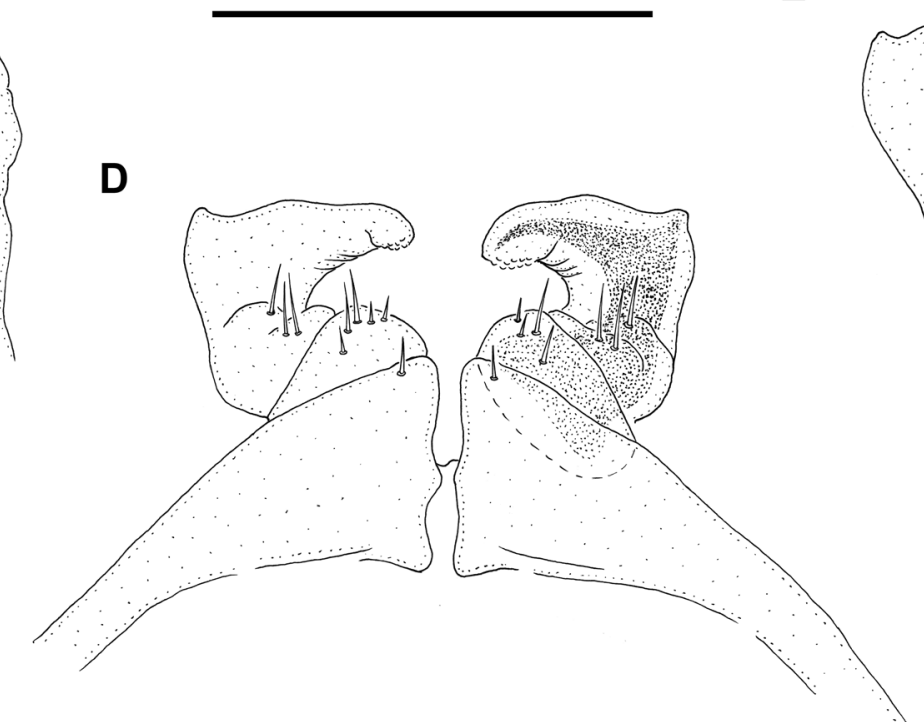

Fig. 31. Leucogeorgia oculata sp. nov., paratype $\widehat{\partial}$ from Lagonaki Plateau (ZMUM). A. Left gonopods, lateral view. B. Left gonopods, mesal view. C. Penes, posterior view. D. Leg-pair 1, anterior view. E. Left leg 1, lateral view. Abbreviations: $\mathrm{am}=$ accessory membrane; $\mathrm{f}=$ flagellum; $\mathrm{m}=$ mesomere; $\mathrm{mc}=$ mesomeral claw; $\mathrm{ml}=$ mesomeral lamella; $\mathrm{o}=$ opisthomere $; \mathrm{p}=$ promere $; \mathrm{pl}=$ protective lamella; $\mathrm{s}=$ solenomere; $\mathrm{v}=$ velum. Scale bar: $0.2 \mathrm{~mm}$. 


\section{Remarks}

This is probably an endogean subalpine species. It is the only member of the genus characterized by the presence of both a pigmented body and ommatidia, and the absence of metazonal setae. Ghilarov (1972) recorded this species as "Archileucogeorgia sp." (det. J. Gulička) from Pasture Abago as well.

Leucogeorgia prometheus sp. nov.

urn:1sid:zoobank.org:act:CD700B52-FE5E-4C36-967E-8A0125AEF240

Figs 1E, 2C, 32-35, 56, 58

\section{Diagnosis}

This species belongs to the group of Leucogeorgia spp. with neither modified mouthparts nor teeth on the mesomeral claw (vs teeth present in L. abchasica, L. borealis sp. nov., L. gioi sp. nov., L. oculata sp. nov. and $L$. satunini). Leucogeorgia prometheus sp. nov. differs from L. golovatchi sp. nov. by having a longer mesomeral claw and a short solenomere not exceeding the height of the mesomeral lamella (vs a shorter mesomeral claw and a longer solenomere clearly exceeding the height of the mesomeral lamella in L. golovatchi sp. nov.). Leucogeorgia prometheus sp. nov. differs from L. lobata sp. nov. by the absence of a strongly developed lobe on the mesomeral lamella, with a deep rift between the mesomeral claw and lobe (vs presence of a strongly developed lobe on the mesomeral lamella, with a deep rift between the mesomeral claw and lobe in L. lobata sp. nov.).

\section{Etymology}

This new species is named after its type locality, the Kumistavi Cave, popularly known as the Prometheus Cave. Noun in apposition.

\section{Material examined}

\section{Holotype}

CENTRAL-WEST GEORGIA - Tsqaltubo District • ${ }^{\lambda}$; Sataplia-Tskaltubo karst Massif, Kumistavi village, Kumistavi (= Prometheus, = Orpiri I) Cave; $42.37^{\circ}$ N, 42.60 E; 11 Jun. 2019; H. Reip leg.; SMNG.

\section{Paratypes}

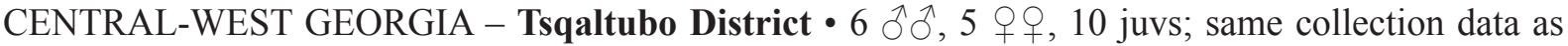

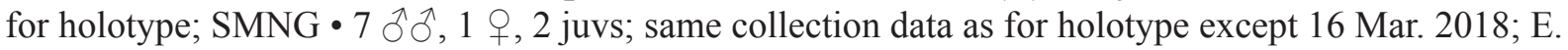

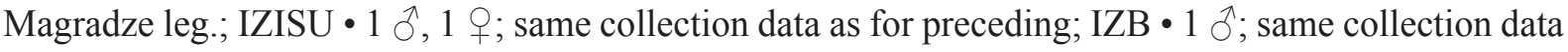
as for holotype except 1 May 2018; J. Grego leg.; NHMW 9981.

\section{Other material}

CENTRAL-WEST GEORGIA - Tsqaltubo District - 2 juvs; same collection data as for holotype; 10 Jan. 1981; V. Kiselev leg.; ZMUM • 1 ô; same collection data as for holotype but 7 Jan. 1987; N.T. Zalesskaja leg.; ZMUM $\bullet 7 \hat{\jmath}, 6$ qq, 1 juv.; same collection data as for holotype but 12 Dec. 2009; O. Hell leg.; IZB • 5 đo ; same collection data as for holotype but 17 Apr. 2011; R. Fohlert leg.; ZMUM • 2 + $\odot$; same collection data as for holotype but 10 Mar. 2012; S. Barjadze leg.; IZISU • 1 O , 1 क ; same collection data as for holotype but 1 Aug. 2016; collector unknown; ZMUM • 5 §ิग, 1 क ; same collection data as for holotype but 4-6 Feb. 2017; D.M. Palatov leg.; ZMUM • 1 ; Sataplia-Tskaltubo karst Massif, Kumistavi village, Solkota Cave; $42.38^{\circ} \mathrm{N}, 42.62^{\circ} \mathrm{E} ; 10 \mathrm{Mar}$.

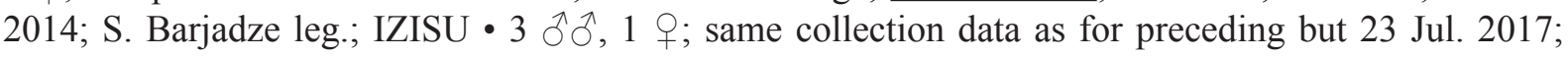
G. Nebieridze leg.; IZISU • 1 + ; same collection data as for preceding but 9 Mar. 2014; S. Barjadze leg.; IZISU • 3 $\widehat{\lambda}, 4$ 우, 5 juvs; Sataplia-Ktkaltubo karst Massif, Kumistavi village, Orpiri II Cave;

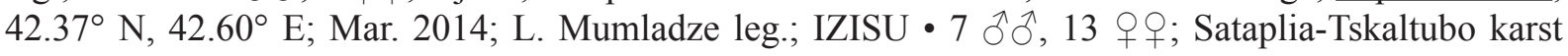
Massif, near Tskaltubo, Tetra Cave; $42.33^{\circ}$ N, $42.62^{\circ}$ E; 29 Aug. 1985; S.I. Golovatch leg.; ZMUM • 

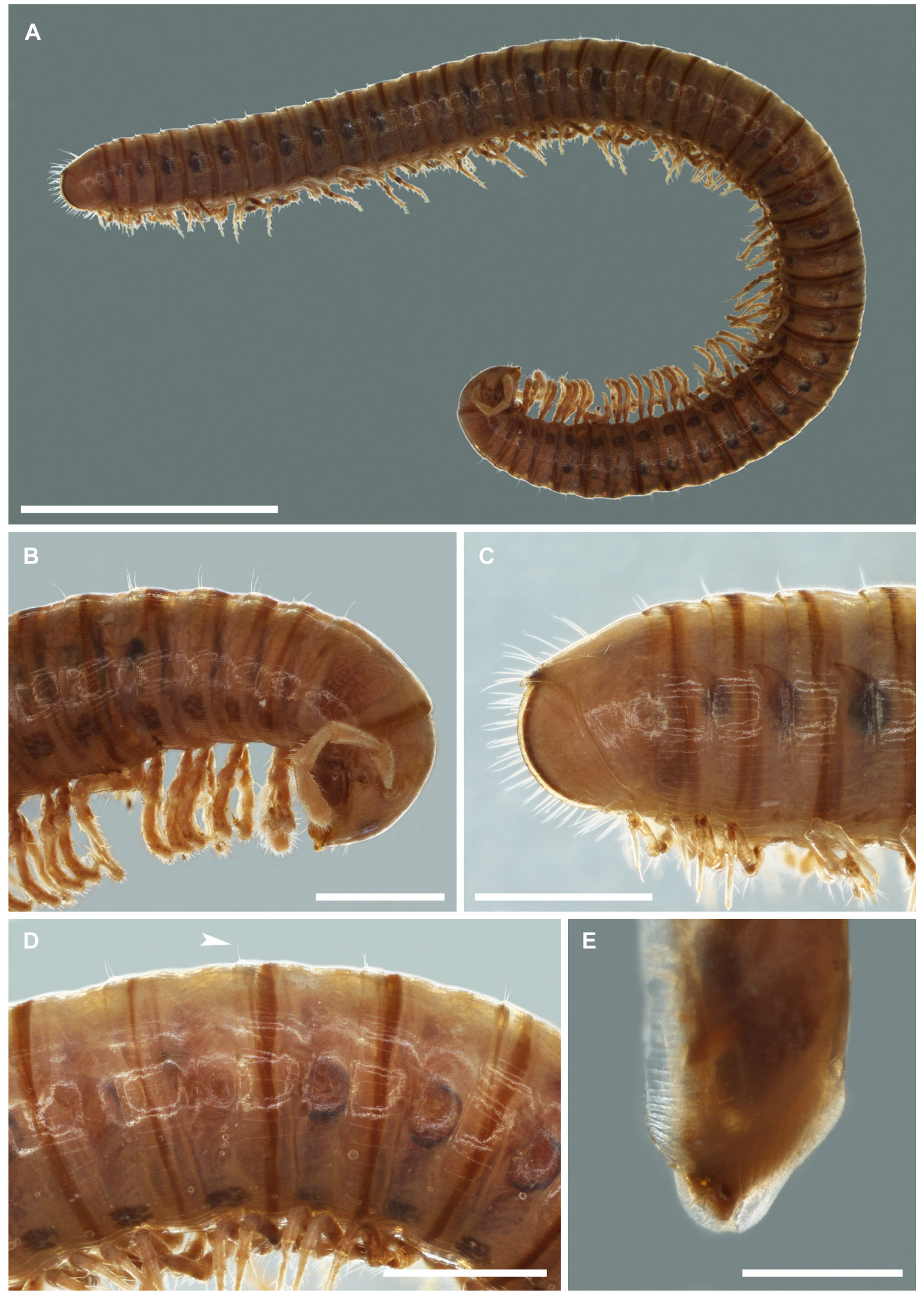

Fig. 32. Leucogeorgia prometheus sp. nov., paratype $\widehat{\jmath}$ from Prometheus Cave (IZISU). A. Habitus, lateral view. B. Anterior part of body, lateral view. C. Posterior part of body, lateral view. D. Midbody rings, lateral view. E. Body ring 7, lateral view. Scale bars: $A=5 \mathrm{~mm} ; \mathrm{B}-\mathrm{D}=1 \mathrm{~mm} ; \mathrm{E}=0.5 \mathrm{~mm}$. 


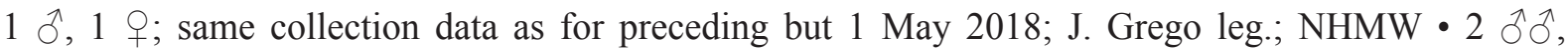
3 우, 1 juv.; same collection data as for preceding but 11 Mar. 2014; S. Barjadze leg.; IZISU • $3 \partial^{\lambda}{ }^{\wedge}$; 1 ㅇ, 1 juv.; Sataplia-Tskaltubo karst Massif, Chuneshi village, Sakire Cave; $42.34^{\circ} \mathrm{N}, 42.60^{\circ} \mathrm{E}$;

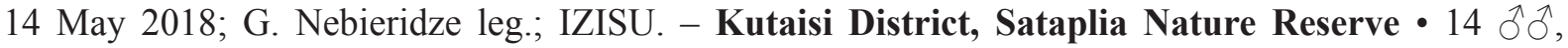
7 우, 6 juvs; Sataplia I Cave; 42.31 ${ }^{\circ}$ N, 42.67 E; 27 Jan. 1984; K. Makarov leg.; ZMUM • 1 q; same

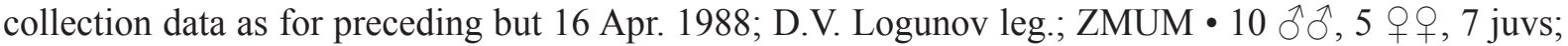
same collection data as for preceding but 5 Jun. 1981; S.I. Golovatch and J. Martens leg.; ZMUM •

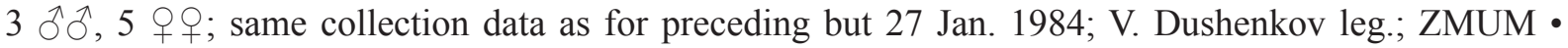
many broken specs; same collection data as for preceding but 8 Aug. 1984; S.I. Golovatch leg.; ZMUM - many specs; same collection data as for preceding but 25 Oct. 1981; S.I. Golovatch leg.;

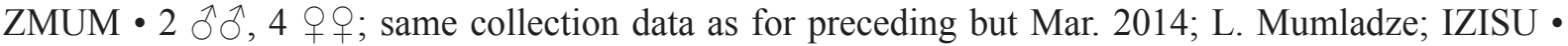
$1 \hat{\delta}, 1$ क; same collection data as for preceding but 11 Mar. 2014; S. Barjadze leg.; IZISU • $4 \hat{\delta} \widehat{\partial}$, 3 우, 12 juvs; same collection data as for preceding but 11 Jun. 2019; H. Reip leg.; SMNG -5 우으,

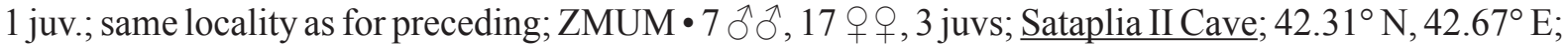
28 Jan. 1987; V. Bogdanov leg.; ZMUM $\bullet 3$ $\widehat{\jmath}, 16$ q $q$, 5 juvs; same collection data as for preceding

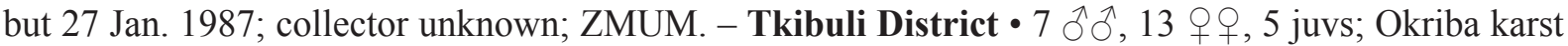
Massif, Tsutskhvati village, Tsutskhvati Cave; $42.27^{\circ}$ N, $42.85^{\circ}$ E; 24 Oct. 1981; S.I. Golovatch leg.; ZMUM -1 ô, Okriba karst Massif, Tsutskhvati village, Tsutskhvati VII Cave; $42.27^{\circ} \mathrm{N}, 42.85^{\circ} \mathrm{E}$; 28 Feb. 2013; S. Barjadze leg.; IZISU.

\section{Description}

SizE AND NUMBER OF BODY RINGS. Holotype male $29 \mathrm{~mm}$ long, vertical diameter of largest body ring 1.9 $\mathrm{mm}$, body with 43 podous rings +0 apodous rings + telson. Paratype males $16.5-27 \mathrm{~mm}$ long, vertical diameter of largest body ring $1.3-1.9 \mathrm{~mm}$, body with 35-44 podous rings $+0-3$ apodous rings + telson. Paratype females 23-29 mm long, vertical diameter of largest body rings $1.5-1.9 \mathrm{~mm}$, body with 40-44 podous rings $+0-1$ apodous rings + telson.

Colour (Figs 1E, 32). Living animals yellowish white. Specimens from alcohol brownish.

HeAd (Figs 32B, 33D-E). Without ommatidia. Frontal setae absent. Labrum with three teeth, four supralabral setae and 14 to $16(7+7,7+8$ or $8+8)$ labral setae. Gnathochilarium with rhomboid promentum; lamellae linguales with 3-5 setae each in one row; stipites with $3+3$ long distolateral and 5-7 short medial setae each. Antennae $2.9 \mathrm{~mm}$ long in holotype male, their length ca $150 \%$ of vertical diameter of largest body ring. Lengths of antennomeres I-VIII (in mm): 0.2 (I), 0.67 (II), 0.59 (III), 0.45 (IV), $0.55(\mathrm{~V}), 0.25$ (VI), 0.14 (VII) and 0.05 (VIII). Length/width ratio of antennomeres I-VII: 1 (I), 3.7 (II), 3.3 (III), 2.5 (IV), 2.4 (V), 1.1 (VI) and 1 (VII). Antennomeres V and VI each with a terminal corolla of large sensilla basiconica bacilliformia; antennomere VII with a terminal corolla of small sensilla basiconica bacilliformia.

Body RINGS (Fig. 32D). Entire metazonal area with longitudinal striations. Length of midbody setae ca $7 \%$ of vertical diameter of rings.

Telson (Fig. 32C). Epiproct with a short and blunt preanal process, sloping slightly downwards and covered with dorsal and lateral setae. Paraprocts rounded, with numerous setae. Hypoproct without any modifications.

LeGs IN MALES. First pair of legs modified, hook-shaped (Figs 33A-C, 35E-F), with three podomeres; coxa with one seta; prefemur with 6-9 setae; femora, postfemora and tibiotarsi coalesced, with 5-6 setae (3-5 on remnants of femora and $1+1$ on remnants of postfemora). Podomeres tuberculate. Postfemoral and tibial ventral pads well-developed on anterior legs, then gradually disappearing towards posterior legs.

Ventral Margin of Body Ring 7 (Fig. 32E). Strongly developed, rounded in lateral view. 

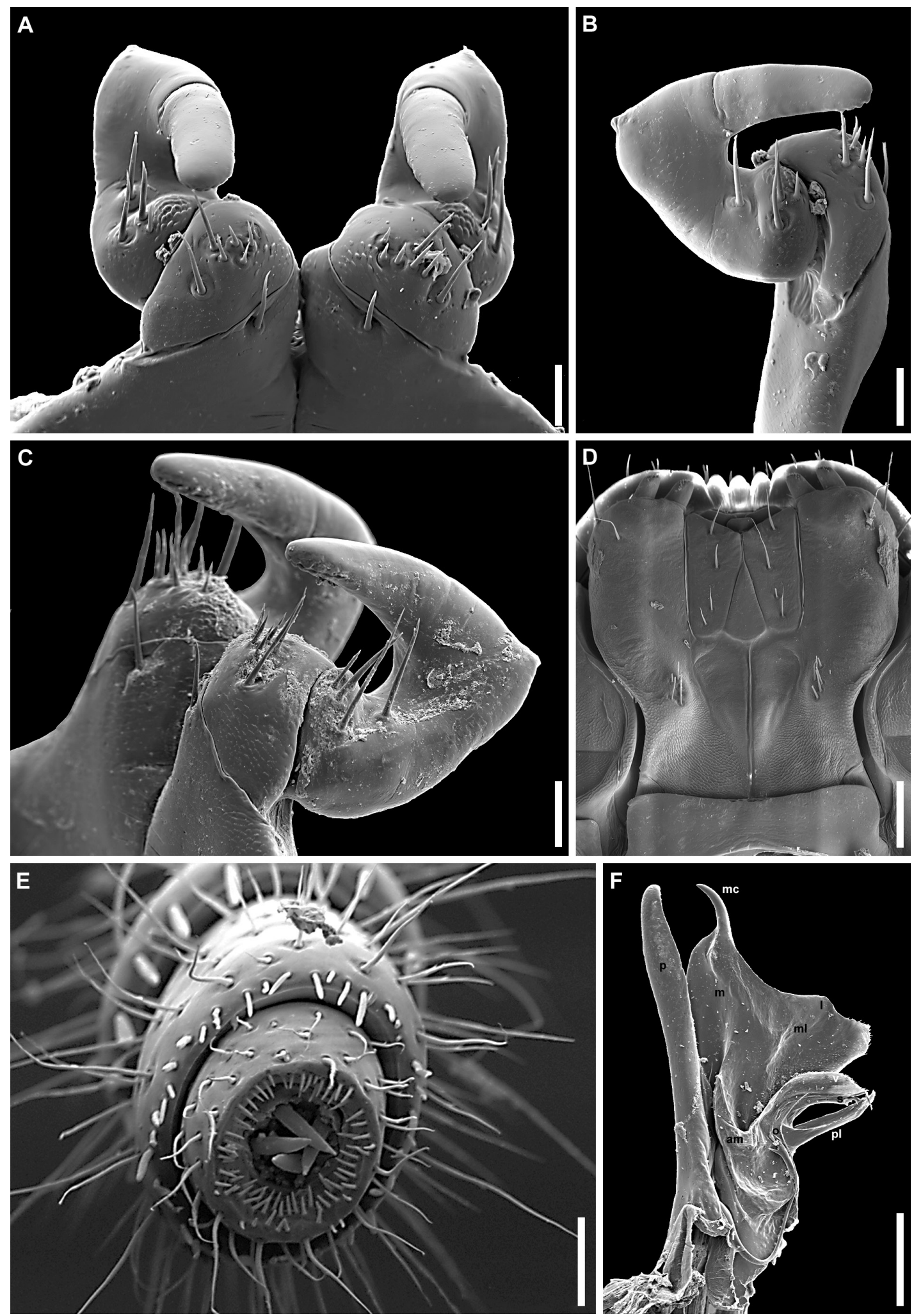

Fig. 33. Leucogeorgia prometheus sp. nov., non-type $\widehat{\partial}$ from Sataplia I Cave (ZMUM). A. Leg-pair 1, anterior view. B. Left leg 1, lateral view. C. Leg-pair 1, anterolateral view. D. Head, ventral view. E. Tip of antenna. F. Left gonopods, mesal view. Abbreviations: am = accessory membrane; $\mathrm{f}=$ flagellum; $\mathrm{l}=$ lobe $; \mathrm{m}=$ mesomere; $\mathrm{mc}=$ mesomeral claw; $\mathrm{ml}=$ mesomeral lamella $; \mathrm{o}=$ opisthomere $; \mathrm{p}=$ promere; $\mathrm{pl}=$ protective lamella; $\mathrm{s}=$ solenomere; $\mathrm{v}=$ velum. Scale bars: $\mathrm{A}-\mathrm{B}, \mathrm{E}=0.05 \mathrm{~mm} ; \mathrm{C}-\mathrm{D}, \mathrm{F}=0.2 \mathrm{~mm}$. 
Penes (Fig. 35D). In form of a short trapezoid, apically with two small subtriangular lobes.

Gonopods (Figs 33F, 34, 35A-C). Promere (p) long and slender, with a flagellum (f); apical part spatulate, with denticulated margins; basal half with two developed ridges. Mesomere (m) with a
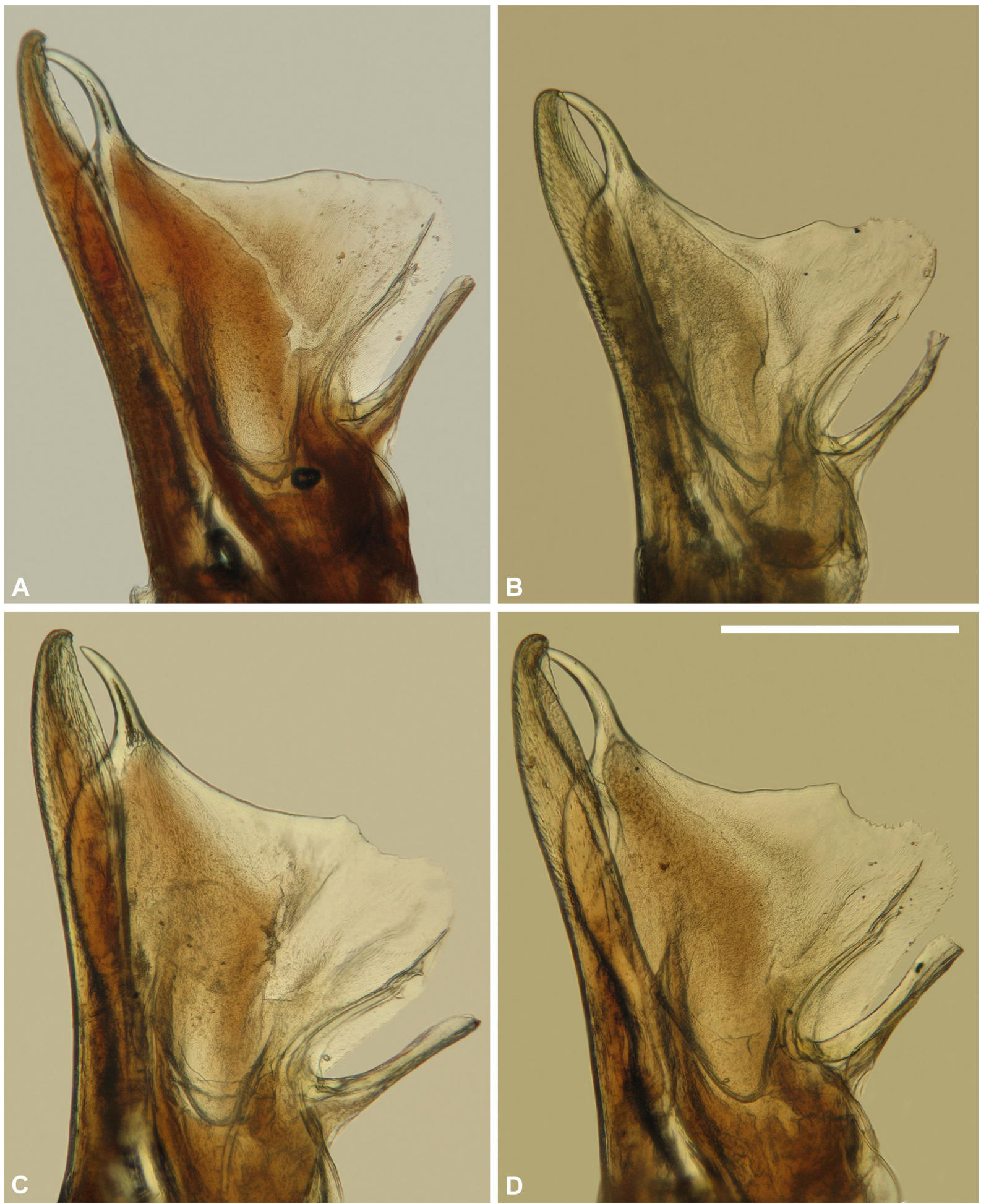

Fig. 34. Leucogeorgia prometheus sp. nov., paratype $\widehat{\jmath} \hat{\jmath}$ from Prometheus Cave (IZISU). A-D. Left gonopods, mesal views. Scale bar: $0.3 \mathrm{~mm}$. 
A

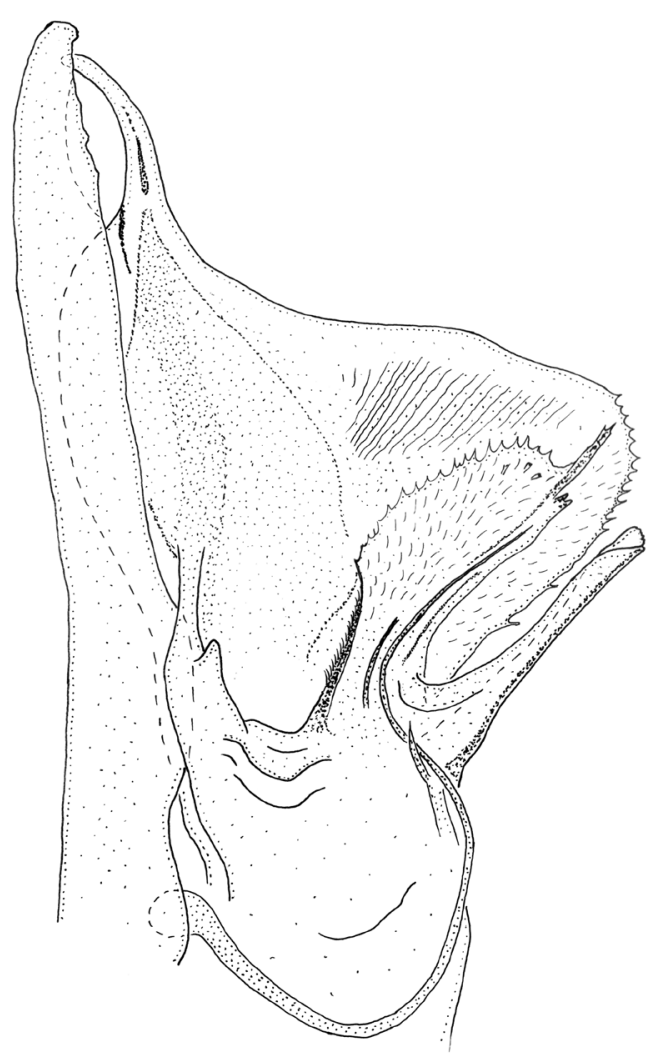

C

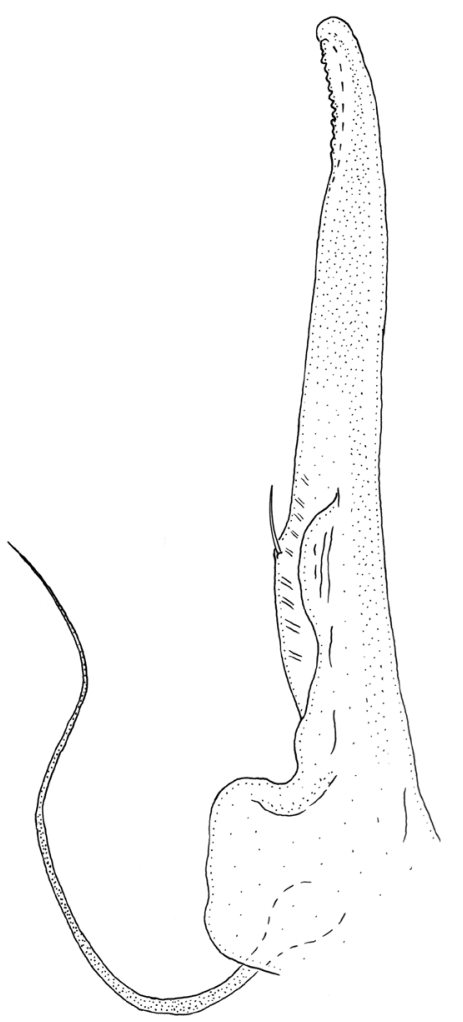

B

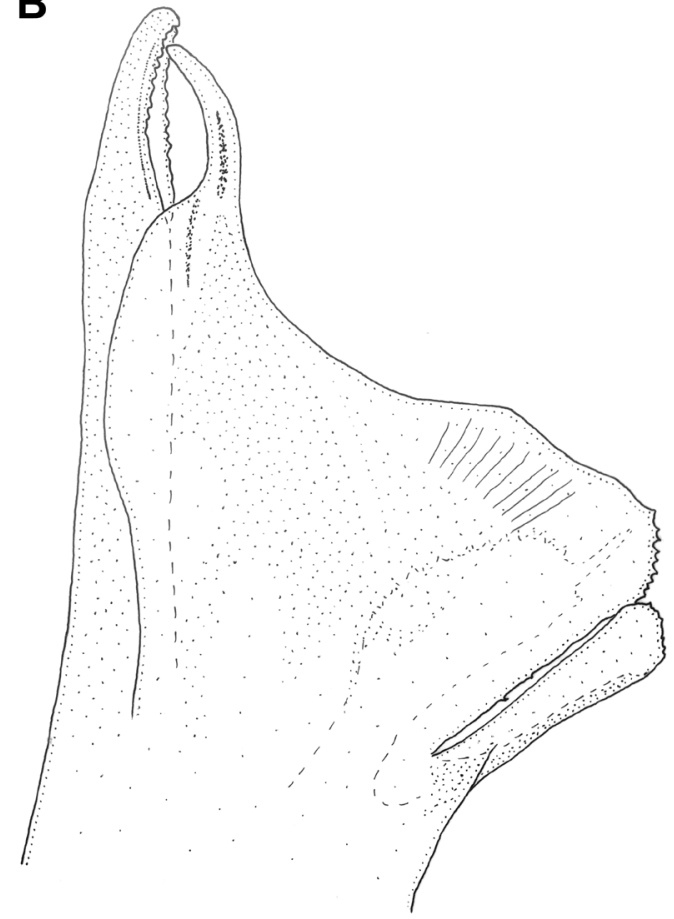

E
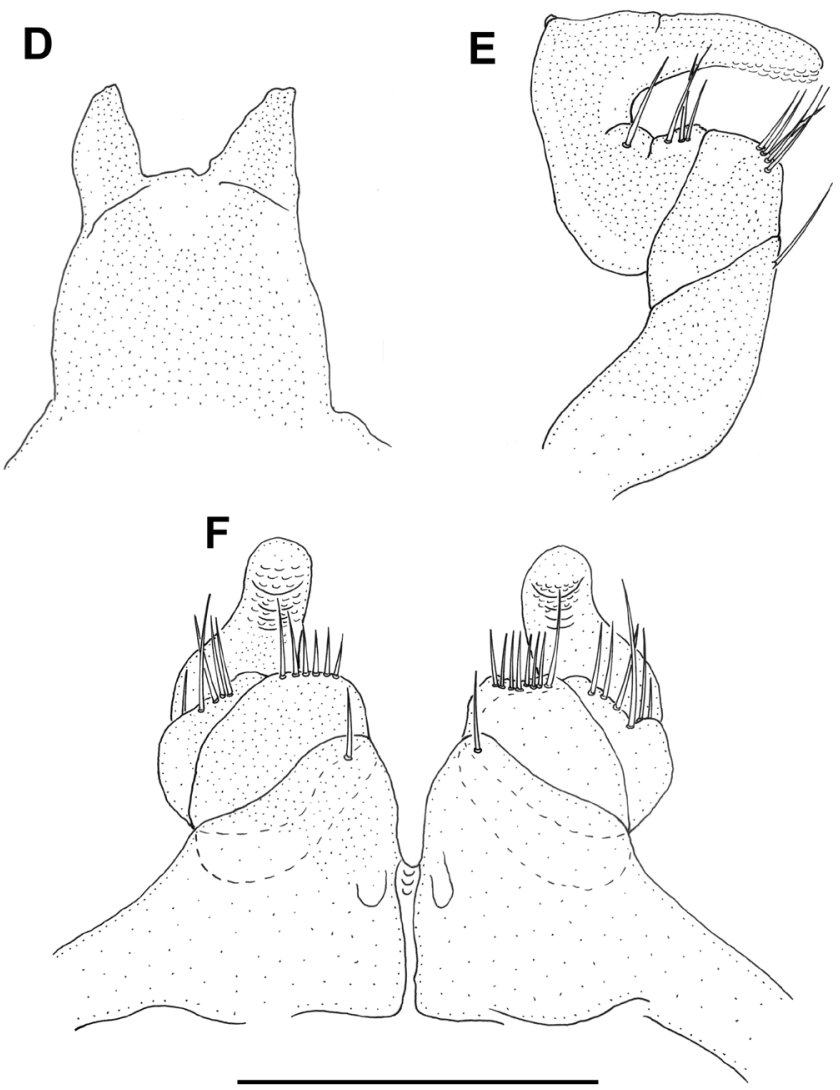

Fig. 35. Leucogeorgia prometheus sp. nov., paratype $\curvearrowright$ from Prometheus Cave (IZISU). A. Left gonopods, mesal view. B. Right gonopods, lateral view. C. Left promere, lateral view. D. Penes, posterior view. E. Left leg 1, lateral view. F. Leg-pair 1, anterior view. Scale bar: $0.3 \mathrm{~mm}$. 
slender mesomeral claw (mc) devoid of teeth, slightly curved anteriad; mesomeral lamella (ml) with or without a poorly developed lobe (1), distal margin smooth, posterior part finely fimbriate. Opisthomere (o) bipartite. Anterior branch of o with a solenomere (s) with a medium-sized tip, and a well-developed and fimbriate velum (v). Posterior branch of o in form of a shield-like protective lamella ( $\mathrm{pl}$ ). Mesomere and opisthomere connected basally with an accessory membrane (am).

\section{Distribution}

Known from several caves in the Tsqaltubo, Kutaisi and Tkibuli districts of Georgia (Fig. 58, light blue triangles).

\section{Remarks}

The occurrence of this remarkable species has been noted several times by tourists visiting the famous touristic caves Prometheus or Sataplia. Although a fairly large and easy-to-spot julid, Leucogeorgia prometheus sp. nov. has never been studied scientifically. This species is very abundant and does not seem to be endangered by the operation of these show caves, because it was collected several times in extremely large numbers. Nor have the extensive collections undermined the local populations. The animals were found especially abundant on rotting timber poles that support the electric lamps inside the caves (Golovatch pers. comm.), living there together with the glomerid millipede, Trachysphaera fragilis (Golovatch, 1976), likewise cavernicolous, common and abundant in the same region (Golovatch \& Turbanov 2017). In contrast, only very few specimens of Leucogeorgia prometheus sp. nov. were spotted grazing on the lamp flora, being more abundant also in muddy areas without any sign of introduced organic material. As a guess, the true habitats of this species might not be cave chambers proper, but the subterranean small crevices and cracks.

\section{New species with modified mouthparts}

Leucogeorgia caudata sp. nov. urn:1sid:zoobank.org:act:301B3880-9D65-42A7-B2ED-FAC7304C326D

Figs 1B, 36-38, 56-57

\section{Diagnosis}

This species belongs to the group of Leucogeorgia spp. with modified mouthparts and teeth on the mesomeral claw (vs teeth absent in L. longipes). Leucogeorgia caudata sp. nov. clearly differs from all other congeners by having an epiproct with a very long and sharp caudal process, apically with a hyaline tip slightly curved upwards (vs absence of such a long and sharp process with a hyaline tip in all other congeners) and elongate antennae with the length $200 \%$ of the vertical diameter of the largest body ring (vs shorter antennae, $\leq 190 \%$ of the vertical diameter of the largest body ring in other species of Leucogeorgia with modified mouthparts).

\section{Etymology}

From the Latin 'caudata' (= 'tailed'), reflecting the presence of a long and sharp caudal process on the epiproct. Adjective in feminine gender.

\section{Material examined}

\section{Holotype}

ABKHAZIA - Gudauty District - ○े; Gumishkhinsky karst Massif, Novyi Afon, Novoafonskaya (= New Athos) Cave, Corallite Gallery; 43.09 N, 40.81 E; 18-20 May 2016; S.A. Kapralov leg.; ZMUM. 

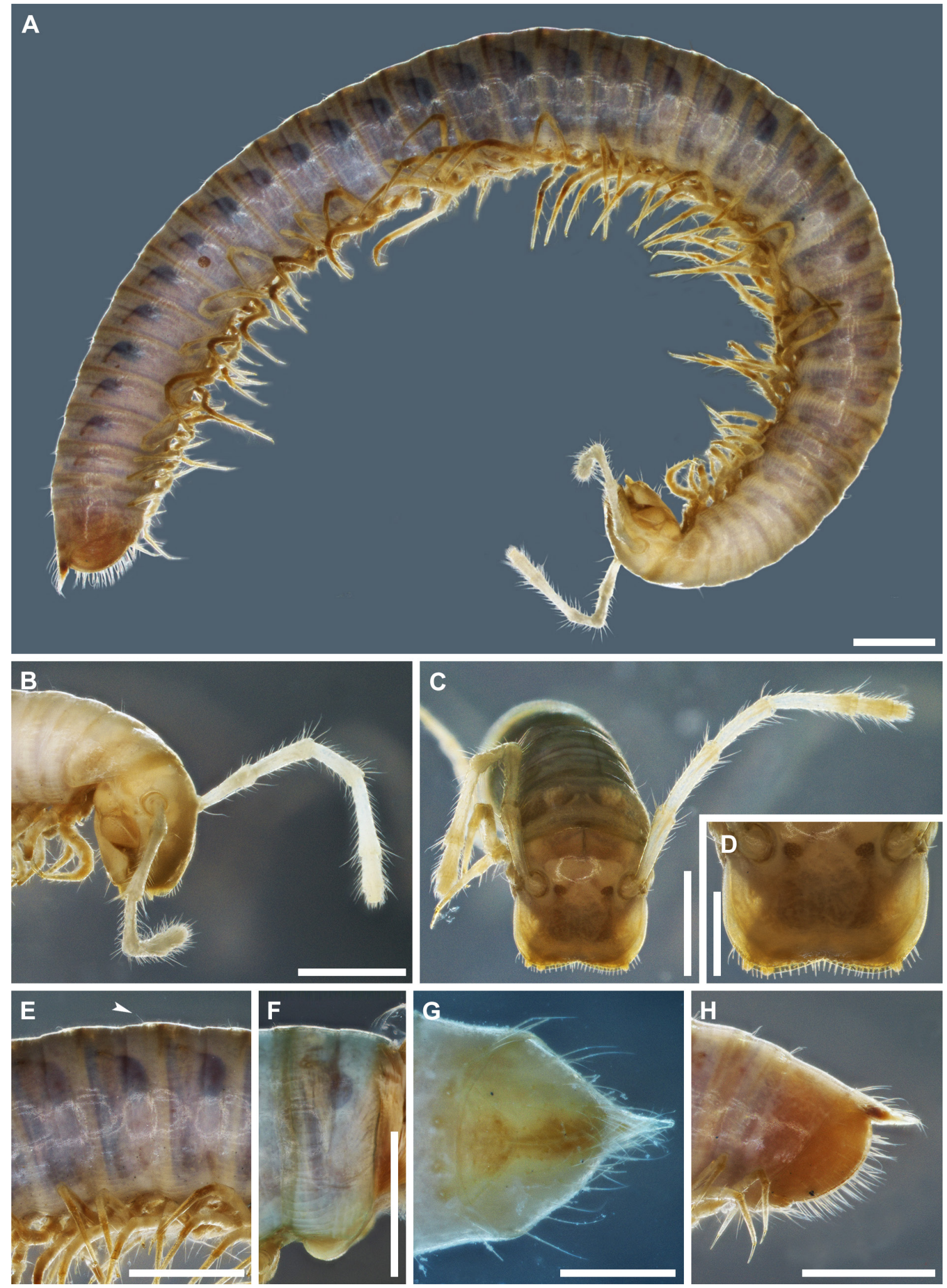

Fig. 36. Leucogeorgia caudata sp. nov., type $\widehat{\partial} \hat{\partial}$ from Novoafonskaya Cave. A. Holotype, habitus, lateral view (ZMUM). B. Holotype, head, lateral view. C. Paratype, head and anterior part of body, anterior view (IZB). D. Paratype, labrum, dorsal view (IZB). E. Holotype, midbody rings, lateral view. F. Paratype, body ring 7, lateral view (IZB). G. Paratype, telson, ventral view (IZB). H. Holotype, teslon, lateral view. Arrow indicates metazonal seta. Scale bars: $A-C, E-F, H=1 \mathrm{~mm} ; \mathrm{D}, \mathrm{G}=0.5 \mathrm{~mm}$. 
Paratypes

ABKHAZIA - Gudauty District $\bullet 1 \hat{O}, 1$; ; same collection data as for holotype; ZMUM $\bullet 1 \hat{\partial}, 1$ + ; same collection data as for holotype; IZB -5 우; same collection data as for holotype but White Mountain; 2 Jan. 2017; ZMUM.

\section{Other material}

ABKHAZIA - Sukhum District • 1 ภ, 2 우, 1 juv.; Gumishkhinskiy karst Massif, near Verkhnaia Eshera village, $\underline{\text { Adzaba Cave, }}, 50-100 \mathrm{~m}$ from entrance; $43.07^{\circ} \mathrm{N}, 40.99^{\circ} \mathrm{E} ; 14$ Sep. 2014; I.S. Turbanov leg.; ZMUM.

\section{Description}

SizE AND NUMBER OF BODY RINGS. Holotype male $20 \mathrm{~mm}$ long, vertical diameter of largest body ring 1.55 $\mathrm{mm}$, body with 34 podous rings +1 apodous ring + telson. Longer paratype male $31 \mathrm{~mm}$ long, vertical diameter of largest body ring $1.7 \mathrm{~mm}$, body with 40 podous rings +0 apodous ring + telson. Smaller paratype male body with 38 podous rings +1 apodous ring + telson. Paratype females 19-25 mm long, vertical diameter of largest body ring $1.6-2 \mathrm{~mm}$, body with $32-38$ podous rings $+0-2$ apodous rings + telson.

Colour (Figs 1B, 36). Living animals with whitish head, legs and telson; due to thin and transparent cuticle, body looks blackish, with some greyish or blackish patterns lateroventrally. Yellowish white to yellowish brown or greyish white in alcohol.

Head (Figs 36B-D, 37C-E). Without ommatidia. Frontal setae absent. Labrum without labral teeth, with 4 supralabral setae and 26-30 labral setae. Gnathochilarium with a triangular promentum; lamellae linguales with $1+1$ long distal setae and $3+3$ or $4+4$ long proximal setae; stipites with $3+3$ long distolateral setae; no other setae. Antennae $3.1 \mathrm{~mm}$ long in holotype male, their length $200 \%$ of vertical diameter of largest body ring. Lengths of antennomeres I-VIII (in mm): 0.11 (I), 0.57 (II), 0.71 (III), 0.58 (IV), 0.65 (V), 0.33 (VI), 0.1 (VII) and 0.05 (VIII). Length/width ratio of antennomeres I-VII: 0.8 (I), 2.8 (II), 3.5 (III), 3 (IV), 3.3 (V), 1.7 (VI) and 0.7 (VII). Antennomeres V and VI each with a terminal corolla of large sensilla basiconica bacilliformia; antennomere VII with a terminal corolla of small sensilla basiconica bacilliformia.

Body RINGS (Fig. 36E). Entire metazonal area with longitudinal striations. Length of midbody setae ca $8 \%$ of vertical diameter of rings.

Telson (Fig. 36G-H). Epiproct with a very long and sharp caudal process, apically with a hyaline tip slightly curved upwards; covered with dorsal and lateral setae. Paraprocts rounded, densely setose. Hypoproct subtrapezoid, in paratype female with 11 long setae.

LegS IN MALEs. First pair of legs modified, hook-shaped (Figs 37A-B, 38C), with three podomeres; coxa with one seta; prefemur with 5-6 setae; femora, postfemora and tibiotarsi coalesced; femur with 3-4 setae; postfemur with one seta. Tibiotarsal part with a small distal lobe and either with or without one seta. Tip slightly tuberculate. Postfemoral and tibial ventral pads developed on pregonopodal legs, then gradually disappearing on postgonopodal legs.

Ventral margin of Male body Ring 7 (Fig. 36F). Well-developed, low, rounded in lateral view.

Penes (Fig. 38D). Elongate, apically with two small subtriangular lobes.

Gonopods (Figs 37F, 38A-B). Promere (p) long and slender, slightly curved anteriad, with a flagellum (f); apical part spatulate, with denticulate margins; basal half with two developed ridges. Mesomere (m) with a robust and denticulate mesomeral claw (mc); mesomeral lamella (ml) slightly convex, 

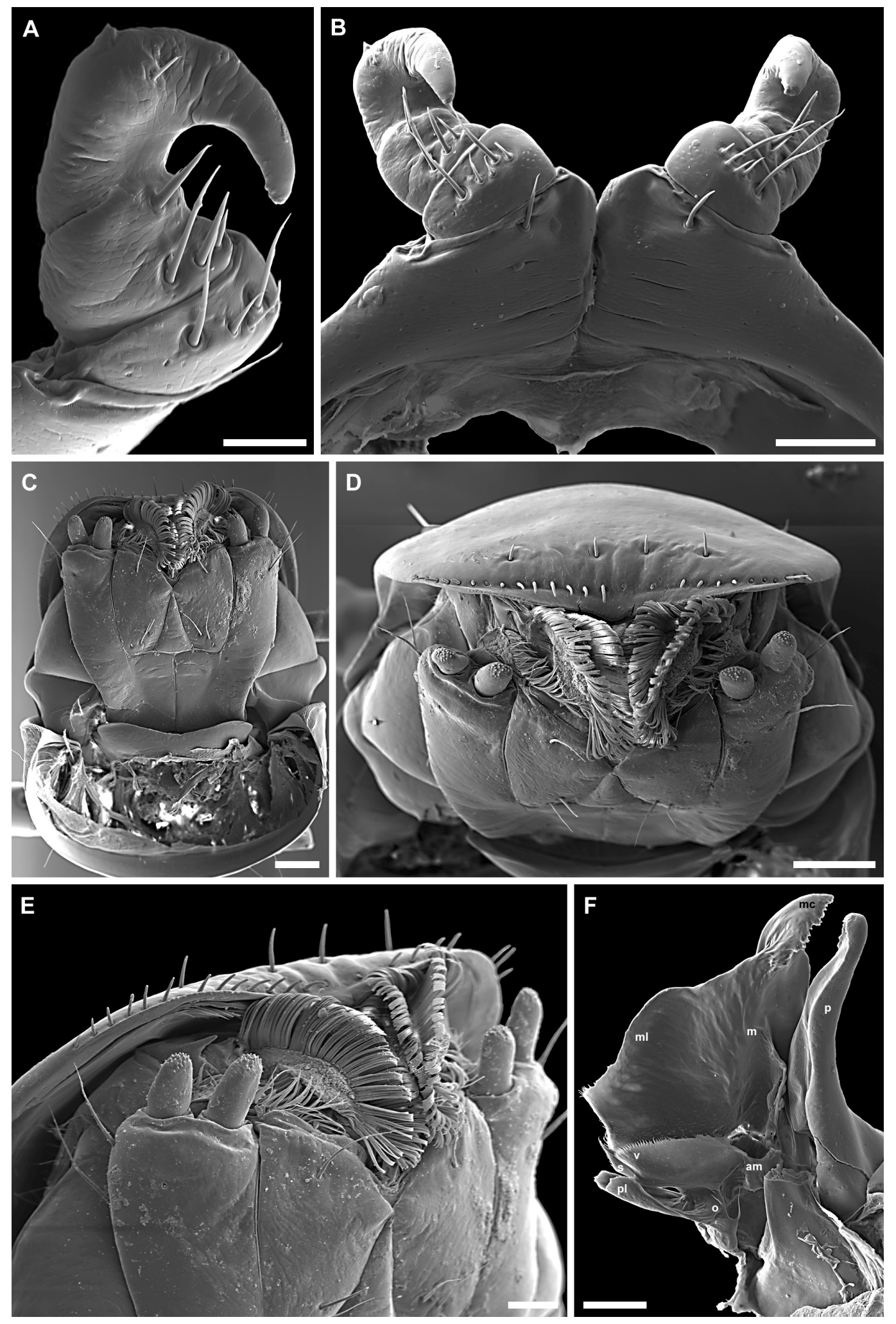

Fig. 37. Leucogeorgia caudata sp. nov., non-type $\widehat{\partial} \widehat{\partial}$ from Adzaba Cave (ZMUM). A. Left leg 1, lateral view. B. Leg-pair 1, anterior view. C. Head, ventral view. D. Head, anterior view. E. Head, ventrolateral view. F. Right gonopods, mesal view. Abbreviations: am $=$ accessory membrane; $\mathrm{m}=$ mesomere; $\mathrm{mc}=$ mesomeral claw; $\mathrm{ml}=$ mesomeral lamella; $\mathrm{o}=$ opisthomere; $\mathrm{p}=$ promere; $\mathrm{pl}=$ protective lamella; $\mathrm{s}=$ solenomere; $\mathrm{v}=$ velum. Scale bars: $\mathrm{A}=0.05 \mathrm{~mm} ; \mathrm{B}, \mathrm{E}-\mathrm{F}=0.1 \mathrm{~mm} ; \mathrm{C}-\mathrm{D}=0.2 \mathrm{~mm}$. 
starting from mesal side of $\mathrm{mc}$, distal margin serrate, posterior part finely fimbriate. Opisthomere (o) bipartite. Anterior branch of o with a solenomere (s) with a medium-sized tip, and a well-developed and fimbriate velum (v). Posterior branch of o in form of a shield-like protective lamella (pl). Mesomere and opisthomere connected basally with an accessory membrane (am).

\section{Distribution}

Known only from two neighbouring caves in the Gudauty and Sukhum districts of Abkhazia (Fig. 57, blue square).

A

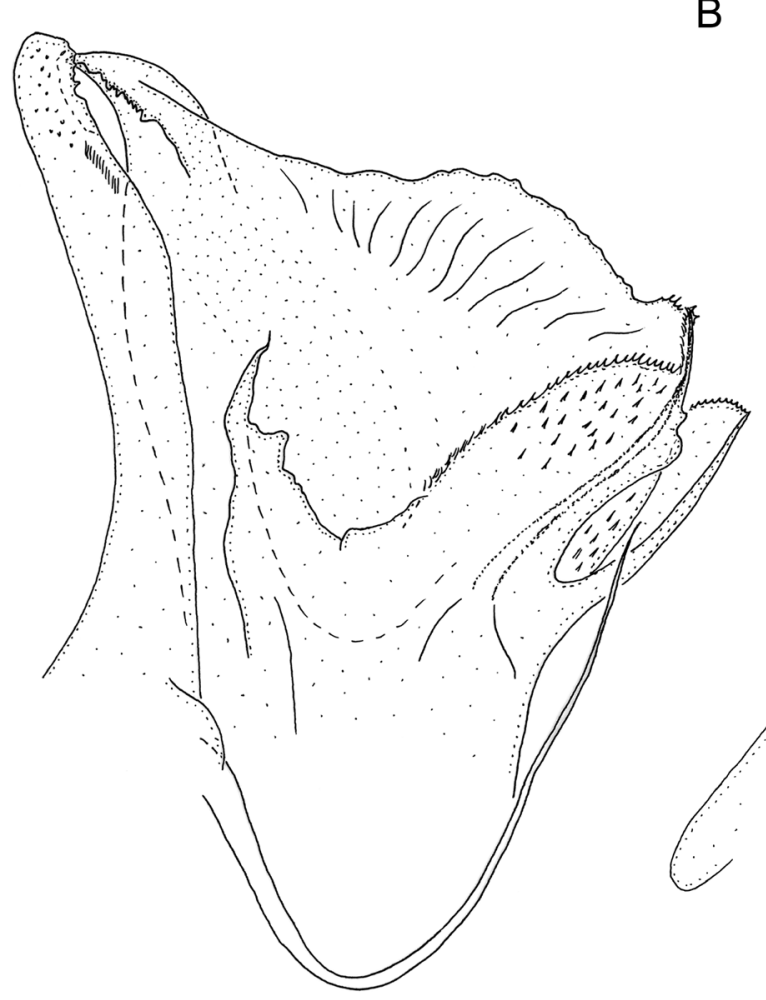

C

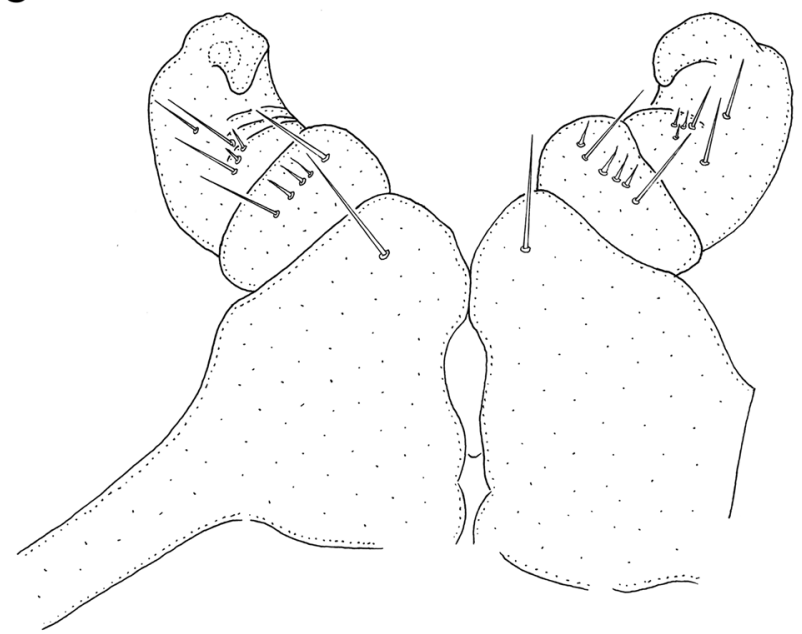

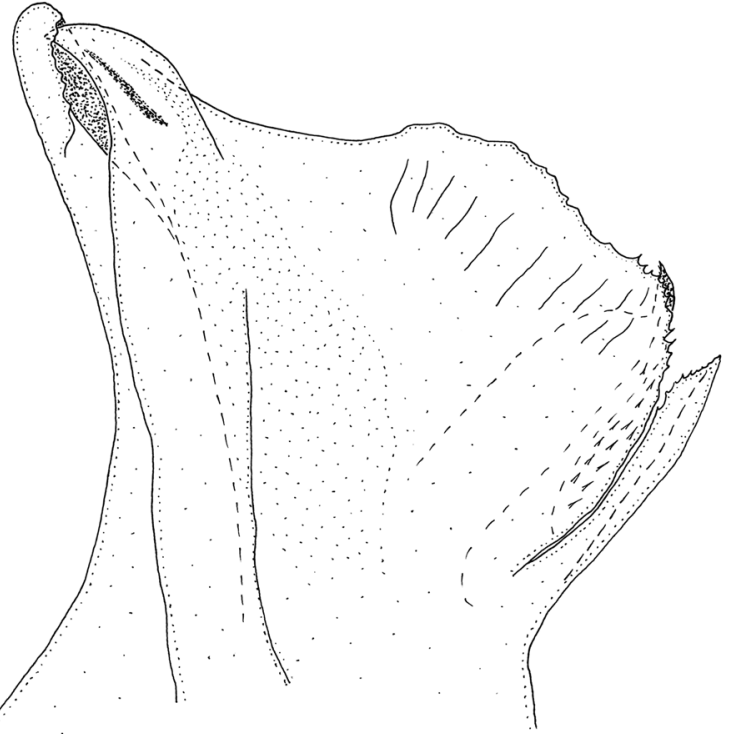

D

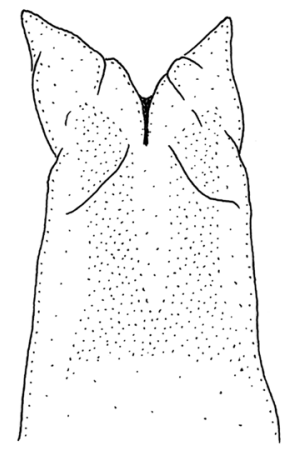

Fig. 38. Leucogeorgia caudata sp. nov., paratype $\widehat{\jmath}$ from Novoafonskaya Cave (IZB). A. Left gonopods, mesal view. B. Right gonopods, lateral view. C. Leg-pair 1, anterior view. D. Penes, posterior view. Scale bar: $0.3 \mathrm{~mm}$. 


\section{Remarks}

In the Novoafonskaya Cave, this species lives in sympatry with L. rediviva, which also has modified mouthparts.

Leucogeorgia mystax sp. nov. urn:1sid:zoobank.org:act:9AE0998A-E021-4120-B1CA-DC5A021D20D0

Figs 39-41, 56-57

\section{Diagnosis}

This species belongs to the group of Leucogeorgia spp. with modified mouthparts and teeth on the mesomeral claw (vs teeth absent in L. longipes). Leucogeorgia mystax sp. nov. clearly differs from all congeners by its highly modified mouthparts, viz., two rounded labral lobes with a deep incision in between, and by having a unique gnathochilarium with a distolateral bundle of long setae on the stipites and distal (anterior) rows of long setae on both stipites and lamellae linguales (vs such structures absent in all other congeners).

\section{Etymology}

From the Latin 'mystax' (= 'moustache'), reflecting the presence of long setae laterally on the gnathochilarium, resembling moustaches. Noun in apposition.

\section{Material examined}

\section{Holotype}

ABKHAZIA - Gagry District - ${ }^{\lambda}$; Gagra Mt Ridge, Arabika karst Massif, Lastochkino Krylo area, Nytshka Cave, depth -7 m; $43.45^{\circ}$ N, 40.31 E; 27 Aug. 2014; I.S. Turbanov leg.; ZMUM.

\section{Paratypes}

ABKHAZIA - Gagry District • 1 \%; same collection data as for holotype; ZMUM・ 1 ; same collection data as for holotype; IZB.

\section{Description}

SiZE AND NUMBER OF BODY RINGs. Holotype male $15 \mathrm{~mm}$ long, vertical diameter of largest body ring 1 $\mathrm{mm}$, body with 29 podous rings +1 apodous ring + telson. Paratype females $15-16 \mathrm{~mm}$ long, vertical diameter of largest body ring $1.1-1.2 \mathrm{~mm}$, body with 30 podous rings $+0-1$ apodous ring + telson.

CoLour (Fig. 39). Yellowish white in alcohol.

HeAd (Figs 39B-D, 40A-G). Without ommatidia. Frontal setae absent. Labrum without labral teeth, but with two rounded lobes with a deep incision in between; each lobe with ca 7-8 long labral setae. Gnathochilarium (holotype male) with rhomboid promentum; lamellae linguales each with two irregular, transverse, distal rows of $9+11$ long setae and one longitudinal row of $4+6$ shorter setae; stipites with two irregular, transverse, distal rows of 9-10 long setae and a distolateral bundle of long setae. Antennae long, $1.8 \mathrm{~mm}$ long in holotype male, their length $180 \%$ of vertical diameter of largest body ring. Lengths of antennomeres I-VIII (in mm): 0.09 (I), 0.39 (II), 0.40 (III), 0.26 (IV), 0.32 (V), 0.23 (VI), 0.07 (VII) and 0.04 (VIII). Length/width ratio of antennomeres I-VII: 0.8 (I), 3 (II), 3.3 (III), 2 (IV), 2.1 (V), 1.6 (VI) and 0.6 (VII). Antennomeres V and VI each with a terminal corolla of large sensilla basiconica bacilliformia; antennomere VII with a terminal corolla of small sensilla basiconica bacilliformia.

Body RINGs (Fig. 39E). Ventral side of metazonal area with longitudinal striations. Dorsal side of metazonal area smooth. Metazonal setae abraded from midbody rings. Length of body ring 7 setae ca $6 \%$ of vertical diameter of ring. 

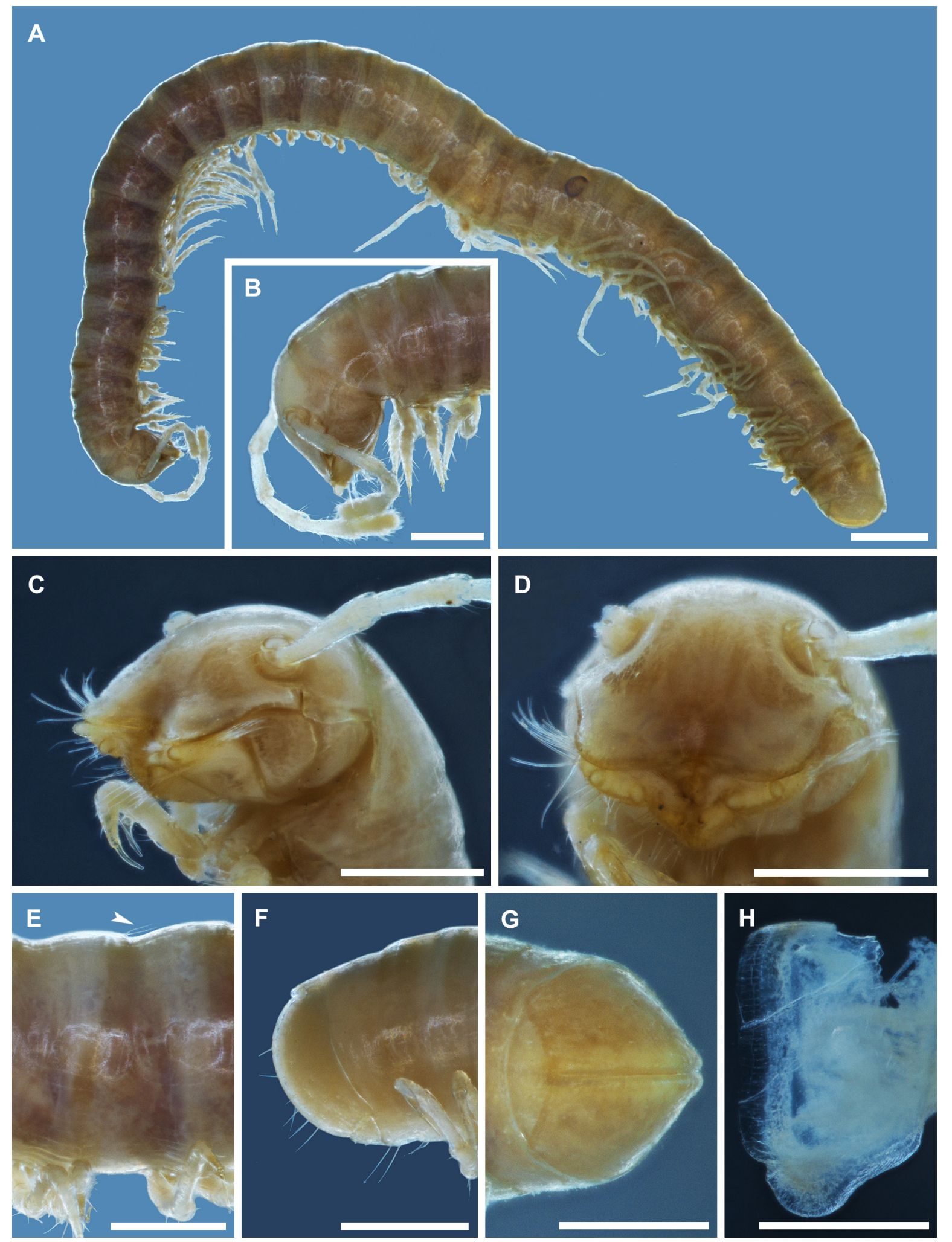

Fig. 39. Leucogeorgia mystax sp. nov., types from Nytshka Cave. A. Paratype ${ }_{+}$, habitus, lateral view (ZMUM). B. Paratype $q$, , head, lateral view (ZMUM). C. Paratype $q$, head, anterolateral view (IZB). D. Paratype $q$, head, anterior view (IZB). E. Paratype + , midbody rings, lateral view (ZMUM). F. Holotype $\overbrace{}^{\lambda}$, telson, lateral view (ZMUM). G. Paratype + , telson, ventral view (IZB). H. Holotype, body ring 7, lateral view. Scale bars: $A=1 \mathrm{~mm} ; \mathrm{B}-\mathrm{H}=0.5 \mathrm{~mm}$. 

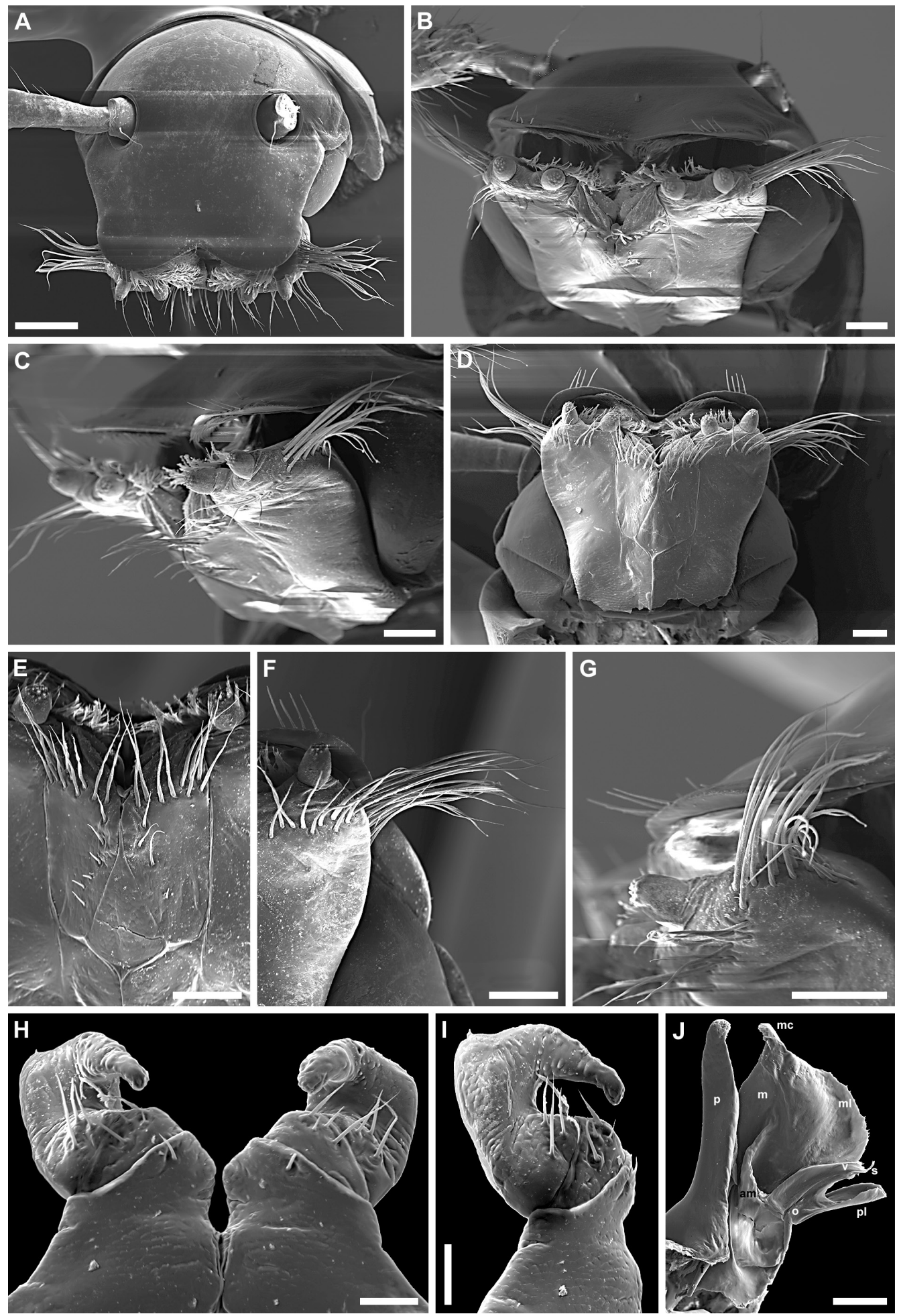

Fig. 40. Leucogeorgia mystax sp. nov., holotype $\widehat{\jmath}$ from Nytshka Cave (ZMUM). A. Head, dorsal view. B. Head, anterior view. C. Head, anterolateral view. D. Head, ventral view. E. Lamellae linguales, ventral view. F. Left stipe, ventral view. G. Left stipe, lateral view. H. Leg-pair 1, anterior view. I. Left leg 1, lateral view. J. Left gonopods, mesal view. Abbreviations: am = accessory membrane; $\mathrm{f}=$ flagellum $; \mathrm{m}=$ mesomere $; \mathrm{mc}=$ mesomeral claw; $\mathrm{ml}=$ mesomeral lamella; $\mathrm{o}=$ opisthomere; $\mathrm{p}=$ promere; $\mathrm{pl}=$ protective lamella; $\mathrm{s}=$ solenomere; $\mathrm{v}=$ velum. Scale bars: $\mathrm{A}=0.2 \mathrm{~mm} ; \mathrm{B}-\mathrm{G}, \mathrm{J}=$ $0.1 \mathrm{~mm} ; \mathrm{H}-\mathrm{I}=0.05 \mathrm{~mm}$. 
Telson (Fig. 39F-G). Epiproct with a very short and blunt caudal process, covered with dorsal and lateral setae. Paraprocts rounded, setose, mesal edges slightly bulging. Hypoproct lanceolate, most probably with two apical setae. Setae on telson mainly abraded.

LEGS IN MALES. First pair of legs modified, hook-shaped (Figs 40H-I, 41C), with three podomeres; coxa with one seta; prefemur with four setae; femora, postfemora and tibiotarsi coalesced; femur with two setae; postfemur with one seta. Tibiotarsal part with a small distal lobe. Tip slightly tuberculate. Postfemoral and tibial ventral pads developed on pregonopodal legs, then gradually disappearing on postgonopodal legs.

Ventral MARGin of MALE Body RING 7 (Fig. 39H). Strongly developed, rounded in lateral view.

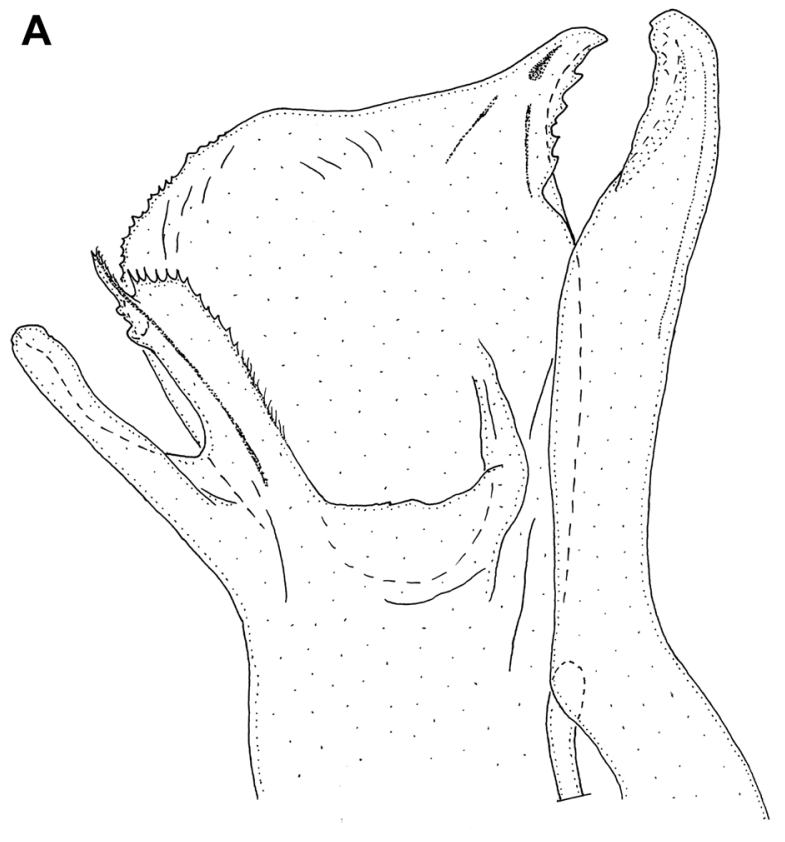

C

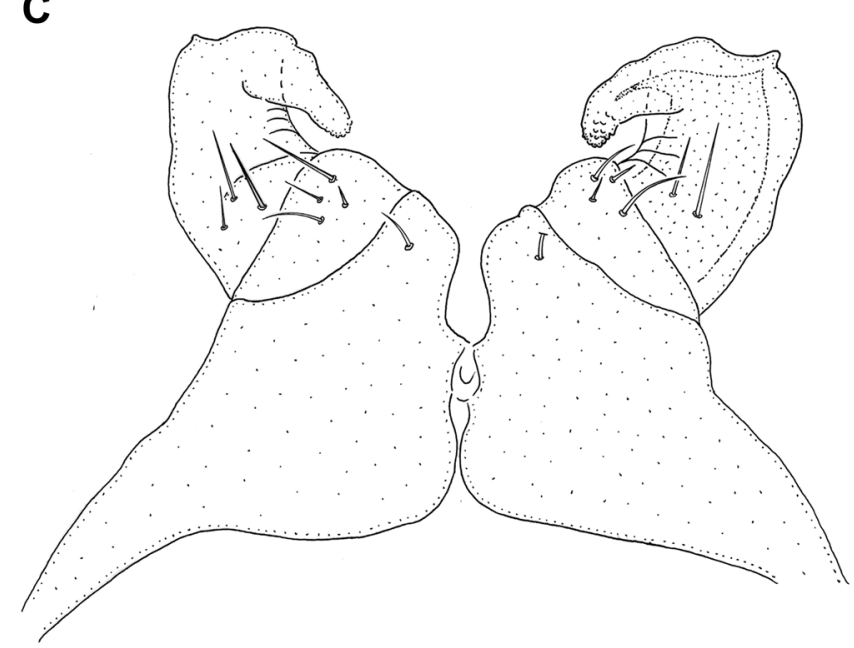

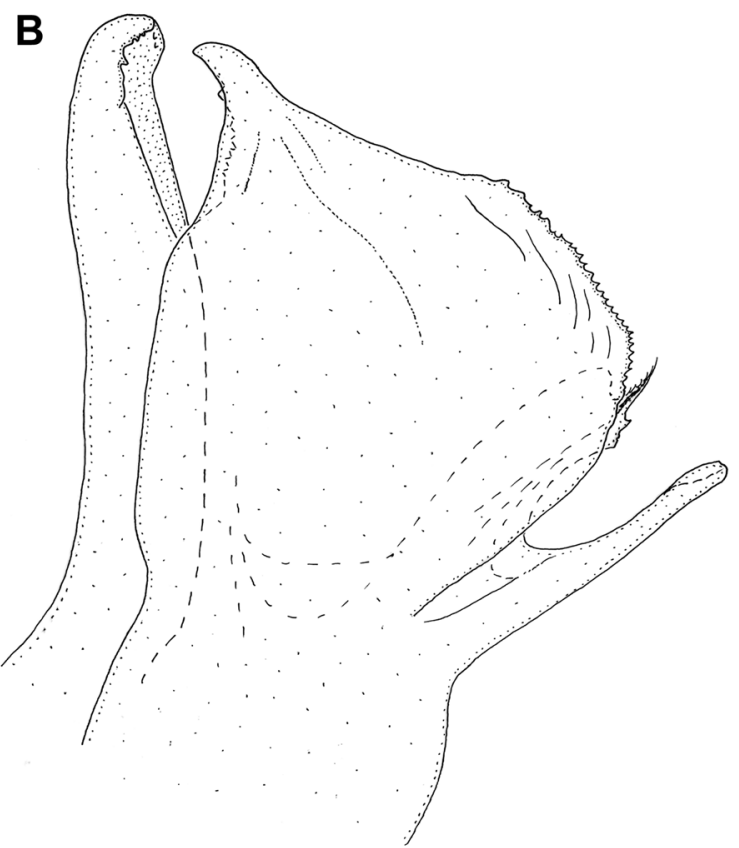

D

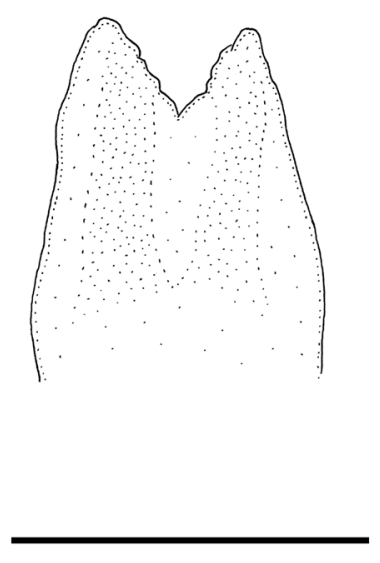

Fig. 41. Leucogeorgia mystax sp. nov., holotype $\widehat{\jmath}$ from Nytshka Cave (ZMUM). A. Right gonopods, mesal view. B. Right gonopods, lateral view. C. Leg-pair 1, anterior view. D. Penes, posterior view. Scale bar: $0.2 \mathrm{~mm}$. 
Penes (Fig. 41D). Short, apically with two small subtriangular lobes.

Gonopods (Figs 40J, 41A-B). Promere (p) long and slender, slightly curved anteriad, with a flagellum (f); apical part spatulate, with denticulate margins; basal half with two developed ridges. Mesomere (m) with a robust and denticulate mesomeral claw $(\mathrm{mc})$, mesomeral lamella $(\mathrm{ml})$ with a serrate posterodistal margin, posterior part smooth. Opisthomere (o) bipartite. Anterior branch of o with a solenomere (s), with a medium-sized tip, and a well-developed velum (v), fimbriate at anterior margin. Posterior branch of o in form of a shield-like protective lamella (pl). Mesomere and opisthomere connected basally with an accessory membrane (am).

\section{Distribution}

Known only from its type locality (Fig. 57, red square).

\section{Remarks}

This species, with the most bizarre mouthpart modifications, lives in syntopy with L. turbanovi sp. nov., also with modified mouthparts.

Leucogeorgia profunda sp. nov. urn:1sid:zoobank.org:act:2FE7074E-8768-4D83-8C88-20A3F312A49F

Figs $1 F$, 42-43, 56-57

\section{Diagnosis}

This species belongs to the group of Leucogeorgia spp. with modified mouthparts and teeth on the mesomeral claw (vs teeth absent from L. longipes). Leucogeorgia profunda sp. nov. differs from $L$. rediviva, $L$. redivivoides $\mathrm{sp}$. nov. and $L$. caudata sp. nov. by having a mesomeral claw that continues directly with the margin of the lamella, both parts being fully coalesced (vs mesomeral claw and lamella clearly connected mesally in L. rediviva, L. redivivoides sp. nov. and L. caudata sp. nov.). Leucogeorgia profunda sp. nov. differs from both $L$. mystax sp. nov. and L. turbanovi sp. nov. by having a more slender and elongate mesomeral claw (vs a more robust and shorter mesomeral claw in L. mystax sp. nov. and L. turbanovi sp. nov.). In addition to some other external characters, $L$. profunda sp. nov. differs from other congeners with modified mouthparts and teeth on the mesomeral claw by having a characteristic rounded extension of the hypoproct's posterior margin in both sexes and shorter antennae, with the length $160 \%$ of the vertical diameter of the largest body ring (vs absence of such a rounded extension in congeners with modified mouthparts and teeth on the mesomeral claw and the presence of longer antennae, with the length $\geq 170 \%$ of the vertical diameter of the largest body ring).

\section{Etymology}

From the Latin 'profunda' (= 'deep'), referring to this being the world's deepest-occurring julid species so far, found as deep as $-1650 \mathrm{~m}$ below the surface. Adjective in feminine gender.

\section{Material examined}

Holotype

ABKHAZIA - Gagry District - ô; Gagra Mt Ridge, Arabika karst Massif, Ortobalagan Valley, Krubera (= Krubera-Voronya) Cave, $-1650 \mathrm{~m}$ deep; $43.41^{\circ} \mathrm{N}, 40.31^{\circ} \mathrm{E}$; 20 Aug. 2015; I. Sofiniya and G.V. Samokhin leg.; ZMUM.

\section{Paratype}

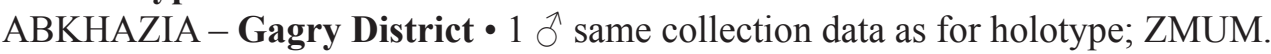


Other material

ABKHAZIA - Gagry District • 1 $\%$; Gagra Mt Ridge, Arabika karst Massif, Veryovkina Cave, $-1360 \mathrm{~m}$ deep; $43.41^{\circ}$ N, $40.35^{\circ}$ E; 1 Mar. 2018; P.E. Demidov leg.; IZB • 1 q; Gagra Mt Ridge, Arabika karst Massif, Sarma Cave, $-1260 \mathrm{~m}$ deep, Transsib meander, cascade of cliffs under KSS; $43.38^{\circ} \mathrm{N}, 40.38^{\circ} \mathrm{E}$; 15 Sep. 2011; P.V. Rudko leg.; ZMUM 1 क; Gagra Mt Ridge, Arabika karst Massif, Sarma Cave, $-1370 \mathrm{~m}$ deep, well K25; $43.38^{\circ}$ N, $40.38^{\circ}$ E; 17 Sep. 2011; P.V. Rudko leg.; ZMUM.

\section{Description}

SIZE AND NUMBER OF BODY RINGS. Holotype male $31 \mathrm{~mm}$ long, vertical diameter of largest body ring 1.9 $\mathrm{mm}$, body with 43 podous rings +0 apodous ring + telson. Paratype male $30 \mathrm{~mm}$ long, vertical diameter of largest body ring $1.9 \mathrm{~mm}$, body with 42 podous rings +0 apodous ring + telson. Non type females $32-44 \mathrm{~mm}$ long, vertical diameter of largest body ring $2.3-2.6 \mathrm{~mm}$, body with $40-52$ podous rings + $0-2$ apodous rings + telson.

Colour (Figs 1F, 42). Living animal with whitish head, anterior rings, legs and several posterior rings; due to thin and transparent cuticle, body looks blackish, with some greyish or blackish patterns. Yellowish white to yellowish brown or brown in alcohol.

Head (Fig. 42B). Without ommatidia. Frontal setae absent. Labrum without labral teeth (paratype male with three small labral teeth), with four supralabral setae and 30 labral setae in paratype male. Gnathochilarium with a triangular promentum; lamellae linguales with $1+1$ long distal and 5+5 long proximal setae; stipites with $3+3$ long distal setae; no other setae. Antennae $3 \mathrm{~mm}$ long in holotype male, their length ca $160 \%$ of vertical diameter of largest body ring. Lengths of antennomeres I-VIII (in mm): 0.17 (I), 0.6 (II), 0.67 (III), 0.58 (IV), 0.53 (V), 0.25 (VI), 0.15 (VII) and 0.05 (VIII). Length/width ratio of antennomeres I-VII: 0.7 (I), 2.7 (II), 3 (III), 2.6 (IV), 1.9 (V), 1 (VI) and 1 (VII). Antennomeres V and VI each with a terminal corolla of large sensilla basiconica bacilliformia; antennomere VII with a terminal corolla of small sensilla basiconica bacilliformia.

Body RINGs (Fig. 42D). Entire metazonal area with longitudinal striations. Length of midbody setae ca $8 \%$ of vertical diameter of rings.

Telson (Fig. 42C, E). Epiproct with a more or less long, robust and triangular caudal process, covered with dorsal and lateral setae. Paraprocts rounded, setose, mesal edges slightly bulging. Posterior margin of hypoproct with a characteristic rounded extension with two long apical setae.

LegS IN MALES. First pair of legs modified, hook-shaped (Fig. 43C), with three podomeres; coxa with three setae; prefemur with 8-9 setae; femora, postfemora and tibiotarsi coalesced; femur with 4-5 setae; postfemur with one seta. Tip slightly tuberculated. Postfemoral and tibial ventral pads poorly developed on pregonopodal legs, then gradually disappearing on postgonopodal legs.

Ventral MARGIN OF MALE BODY RING 7 (Fig. 42F-G). Well-developed, low, more or less subquadrangular in lateral view.

Penes (Fig. 43D). Short, apically with two small subtriangular lobes.

Gonopods (Fig. 43A-B). Promere (p) long and slender, slightly curved anteriad, with a flagellum (f); apical part spatulate, with denticulate margins; basal half with two developed ridges. Mesomere (m) with a robust and denticulate mesomeral claw $(\mathrm{mc})$ proceeding directly to a mesomeral lamella $(\mathrm{ml}) ; \mathrm{ml}$ poorly serrate, posterior part slightly fimbriate. Opisthomere (o) bipartite. Anterior branch of o with a solenomere (s) with a medium-sized tip, and a well-developed and fimbriate velum (v). Posterior branch of o in form of a shield-like protective lamella (pl). Mesomere and opisthomere connected basally with an accessory membrane (am). 

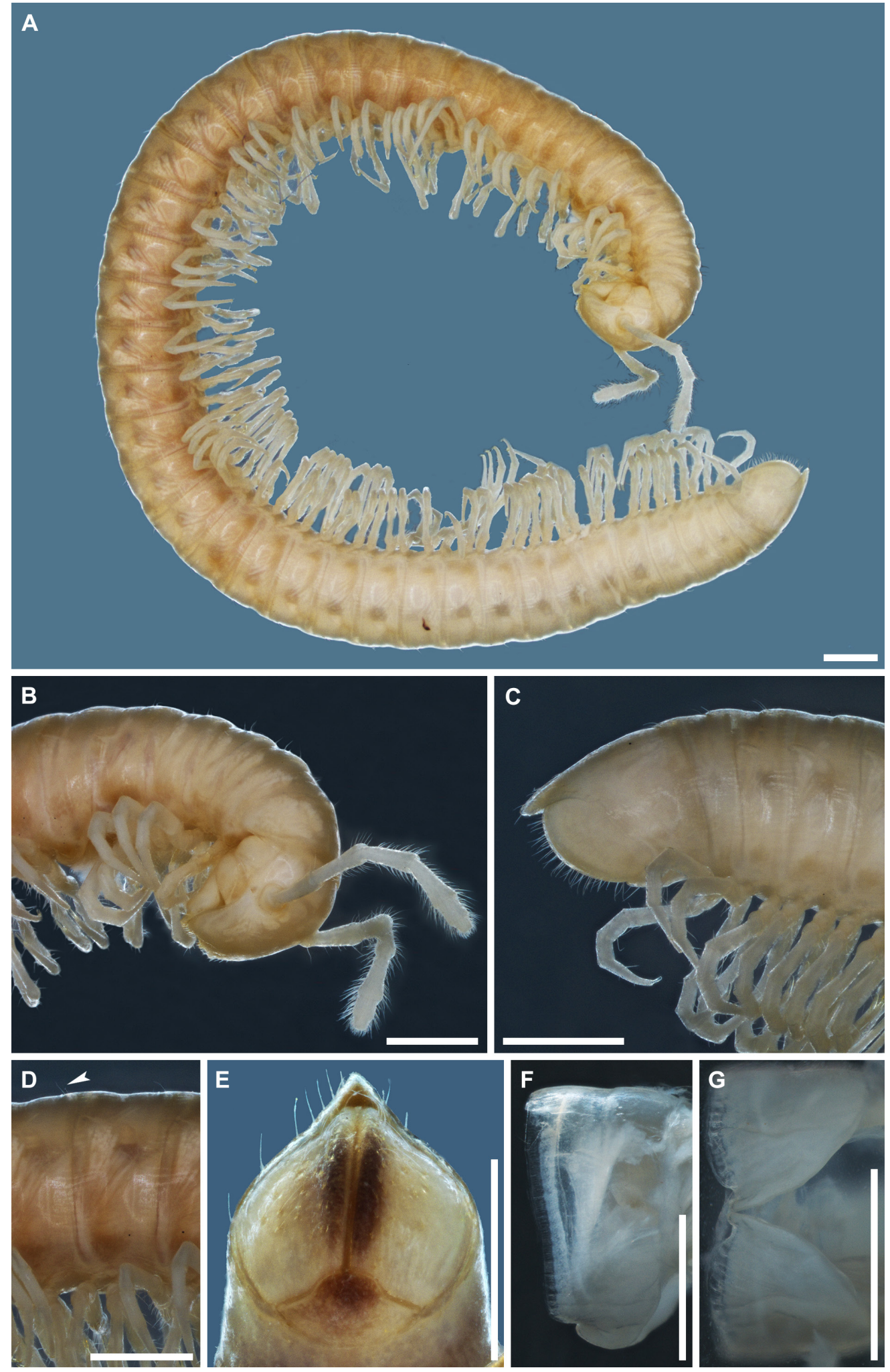

Fig. 42. Leucogeorgia profunda sp. nov. (A-D: holotype ô from Krubera Cave (ZMUM); E: non-type 9 from Veryovkina Cave (IZB); F-G: paratype $\widehat{o}$ from Krubera Cave (ZMUM)). A. Habitus, lateral view. B. Anterior part of body, lateral view. C. Posterior part of body, lateral view. D. Midbody segments, lateral view. E. Telson, posterior view. F. Body ring 7, lateral view. G. Body ring 7, ventral view. Arrow indicates metazonal setae. Scale bars: $1 \mathrm{~mm}$. 


\section{Distribution}

Known only from three deep caves in the Arabika karst Massif (Fig. 57, green square). The occurrence of this species in these three neighbouring caves has previously been recorded by Sidorov et al. (2014), Turbanov (2015) and Turbanov et al. (2018).

A

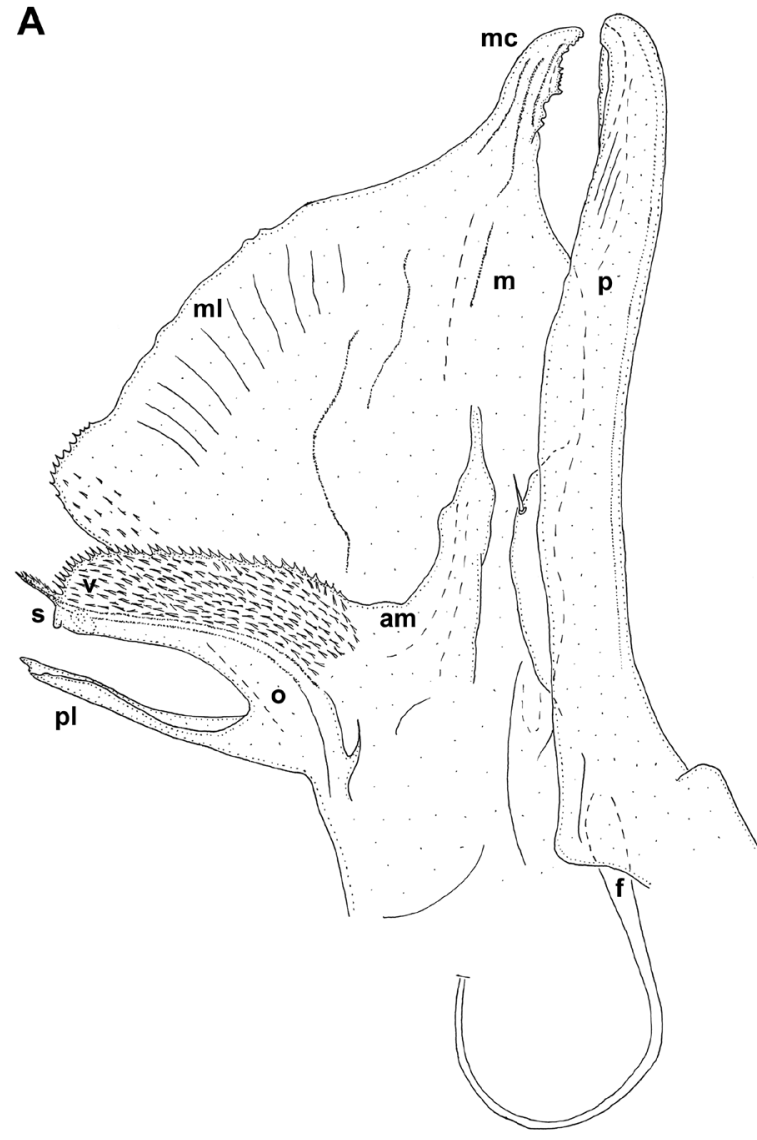

C

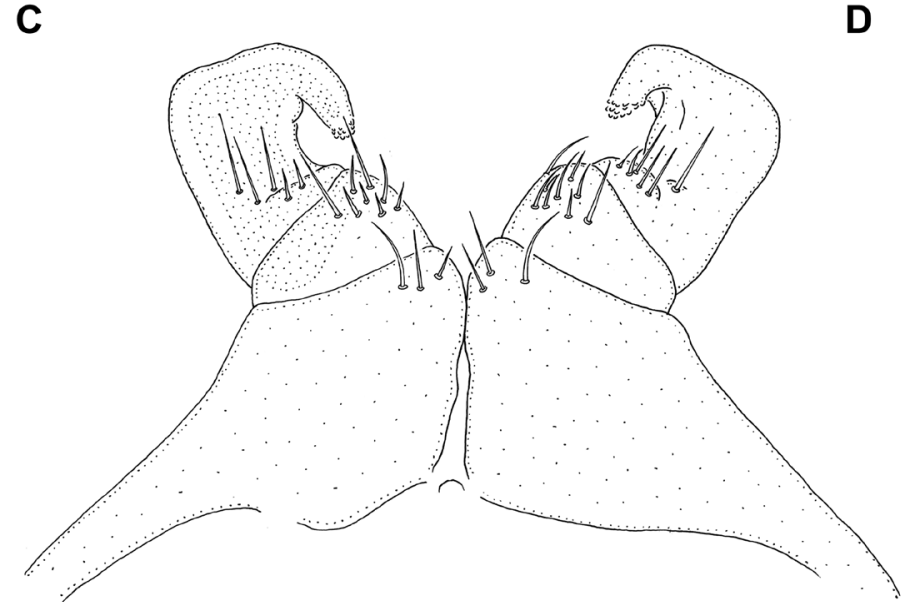

B
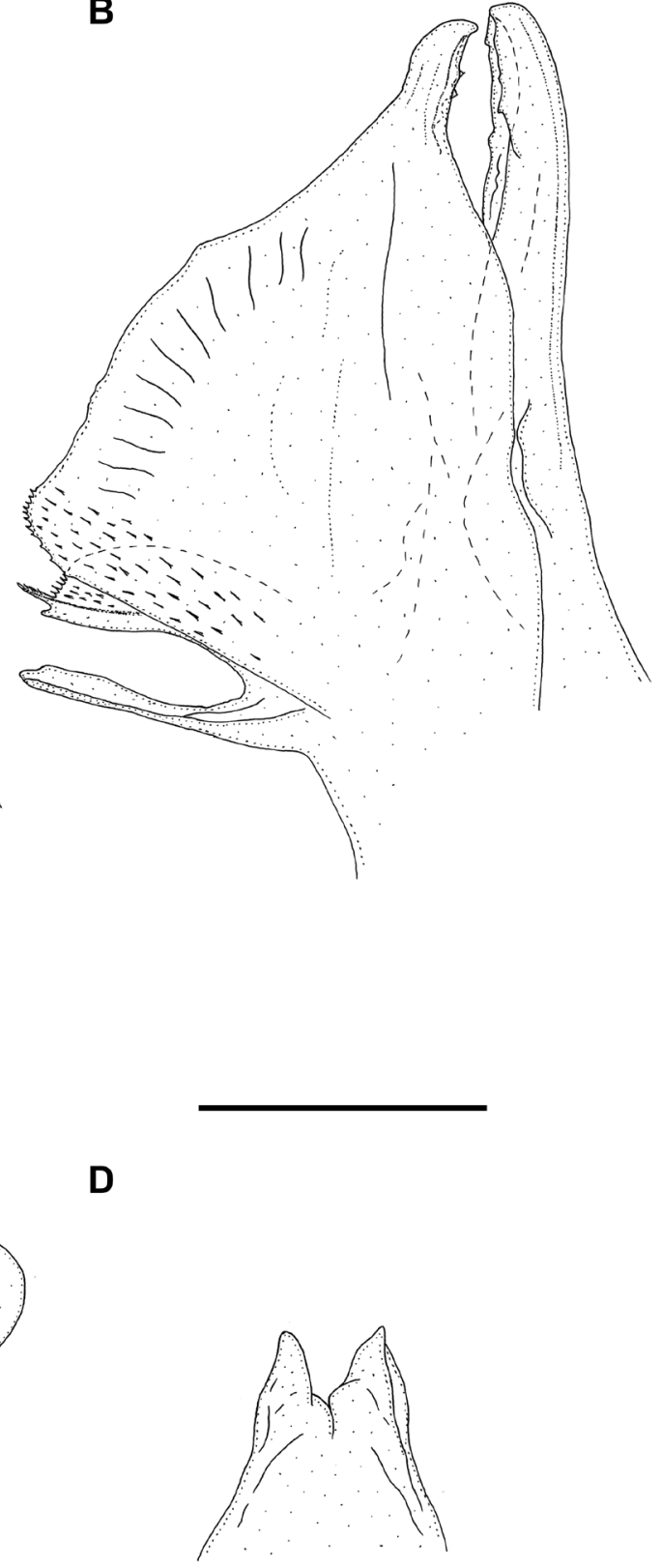

Fig. 43. Leucogeorgia profunda sp. nov., paratype $\widehat{\jmath}$ from Krubera Cave (ZMUM). A. Right gonopods, mesal view. B. Left gonopods, lateral view. C. Leg-pairs 1, anterior view. D. Penes, posterior view. Abbreviations: $\mathrm{am}=$ accessory membrane; $\mathrm{f}=$ flagellum; $\mathrm{m}=$ mesomere; $\mathrm{mc}=$ mesomeral claw; $\mathrm{ml}=$ mesomeral lamella; $\mathrm{o}=$ opisthomere; $\mathrm{p}=$ promere; $\mathrm{pl}=$ protective lamella; $\mathrm{s}=$ solenomere; $\mathrm{v}=$ velum. Scale bar: $0.3 \mathrm{~mm}$. 


\section{Remarks}

This new species represents the deepest julid species ever to be encountered, as well as the second deepest-occurring millipede globally. Leucogeorgia profunda sp. nov. was found in the deep parts of three caves, viz., Sarma (-1270 m and $-1370 \mathrm{~m})$, Veryovkina $(-1360 \mathrm{~m})$ and Krubera $(-1650 \mathrm{~m})$. Only the chordeumatidan millipede, Heterocaucaseuma deprofundum Antić \& Reboleira, 2018, has been found deeper, i.e., in the Krubera Cave at depths of down to -1980 m (Antić et al. 2018a). Interestingly, Leucogeorgia profunda sp. nov. lives in the Krubera Cave sympatrically with L. turbanovi sp. nov., also with modified mouthparts, but apparently the two species occupy separate niches, since L. profunda sp. nov. has been found in the deep part of the cave $(-1650 \mathrm{~m})$, while $L$. turbanovi sp. nov. occurs closer to the surface $(-100 \mathrm{~m})$. It seems noteworthy that these three caves and their biotic communities are the deepest not only in the Caucasus, but also in the world (Shelepin 2019).

Leucogeorgia redivivoides sp. nov. urn:lsid:zoobank.org:act:BCBC9EBF-506F-4EF2-A3A4-3FABE0756DED

Figs 44-46, 56-57

\section{Diagnosis}

This species belongs to the group of Leucogeorgia spp. with modified mouthparts and teeth on the mesomeral claw (vs teeth absent from L. longipes). Leucogeorgia redivivoides sp. nov. differs from L. mystax sp. nov., L. profunda sp. nov. and L. turbanovi sp. nov. by having a mesomeral claw that does not directly continue with the margin of the lamella, but with a clear connection on the mesal side (vs mesomeral claw continues directly with the margin of the lamella, both parts being fully coalesced in L. mystax sp. nov., L. profunda sp. nov. and L. turbanovi sp. nov.). Leucogeorgia redivivoides sp. nov. differs from $L$. caudata sp. nov. by having a more slender mesomeral claw and the absence of a very long and sharp process on the epiproct with a hyaline tip (vs a more robust mesomeral claw and the presence of a long and sharp process with a hyaline tip in L. caudata sp. nov.). Leucogeorgia redivivoides sp. nov. differs from the most similar species, L. rediviva sp. nov., by having a flattened and centrally slightly serrate mesomeral lamella (vs a more smooth and high central part of the mesomeral lamella in the form of a lobe in L. rediviva), a subrhomboid hypoproct (vs lanceolate in L. rediviva), a low, more subquadrangular ventral margin of male body ring 7 , with a right posterior angle (vs a well-developed and rounded ventral margin of body ring 7 in L. rediviva) and a stocky body with 28-35 podous rings in males (vs somewhat elongate, with 38-47 podous rings in males of L. rediviva).

\section{Etymology}

The species name is a combination of the name 'rediviva' and the Ancient Greek suffix '-oides', referring to the species' particularly strong resemblance to Leucogeorgia rediviva. Adjective.

\section{Material examined}

Holotype

ABKHAZIA - Gulripsh District • $\widehat{\jmath}$; Tsebeldinsky karst Massif, near Amtkel village, Nizhnyaya Shakuranskaya Cave, $700 \mathrm{~m}$ from entrance; $43.03^{\circ} \mathrm{N}, 41.33^{\circ} \mathrm{E}$; 16 Sep. 2014; I.S. Turbanov leg.; ZMUM.

\section{Paratypes}

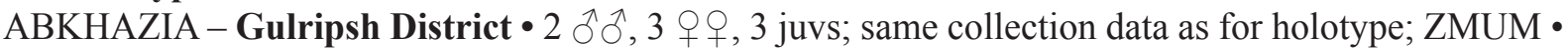
$1 \hat{\jmath}, 1$; ; same collection data as for holotype; IZB $\bullet 1 \hat{\jmath}, 1$ q; same collection data as for holotype; SMNG.

\section{Description}

SIZE AND NUMBER OF BODY RINGS. Holotype male $24 \mathrm{~mm}$ long, vertical diameter of largest body ring 1.95 $\mathrm{mm}$, body with 34 podous rings +1 apodous ring + telson. Paratype males $16.5-24 \mathrm{~mm}$ long, vertical 

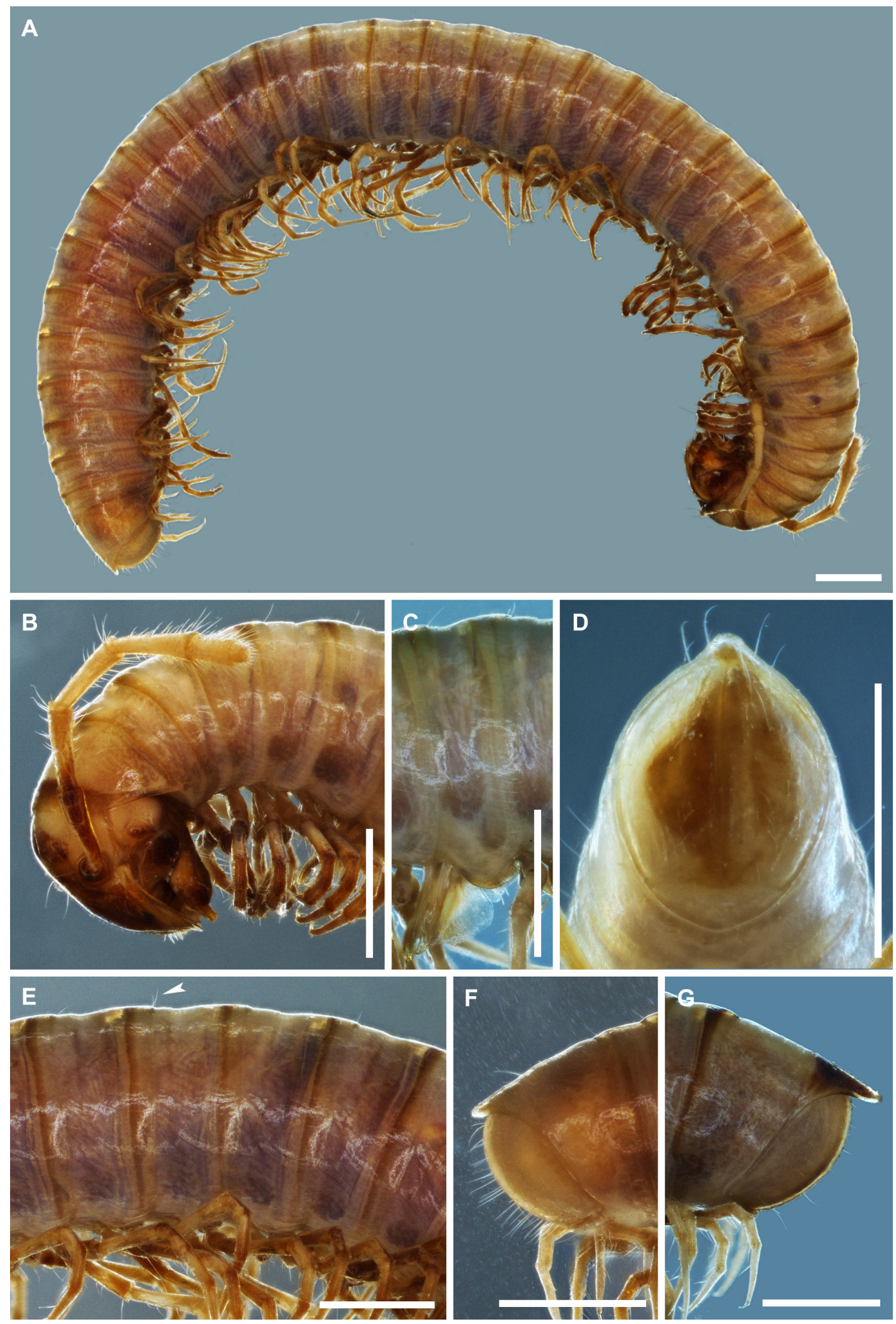

Fig. 44. Leucogeorgia redivivoides sp. nov., types from Nizhnyaya Shakuranskaya Cave (ZMUM) (AC, E-F: holotype $\delta^{\lambda}$; D: paratype $\delta^{\lambda}$; G: paratype + ). A. Habitus, lateral view. B. Anterior part of body, lateral view. C. Body ring 7, lateral view. D. Telson, posterior view. E. Midbody rings, lateral view. F. Telson, lateral view. G. Telson, lateral view. Arrow indicates metazonal setae. Scale bars: $1 \mathrm{~mm}$. 
diameter of largest body ring $1.7-1.95 \mathrm{~mm}$, body with $28-35$ podous rings $+0-1$ apodous ring + telson. Paratype females $25.5-26.5 \mathrm{~mm}$ long, vertical diameter of largest body ring $2.3 \mathrm{~mm}$, body with 34-39 podous rings $+0-1$ apodous ring + telson.

CoLour (Fig. 44). In alcohol brownish, with dark brown rings on prozonae.

HEAD (Figs 44B, 45C). Without ommatidia. Frontal setae absent. Labrum without labral teeth, with 2+2, $3+2$ or $4+3$ supralabral setae and 26-32 labral setae. Gnathochilarium (paratype males) with a triangular
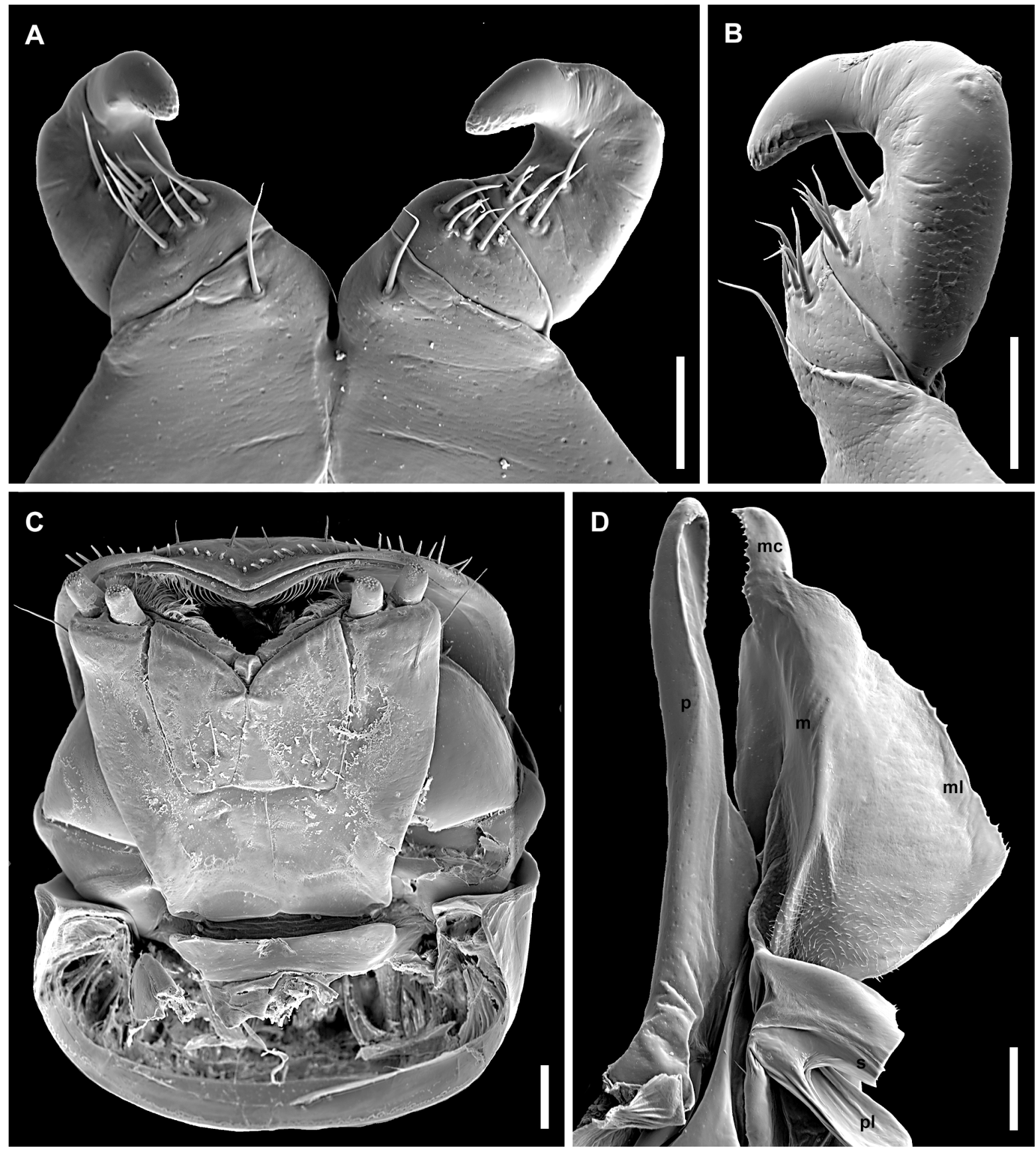

Fig. 45. Leucogeorgia redivivoides sp. nov., paratype $\widehat{\partial}$ from Nizhnyaya Shakuranskaya Cave (SMNG). A. Leg-pair 1, anterior view. B. Right leg 1, lateral view. C. Head, ventral view. D. Left gonopods, mesal view. Abbreviations: $\mathrm{m}=$ mesomere; $\mathrm{mc}=$ mesomeral claw; $\mathrm{ml}=$ mesomeral lamella; $\mathrm{p}=$ promere; $\mathrm{pl}=$ protective lamella; $\mathrm{s}=$ solenomere. Solenomere broken. Scale bars: A-B, D = $0.1 \mathrm{~mm} ; \mathrm{C}=0.2 \mathrm{~mm}$. 
promentum; lamellae linguales in one paratype male with $4+4$ proximal setae, in another paratype male with $3+2$ proximal, $1+0$ medial and $1+1$ distal setae $(5+3$ setae); stipites in one paratype male with $1+2$ long distolateral setae, in another paratype male with $3+3$ distolateral setae; no other setae. Antennae $3.7 \mathrm{~mm}$ long in holotype male, their length ca $190 \%$ of vertical diameter of largest body ring. Lengths of antennomeres I-VIII (in mm): 0.15 (I), 0.79 (II), 0.76 (III), 0.73 (IV), 0.72 (V), 0.38 (VI), 0.14 (VII) and 0.03 (VIII). Length/width ratio of antennomeres I-VII: 0.7 (I), 3.6 (II), 3.4 (III), 3.8 (IV), 3.8 (V), 1.8 (VI) and 0.9 (VII). Length of antennae in other males $180-190 \%$ of vertical diameter of largest body rings. Antennomeres V and VI each with a terminal corolla of large sensilla basiconica bacilliformia; antennomere VII with a terminal corolla of small sensilla basiconica bacilliformia.

Body RINGS (Fig. 44E). Ventral and ventrolateral sides of metazonal areas with longitudinal striations. Dorsal side with poorly visible striations. Length of midbody setae ca $8 \%$ of vertical diameter of rings.

Telson (Fig. 44D, F-G). Epiproct variable, with a short to somewhat longer, blunt preanal process. Paraprocts rounded, setose, mesal edges slightly bulging. Hypoproct subrhomboid, covered with ca eight long setae in paratype male.

LEGS IN MALEs. First pair of legs modified, hook-shaped (Figs 45A-B, 46E), with three podomeres; coxa with one seta; prefemur with 4-5 setae; femora, postfemora and tibiotarsi coalesced; femur with four setae; postfemur with one seta. Tibiotarsal part with a small distal lobe. Tip slightly tuberculate. Postfemoral and tibial ventral pads poorly developed on pregonopodal legs, then gradually disappearing on postgonopodal legs.

Ventral MARGin OF MALE BODY RING 7 (Fig. 44C). Low, rounded, more subquadrangular in lateral view, with a right posterior angle.

Penes (Fig. 46F). Elongate, apically with two long subtriangular lobes.

Gonopods (Figs 45D, 46A-D). Promere (p) long and slender, with a flagellum (f); apical part spatulate, with denticulate margins; basal half with two developed ridges. Mesomere (m) with a well-developed and denticulate mesomeral claw $(\mathrm{mc})$; mesomeral lamella $(\mathrm{ml})$ gradually decreasing in height posteriad, distal margin serrate, posterior part finely fimbriate. Opisthomere (o) bipartite. Anterior branch of o with a solenomere (s) with a medium-sized tip, and a well-developed and fimbriate velum (v). Posterior branch of o in form of a shield-like protective lamella (pl). Mesomere and opisthomere connected basally with an accessory membrane (am).

\section{Distribution}

Known only from its type locality (Fig. 57, orange square).

\section{Remarks}

Like $L$. rediviva, this new species is characterized by a variable length of the process on the telson, which can be longer or shorter.

As it has been found $700 \mathrm{~m}$ from the entrance of the cave together with one female of another species of Leucogeorgia (probably L. abchasica) without modified mouthparts, these two species are probably syntopic. 
A

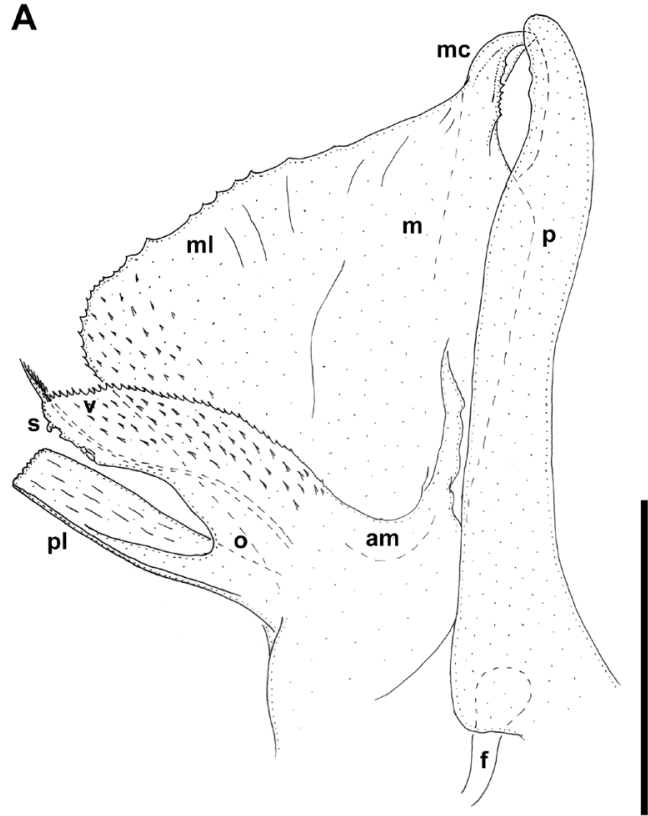

C

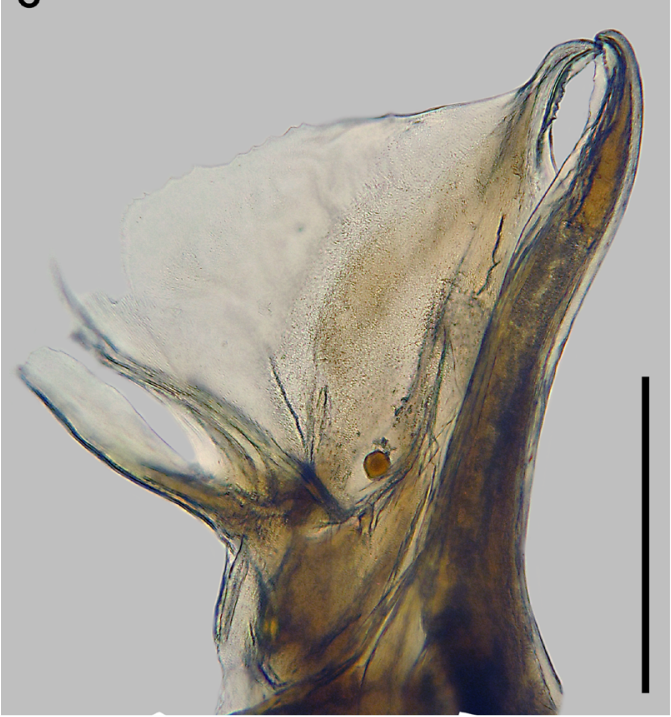

E

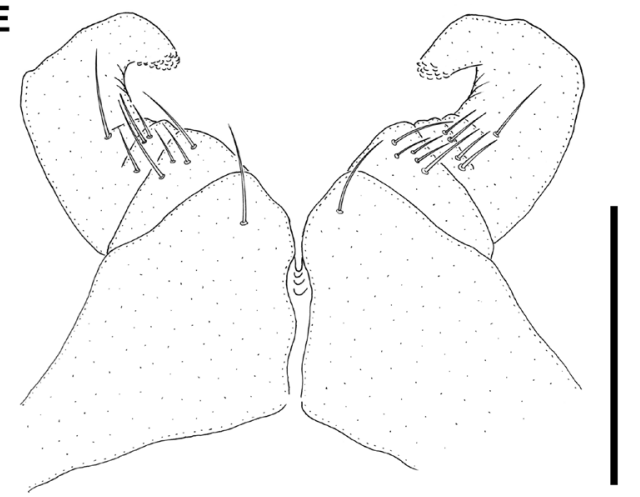

B

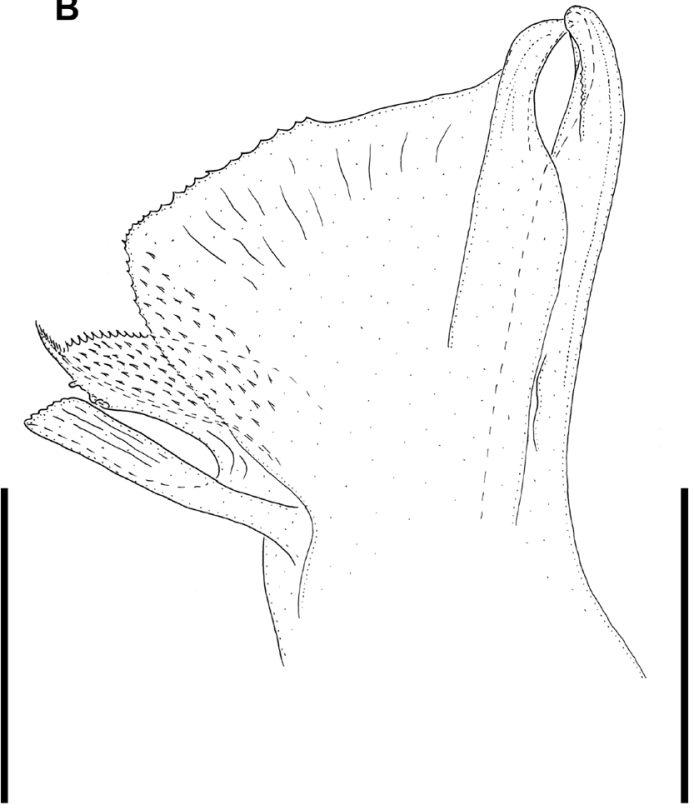

D

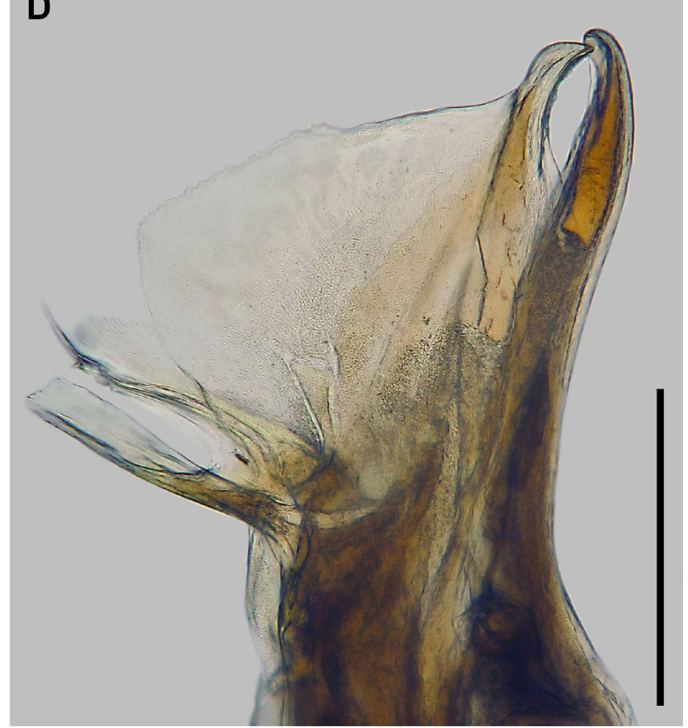

$\mathbf{F}$

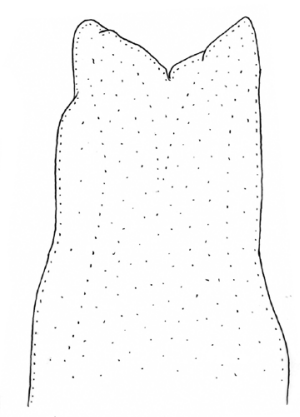

Fig. 46. Leucogeorgia redivivoides sp. nov., paratype $\widehat{\partial} \partial$ from Nizhnyaya Shakuranskaya Cave (ZMUM). A. Right gonopods, mesal view. B. Left gonopods, lateral view. C. Right gonopods, mesal view. D. Left gonopods, lateral view. E. Leg-pair 1, anterior view. F. Penes, posterior view. Scale bars: $0.3 \mathrm{~mm}$. 
Leucogeorgia turbanovi sp. nov. urn:1sid:zoobank.org:act:75EECC8C-DAAB-49F7-B6EF-BEAD1FCE546F

Figs $1 \mathrm{G}, 47-49,56-57$

\section{Diagnosis}

This species belongs to the group of Leucogeorgia spp. with modified mouthparts and teeth on the mesomeral claw (vs teeth absent in L. longipes). Leucogeorgia turbanovi sp. nov. differs from $L$. rediviva, $L$. redivivoides $\mathrm{sp}$. nov. and $L$. caudata $\mathrm{sp}$. nov. by having a mesomeral claw that continues directly with the margin of the lamella, both being fully coalesced (vs mesomeral claw and lamella being clearly connected mesally in $L$. rediviva, $L$. redivivoides sp. nov. and $L$. caudata $\mathrm{sp}$. nov.). Leucogeorgia turbanovi sp. nov. differs from L. mystax sp. nov. by the absence of highly modified mouthparts, viz., two rounded labral lobes with a deep incision in between and a unique gnathochilarium with a distolateral bundle of long setae on the stipites and distal rows of long setae on both stipites and lamellae linguales (vs presence of such structures in L. mystax sp. nov.). Leucogeorgia turbanovi sp. nov. differs from $L$. profunda sp. nov. by having a stout mesomeral claw (vs slender in L. profunda sp. nov.), longer antennae with a length of $170 \%$ of the vertical diameter of the largest body ring (vs shorter antennae with a length of $160 \%$ of the vertical diameter of the largest body ring in $L$. profunda sp. nov.) and a subrhomboid hypoproct (vs hypoproct posterior margin with a characteristic rounded extension in L. profunda sp. nov.).

\section{Etymology}

This new species is dedicated to Ilya Turbanov, a well-known Russian biospeleologist, the collector of some specimens of this species. Noun in the genitive case.

\section{Material examined}

\section{Holotype}

RUSSIA - Krasnodar Province - Ō; Greater Sochi, Alek-Dzykhrinsky karst Massif, Dzykhra Mt, Pechalnaya Cave; $43.57^{\circ} \mathrm{N}, 40.07^{\circ}$ E; 825 m a.s.1.; 3 Oct. 1985; N. Mugue leg.; ZMUM.

\section{Paratypes}

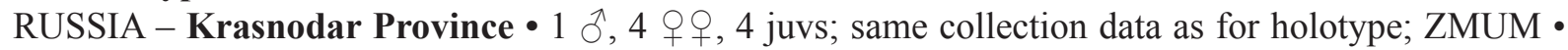
1 ऽ, 1 क; same collection data as for holotype; IZB $\bullet 1 \hat{\jmath}, 1$ q; same collection data as for holotype; SMNG.

\section{Other material}

ABKHAZIA - Gagry District • 1 ô; Arabika karst Massif, Gagra Mt Ridge, Ortobalagan Valley, Krubera (= Krubera-Voronya) Cave, $-100 \mathrm{~m}$ deep; $43.41^{\circ} \mathrm{N}, 40.31^{\circ} \mathrm{E} ; 2256 \mathrm{~m}$ a.s.1.; 29 Aug. 2015; I.S. Turbanov leg.; ZMUM • 1 q; Arabika karst Massif, Gagra Mt Ridge, Pozharnaya Cave, $-120 \mathrm{~m}$ deep; $43.42^{\circ} \mathrm{N}, 40.33^{\circ}$ E; $2187 \mathrm{~m}$ a.s.1.; 15 Aug. 2015; F.L. Tsherednitshenko leg.; ZMUM • 1 \%; Arabika karst Massif, Orlinoye Gnezdo Cave, $-30 \mathrm{~m}$ deep; $43.38^{\circ} \mathrm{N}, 40.38^{\circ} \mathrm{E} ; 2205 \mathrm{~m}$ a.s.1.; 27 Aug. 2012; E. Golubnichaya leg.; ZMUM • 1 क; Arabika karst Massif, Lastochkino Krylo area, Nytshka Cave, $-7 \mathrm{~m}$ deep; $43.45^{\circ} \mathrm{N}, 40.31^{\circ}$ E; $2157 \mathrm{~m}$ a.s.1.; 27 Aug. 2014; I.S. Turbanov leg.; ZMUM.

\section{Description}

SIZE AND NUMBER OF BODY RINGS. Holotype male $18 \mathrm{~mm}$ long, vertical diameter of largest body ring 1.35 $\mathrm{mm}$, body with 29 podous rings +2 apodous rings + telson. Paratype males 19-24 mm long, vertical diameter of largest body ring $1.35-1.6 \mathrm{~mm}$, body with 32-36 podous rings $+0-1$ apodous ring + telson. Paratype females 21-28 mm long, vertical diameter of largest body ring 1.7-2 mm, body with 33-40 podous rings $+0-1$ apodous ring + telson. 

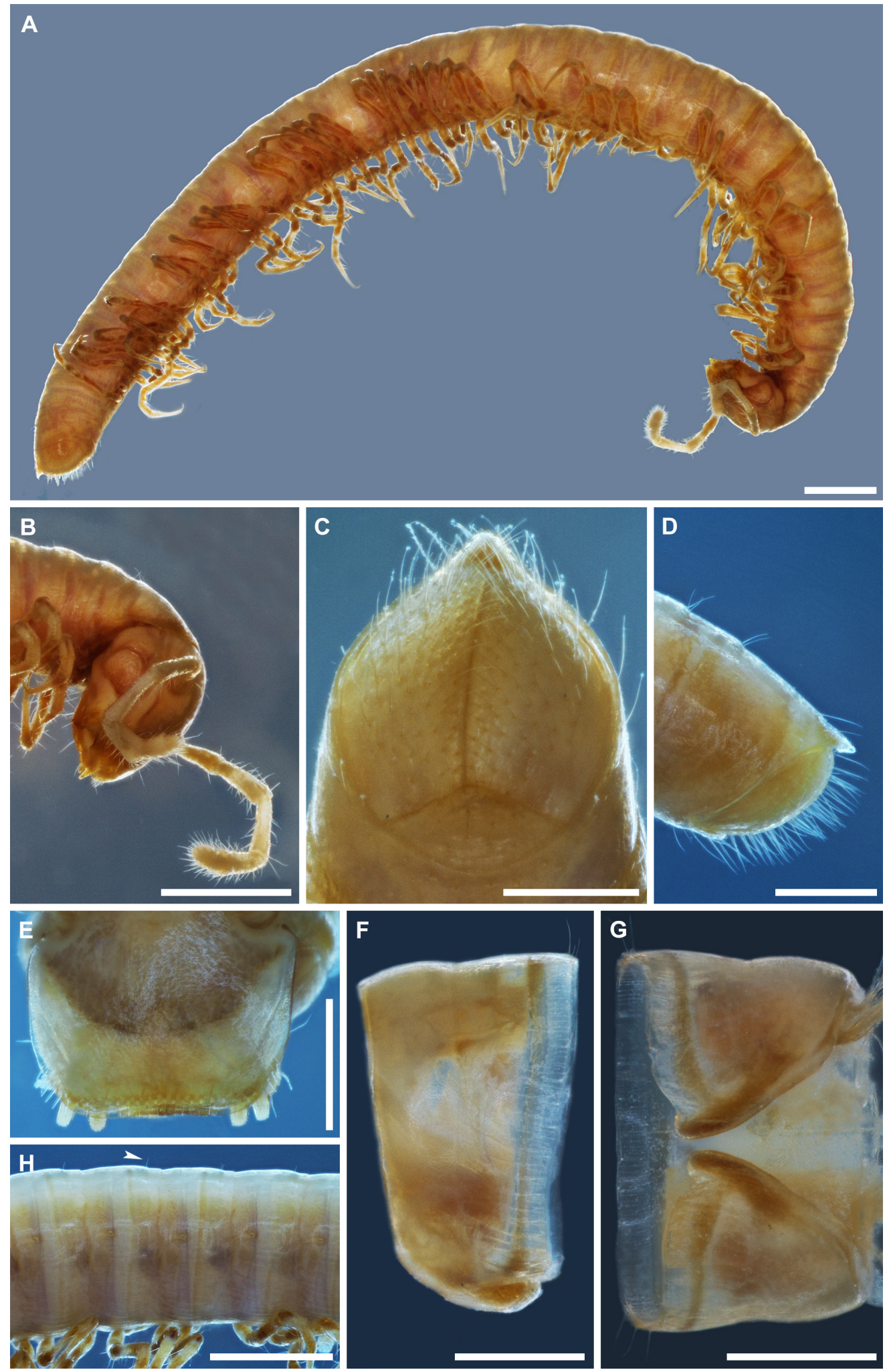

Fig. 47. Leucogeorgia turbanovi sp. nov., types from Pechalnaya Cave (ZMUM). A. Holotype ${ }^{7}$, habitus, lateral view. B. Holotype, anterior part of body, lateral view. C. Paratype $\odot$, telson, posterior view. D. Holotype, posterior part of body, lateral view. E. Paratype $\overbrace{}^{\lambda}$, head, dorsal view. F. Paratype ${ }^{\lambda}$, body ring 7, lateral view. G. Paratype $\hat{\delta}$, body ring 7, ventral view. Arrow indicates metazonal seta. Scale bars: A-B, $\mathrm{H}=1 \mathrm{~mm} ; \mathrm{C}-\mathrm{G}=0.5 \mathrm{~mm}$. 

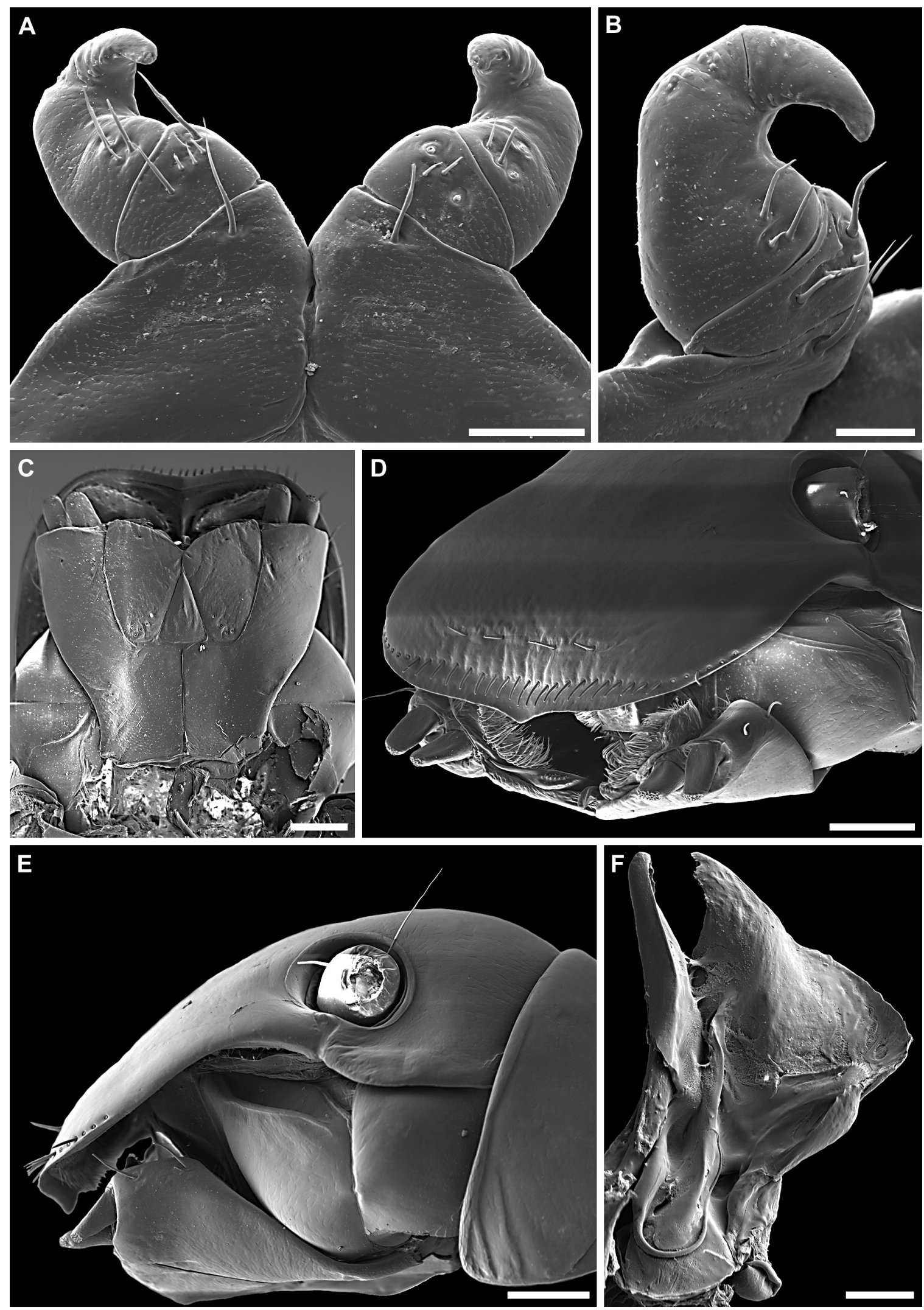

Fig. 48. Leucogeorgia turbanovi sp. nov., paratype $\widehat{\jmath}$ from Pechalnaya Cave (SMNG). A. Leg-pair 1, anterior view. B. Left leg 1, lateral view. C. Head, ventral view. D. Head, anterolateral view. E. Head, lateral view. F. Left gonopods, mesal view. Scale bars: A, F $=0.1 \mathrm{~mm} ; \mathrm{B}=0.05 \mathrm{~mm}$; $\mathrm{C}-\mathrm{E}=0.2 \mathrm{~mm}$. 
Colour (Figs 1G, 47). Living animal with whitish head, legs and telson; due to thin and transparent cuticle, body looks blackish, with some greyish or blackish patterns. Yellowish white to yellowishbrown in alcohol.

Head (Figs 47B, E, 48C-E). Without ommatidia. Frontal setae absent. Labrum without labral teeth, with 4 supralabral setae (one paratype male with 5) and 29-35 labral setae. Gnathochilarium with a triangular promentum; lamellae linguales with $1+1$ long distal and $4+4$ long proximal setae; stipites with $3+3$ long distolateral setae; no other setae. Antennae $2.3 \mathrm{~mm}$ long in holotype male, their length ca $170 \%$ of vertical diameter of largest body ring. Lengths of antennomeres I-VIII (in mm): 0.1 (I), 0.35 (II), 0.54 (III), 0.48 (IV), 0.57 (V), 0.22 (VI), 0.1 (VII) and 0.04 (VIII). Length/width ratio of antennomeres I-VII: 0.8 (I), 2 (II), 3.4 (III), 3 (IV), 2.8 (V), 1.2 (VI) and 0.8 (VII). Antennomeres V and VI each with

A

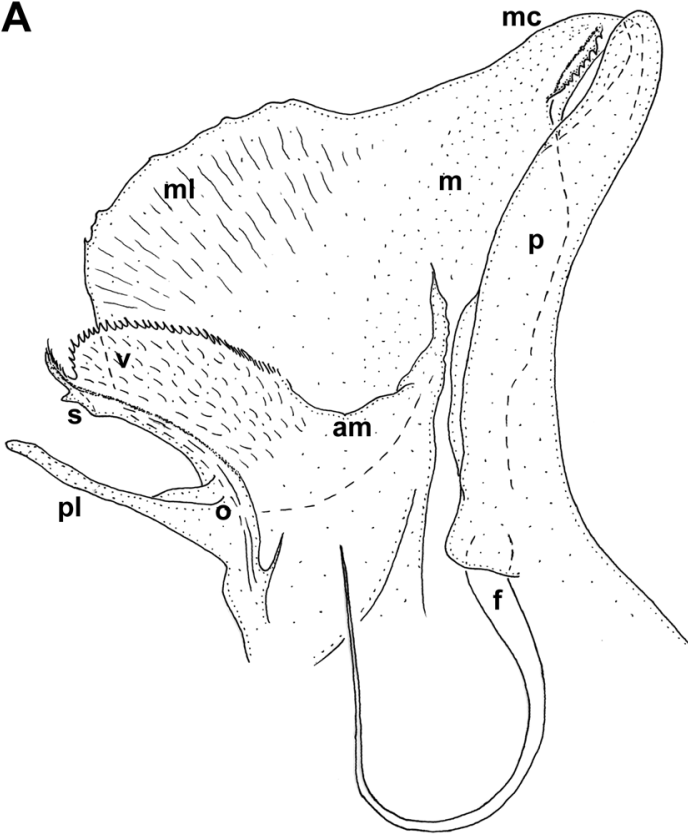

C

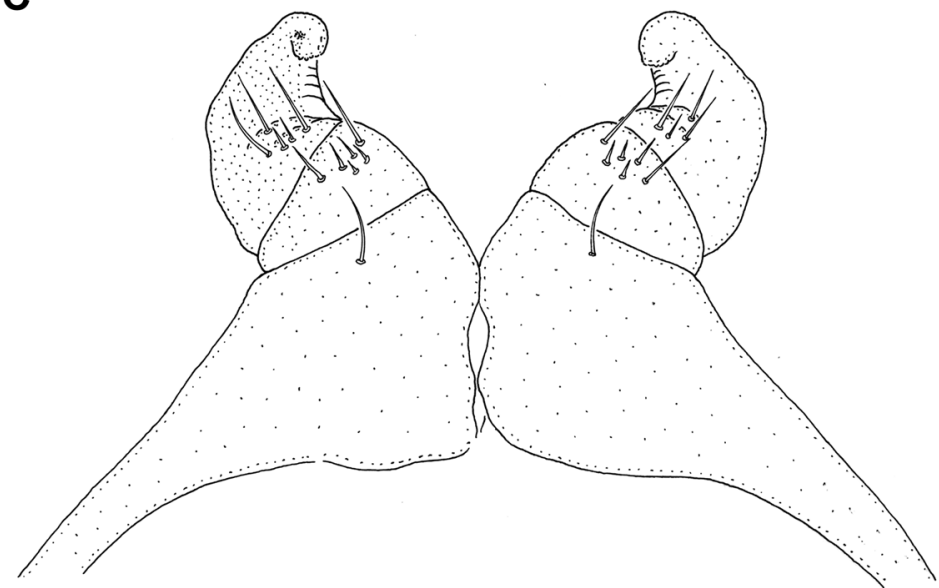

B

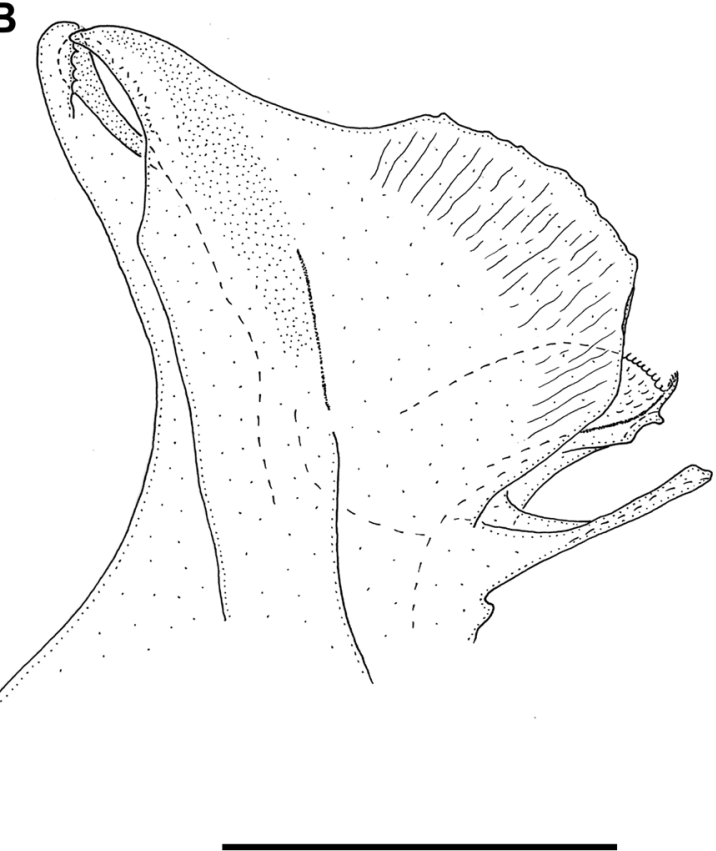

D

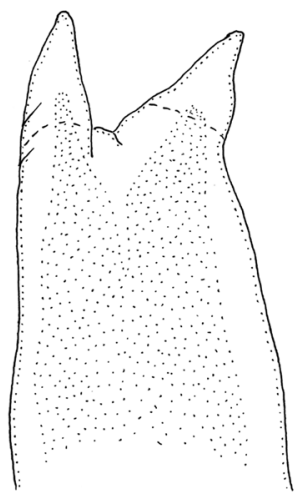

Fig. 49. Leucogeorgia turbanovi sp. nov., paratype $\widehat{\delta}$ from Pechalnaya Cave (ZMUM). A. Right gonopods, lateral view. B. Right gonopods, lateral view. C. Leg-pair 1, anterior view. D. Penes, posterior view. Abbreviations: $\mathrm{am}=$ accessory membrane; $\mathrm{f}=$ flagellum; $\mathrm{m}=$ mesomere; $\mathrm{mc}=$ mesomeral claw; $\mathrm{ml}=$ mesomeral lamella; $\mathrm{o}=$ opisthomere; $\mathrm{p}=$ promere; $\mathrm{pl}=$ protective lamella; $\mathrm{s}=$ solenomere; $\mathrm{v}=$ velum. Scale bar: $0.3 \mathrm{~mm}$. 
a terminal corolla of large sensilla basiconica bacilliformia; antennomere VII with a terminal corolla of small sensilla basiconica bacilliformia.

Body RINGs (Fig. 47H). Ventral and ventrolateral sides of metazonal area with longitudinal striations. Dorsal side with poorly visible striations. Length of midbody setae ca $6 \%$ of vertical diameter of rings.

TeLson (Fig. 47C-D). Epiproct with a short, acuminate and triangular process covered with dorsal and lateral setae. Paraprocts rounded, densely setose. Hypoproct subrhomboid, covered with ca seven long setae in paratype male.

LEgS IN MALES. First pair of legs modified, hook-shaped (Figs 48A-B, 49C), with three podomeres; coxa with one seta; prefemur with 4-6 setae; femora, postfemora and tibiotarsi coalesced; femur with 2-3 setae; postfemur with one seta. Tibiotarsal part with a small distal lobe. Tip slightly tuberculate. Postfemoral and tibial ventral pads poorly developed on pregonopodal legs, then gradually disappearing on postgonopodal legs.

Ventral margin of Male body Ring 7 (Fig. 47F). Poorly developed, low, rounded in lateral view.

Penes (Fig. 49D). Elongate, apically with two long subtriangular lobes.

Gonopods (Figs 48F, 49A-B). Promere (p) long and slender, slightly curved anteriad, with a flagellum (f); apical part spatulate, with denticulate margins; basal half with two developed ridges. Mesomere (m) with a robust and denticulate mesomeral claw $(\mathrm{mc})$; mesomeral lamella $(\mathrm{ml})$ slightly convex, distal margin serrate, posterior margin finely fimbriate. Opisthomere (o) bipartite. Anterior branch of o with a solenomere (s) with a short tip, and a well-developed and fimbriate velum (v). Posterior branch of o in form of a shield-like protective lamella ( $\mathrm{pl})$. Mesomere and opisthomere connected basally with an accessory membrane (am).

\section{Distribution}

Known from several caves in the Alek-Dzykhrinsky and Arabika karst massifs (Fig. 57, black square). The occurrence of this species in some of these caves has previously been recorded by Sidorov et al. (2014), Turbanov (2015) and Turbanov et al. (2018).

\section{Remarks}

This new species occurs sympatrically or even syntopically with two other species of Leucogeorgia with modified mouthparts. In the Krubera Cave, it lives sympatrically with L. profunda sp. nov. (see above), while in the Nytshka Cave it is syntopic with L. mystax sp. nov.

Genus Martvilia gen. nov. urn:Isid:zoobank.org:act:2B37D666-2887-45E0-AC8D-ECE226C08BD8

Figs 50-51, 56, 58

\section{Diagnosis}

Differs from all other members of the tribe Leucogeorgiini by having an almost completely free mesomere separated by a deep incision from the mesomeral lamella. These two structures are connected only in the basal third in mesal view. Like some members of the genus Leucogeorgia, this genus is characterized by modified mouthparts.

\section{Etymology}

This new genus is named after the type locality of its type species, Martvili village. The name is a feminine noun. 


\section{Type species}

Martvilia parva gen. et sp. nov., by present designation and monotypy.

Martvilia parva gen. et sp. nov. urn:lsid:zoobank.org:act:8EDFD6FB-21FA-4C5D-8B56-89EE5EAEFC74

Figs $50-51,56,58$

\section{Diagnosis}

As for the genus.

\section{Etymology}

From the Latin 'parvus' (= 'small'), reflecting the small size of the species. Adjective.

\section{Material examined}

\section{Holotype}

CENTRAL-WEST GEORGIA - Samegrelo-Zemo Svaneti - ô; Askhi karst Massif, near Martvili, Jortsku Cave; $42.51^{\circ}$ N, $42.42^{\circ}$ E; 2 Feb. 2017; D.M. Palatov and A.M. Sokolova leg.; ZMUM.

\section{Paratypes}

CENTRAL-WEST GEORGIA - Samegrelo-Zemo Svaneti • $1 \hat{\jmath}, 1$; ; same collection data as for holotype; ZMUM.

\section{Other material}

CENTRAL-WEST GEORGIA - Samegrelo-Zemo Svaneti • 1 q; Martvili District, Askhi karst Massif, near Balda village, Motena Cave; $42.47^{\circ}$ N, $42.39^{\circ}$ E; 30 Jan. 2017; D.M. Palatov leg.; IZB.

\section{Description}

SIZE AND NUMBER OF BODY RINGS. Holotype male $12 \mathrm{~mm}$ long, vertical diameter of largest body ring 1.15 $\mathrm{mm}$, body with 27 podous rings +1 apodous ring + telson. Paratype male $15 \mathrm{~mm}$ long, vertical diameter of largest body ring $1.2 \mathrm{~mm}$, body with 30 podous rings +2 apodous rings + telson. Paratype female $11.5 \mathrm{~mm}$ long, vertical diameter of largest body ring $1.15 \mathrm{~mm}$, body with 25 podous rings +1 apodous ring + telson. Non-type female $15 \mathrm{~mm}$ long, vertical diameter of largest body ring $1.5 \mathrm{~mm}$, body with 33 podous rings +0 apodous ring + telson.

CoLour (Fig. 50). Yellowish white in alcohol.

HeAd (Fig. 50B). Without ommatidia. Frontal setae absent. Mouthparts modified. Labrum without labral teeth, with five supralabral setae in holotype and paratype males, and 24 labral setae in paratype male. Gnathochilarium (paratype male) with a subtriangular promentum; lamellae linguales with $2+2$ long distal setae; stipites with $2+2$ long distolateral setae; no other setae. Antennae $1.7 \mathrm{~mm}$ long in holotype male, their length ca $150 \%$ of vertical diameter of largest body ring. Lengths of antennomeres I-VIII (in mm): 0.11 (I), 0.43 (II), 0.33 (III), 0.3 (IV), 0.29 (V), 0.16 (VI), 0.06 (VII) and 0.02 (VIII). Length/width ratio of antennomeres I-VII: 0.8 (I), 2.8 (II), 2.2 (III), 2 (IV), 1.7 (V), 0.9 (VI) and 0.57 (VII). Antennomeres V and VI each with a terminal corolla of large sensilla basiconica bacilliformia; antennomere VII with a terminal corolla of small sensilla basiconica bacilliformia.

BoDY RINGS (Fig. 50D). Ventral and ventrolateral sides of metazonal areas with longitudinal striations. Dorsal side with poorly visible striations. Midbody setae short, barely visible, ca $4 \%$ of vertical diameter of rings. 

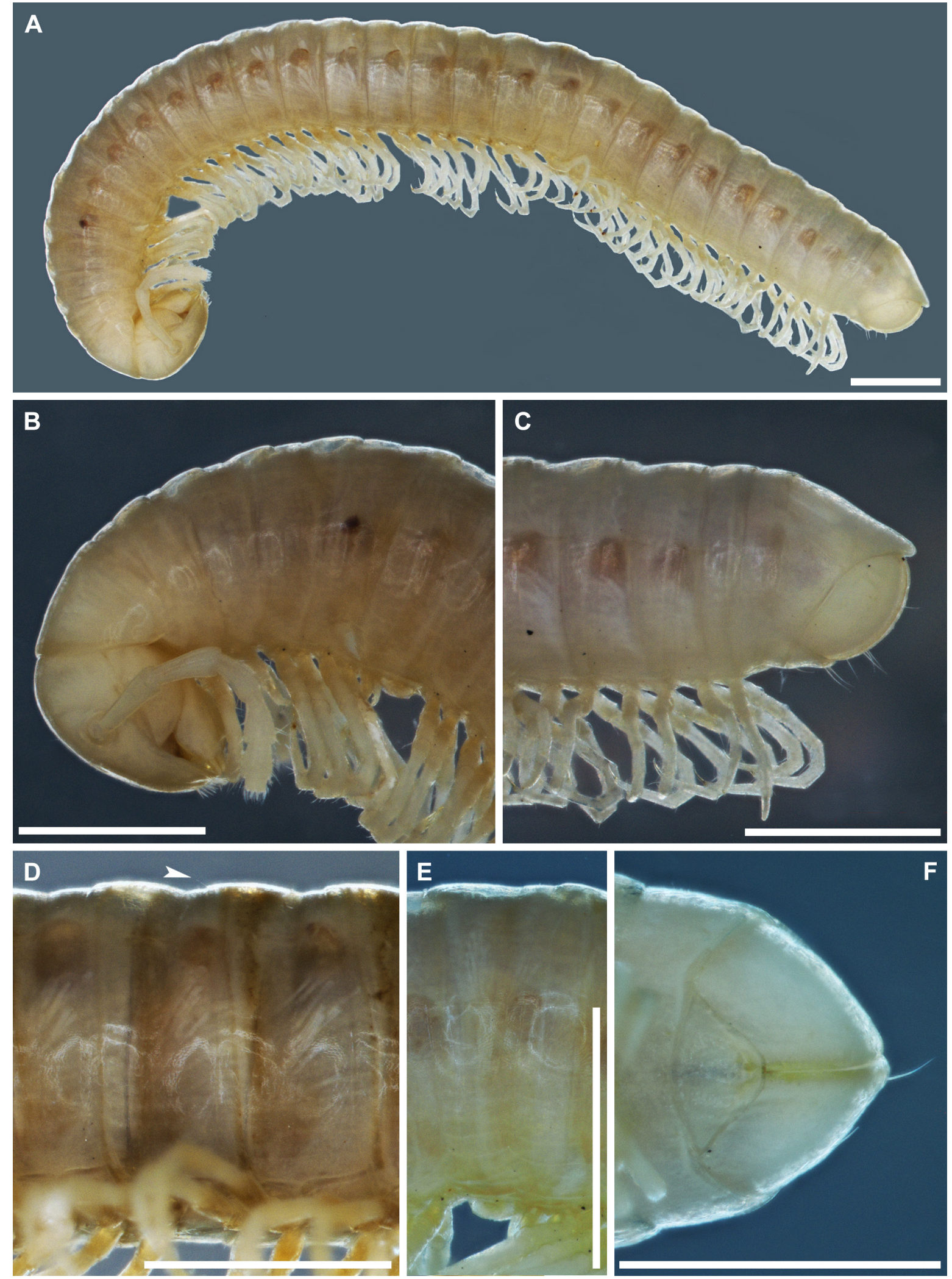

Fig. 50. Martvilia parva gen. et sp. nov. (A-C, E: holotype $\widehat{\partial}$ from Jortsku Cave (ZMUM); D, F: non-type $q$ from Motena Cave (IZB)). A. Habitus, lateral view. B. Anterior part of body, lateral view. C. Posterior part of body, lateral view. D. Midbody rings, lateral view. E. Body ring 7, lateral view. F. Telson, posterior view. Arrow indicates metazonal seta. Scale bars: $1 \mathrm{~mm}$. 
Telson (Fig. 50C, F). Epiproct with a short and blunt caudal process. Paraprocts rounded, with a few setae. Hypoproct subtrapezoid, with two long apical setae. Setae on telson mainly broken off.

LEGS IN MALES. First pair of legs modified, hook-shaped (Fig. 51D), with three podomeres; coxa with one seta; prefemur with two setae; femora, postfemora and tibiotarsi coalesced; femur with two setae, postfemur with one seta. Tip slightly tuberculate. Postfemoral and tibial ventral pads poorly developed on pregonopodal legs, then gradually disappearing on postgonopodal legs.

A

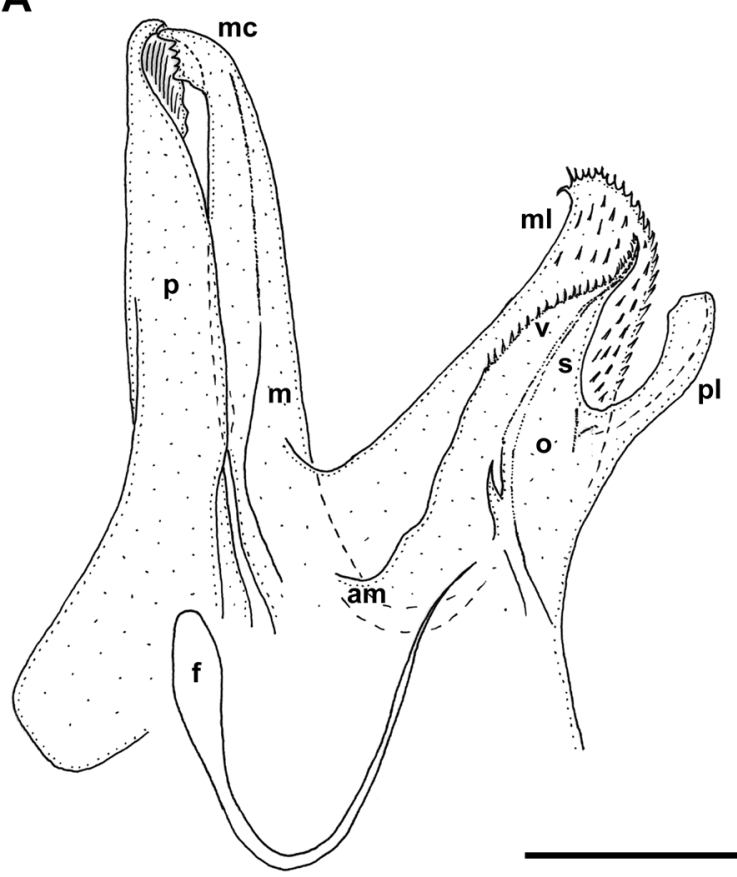

B

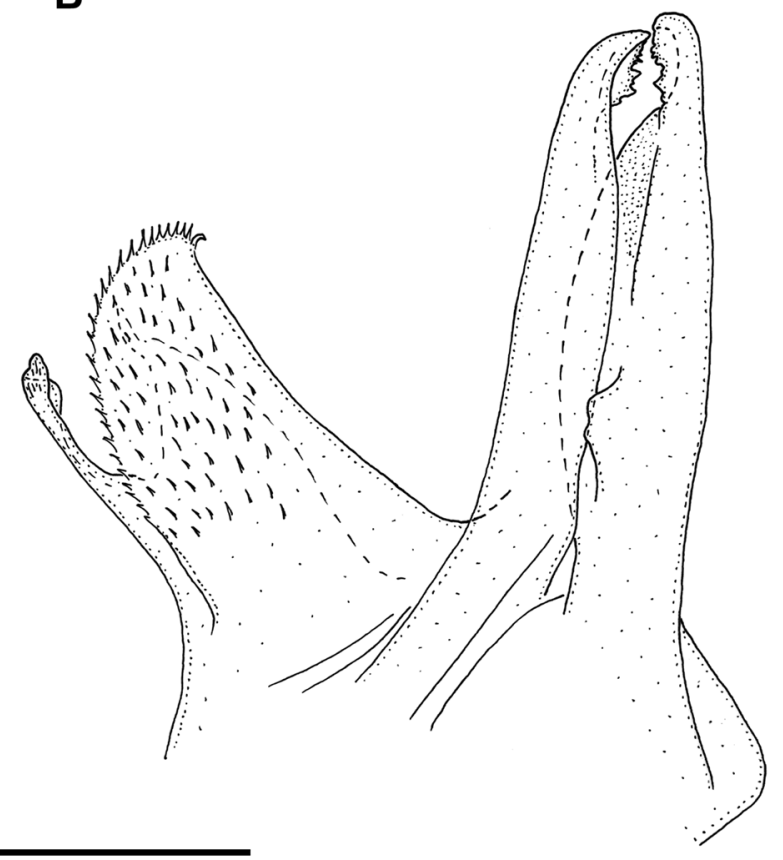

C

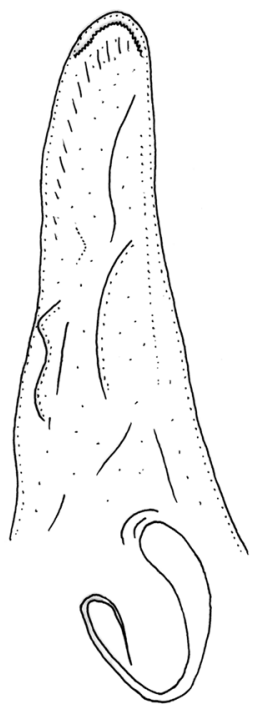

D
$\mathbf{E}$

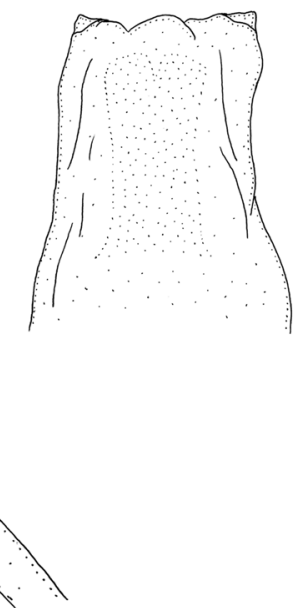

Fig. 51. Martvilia parva gen. et sp. nov., type $\widehat{\partial}$ (ZMUM). A. Holotype, left gonopods, mesal view. B. Holotype, left gonopods, lateral view. C. Paratype, right promere, posteromesal view. D. Paratype, leg-pair 1, anterior view. E. Paratype, penes, posterior view. Abbreviations: am = accessory membrane; $\mathrm{f}=$ flagellum; $\mathrm{m}=$ mesomere; $\mathrm{mc}=$ mesomeral claw; $\mathrm{ml}=$ mesomeral lamella; $\mathrm{o}=$ opisthomere; $\mathrm{p}=$ promere; $\mathrm{pl}=$ protective lamella; $\mathrm{s}=$ solenomere; $\mathrm{v}=$ velum. Scale bar: $0.3 \mathrm{~mm}$. 
Ventral MARGin OF MALE Body Ring 7 (Fig. 50E). Poorly developed, low, subquadrangular in lateral view.

Penes (Fig. 51E). More or less elongate, subquadrangular, apically with short subtriangular lobes.

Gonopods (Fig. 51A-C). Promere (p) long and slender, straight, wider at base in anteroposterior view, with a flagellum (f); apical part excavate, with denticulate margins; basal half with two ridges. Mesomere (m) with a slender, straight, columnar anterior part, apically with a denticulate mesomeral claw $(\mathrm{mc})$; mesomeral lamella $(\mathrm{ml})$ reduced in size, directed posteriad, anterior margin smooth, posterodistal margin fimbriate, entire lamella covered with fimbriae. Opisthomere (o) bipartite. Anterior branch of o with a solenomere (s) with a medium-sized tip and a fimbriate velum (v). Posterior branch of o in form of a shield-like protective lamella (pl). Mesomere and opisthomere connected basally with an accessory membrane (am).

\section{Distribution}

Known only from two caves in Samegrelo-Zemo Svaneti (Fig. 56, green triangles; Fig. 58, red circles).

\section{Remarks}

In both caves, this species has been found together with Leucogeorgia lobata sp. nov.

\section{Key to the species of Caucasian Leugogeorgiini}

1. Mouthparts normal .2

- Mouthparts modified 9

2. Head with ommatidia; metazonal setae absent (Figs 29-31) .............Leucogeorgia oculata sp. nov.

- Head without ommatidia; metazonal setae present 3

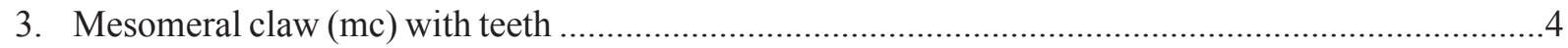

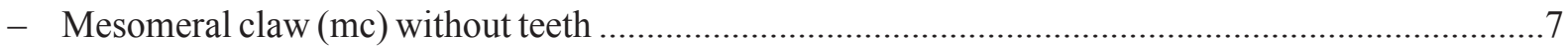

4. Mesomeral claw (mc) stocky and robust (Figs 16-18) ...................eucogeorgia borealis sp. nov.

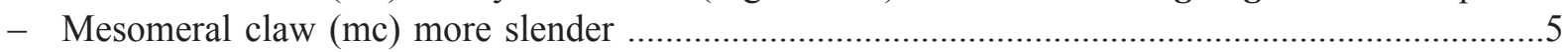

5. Mesomeral claw (mc) with poorly developed teeth (almost absent); mesomeral lamella (ml) strongly serrate distally (Figs 19-21) ....

Leucogeorgia gioi sp. nov.

- Mesomeral claw (mc) with well-developed teeth; mesomeral lamella (ml) not strongly serrated distally ......

6. Mesomeral lamella (ml) sloping down posteriad, without posterior rise; midbody setae ca $5 \%$ of vertical diameter of rings (Figs 3-6) ..........Leucogeorgia abchasica (Lohmander, 1936) comb. nov.

- Mesomeral lamella $(\mathrm{ml})$ flattened, with a posterior rise; midbody setae ca $10 \%$ of vertical diameter of rings (Figs 14-15) ..................................Leucogeorgia satunini (Lohmander, 1936) comb. nov.

7. Body ring 2 in both sexes with well-developed ventral lobes (Figs 22-24)

Leucogeorgia golovatchi sp. nov.

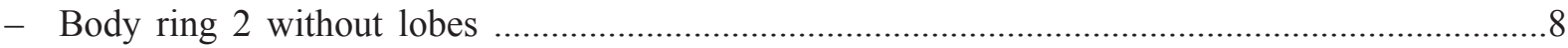

8. Mesomeral lamella (ml) with a strongly developed lobe (1) (Figs 25-26, 27A-C, 28)

Leucogeorgia lobata sp. nov.

- Mesomeral lamella (ml) without such a strongly developed lobe (1); if $\mathrm{ml}$ present, then poorly developed (Figs 32-35)

Leucogeorgia prometheus sp. nov. 
9. Mesomeral lamella $(\mathrm{ml})$ reduced, connected to base of mesomere (Figs 50-51)

Martvilia parva gen. et sp. nov.

- Mesomeral lamella (ml) strongly developed, starting just below mesomeral claw (mc) ......10

10. Mesomeral claw (mc) without teeth (Figs 7-10) ..............Leucogeorgia longipes Verhoeff, 1930

- Mesomeral claw (mc) with teeth .........................................................................................11

11. Labrum strongly divided into two lobes; gnathochilarium with a distolateral bundle of long setae on stipites; lamellae linguales with two irregular rows of long, distal setae (Figs 39-41) ....

Leucogeorgia mystax sp. nov.

- Labrum only slightly concave in middle; gnathochilarium without such groups of setae .........12

12. Posterior margin of hypoproct with a characteristic rounded extension in both sexes (Figs 42-43)

Leucogeorgia profunda sp. nov.

- Posterior margin of hypoproct without rounded extension .13

13. Epiproct with very long and sharp process, apically with a hyaline tip slightly curved upwards (Figs 36-38)

Leucogeorgia caudata sp. nov.

- Epiproct with a short or not too long and sharp process, without hyaline tip

14. Anal valvae densely setose (Figs 47-49)

Leucogeorgia turbanovi sp. nov.

- Anal valvae setose, but not too densely so

15. Body elongate, with 38-47 podous rings in males; hypoproct lanceolate; ventral margin of body ring 7 rounded; mesomeral lamella $(\mathrm{ml})$ with a rather smooth, high and lobe-shaped central part (Figs 11-13)

Leucogeorgia rediviva Golovatch, 1983

- Body stocky, with 28-35 podous rings in males; hypoproct subrhomboid; ventral margin of body ring 7 low, more subquadrangular; mesomeral lamella flattened, slightly denticulate in central part (Figs 44-46) Leucogeorgia redivivoides sp. nov.

\section{Additional Leucogeorgia material examined}

We have also examined some females and juveniles of the genus Leucogeorgia from several other caves, but we do not dare assign them to any of the species treated above (Figs 57-58). Species with modified mouthparts were found in Mchishta (= Akshasha) Cave (43.24 $\left.\mathrm{N}, 40.51^{\circ} \mathrm{E}\right)$ and Kelasurskaya Cave $\left(43.02^{\circ} \mathrm{N}, 41.14^{\circ} \mathrm{E}\right)$. Species with normal mouthparts were found in Nizhnyaya Shakuranskaya Cave $\left(43.03^{\circ} \mathrm{N}, 41.33^{\circ} \mathrm{E}\right)$, Tkibula-Dzevrula Cave $\left(42.34^{\circ} \mathrm{N}, 42.99^{\circ} \mathrm{E}\right)$, Nikortsminda Cave $\left(42.46^{\circ} \mathrm{N}\right.$, $\left.43.07^{\circ} \mathrm{E}\right)$, Bolshaya Kazachebrodskaya (= Verkhnyaya Mzymtinskaya = Akhshtyrskaya) Cave $\left(43.52^{\circ} \mathrm{N}, 39.99^{\circ} \mathrm{E}\right)$, Zamshevaya Cave and Tsotne Dadiani Cave $\left(42.75^{\circ} \mathrm{N}, 42.13^{\circ} \mathrm{E}\right)$ at the bottom of funnel 1 and at the bottom of funnel 2. These samples are deposited in the ZMUM collection.

\section{Species richness estimation}

Of our 16 Caucasian Leucogeorgiini species, L. prometheus sp. nov. and L. abchasica are the most widespread ones, with nine cave locations each. Four new species are known from only one cave (see Table 1). In most cases each species is represented by only a few specimens in each cave (except L. prometheus). In total, we have 58 species-cave (locality) records, where caves with two species are counted twice.

The species richness estimation revealed a mean CHAO1-estimator of 18, with lower and upper 95\% boundaries of confidence intervals of 16 and 32, respectively. This means that we could expect from 16 


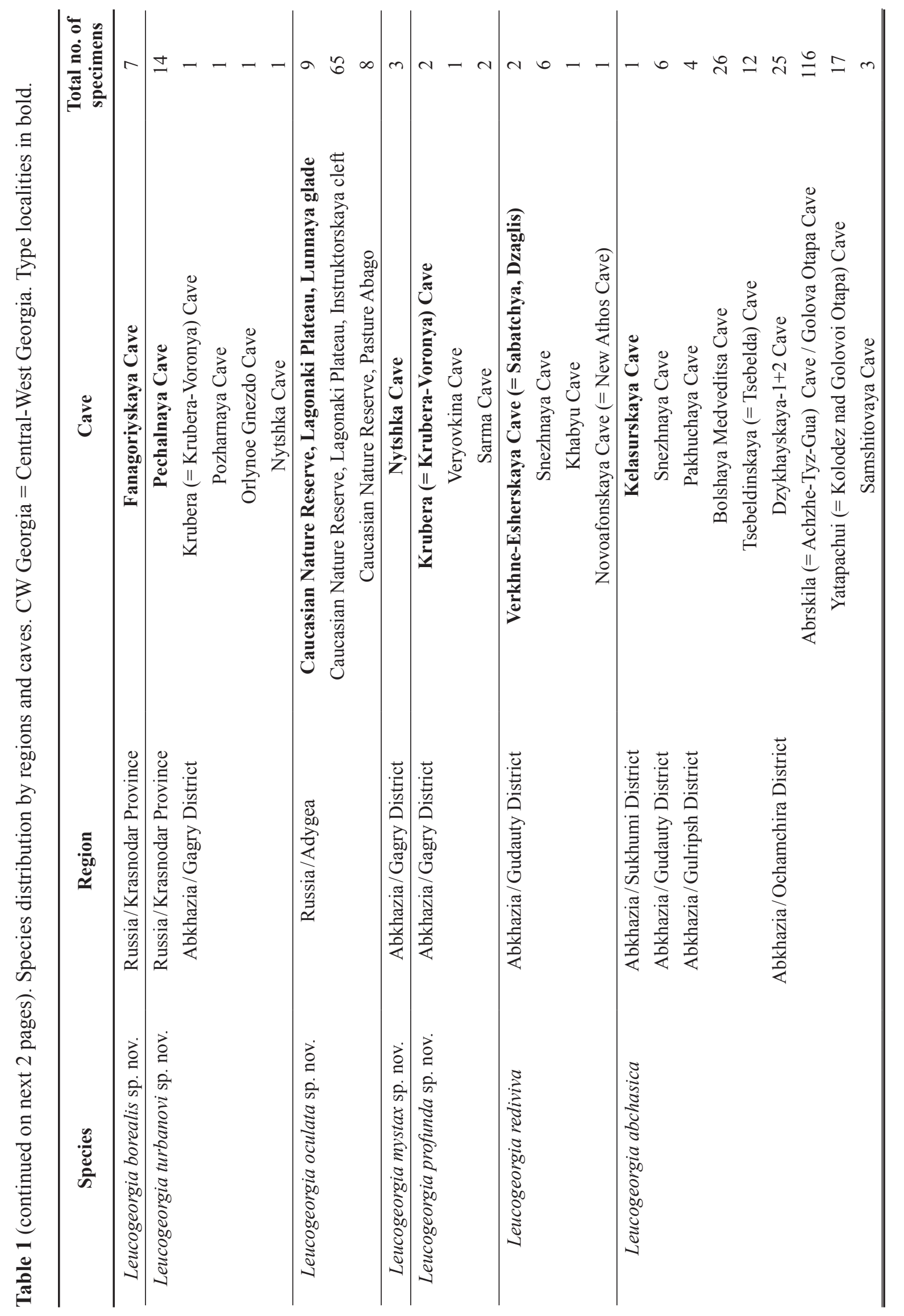


ANTIĆ D.Ž. \& REIP H.S., Revision of Caucasian Leucogeorgiini

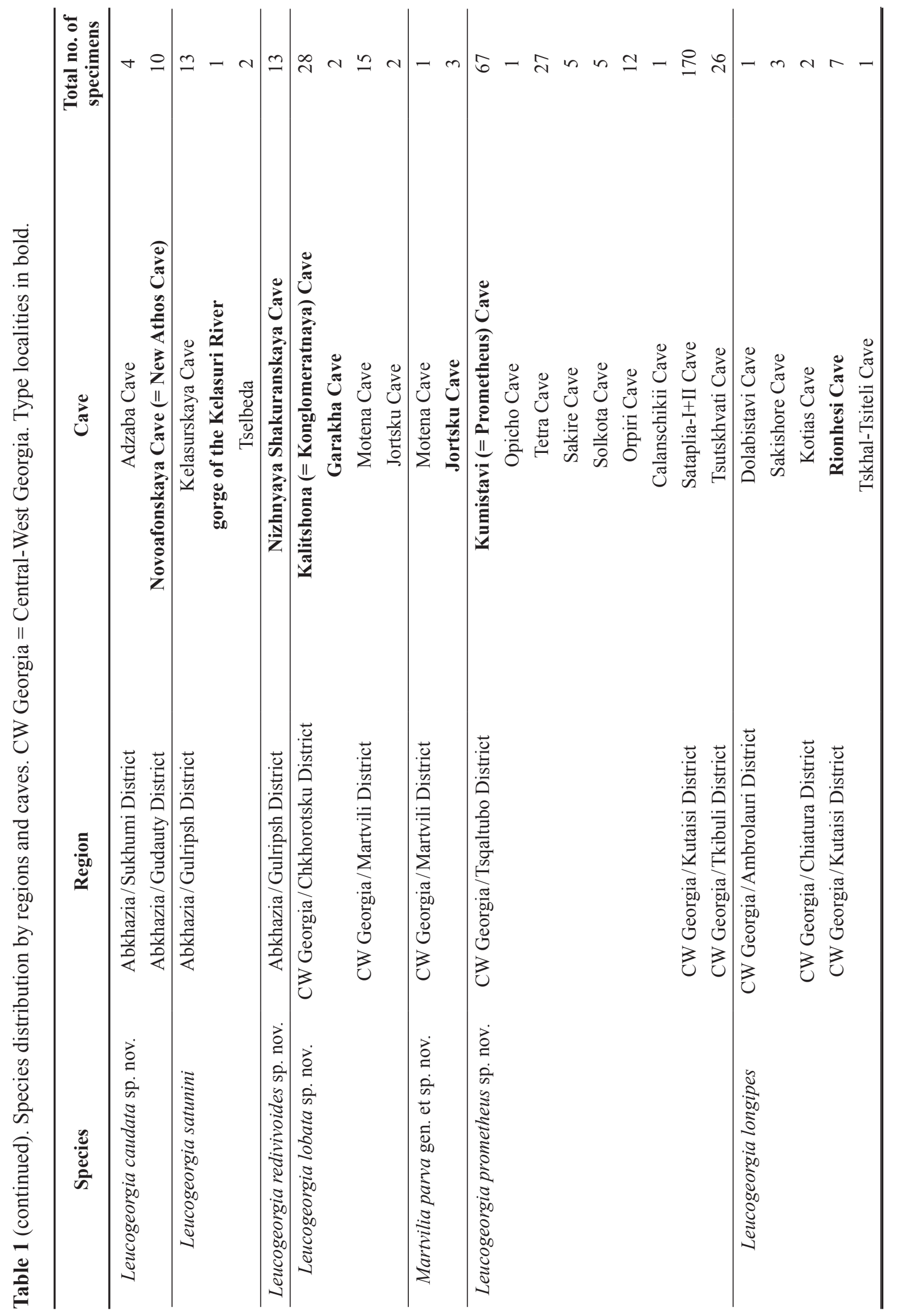




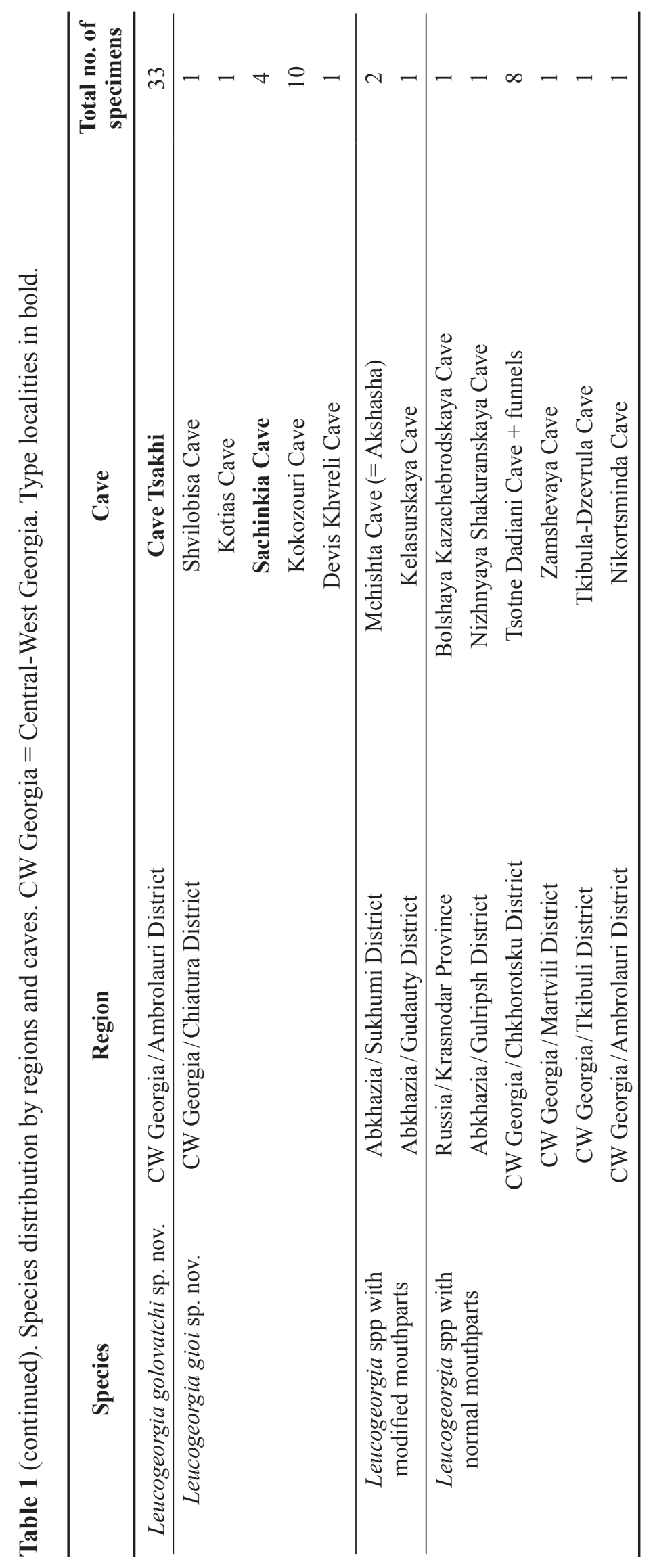


to 32 species of Leucogeorgiini in the western Caucasus, most likely 18 species. Thus, most probably only two species are yet to be discovered. Based on this species richness estimation, our revision has captured the species diversity of the Leucogeorginii almost completely.

It is discouraging that, according to the estimation, in order to locate these two missing species, probably another 41 localities inhabited by Leucogeorgiini species (in addition to the 58 already known locations) need to be investigated (Fig. 52).

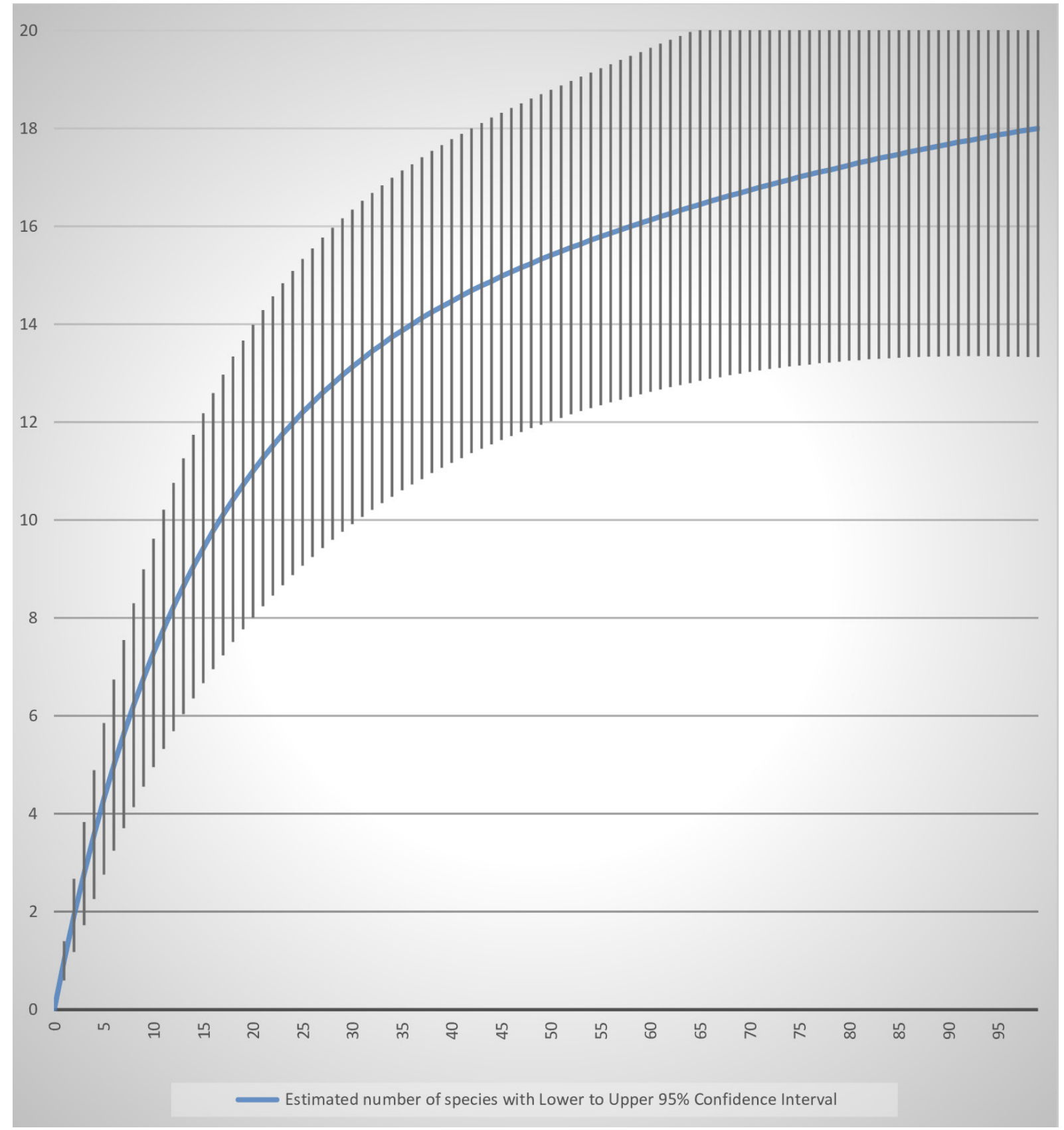

Fig. 52. Species estimation-extrapolated rarefaction curve. $X$-axis: cave location with species of Leucogeorgiini (each cave-species record counts separately); Y-axis: estimated number of species. 
Additional leucogeorgiinine species examined

Chromatoiulus podabrus (Latzel, 1884)

Figs $53 \mathrm{~A}-\mathrm{B}, 54 \mathrm{~A}-\mathrm{B}$

\section{Material examined}

NORTH MACEDONIA - Šar Mountains • 1 đ̊; Jelak; IZB.

\section{Heteroiulus intermedius (Brölemann, 1892)}

Fig. 54D-E

\section{Material examined}

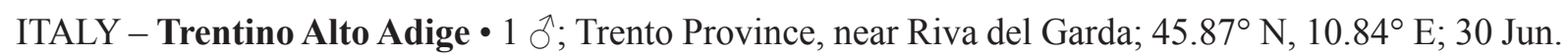
2015; M. Bodner leg.; IZB.

\section{Lamellotyphlus sotirovi Makarov, Mitić \& Ćurčić, 2002}

Figs 53D, 54G-H

Material examined (topotypic)

SERBIA - Miroč Mountain • 1 ð’; Donji Milanovac, village Golubinje, Buronov Ponor Cave; 17 Mar. 2015; D. Antić and Đ. Marković leg.; IZB.

\section{Nepalmatoiulus birmanicus (Pocock, 1893)}

Figs 53C, 54C

\section{Material examined}

THAILAND - Krabi Province ・ 2 ふふ; Krabi, Maritime Park and Spa Resort; 26 Jul. 2017; D. Antić leg.; IZB.

\section{Pteridoiulus aspidiorum Verhoeff, 1913}

Figs 53F, 54F

\section{Material examined}

AUSTRIA - Carinthia • 1 § ; St. Oswald, Nockberge; $46.86^{\circ}$ N, $13.75^{\circ}$ E, 1905 m a.s.1.; 18 Jun. 2016; M. Bodner leg.; IZB.

\section{Telsonius nycteridonis Strasser, 1976}

Figs 53E, 54I

\section{Material examined}

Lectotype (here designated)

GREECE - Macedonia - ${ }^{\text {; }}$; Nycteridon Cave, village Petralona; 10 Oct. 1974; P. Beron and V. Beškov leg.; "Telsonius n. g. nycter. n. sp. Holotype đ’; Grotte 'Spilja nycteridon', v. Petralona, distr. Salonique, Grèce du Nord; 10.10.1974; P. Beron, V. Beškov leg.”; NMNHS 10810 (alcohol material, body in four pieces), NMNHS 10810a (microscopic slide labeled as "Holotypus", with gnathochilarium, leg-pairs 1 and 2, legs 3 and 4), NMNHS 10810b (microscopic slide labeled as "Holotypus", with right gonopods, part of body ring 7 and one antenna). 

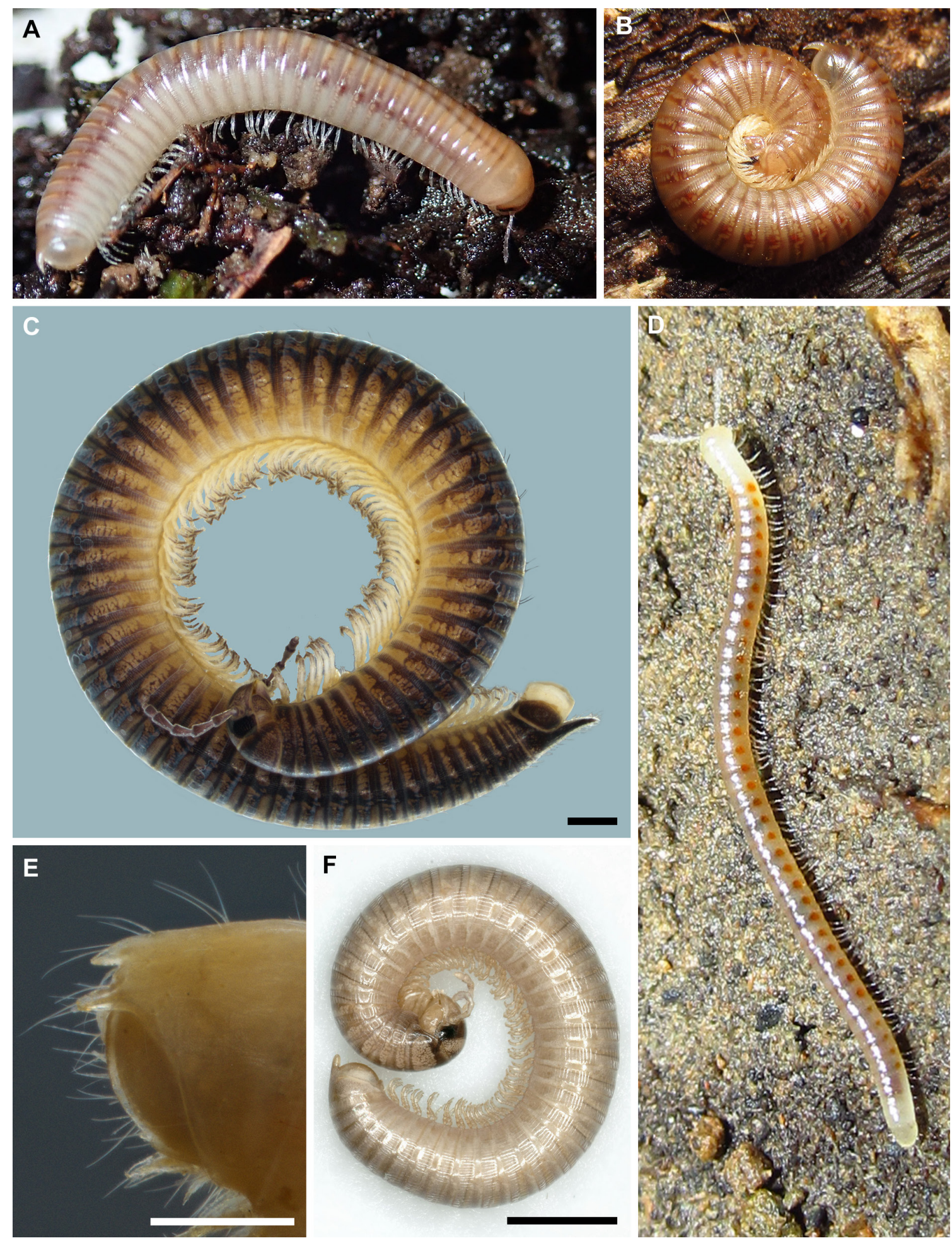

Fig. 53. A-B. Chromatoiulus podabrus (Latzel, 1884), in situ, specimens from near Trebinje, Bosnia and Herzegovina (photos: Marjan Komnenov (A); Dragan Antić (B)). C. Nepalmatoiulus birmanicus (Pocock, 1893), habitus, lateral view, ô from Krabi, Thailand (IZB). D. Lamellotyphlus sotirovi Makarov, Mitić \& Ćurčić, 2002, in situ, topotype specimen from Buronov Ponor Cave (IZB) (photo: Dragan Antić). E. Telsonius nycteridonis Strasser, 1976, lectotype $\widehat{\jmath}$ from Nycteridon Cave, Greece (NMNHS 10810), telson, dorsolateral view. F. Pteridoiulus aspidiorum Verhoeff, 1913, habitus, lateral view, $\widehat{O}$ from Nockberge, Austria (photo: Michaela Bodner). Scale bars: C, F $=1 \mathrm{~mm} ; \mathrm{E}=0.5 \mathrm{~mm}$. 

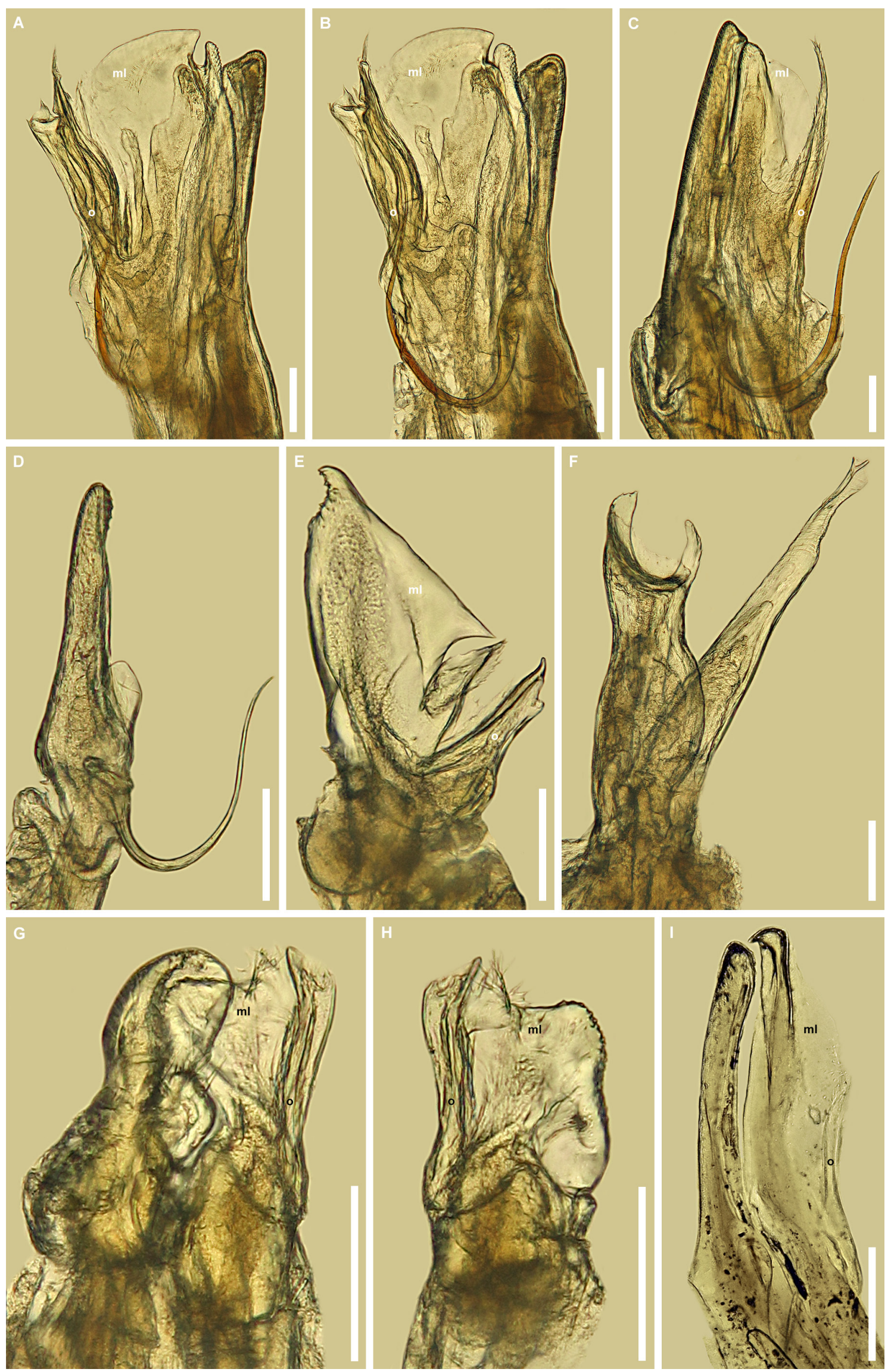


\section{Remarks}

On the labels of the vial and on the two microscopic slides of the lectotype male of Telsonius nycteridonis, Strasser clearly indicated "holotypus", but he did not designate a holotype in the original description of the species (Strasser 1976). According to ICZN 72.4.7: "The mere citation of "Type" or equivalent expression, in a published work other than that in which the nominal species-group taxon is established, or in an unpublished catalogue of a museum, or on a label, is not necessarily evidence that a specimen is or is fixed as any of the kinds of types referred to in this Chapter". The designation of the holotype and paratypes is only valid if it appears in the original description of the species. Since this is not the case with Telsonius nycteridonis, the type male of this species in NMNHS is to be considered as a syntype which we herewith designate as the lectotype to fix the taxonomy of this species.

\section{Discussion}

\section{Notes on troglomorphism and mouthpart modifications in Caucasian Leucogeorgiini}

All described species of the genus Leucogeorgia, with the exception of L. satunini and L. oculata sp. nov., are found exclusively in caves. Since L. satunini, in addition to in Kelasuri Cave, was also encountered in the gorge of the Kelasuri River and in forest litter near Tsebelda (Golovatch 1985), this species is rather to be considered as troglophilic. Leucogeorgia oculata sp. nov. can be considered as an endogean species, which is currently known only from subalpine litter and meadow soil. All other described species of this genus can be regarded as troglobites, with more or less pronounced troglomorphic characteristics, such as body depigmentation, elongate appendages and the loss of ommatidia. However, in addition to these troglomorphic traits, some of the species of Leucogeorgia have gone a step further. Almost half of them ( 7 species) are characterized by highly modified mouthparts, presumably for filtering the diet in water or on thin films of water in very humid places in the caves. These modifications are clearly reflected in the reduction of the biting parts of the mandibles, in the hypertrophied pectinate lamellae, as well as in modifications of the labrum and gnathochilarium.

Reduced biting parts of the mandible mean the internal and external teeth are underdeveloped, while these structures are strongly developed in congeners with normal mouthparts (Fig. 55A-B, white arrows; for more details see Enghoff 1985: 69, figs 1-2).

Another obvious modification is the hypertrophy of the pectinate lamellae, whose teeth are long, thin and densely packed, in contrast to congeners with normal mouthparts where the teeth of the pectinate lamellae are shorter, more sparse and appear stronger (Fig. 55, black arrow; for more details see Enghoff 1985: 70, figs 6-7). Both of these modifications (reduction of biting parts and hypertrophy of pectinate lamellae) strongly suggest and support a presumed filtered diet.

Fig. 54 (on page 92). Gonopods of some other Leucogeorgiini. A. Chromatoiulus podabrus (Latzel, 1884), left gonopods, lateral view, ô from Šar Mountains, Northern Macedonia (IZB). B. Chromatoiulus podabrus (Latzel, 1884), right gonopods, mesal view, ô from Šar Mountains, Northern Macedonia (IZB). C. Nepalmatoiulus birmanicus (Pocock, 1893), right gonopods, mesal view, $\widehat{\jmath}$ from Krabi, Thailand (IZB). D. Heteroiulus intermedius (Brölemann, 1892), left promere, mesal view, $\widehat{o}$ from near Riva del Garda, Italy (IZB). E. Heteroiulus intermedius (Brölemann, 1892), left posterior gonopod, mesal view, § from near Riva del Garda, Italy (IZB). F. Pteridoiulus aspidiorum Verhoeff, 1913, left gonopods, mesal view, $\widehat{\jmath}$ from Nockberge, Austria (IZB). G. Lamellotyphlus sotirovi Makarov, Mitić \& Ćurčić, 2002, topotype $\delta$ from Buronov Ponor Cave, left gonopods, mesal view (IZB). H. Lamellotyphlus sotirovi Makarov, Mitić \& Ćurčić, 2002, topotype $\widehat{\jmath}$ from Buronov Ponor Cave, right posterior gonopod, mesal view (IZB). I. Telsonius nycteridonis Strasser, 1976, lectotype $\lesssim$ from Nycteridon Cave, Greece, right gonopods, lateral view (NMNHS 10810b). Abbreviations: $\mathrm{ml}=$ mesomeral lamella; $\mathrm{o}=$ opisthomere. Scale bars: $0.1 \mathrm{~mm}$. 

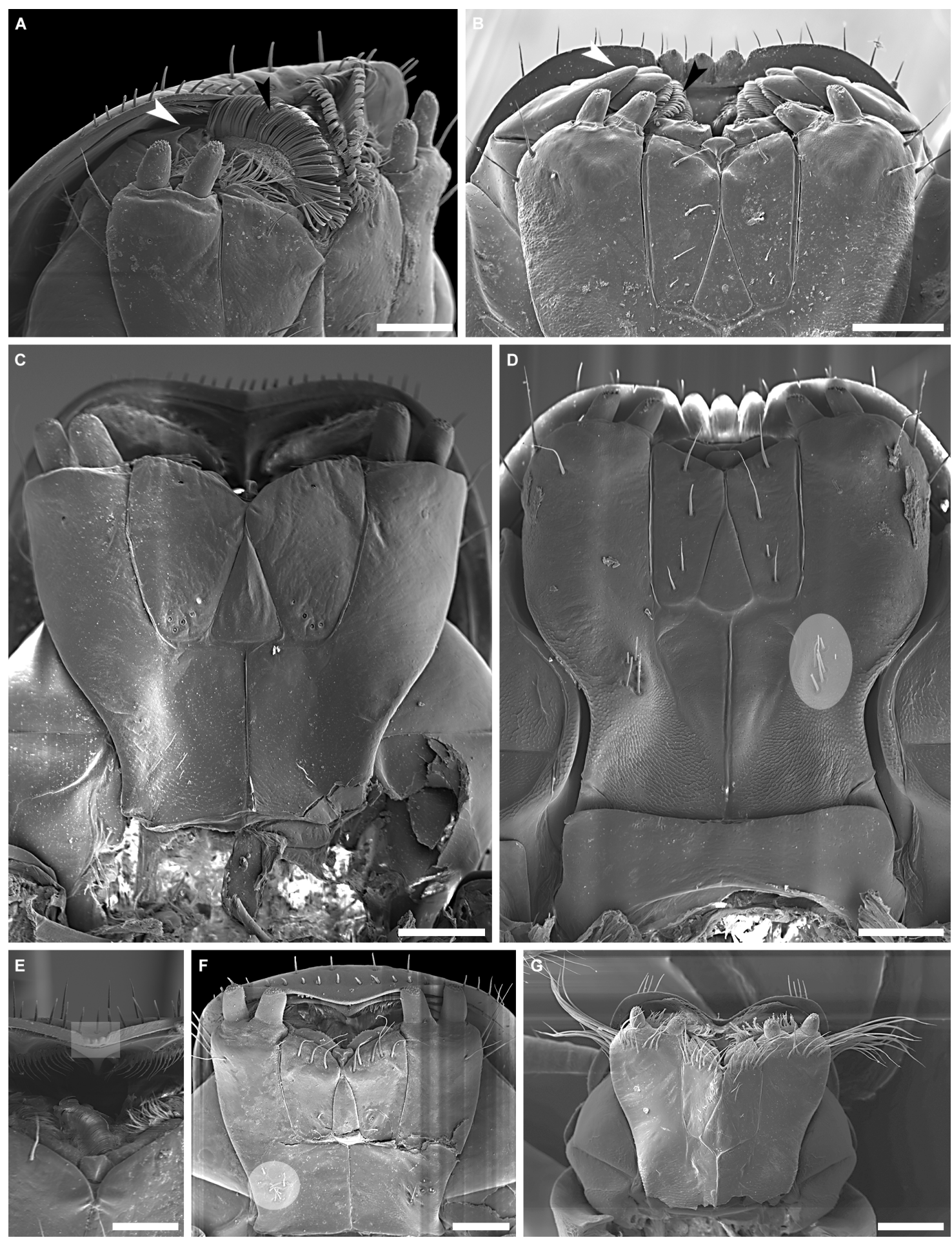

Fig. 55. Head of species in the genus Leucogeorgia Verhoeff, 1930. A. L. caudata sp. nov., § from Adzaba Cave, ventrolateral view (ZMUM). B. L. prometheus sp. nov., o from Sataplia II Cave, ventral view (ZMUM). C. L. turbanovi sp. nov., paratype $\hat{\jmath}$, ventral view (SMNG). D. L. prometheus sp. nov., $\widehat{\jmath}$ from Sataplia I Cave, ventral view (SMNG). E. L. rediviva Golovatch, 1983, §ิ from Khabyu Cave, ventral view (SMNG). F. L. longipes Verhoeff, 1930, § from Dolabistavi Cave, ventral view (SMNG). G. L. mystax sp. nov., holotype $\hat{\jmath}$, ventral view (ZMUM). White arrows indicate mandibular teeth, black arrows indicate pectinate teeth, transparent oval and circle show medial group of shorter setae on stipites, transparent rectangle shows three reduced labral teeth. Scale bars: $0.2 \mathrm{~mm}$. 
Further modifications concern the labrum. While the labrum in species with normal mouthparts is characterized by three well-developed, medial, labral teeth, as well as the presence of always four supralabral setae and a smaller number (12-18) of labral setae, in congeners with modified mouthparts the situation is different. These animals are characterized by a reduction of labral teeth. The reduction can be complete, with the labral teeth completely absent (see Fig. 55C, F-G), but it can also be partial when the individual has three strongly reduced, small labral teeth (see Fig. 55E, transparent rectangle). As mentioned above and for the reasons given, the presence of three small labral teeth in some specimens is not to be considered of taxonomic value. Some species with modified mouthparts show a tendency to increase the number of supralabral setae, as some of them, viz., L. rediviva, L. redivivoides sp. nov. and L. turbanovi sp. nov., can have 5-7 supralabral setae, i.e., more than the 'normal' four. As far as the labral setae are concerned, the species with modified mouthparts are characterized by a higher number (26-35) of setae compared to congeners with normal mouthparts (12-18). The two exceptions are L. longipes and L. mystax sp. nov., both having the number of labral setae within the range of their congeners with normal mouthparts.

Finally, these two ecological groups also differ in the structure of the gnathochilarium. In species with modified mouthparts, this structure has the shape of an inverted trapezoid, whose width gradually decreases from the anterior (distal) to the posterior (proximal) part, while their lamellae linguales are noticeably wider (Fig. 55C). On the other hand, species with normal mouthparts have a gnathochilarium whose width is sharply decreased in its posterior (proximal) half, while the lamellae linguales are noticeably narrower compared to those in the modified relatives (Fig. 55D). Additionally, the gnathochilarium differs between those groups in setation. Almost all species with modified mouthparts (except L. longipes) are characterized by the absence of a medial group of shorter setae on the stipites, which are present in species with normal mouthparts (Fig. 55D, transparent oval) and L. longipes, but in the latter species these setae are moved more posteriorly (proximal) (Fig. 55F, transparent circle). Besides this, in most species with modified mouthparts the lamellae linguales are provided with $1+1$ long distal (anterior) and several posterior (proximal) shorter setae, while congeners with normal mouthparts show a continuous row of setae on both lamellae linguales. Exceptions to the above are again L. longipes and L. mystax sp. nov., which are characterized by an increased number of distal (anterior) setae on the lamellae linguales: $3-5$ in L. longipes and 9-11 in L. mystax sp. nov. Furthermore, the gnathochilarium in L. mystax sp. nov. looks bizarre, with two irregular, transverse, distal (anterior) rows of 9-10 long setae and disto(antero)lateral bundles of long setae on the stipites (Fig. 55G). According to Giurginca et al. (2020: 467, fig. 2a-c), their recently described blaniulid, Archiboreoiulus serbansarbui Giurginca, Vănoaica, Šusrt \& Tajovský, 2020, also appears to have similar bundles of long setae on the stipites, reminiscent of 'moustaches', as well as long setae on the lamellae linguales, but these structures, unfortunately, are not mentioned in their description. Similar modifications of the mouthparts seen in Leucogeorgia are also characteristic of Martvilia parva gen. et sp. nov.

In addition to the modified mouthparts, these species differ from relatives with normal mouthparts by the presence of longer legs ending with strongly developed claws, a slightly stocky body, with less numerous body rings compared to their length, longer antennae (an exception is L. longipes) and a somewhat elongate head, which is dorso-ventrally more flattened. Thus, such specimens can easily be distinguished at first sight from their relatives with normal mouthparts.

The phenomenon of modified mouthparts, although rare, is well documented in several EuroMediterranean cave Julida, as well as in a few genera of the order Polydesmida (Enghoff 1985; Antić et al. 2017). Similar mouthpart modifications within the family Julidae, in addition to those in Leucogeorgia and Martvilia gen. nov., have long been known to exist in the genera Trogloiulus Manfredi, 1931 and Typhloiulus Latzel, 1884, with two and four cave species with modified mouthparts, respectively. These modifications obviously looked so striking to Verhoeff (1930) that he established a separate family for the genus Leucogeorgia alone. However, as Enghoff (1985) pointed out, such modifications reflect 
only special adaptations to the ecological conditions (presumed semi-aquatic life) in which these species live and must have developed several times independently within millipedes. Therefore, they are of limited phylogenetic significance. Within the genera Trogloiulus and Typhloiulus, this has been proven by the existence of closely related congeners with normal mouthparts. Especially within Typhloiulus, it seems that the four known species with modified mouthparts are not too closely related to one another, being classified in different subgenera and showing their closest relatives with normal mouthparts. Thus, a formal synonymization of the genus Archileucogeorgia Lohmander, 1936 syn. nov., as a junior subjective synonym, under the older name Leucogeorgia Verhoeff, 1930 is completely justified (see also below).

It is noteworthy that in some caves, two species of the genus Leucogeorgia with modified mouthparts can co-exist. Since such species have been revealed, in almost all cases, in different parts of their caves, the question arises whether they occupy different niches or occur syntopically. One good example of separating two species of the same genus with the same modifications concerns the Krubera Cave, where $L$. turbanovi sp. nov. lives closer to the surface to a depth of $-100 \mathrm{~m}$, while $L$. profunda sp. nov. occurs in the deep part of the cave $(-1650 \mathrm{~m})$. In addition to the Krubera Cave, these two species can be found in several other caves, albeit not sympatrically. They demonstrate patterns of vertical distribution similar to that in the Krubera Cave, where L. turbanovi sp. nov. lives closer to the surface $(-7 \mathrm{~m},-30 \mathrm{~m}$, $-120 \mathrm{~m})$, while $L$. profunda sp. nov. is found much deeper $(-1260 \mathrm{~m},-1360 \mathrm{~m},-1370 \mathrm{~m})$. This may be evidence that these two species are parapatric and are not in contact with each other. Contrary to this is the presence of L. mystax sp. nov. and L. turbanovi sp. nov. in the Nytshka Cave at a depth of $-7 \mathrm{~m}$. This pair of species is likely to be syntopic. Although they have modified mouthparts, their drastic differences seem to be evidence of their having different lifestyles and diets. In several other caves, we have further examples where two species of the genus Leucogeorgia live sympatrically, one with modified and the other with normal mouthparts. This is much easier to explain, given that both represent ecologically different forms, one of which prefers to feed on terrestrial organic matter in decay, while the other has most likely resolved the problem of finding food by occasionally entering the water. It is also worth mentioning that in the Kelasurskaya Cave as many as three different species of Leucogeorgia are found to occur, viz., L. abchasica and L. satunini, the latter also recorded outside the cave, as well as an unidentified Leucogeorgia with modified mouthparts.

What we can say with certainty now is that the western Caucasus is the region that seems to support the largest number of julid species with modified mouthparts, as many as eight. Future studies must also focus on the ecology of these fascinating animals. Examining their ways of feeding, their vertical distributions, their ways of speciation in sympatry or even syntopy, as well as their occasional life in water could be of importance for understanding the evolution of and colonization by cave organisms.

\section{Notes on the distribution of and relationships within the genus Leucogeorgia}

With its unique flora, fauna and ecosystems, the Caucasus ecoregion has long been known as one of the world's biodiversity hotspots (Zazanashvili et al. 2004). As far as the millipede fauna is concerned, it is very rich and highly diverse, with $>160$ species, $>50$ genera, 14 families and eight orders presently being known. All species in the orders Platydesmida, Polyzoniida, Siphonocryptida, Glomerida and Chordeumatida, as well as most species of Julida and Polydesmida, are native, being endemic or subendemic to the Caucasus, but most of the genera and all of the families and orders they represent are widely distributed at least across the Euro-Mediterranean Realm. The endemism of the Diplopoda in the Caucasus is overwhelming, amounting to $>85 \%$ and $50 \%$ at the specific and generic levels, respectively. As many as 25 millipede genera are endemic or subendemic to the Caucasus, including all 21 genera and 44 species of Chordeumatida, all in the Holarctic family Anthroleucosomatidae, that are presently known to inhabit the region (Antić \& Makarov 2016; Antić et al. 2018a; Kokhia \& Golovatch 2018, 2020). There are neither families nor orders of Diplopoda that are confined to the Caucasus region alone. 
Biogeographically, most of the millipede richness and diversity in the Caucasus is shared by two major realms of the eastern Mediterranean, viz., the Colchidan province in the west, lying along the eastern coast of the Black Sea, and the Hyrcanian province in the east, spanning along the southwestern and southern coasts of the Caspian Sea (e.g., Wulff 1944; Iablokov-Khnzorian 1961). The western Caucasus fully belongs to the Colchidan biogeographic province.

The Caucasus, especially the western Caucasus, has long been recognized as a major refuge for a large number of cave invertebrates. One of the first major studies related to the cave fauna of the western Caucasus was that of Birstein (1950), who noticed the great potential of this region, although he had to deal with a limited number of samples and data. More recently, Culver et al. (2006) concluded that "There are potential subterranean hotspots in the karst regions of western Caucasus...". Cave Diplopoda of the western Caucasus, despite several earlier sporadic records and/or descriptions, have hitherto been surveyed only once, by Golovach (1985), who was forced to also consider numerous species that were unidentified at that time. The number of described cavernicolous millipedes in the Caucasus has since increased very significantly (e.g., Antić \& Makarov 2016; Antić et al. 2018a) and it continues to grow, e.g., with the present contribution.

All Caucasian Leucogeorgiini appear to be restricted to the western Caucasus. Their species range from the Fanagoriyskaya Cave in Krasnodar Province, Russia in the northwest to the Kotias Cave in Chiatura District, Georgia in the southeast (Fig. 56). As noted above, since mouthpart modifications are of no

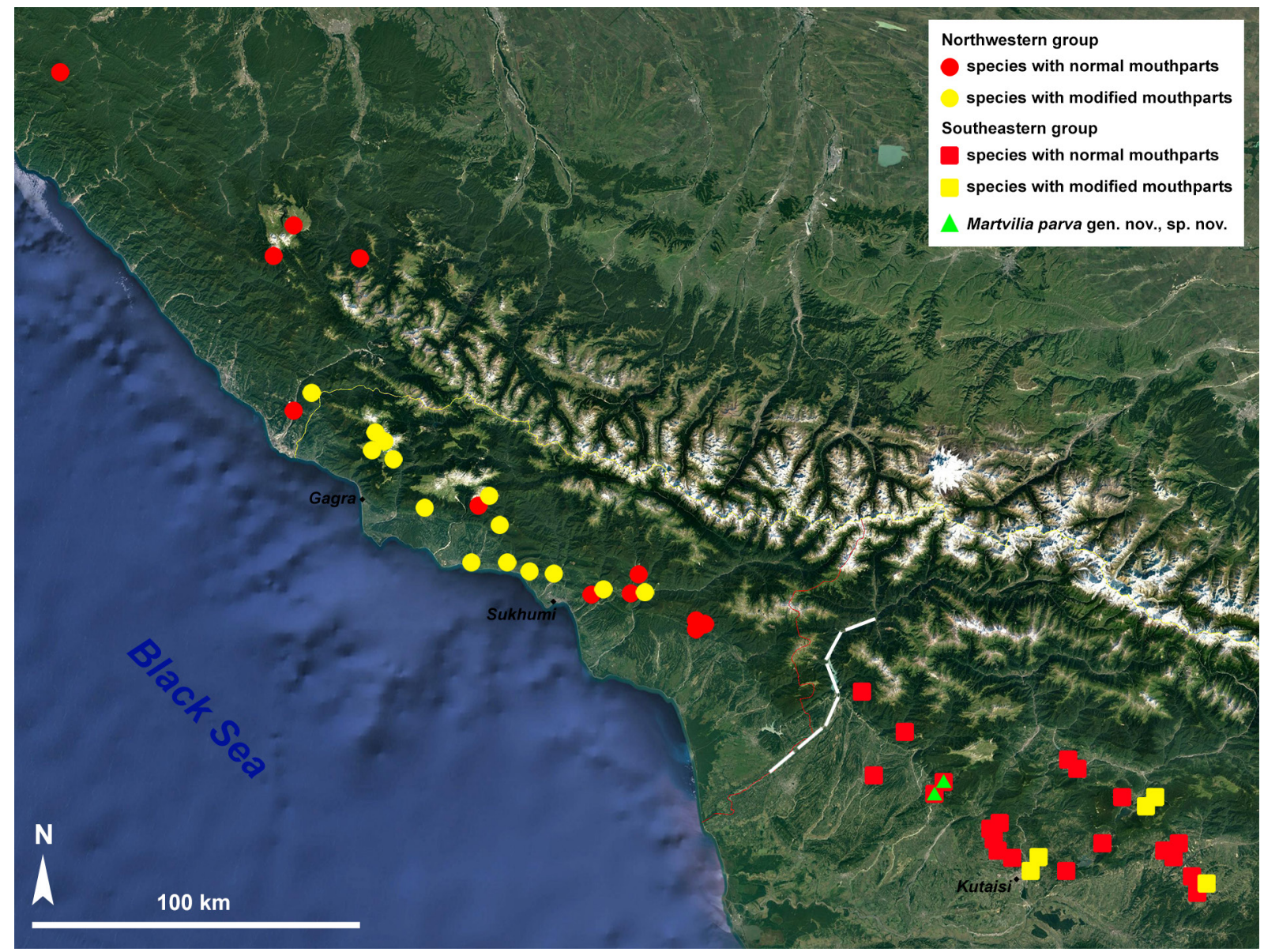

Fig. 56. General distribution of the Caucasian leucogeorgiinines. The white dashed line hypothetically indicates the boundary between the northwestern and southeastern groups of species of the genus Leucogeorgia Verhoeff, 1930. 
particular phylogenetic significance, the genera Archileucogeorgia and Leucogeorgia are herewith synonymized. Moreover, if we pay attention to the gonopods as one of the most important characters in helminthomorph millipedes, two clear-cut groups can be distinguished within Leucogeorgia, each including representatives with modified and normal mouthparts. This fits very nicely biogeographically. Birstein (1950), like some of his predecessors, observed that within the western Caucasus there is a more or less clear division between the cave faunas of the northwestern and southeastern parts of the region. Such a division is obvious in the genus Leucogeorgia as well.

The first group ranges from the northwestern karst area in Krasnodar Province in the northwest to the Panavsky karst Massif in the southeast (Figs 56-57). This group includes L. borealis sp. nov., $L$. abchasica and $L$. satunini with normal mouthparts, as well as $L$. caudata sp. nov., L. mystax sp. nov., L. profunda sp. nov., L. redidivoides sp. nov., L. turbanovi sp. nov. and L. rediviva with modified mouthparts. In addition, this group comprises the only endogeous member of the genus, L. oculata sp. nov. All of these species are characterized by having more or less robust mesomeral claws with developed teeth. The robustness of the mesomeral claw seems to change from northwest to southeast, from a more robust to a less robust condition. Thus, here we have L. abchasica, as the southeasternmost species of this group, which is characterized by the least robust mesomeral claw and, in some cases,

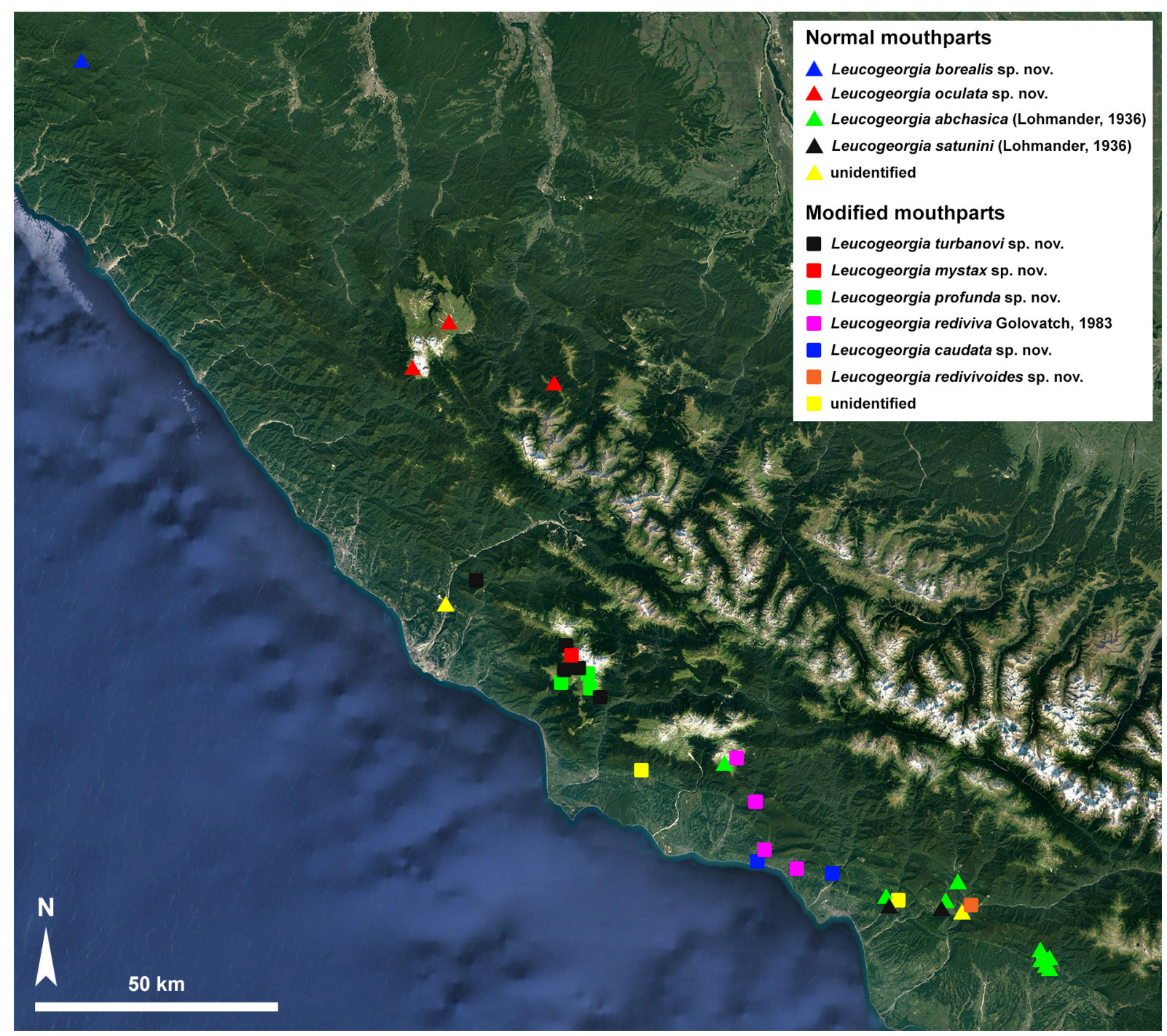

Fig. 57. Distribution of the northwestern group of the genus Leucogeorgia Verhoeff, 1930. 
with a reduced number of teeth on it. As far as the structure of the mesomeral claw is concerned, it seems, although probably superficially, that in some regions, species with modified mouthparts have their counterparts with normal mouthparts.

The second group ranges from the Odishi Plateau and Askhi karst Massif, as part of the Egrisi Mountain Range in the northwest, to the Zemo Imereti Plateau to the southeast (Figs 56, 58). This group is half as diverse as the previous one and includes $L$. gioi sp. nov., L. golovatchi sp. nov., L. lobata sp. nov. and $L$. prometheus sp. nov. with normal mouthparts, as well as L. longipes as the sole member with modified mouthparts. Interestingly, all of them are characterized by having slender and more or less anteriorly curved mesomeral claws, thus completely different compared to the 'northwestern' group. Besides this, all but one are characterized by the complete absence of teeth on the mesomeral claw. Only L. gioi sp. nov. shows a few poorly developed teeth on the mesomeral claw and thus could superficially be regarded as almost toothless.

According to Birstein (1950), who, as mentioned earlier, recognized the cave fauna of the western Caucasus as being divided into a northwestern and a southeastern part, the boundary between the subfaunas lies more to the northwest compared to what we have found in the genus Leucogeorgia. According to our data, the border between these two groups could be the Enguri River Basin (Fig. 56, white dashed line), where the Kodori and Egrisi mountain ranges collide. A similar distribution can be seen in the cave anthroleuchosomatids (Antić \& Makarov 2016). On the one hand, the cave representatives of the Caucaseuma complex, viz., the genera Caucaseuma Strasser, 1970, Brachychaetosoma Antić \&

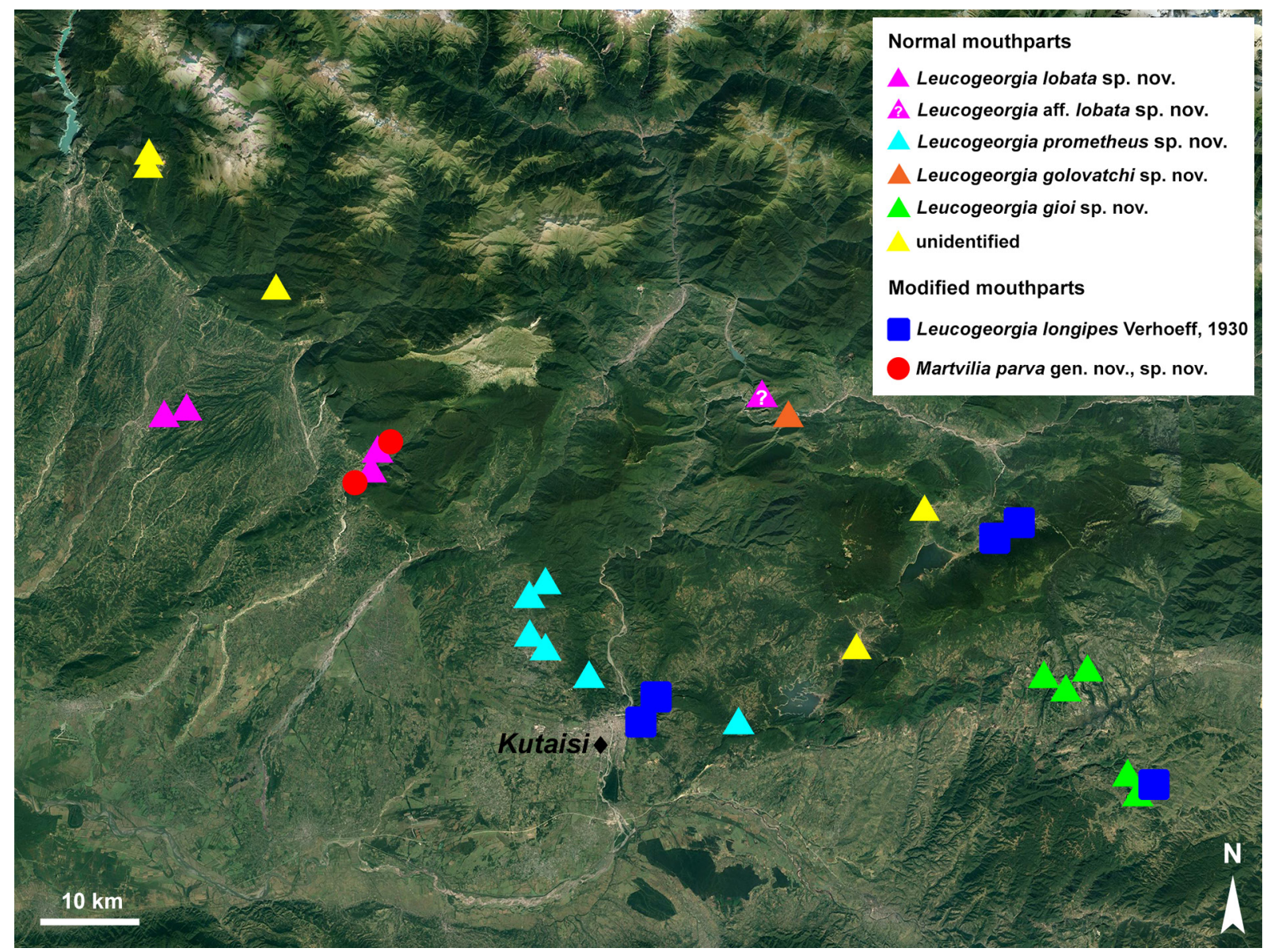

Fig. 58. Distribution of the southeastern group of the genus Leucogeorgia Verhoeff, 1930 and the species Martvilia parva gen. et sp. nov. 
Makarov, 2016 and Heterocaucaseuma Antić \& Makarov, 2016, cover the northwestern part of the western Caucasus. On the other hand, the caves of the southeastern part are only inhabited by two representative genera, Achanthophorella Antić \& Makarov, 2016 and Ratcheuma Golovatch, 1985, both belonging to completely different anthroleucosomatid generic complexes, the Flagellophorella and Ratcheuma ones, respectively. The only exception is the monotypic troglobitic genus Georgiosoma Antić \& Makarov, 2016 from the Caucaseuma complex, which inhabits a cave in the southeastern part of the western Caucasus.

The presence of two biogeographic groups within the genus Leucogeorgia, which differ from each other in the structure of the mesomeral claw, regardless of whether or not they have modified mouthparts, substantiates our synonymization of the genera Archileucogeorgia and Leucogeorgia.

\section{Notes on the relationships within the tribe Leucogeorgiini}

The monophyly of the tribe Leucogeorgiini has previously already been questioned by Enghoff (1987), since there are no synapomorphies to support it. At the same time, that paper is the latest one that refers to the composition of the tribe Leucogeorgiini based on morphological characters. Enghoff (1987) mainly followed the previous authors (Strasser 1976; Hoffman 1980; Mauriès 1983), but he also added the genus Lamellotyphlus Tabacaru, 1976 to this tribe. The tribe thus included the following eight genera:

\section{- Leucogeorgia}

- Archileucogeorgia (now considered as a junior subjective synonym of Leucogeorgia)

- Syniulus Strasser, 1974

- Paratyphloiulus Mauriès, 1983 (considered as a synonym of Syniulus sensu Kime \& Enghoff 2017)

- Telsonius Strasser, 1976

- Lamellotyphlus Tabacaru, 1976

- Chromatoiulus Verhoeff, 1894

- Heteroiulus Verhoeff, 1897

All these genera are characterized by having more or less strongly developed longitudinal lamella on the posterior gonopods, a trait that can also be seen in some other julids, such as Oncoiulini or some members of Typhloiulini.

More recently, Enghoff et al. (2011, 2013) were able to confirm, using molecular evidence, that such a composition of the tribe Leucogeorgiini, based on a relatively small number of morphological characters alone, seems really unnatural. Although not all genera of this tribe were included in the study, the results obtained appeared confusing, while they did allow for some more conclusions to be made. In addition, the recent work of Makarov et al. (2017) revealed the systematic position of the genus Lamellotyphlus. According to these papers, the tribe Leucogeorgiini presently seems to be non-monophyletic, comprising two distant clades.

On the one hand, we have a clade consisting of the genus Archileucogeorgia (now Leucogeorgia) as the sister to the genera Heteroiulus and Pteridoiulus Verhoeff, 1913, as monophyletic (Enghoff et al. 2013). Such a grouping of the genera Leucogeorgia and Heteroiulus is supported by the structure of their gonopods. Both genera are characterized by a strongly developed mesomere featuring a mesomeral claw and a strongly developed mesomeral lamella, where the mesomere is almost completely separated from the opisthomere (see Figs 2, 54F), a character state which could be treated as apomophic. In the past, of course the genus Pteridoiulus was never assigned to the tribe Leucogeorgiini, but formed a group of its own (Pteridoiulini, Pteridoiulinae or Pteridoiulidae). This was based on the structure of the gonopods, especially the posterior ones, which resemble two long 'rods' (Fig. 54F) and, according to Enghoff et al. (2013), are strongly autapomorphic. No one could have guessed that molecular analyses would group this 
genus into a clade together with Leucogeorgia and Heteroiulus, both latter genera being characterized by completely different structures of the posterior gonopods. The only feature that connects the sister genera Heteroiulus and Pteridoiulus from this perspective, in addition to their occurrence in the Alps, is the structure of their body. Both these genera are characterized by a small, 'cylindroiuloid' body, with neither frontal nor metazonal setae as a synapomorphy, a well-developed process on the telson, as well as the presence of $3+3$ setae on the paraprocts (Fig. 53F). Thus, superficially, they do resemble each other. The genus Leucogeorgia, as well as Martvilia parva gen. et sp. nov., on the other hand, includes mainly troglobites which are, like the preceding two genera, characterized by the absence of frontal setae, but show metazonal setae and more numerous setae on the paraprocts. However, the only endogean species of this genus, L. oculata sp. nov., does resemble Heteroiulus and Pteridoiulus, being characterized by the absence of metazonal setae, the presence of a well-developed process on the telson, as well as the presence of $3+3$ setae on the paraprocts.

The second clade, quite distant from the first one, includes three genera, namely the epigean East to Southeast Asian genera Anaulaciulus Pocock, 1895 and Nepalmatoiulus Mauriès, 1983, as well as the troglobitic Balkan genus Lamellotyphlus (see Enghoff et al. 2013; Makarov et al. 2017). Like Pteridoiulus, the genus Anaulaciulus has never been considered within the tribe Leucogeorgiini, since it is characterized by the complete absence of a mesomere or mesomeral process. On the other hand, Enghoff (1987) recognized that the genus Lamellotyphlus may be close to Nepalmatoiulus (although together with six other genera within the Leucogeorgiini), which is now confirmed molecularly, where Lamellotyphlus and Nepalmatoiulus are sister genera (Makarov et al. 2017). Unlike the previous clade, these three genera are characterized by the presence of frontal setae. Leaving aside the genus Anaulaciulus, some homologies in the structure of the posterior gonopods can be observed in the genera Lamellotyphlus and Nepalmatoiulus. The recently published SEM pictures of the genus Nepalmatoiulus by Mikhaljova (2020) allowed us to notice that, unlike in the genera Leucogeorgia and Heteroiulus, there is no division of the posterior gonopods into a mesomere and an opisthomere, but these structures are completely fused, leaving only a free part of the solenomere distally. A completely fused meso-opisthomere is also characteristic of Lamellotyphlus. Furthermore, both Nepalmatoiulus and Lamellotyphlus are characterized by the presence of an anterodistal mesomeral process, although it looks more primitive in Lamellotyphlus, where it is not so obvious as in Nepalmatoiulus (see Fig. 53C, G-H). Since both molecular evidence and some gonopodal characters have shown the genera Nepalmatoiulus and Lamellotyphlus to be related, the latter genus can then be considered as a highly relict taxon.

The remaining genera that Enghoff (1987) considered to represent Leucogeorgiini have unfortunately not yet been processed molecularly and there are almost no other data on their species, apart from the original descriptions and drawings. We have had the opportunity to study representatives of two of these genera, the Italo-Balkan epigean Chromatoiulus podabrus (Latzel, 1884) and the type male of the troglobitic Greek Telsonius nycteridonis Strasser, 1976. Our examination reveals that the mesomeral lamella in C. podabrus seems to be fully divided from the opisthomere, reaching the posteriormost margin of the opisthomere on the lateral side. Something like this can also be seen in Leucogeorgia and Martvilia gen. nov. Chromatoiulus podabrus, like some Leucogeorgia, Martvilia gen. nov., Heteroiulus and Pteridoiulus, is also characterized by the absence of frontal and metazonal setae, the presence of $3+3$ setae on the paraprocts and of a well-developed process on the telson; thus, superficially it resembles Heteroiulus, Pteridoiulus and L. oculata sp. nov. On the other hand, parts of each posterior gonopod of T. nycteridonis seem to be fully merged, this showing a similarity to Nepalmatoiulus. Additionally, T. nycteridonis is characterized by the presence of frontal setae as seen in both Nepalmatoiulus and Lamellotyphlus.

Finally, based on the original descriptions and drawings alone, the troglobitic Syniulus, with three species from Sardinia and Spain, appears to show a posterior gonopod structure similar to the one observed in Leucogeorgia, Martvilia gen. nov., Heteroiulus and Chromatoiulus, where the mesomeral lamella is 
divided from the opisthomere. In addition, Syniulus is characterized by the absence of frontal setae, as in the other previously mentioned genera, as well as the absence of metazonal setae as in Chromatoiulus, Heteroiulus, Pteridoiulus and L. oculata sp. nov.

Considering all the above, as well as the observations partially supported by molecular evidence, the tribe Leucogeorgiini seems to be non-monophyletic and currently consists of two independent clades. On the one hand, there is a clade that in our opinion could include the genera Leucogeorgia, Martvilia gen. nov., Chromatoiulus, Heteroiulus, Syniulus (with Paratyphloiulus), as well as the deviant genus Pteridoiulus (only by molecular analyses). If this group does prove to be monophyletic in the future, including the genus Pteridoiulus, then the name of the tribe should be replaced by the name Pteridoiulini Verhoeff, 1913, because it is older than the name Leucogeorgiini Verhoeff, 1930. Since we have not really dealt with the phylogenetic relationships within this group in this paper, being based primarily on taxa from the western Caucasus, we use the more familiar name - Leucogeorgiini. On the other hand, there is a clade that consists of the East to Southeast Asian genera Nepalmatoiulus and Anaulaciulus, the latter morphologically deviant, as well as the genus Lamellotyphlus, and possibly also the genus Telsonius, both latter troglobitic genera from the Balkans, and probably both highly relict. In the first group, only the genera Leucogeorgia and Martvilia gen. nov. are characterized by a deep division of the opisthomere, while Martvilia gen. nov. is also special in the presence of an almost free mesomere, an apomorphic condition seen in 'higher' julids.

As mentioned above, there are some other julids that are characterized by a strongly developed opisthomesomeral lamella, such as the tribes Oncoiulini and Typhloiulini. However, this lamella completely connects the mesomeral and opisthomeral parts in Oncoiulini, as well as in some Typhloiulini, including in the type species of the type genus Typhloiulus Latzel, 1884, viz., Typhloiulus strictus (Latzel, 1884) (including $T$. serborum Ćurčić \& Makarov, 2005, probably a junior subjective synonym of $T$. strictus, and T. parvulus Antić \& Dražina, 2018). Nevertheless, Enghoff et al. (2013) and Makarov et al. (2017) showed that the analyzed Oncoiulini (Unciger Brandt, 1841) and Tyhloiulini with a lamella group separately from each other and from both clades of Leucogeorgiini. One more genus of an uncertain position, currently assigned to Typhloiulini, is the Romanian monotypic genus Banatoiulus Tabacaru, 1985. This genus superficially resembles Lamellotyphus and is characterized by the completely merged mesomeral and opisthomeral parts and, as in Lamellotyphlus, it only has a presumed mesomeral lobe. Since the presence of an opisthomesomeral lamella is a plesiomorphic character state, such a structure could be retained in some representatives of phylogenetically distant taxa and as such it is of little informative value for the interpretation of a phylogeny between groups. This rather confusing situation in the tribe Leucogeorgiini is quite far from being settled. As polyphyletic or paraphyletic groups do not exist in reality, they are just the fruit of our misclassification. Now, more than 30 years after Enghoff's paper, we can only repeat his words: "...the interrelationships between leucogeorgiine genera are left to future studies" (Enghoff 1987).

\section{Notes on species abundance and ecology}

Interestingly, some species are known only from a few specimens, e.g., L. turbanovi sp. nov., L. profunda sp. nov. and $L$. longipes. Furthermore, four species are only known from one cave each, viz., L. borealis sp. nov., L. mystax sp. nov., L. redivivoides sp. nov. and L. golovatchi sp. nov. Many of those caves were intensively and repeatedly searched for specimens. No stable population can exist with just a few specimens. The majority of the specimens of the populations must therefore be hidden inside crevices, tubes and other subterranean interstitial habitats, such as "MSS" (milieu souterrain superficiel, or mesovoid shallow substratum). The proven high regional abundance of some species $-L$. prometheus sp. nov. and L. abchasica - speaks for an active intercave exchange of these millipedes. This will also be the case for the deep-dwelling species like L. profunda sp. nov. or L. turbanovi sp. nov., which also could be verified for several caves each. 
On the other hand, we do not have yet proof for this expected 'life behind the walls'. Like all other cave life, leucogeorgiine millipedes are not directly exposed to terranean diurnial or seasonal cycles and the local population can be regarded as fragile against any new environmental changes. Therefore, it is highly necessary to restrict the impact of any human activity to a minimum. This also applies to the scientific collecting of specimens, which should always be limited to a sustainable minimum.

\section{Notes on species richness estimation}

With 16 species of Leucogeorgiini having been revealed to date, almost all of the 18 average species to be expected have already been discovered. To find the two as yet 'missing' species would necessitate almost the same effort as expended until now. To find another 41 occurrences of leucogeorgiine species sounds almost impossible if we assume that all major caves in the western Caucasus are known. Anyhow, if at some time the real habitat of the cave millipedes, the still unknown 'life behind the walls', can be accessed, new species will be discovered for sure. In this case, the potential species number will be shifted more towards the maximum of 32 expectable species based on the $95 \%$ upper boundary of the confidence interval. This will also be part of the already ongoing further studies.

\section{Acknowledgements}

We are immensely grateful to our friend and colleague Sergei Golovatch (ZMUM), who provided us with the vast majority of the material studied here. His collection of millipedes from the Caucasus is wellknown and has spawned a number of revisionary works on Caucasian millipedes. He also kindly edited an advanced draft. Further, a lot of fresh material was provided by our colleagues Ilya Turbanov (Borok, Yaroslavl Region), Shalva Barjadze (IZISU) and Giorgi Nebieridze (Tbilisi), and we are really grateful to them, as well as to all other cave explorers and biologists who collected the material of Leucogeorgia considered here. This work would not be complete without in situ photos, some of them having been provided by Ilya Turbanov, Sergei Ivanov and Olga Chervyatsova. Our thanks are also extended to our friends and colleagues Nesrine Akkari (NHMW) and Pavel Stoev (NMNHS), who kindly made the type material of K.W. Verhoeff and K. Strasser available to us for study, as well as to Oliver Macek (NHMW) and Michaela Bodner (Graz) for providing pictures of the lectotype and paralectotype of $L$. longipes and of $P$. aspidiorum, respectively. Michaela Bodner provided specimens of $H$. intermedia and $P$. aspidiorum. We thank Karin Voigtländer (SMNG) for supporting us with the SEM imaging of the specimens. DA thanks Nenad Lazarević (IZB) and Milica Stjepić (Ruma) for their technical suport. HR also thanks Eckard Göbel (Weimar) for the technical support of the 2019 cave exploration tour in Georgia. Both reviewers, Sergei Golovatch (ZMUM) and Henrik Enghoff (Copenhagen), as well as editor Nesrine Akkari (NHMW), made many corrections that improved this manuscript, and we are grateful to them for that.

This study was partly supported by the Serbian Ministry of Education, Science and Technology (grant no. 173038).

\section{References}

Antić D.Ž. \& Makarov S.E. 2016. The Caucasus as a major hotspot of biodiversity: Evidence from the millipede family Anthroleucosomatidae (Diplopoda, Chordeumatida). Zootaxa 4211 (1): 1-205.

https://doi.org/10.11646/zootaxa.4211.1.1

Antić D.Ž., Dudić B.D., Gajić M.R. \& Lučić L.R. 2017. The first hydrophilous cave-dwelling millipede from Serbia - Typhloiulus balcanicus sp. nov. (Diplopoda, Julida, Julidae). Zootaxa 4226 (1): 137-143. https://doi.org/10.11646/zootaxa.4226.1.8 
Antić D.Ž., Turbanov I.S. \& Reboleira A.S.P.S. 2018a. From the depths: Heterocaucaseuma deprofundum sp. nov., the world's deepest-occurring millipede (Diplopoda, Chordeumatida, Anthroleucosomatidae) from caves in the western Caucasus. Zootaxa 4377 (1): 110-124. https://doi.org/10.11646/zootaxa.4377.1.7

Antić D.Ž., Dražina T., Rađa T., Lučić L.R. \& Makarov S.E. 2018b. Review of the genus Typhloiulus Latzel, 1884 in the Dinaric region, with a description of four new species and the first description of the male of Typhloiulus insularis Strasser, 1938 (Diplopoda: Julida: Julidae). Zootaxa 4455 (2): 258-294. https://doi.org/10.11646/zootaxa.4455.2.2

Barjadze S., Asanidze Z., Gavashelishvili A. \& Soto-Adames F.N. 2018. The hypogean invertebrate fauna of Georgia (Caucasus). Zoology in the Middle East 65 (1): 1-10.

https://doi.org/10.1080/09397140.2018.1549789

Birstein J.A. 1950. Cave fauna of the Western Transcaucasia. Zoologicheskii Zhurnal 29: 354-366. [In Russian.]

Chao A. 1984. Nonparametric estimation of the number of classes in a population. Scandinavian Journal of Statistics 11 (4): 265-270.

Colwell R.K. 2013. EstimateS: Statistical estimation of species richness and shared species from samples. Version 9. Available from http://purl.oclc.org/estimates [accessed 20 Jul. 2020].

Colwell R.K., Chao A., Gotelli N.J., Lin S.Y., Mao C.X., Chazdon R.L. \& Longino J.T. 2012. Models and estimators linking individual-based and sample-based rarefaction, extrapolation, and comparison of assemblages. Journal of Plant Ecology 5: 3-21. https://doi.org/10.1093/jpe/rtr044

Culver D.C., Deharveng L., Bedos A., Lewis J.J., Madden M., Reddell J.R., Sket B., Trontelj P. \& White D. 2006. The mid-latitude biodiversity ridge in terrestrial cave fauna. Ecography 29: 120-128.

https://doi.org/10.1111/j.2005.0906-7590.04435.x

Enghoff H. 1985. Modified mouthparts in hydrophilous cave millipedes (Diplopoda). Bijdragen tot de Dierkunde 55 (1): 67-77.

Enghoff H. 1987. Revision of Nepalmatoiulus Mauriès 1983 - a Southeast Asiatic genus of millipedes (Diplopoda: Julida: Julidae). Courier Forschungsinstitut Senckenberg 93: 241-331.

Enghoff H., Petersen G. \& Seberg O. 2011. Phylogenetic relationships in the millipede family Julidae. Cladistics 27: 1-11. https://doi.org/10.1111/j.1096-0031.2011.00360.x

Enghoff H., Petersen G. \& Seberg O. 2013. The aberrant millipede genus Pteridoiulus and its position in a revised molecular phylogeny of the family Julidae (Diplopoda: Julida). Invertebrate Systematics 27: 515-529. https://doi.org/10.1071/IS13016

Ghilarov M.S. 1972. Soil fauna of brown soils of the Caucasus Major Range. In: Ghilarov M.S. (ed.) Problems of Soil Zoology. Materials of the IV All-Union Conference, Baku, 1972: 37-38. Nauka Publishers, Moscow. [In Russian.]

Giurginca A., Vănoaica L., Šusrt V. \& Tajovský K. 2020. A new species of the genus Archiboreoiulus Brolemann, 1921 (Diplopoda, Julida) from Movile Cave (Southern Dobrogea, Romania). Zootaxa 4802 (3): 463-476. https://doi.org/10.11646/zootaxa.4802.3.4

Golovatch S.I. 1983. Une nouvelle espèce cavernicole du genre Leucogeorgia de la Transcaucasie (Diplopoda, Julidae). Fragmenta Entomologica 17 (1): 47-50.

Golovatch S.I. 1985 [for 1984-85]. Two new genera of cave-dwelling millipedes (Diplopoda) with remarks on the milliped fauna of West Caucasian caves. International Journal of Speleology 14: 39-50. 
ANTIĆ D.Ž. \& REIP H.S., Revision of Caucasian Leucogeorgiini

Golovatch S.I. \& Turbanov I.S. 2017. The cave millipede Trachysphaera fragilis Golovatch, 1976, new to the fauna of Abkhazia, western Caucasus (Diplopoda: Glomerida: Glomeridae). Russian Entomological Journal 26 (1): 101-102. Available from https://kmkjournals.com/upload/PDF/REJ/26/ent26_1_101_102_Golovatch_Turbanov_for_Inet.pdf [accessed 24 Jul. 2020].

Gotelli N.J. \& Colwell R.K. 2011. Estimating species richness. In: Magurran A.E. \& McGill B.J. (eds) Biological Diversity Frontiers in Measurement and Assessment: 39-54. Oxford University Press, Oxford.

Hoffman R.L. 1980. Classification of the Diplopoda. Muséum d'histoire naturelle, Geneva.

Iablokov-Khnzorian S.M. 1961. An Attempt of Reconstructing the Origins of the Beetle Fauna of Armenia. SSR Armenia Academy of Sciences, Yerevan. [In Russian.]

Kime R.D. \& Enghoff H. 2017. Atlas of European millipedes 2: Order Julida (Class Diplopoda). European Journal of Taxonomy 346: 1-299. https://doi.org/10.5852/ejt.2017.346

Kokhia M.S. \& Golovatch S.I. 2018. A checklist of the millipedes of Georgia, Caucasus (Diplopoda). In: Stoev P. \& Edgecombe G.D. (eds) Proceedings of the 17 $7^{\text {th }}$ International Congress of Myriapodology, Krabi, Thailand. ZooKeys 741: 35-48. https://doi.org/10.3897/zookeys.741.20042

Kokhia M.S. \& Golovatch S.I. 2020. Diversity and distribution of the millipedes (Diplopoda) of Georgia, Caucasus. In: Korsós Z. \& Dányi L. (eds) Proceedings of the $18^{\text {th }}$ International Congress of Myriapodology, Budapest, Hungary. ZooKeys 930: 199-219. https://doi.org/10.3897/zookeys.930.47490

Lohmander H. 1936. Über die Diplopoden des Kaukasusgebietes. Göteborgs Kungliga Vetenskaps- och Vitterhets-Samhälles Handlingar, Series $5 B 5$ (1): 1-196.

Makarov S.E., Bodner M., Reineke D., Vujisić L.V., Todosijević M.M., Antić D.Ž., Vagalinski B., Lučić L.R., Mitić B.M., Mitov P., Anđelković B.D., Lučić S.P., Vajs V., Tomić V.T. \& Raspotnig G. 2017. Chemical ecology of cave-dwelling millipedes: defensive secretions of the Typhloiulini (Diplopoda, Julida, Julidae). Journal of Chemical Ecology 43 (4): 317-326.

https://doi.org/10.1007/s10886-017-0832-1

Mauriès J.P. 1983. Myriapodes du Nepal (Mission I. Löbl et A. Smetana 1981) I. Diplopodes Iuliformes (Iulida, Cambalida et Spirostreptida): Nepalmatoiulus nov. subgen. Revue suisse de Zoologie 90 (1): 127-138. Available from https://www.biodiversitylibrary.org/page/41302580 [accessed 30 Jul. 2020].

Mikhaljova E.V. 2020. New data on the fauna of China, part I: the taxonomy of the millipede family Julidae (Diplopoda). Zootaxa 4729 (1): 47-66. https://doi.org/10.11646/zootaxa.4729.1.3

Shelepin A.L. (ed.) 2019. Atlas of Russia's Caves. Russian Geographical Society \& Russian Union of Speleologists, Moscow. [In Russian.]

Sidorov D.A., Kharlamova L.T., Golubnichnaya E.E., Rudko P.V. \& Sukhachev V.V. 2014. Preliminary data on biodiversity and distribution of troglobionts in caves of Vostochnaya Arabika and Treugolnik Region (West Caucasus), with special focus on Sarma Cave. In: Gunko A.A., Dolotov Yu.A., Gaifutdinov A.M., Filippov A.G., Chervyatsova O.Ya., Kosarev M.N., Garshin D.I., Markov A.V., Parise M., Shaginyan S.M., Bahtadze N.A., Potapov S.S., Mavlyudov B.R., Zhitenev V.S., Trofimova E.V., Ridush B.T. \& Gunko O.G. (eds) Speleology and Speleostology: Proceedings of the $V^{\text {th }}$ International Scientific Conference Dedicated to the Centenary of A.V. Ryumin: 300-303. Nizhny Novgorod Pedogogical University Press, Naberezhnye Chelny, Russia.

Strasser K. 1974. I diplopodi chilognathi della Sardegna. Fragmenta Entomologica 10 (3): 231-293.

Strasser K. 1976. Über Diplopoda-Chilognatha Griechenlands, II. Revue Suisse de Zoologie 83 (3): 579-645. Available from https://www.biodiversitylibrary.org/page/41499156 [accessed 30 Jul. 2020]. 
Turbanov I.S. 2015. Preliminary results of studying the invertebrates of Krubera Cave (Western Caucasus, Abkhazia), collected in August 2015 during the expedition of the Ukrainian Speleological Association. Svet 40: 108-117. [In Russian.]

Turbanov I.S., Demidov P.E., Kolesnikov V.B. \& Turbanova A.A. 2018. Preliminary results of investigation of invertebrate animals study in the Veryovkina Cave (The Western Caucasus, Abkhazia). In: Gunko A.A., Dolotov Yu.A., Gaifutdinov A.M., Filippov A.G., Chervyatsova O.Ya., Garshin D.I., Markov A.V., Parise M., Shaginyan S.M., Turbanov I.S., Bahtadze N.A., Potapov S.S., Mavlyudov B.R., Zhitenev V.S., Trofimova E.V., Gaifutdinova T.V., Amelichev G.N., Tsurikhin E.A. \& Gunko O.G. (eds) Speleology and Speleostology. Collection of Materials of IX In International Scientific Conference: 360-368. Nizhny Novgorod Pedagogical University Press, Naberezhnye Chelny, Russia.

Verhoeff K.W. 1930. Eine cavernicole Symphyognathen-Gattung aus Georgien, Transcaucasien. Mitteilungen über Höhlen- und Karstforschung 1930 (2): 33-39.

Wulff E.V. 1944. A Historical Geography of Plants. USSR Academy of Sciences Publications, Moscow and Leningrad. [In Russian.]

Zazanashvili N., Sanadiradze G., Bukhnikashvili A., Kandaurov A. \& Tarkhnishvili D. 2004. Caucasus. In: Mittermaier R.A., Gil P.G., Hoffmann M., Pilgrim J., Brooks T., Mittermaier C.G., Lamoreux J. \& da Fonseca G.A.B. (eds) Hotspots Revisited, Earth's Biologically Richest and Most Endangered Terrestrial Ecoregions: 148-153. CEMEX/Agrupacion Sierra Madre, Mexico City.

Manuscript received: 4 June 2020

Manuscript accepted: 17 July 2020

Published on: 7 September 2020

Topic editors: Rudy Jocqué and Nesrine Akkari

Desk editor: Danny Eibye-Jacobsen

Printed versions of all papers are also deposited in the libraries of the institutes that are members of the EJT consortium: Muséum national d'histoire naturelle, Paris, France; Meise Botanic Garden, Belgium; Royal Museum for Central Africa, Tervuren, Belgium; Royal Belgian Institute of Natural Sciences, Brussels, Belgium; Natural History Museum of Denmark, Copenhagen, Denmark; Naturalis Biodiversity Center, Leiden, the Netherlands; Museo Nacional de Ciencias Naturales-CSIC, Madrid, Spain; Real Jardín Botánico de Madrid CSIC, Spain; Zoological Research Museum Alexander Koenig, Bonn, Germany; National Museum, Prague, Czech Republic. 